Utah State University

DigitalCommons@USU

$5-2009$

\title{
A Model for Doctoral Students' Perceptions and Attitudes toward Written Feedback for Academic Writing
}

Gulfidan Can

Utah State University

Follow this and additional works at: https://digitalcommons.usu.edu/etd

Part of the Curriculum and Instruction Commons

\section{Recommended Citation}

Can, Gulfidan, "A Model for Doctoral Students' Perceptions and Attitudes toward Written Feedback for Academic Writing" (2009). All Graduate Theses and Dissertations. 227.

https://digitalcommons.usu.edu/etd/227

This Dissertation is brought to you for free and open access by the Graduate Studies at DigitalCommons@USU. It has been accepted for inclusion in All Graduate Theses and Dissertations by an authorized administrator of DigitalCommons@USU. For more information, please contact digitalcommons@usu.edu.

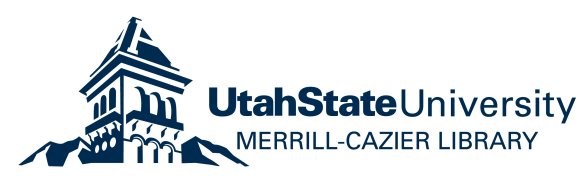




\title{
A MODEL FOR DOCTORAL STUDENTS’ PERCEPTIONS AND ATTITUDES
}

TOWARD WRITTEN FEEDBACK FOR ACADEMIC WRITING

\author{
by \\ Gulfidan Can \\ A dissertation submitted in partial fulfillment \\ of the requirements for the degree \\ of \\ DOCTOR OF PHILOSOPHY
}

in

Instructional Technology

Approved:

Dr. Andrew Walker

Dr. Byron Burnham

Major Professor

Committee Member

Dr. Mimi Recker

Committee Member

Dr. Jamison Fargo

Committee Member

Dr. Sylvia Read

Committee Member

Dr. Byron Burnham

Dean of Graduate Studies

UTAH STATE UNIVERSITY

Logan, Utah 
Copyright @ Gulfidan Can 2009

All Rights Reserved 


\author{
ABSTRACT \\ A Model for Doctoral Students' Perceptions and Attitudes \\ Toward Written Feedback for Academic Writing
}

by

Gulfidan Can, Doctor of Philosophy

Utah State University, 2009

Major Professor: Dr. Andrew Walker

Department: Instructional Technology

The purpose of this study was to investigate social science doctoral students' perceptions and attitudes toward different characteristics of written feedback and written feedback providers for their academic writing. Moreover, it aimed to provide an explanatory model to describe the relationships between these perceptions and attitudes, students' revision decisions, and other potentially relevant factors in their written feedback practices. The investigation was informed by two theoretical frameworks: principles of instructional design and conditions of learning, and situated learning and communities of practice.

The study used a mixed methods approach in which qualitative data collection and analysis was followed by quantitative data collection and analysis. The main purpose of the qualitative phase was to develop a background to build a questionnaire to be used in the quantitative phase. The qualitative data were collected through interviews with 15 participants. Grounded theory data analysis methods were adapted in the qualitative analysis of the data. The quantitative data were collected through a questionnaire with 276 participants in two large mountain west public universities. Descriptive and multivariate correlational data analyses were employed for the analysis of the quantitative data.

The results of this study provided descriptive information on doctoral students' preferences for different types of written feedback and their perceptions and attitudes toward different characteristics of written feedback providers. Moreover, the structural equation modeling (SEM) analysis results showed that 
that there are several factors in the feedback practices of the doctoral students that have significant influences on some other factors in these feedback practices. An eight-factor model was developed constituting the following factors: (a) attitudes toward critical/negative written feedback, (b) motivations for academic writing, (c) perceptions of opportunities to write academic papers with faculty members in the department, (d) attitudes toward asking and searching for written feedback for academic papers, (e) attitudes toward feedback providers' willingness and time to give feedback when asking for written feedback, (f) attitudes toward feedback providers’ personality when asking for written feedback, (g) revision decisions considering the external issues while examining the written feedback, and (h) revision decisions considering the written feedback characteristics and the need for the revisions while examining the written feedback. 


\section{ACKNOWLEDGMENTS}

I would like to express my deepest appreciation to my committee chair, Dr. Andrew Walker, and my former committee chair, Dr. David Wiley, for their supervision, assistance, and support during my dissertation process. I would also like to thank my committee members, Dr. Byron Burnham, Dr. Jamison Fargo, Dr. Sylvia Read, and Dr. Mimi Recker, for their invaluable feedback.

Special thanks to Jason Ridley and the USU writing center staff for quality checking the interview transcripts; Dr. Keith Gibson and Vanessa Van Winkle for conducting content validity reviews; Dr. Nick Eastmond for his review of interview questions; and Natalie Humpherys for her editorial work. I would also like to thank all the doctoral students who contributed to this research as participants or pilot test participants.

My gratitude also goes to my family and all of my friends, especially Devrim Ozdemir, Reyhan Baktur, and Jerry B. Anderson. Thank you for your moral support and encouragement at every difficult stage of my doctoral program.

Gulfidan Can 
CONTENTS

ABSTRACT ...

\section{CHAPTER}

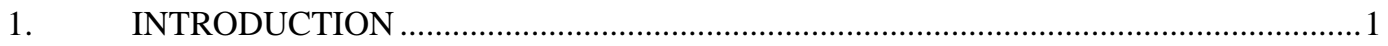

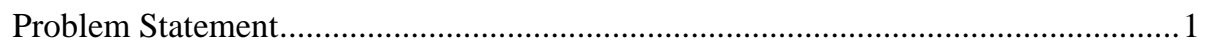

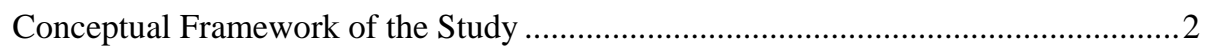

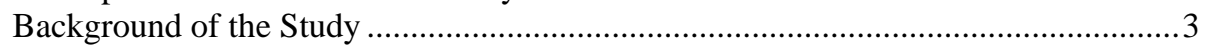

Purpose of the Study .....................................................................................................

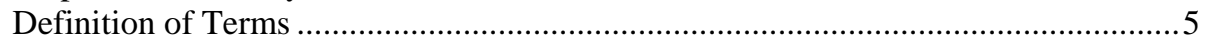

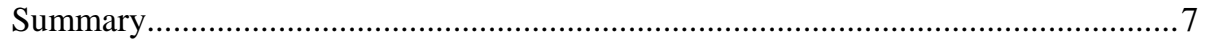

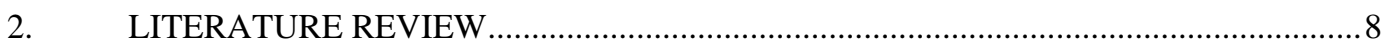

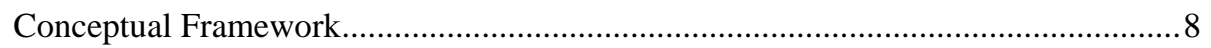

Relevant Research Studies..................................................................................... 17

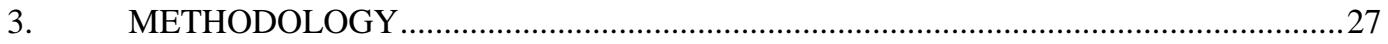

Research Questions.................................................................................................22

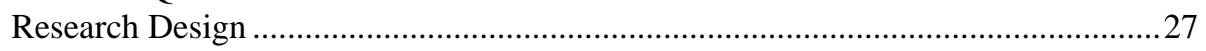

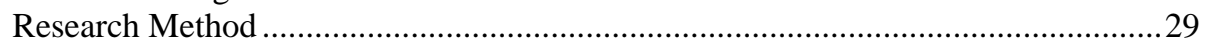

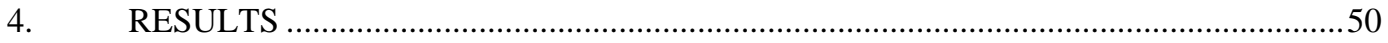

Qualitative Data Analysis ....................................................................................50

Instrument Design...................................................................................................68

Quantitative Data Analysis ...................................................................................69

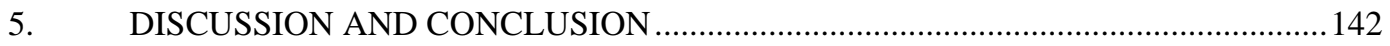

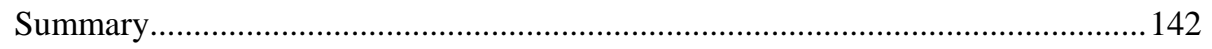

Limitations of the Study .......................................................................................... 142

Discussion of the Findings and Conclusions ............................................................143

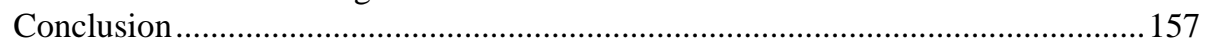

Recommendations for Further Research............................................................159

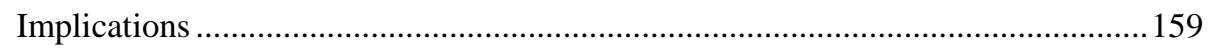

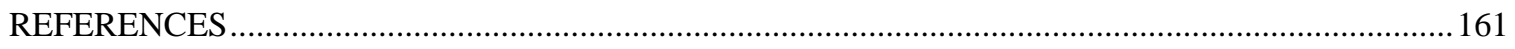

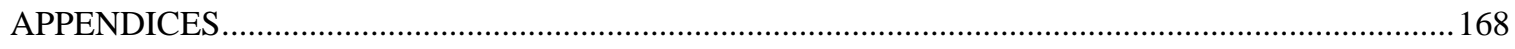

Appendix A: Informed Consent Form for Interviews.....................................................169

Appendix B: Informed Consent Form for Questionnaire ...............................................173

Appendix C: Interview Guide......................................................................................176

Appendix D: Recruit Materials for Interviews .............................................................183

Appendix E: Content Validity Testing Sheet.....................................................................185 
Appendix F: Pilot Test Review Sheet................................................................... 187

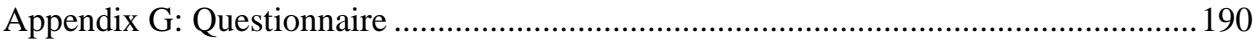

Appendix H: Recruit Materials for Questionnaire .................................................208

Appendix I: Questionnaire Items with Low Reliability and/or

Commonality Scores......................................................................211

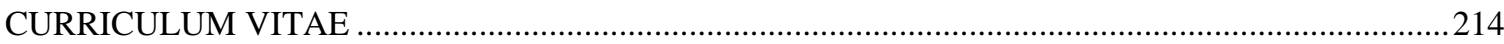




\section{LIST OF TABLES}

3-2 Participants’ Demographic and General Characteristics: Frequencies and Percentages ................42

3-3 Frequencies and Percentages of Participants from Different Colleges or Schools........................43

3-4 Percentages of Participation from Two Universities..............................................................44

3-5 Frequencies and Percentages of Participants from Different Programs ...................................45

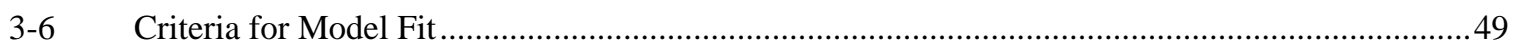

4-1 Open and Axial Coding Results: Main and Subcategories ..................................................53

4-2 Identified Different Feedback Characteristics...................................................................5

4-3 The Most Frequent Relationships Between Main Categories ...................................................67

4-4 Perceived Need for Written Feedback Regarding Different Aspects of Academic Writing: Descriptive Statistics (1-Never, 2-Seldom, 3-Sometimes, 4-Often)......

4-5 Perceived Need for Written Feedback Regarding Different Aspects of Academic Writing: Frequencies and Percentages ............................................................................. 72

4-6 Delivery Preferences: Frequencies and Percentages ......................................................73

4-7 Cross-tabular Presentation of Delivery Preferences...........................................................

4-8 General Feedback Preferences: Descriptive Statistics (1- Strongly Disagree, 2- Disagree, 3- Agree, 4- Strongly Agree)

4-9 General Feedback Preferences: Frequencies and Percentages (SD- Strongly Disagree, D- Disagree, A- Agree, SA-Strongly Agree)

4-10 Categorization of Questionnaire Items Regarding Specific Feedback Preferences .......................79

4-11 Specific Feedback Preferences: Descriptive Statistics (1- Strongly Disagree, 2- Disagree, 3- Agree, 4- Strongly Agree).

4-12 Specific Feedback Preferences: Frequencies and Percentages (SD- Strongly Disagree, D- Disagree, A- Agree, SA-Strongly Agree)

4-13 Attitudes Toward Critical/Negative Written Feedback: Descriptive Statistics (1- Strongly Disagree, 2- Disagree, 3- Agree, 4- Strongly Agree).

4-14 Attitudes Toward Critical/Negative Written Feedback: Frequencies and Percentages (SD- Strongly Disagree, D- Disagree, A- Agree, SA-Strongly Agree). 
4-15 Perceptions and Attitudes Toward Different Written Feedback Providers: Descriptive Statistics (1- Unimportant, 2- Somewhat Important, 3- Important, 4- Very Important)

4-16 Perceptions and Attitudes Toward Different Written Feedback Providers:

Frequencies and Percentages.

4-17 Perceptions Toward Feedback Providers Regarding the Types of Feedback They Give:

Descriptive Statistics (1-Strongly Disagree, 2-Disagree, 3-Agree, 4-Strongly Agree)

4-18 Perceptions Toward Feedback Providers Regarding the Types of Feedback They Give:

Frequencies and Percentages (SD- Strongly Disagree, D- Disagree, A- Agree,

SA-Strongly Agree)

4-19 Revision Decisions in the Case of Disagreement with the Written Feedback:

Descriptive Statistics (1- Never, 2- Seldom, 3- Sometimes, 4- Often)

4-20 Revision Decisions in the Case of Disagreement with the Written Feedback:

Frequencies and Percentages.

4-21 Other Revision Decisions in Relation to the Feedback Providers and the Feedback

Types: Descriptive Statistics (1-Strongly Disagree, 2-Disagree, 3-Agree,

4-Strongly Agree)

4-22 Other Revision Decisions in Relation to the Feedback Providers and the Feedback Types: Frequencies and Percentages (SD- Strongly Disagree, D- Disagree, A- Agree, SA-Strongly Agree)

4-23 Perceptions Toward the Program: Descriptive Statistics (1- Strongly Disagree, 2- Disagree, 3- Agree, 4- Strongly Agree)

4-24 Perceptions Toward the Program: Frequencies and Percentages (SD- Strongly Disagree, D- Disagree, A- Agree, SA-Strongly Agree)....

4-25 Participants’ Engagement in Different Types of Academic Writing: Frequencies and Percentages.

4-26 Participants’ Academic Writing Experiences: Descriptive Statistics

4-27 Perceived Academic Writing Ability: Descriptive Statistics (1-very poor, 2-poor,

3-average, 4-good, 5-very good).

4-28 Perceived Overall Academic Writing Ability: Frequencies and Percentages .....

4-29 Cross-tabular Presentation of the Participants’ Native Language and Perceived

Overall Academic Writing Ability

4-30 Motivations for Academic Writing: Descriptive Statistics (1- Strongly Disagree, 2- Disagree, 3- Agree, 4- Strongly Agree)

4-31 Motivations for Academic Writing: Frequencies and Percentages (SD- Strongly Disagree, D- Disagree, A- Agree, SA-Strongly Agree)

4-32 Attitudes Toward Academic Writing: Descriptive Statistics (1- Strongly Disagree, 2- Disagree, 3- Agree, 4- Strongly Agree) 
4-33 Attitudes Toward Academic Writing: Frequencies and Percentages (SD- Strongly

Disagree, D- Disagree, A- Agree, SA-Strongly Agree)...

4-34 Attitudes Toward Asking for Written Feedback: Descriptive Statistics

(1- Strongly Disagree, 2- Disagree, 3- Agree, 4- Strongly Agree)......

4-35 Attitudes Toward Asking for Written Feedback: Frequencies and Percentages

(SD- Strongly Disagree, D- Disagree, A- Agree, SA-Strongly Agree).

4-36 Attitudes Toward the Feedback Process in General: Descriptive Statistics

(1- Strongly Disagree, 2- Disagree, 3- Agree, 4- Strongly Agree)......

4-37 Attitudes Toward the Feedback Process in General: Frequencies and Percentages

(SD- Strongly Disagree, D- Disagree, A- Agree, SA-Strongly Agree)..

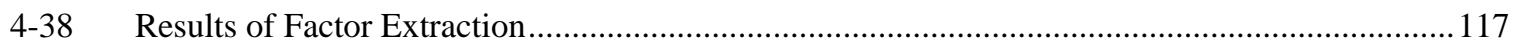

4-39 Parallel Test Results to Determine the Number of Factors in EFA.............................................120

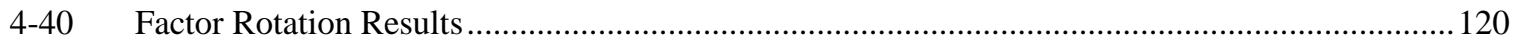

4-41 Main Factors and Variables That Best Represent 10 Factors.........................................................122

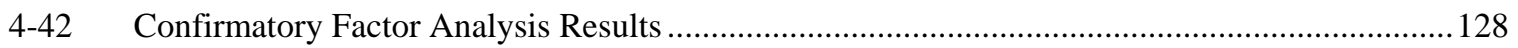

4-43 Standardized Paramater Estimates for 10 Factors- Estimates

(standard errors) - STDYX Standardization....................................................................................129

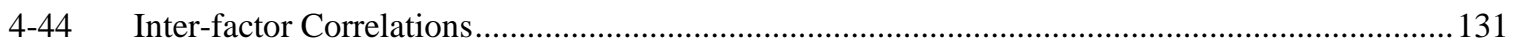

4-45 SEM Results of the Hypothetical Model...............................................................................133

4-46 SEM Results of the Modified Model ………….............................................................................135

4-47 Correlations Between Factor Variables and Students' General Characteristics............................139

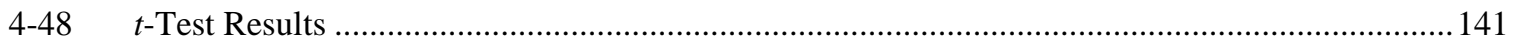

I-1 Questionnaire Items with Low Reliability and/or Commonality Scores .....................................212 


\section{LIST OF FIGURES}

Figure

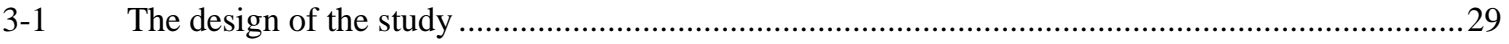

4-1 Qualitative, selective coding analysis using IHMC CMAP Tool............................................66

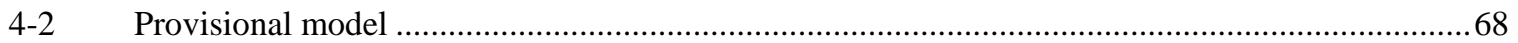

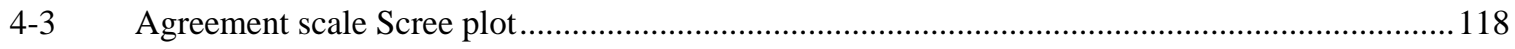

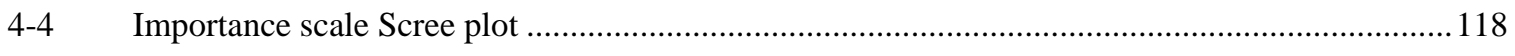

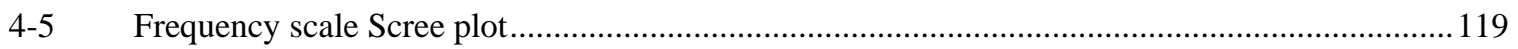

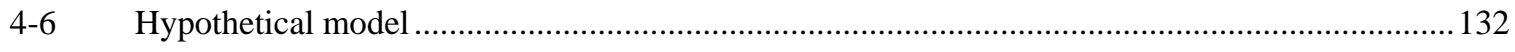

4-7 Modified model........................................................................................................ 134 


\title{
CHAPTER 1
}

\section{INTRODUCTION}

\author{
Problem Statement
}

One of the main goals of doctoral education is to develop scholars with good academic writing skills (Eyres, Hatch, Turner, \& West, 2001). Therefore, doctoral programs require students to engage actively in academic writing practices. Students are expected not only to satisfy the degree completion requirements by writing course assignments and a dissertation, but they are also expected to practice in their contribution to their discipline by writing professional and publishable products (Kamler \& Thomson, 2006; Lovitts, 2001).

The quality and quantity of publications facilitate doctoral students' careers and a university's reputation (Pageadams, Cheng, Gogineni, \& Shen, 1995), and current job entry requirements include items such as a list of publications or grants (Walker, Golde, Jones, Bueschel, \& Hutchings, 2008). Thus there is increased demand and expectation for the quality and quantity of academic writing practices in the doctoral programs (Caffarella \& Barnett, 2000; Lavelle \& Bushrow, 2007). However, despite these demands and expectations, problems are reported regarding students' writing at the doctoral level (Caffarella \& Barnett; Kamler \& Thomson, 2006; Torrance \& Thomas, 1994; Torrance, Thomas, \& Robinson, 1992). These problems may even endanger the successful completion of doctoral degrees for some students (Torrance et al., 1992). Increased demand and the aforementioned reported problems entail the need to effectively help and support students with their writing in the doctoral programs (Lavelle \& Bushrow).

Special academic writing courses, writing centers, and writing groups at the doctoral level are suggested to support students’ academic writing (Biklen \& Casella, 2007; Bolker, 1998; Kamler \& Thomson, 2006; Pageadams et al., 1995; Phelps, Fisher, \& Ellis, 2007; Torrance \& Thomas, 1994; Wilkinson, 2005). These facilities, which are suggested to improve writing, are based on the provision of effective feedback to students. As Kumar and Stracke (2007) stated, “...[T]he feedback process lies at the heart of the learning experience of a PhD student” (p. 462), and as Cafarella and Barnett (2000) stated, graduate students “need” and "want” feedback for their academic writing (p. 48). Providing feedback for 
students' writing is the essential factor in helping students understand the academic writing process, and in improving their academic writing skills and final written products (Caffarella \& Barnett; Kumar \& Stracke).

Based on Gagné's theory, providing effective feedback depends not only on the design of the feedback, but also on other conditions that lie within the learner (Gagné, 1985; Gagné, Briggs, \& Wager, 1992). One of these conditions is the receivers’ perceptions and attitudes toward feedback. Straub (1997) stated the following:

If "successful” comments are, by definition, those that turn students back to their writing and lead them to make better informed choices as writers, we need to continue to investigate how students view different types of comments and how we can make responses that challenge and encourage them to work productively on their writing. (p. 113)

Considering the centrality of the feedback process in the doctoral supervision (Caffarella \& Barnett, 2000), it is crucial to understand students’ reactions toward the feedback process for their academic writing.

Moreover, considering academic writing only from the individual's writing skills approach will limit the understanding of the larger context of the academic community’s practices (Kamler \& Thomson, 2006). Academic writing is a social practice, and the problems related to writing in doctoral education are not only attributed to skill-based issues (Kamler \& Thomson). The feedback practices involve consideration of the broader context of the academic community, discipline, and institution's practices. Coffin et al. (2003) explained:

...[F]eedback will (necessarily) differ in different teaching contexts: while there is evidence that feedback is not always as effective as it might be, what counts as effective feedback will differ, to some extent, between different lecturers and students, academic areas, cultural contexts, etc. (p. 128)

Therefore, a comprehensive understanding of doctoral students' perceptions and attitudes toward feedback practices in the social context of academic writing and feedback practices is necessary.

\section{Conceptual Framework of the Study}

This study uses two theoretical stances in a complementary way: the Principles of Instructional Design and Conditions of Learning (Gagné, 1985; Gagné et al., 1992), and Situated Learning and Communities of Practice (Lave \& Wenger, 1991), which are further discussed in Chapter 2. Using the lens 
of these stances, this study suggests that providing useful and effective feedback for doctoral students' academic writing is essential for their development as scholars. However, to provide this kind of feedback, the feedback providers do not only need to consider instructional principles, but they also need to have an understanding of doctoral students' feedback practices, their opinions and attitudes toward different characteristics of feedback and feedback providers, and the factors that affect their revision decisions.

According to this theoretical stance, academic writing is situated in the social practice of the academic community (Kamler \& Thomson, 2006). Therefore, feedback practices are also considered in regards to different social dynamics in the academic writing environments of doctoral students, including different conventions in disciplines, power relations in the institutions, and the relationship of doctoral students with members of the academic community, and so forth.

\section{Background of the Study}

Only a limited number of studies addressed the perceptions and attitudes of doctoral students toward feedback practices in academic writing (e.g. Eyres et al., 2001; Kumar \& Stracke, 2007), and there are several important limitations of these studies. First, these studies were limited in scope in examining the students' perceptions and attitudes toward different characteristics of feedback and feedback providers. They usually categorized feedback as positive and critical; and categorized feedback providers as being an instructor or a peer. They also mostly examined the students' perceptions or attitudes toward the feedback provided by the instructors.

Second, these studies hardly provided any information about how students' revision decisions are related to their perceptions and attitudes toward feedback characteristics and feedback providers. Although some of these studies acknowledged the feedback process as a part of the academic communities' writing practices, their results provided mostly discrete information without sufficient reference to different dynamics in the students' feedback practices. As a result, no explanatory theory or model was found in the literature that was supported by empirical data about the doctoral students' perceptions and attitudes toward their feedback practices regarding their academic writing.

Finally, they collected data from students in only one program or a discipline while did not 
attempt to sample from similar programs or disciplines. Considering indistinct boundaries of different disciplines and communities of practice, their results might not represent the perceptions and attitudes of doctoral students in similar programs and disciplines. These problems located in a limited number of research studies that inform the practice require further exploration of the perceptions and attitudes of doctoral students toward feedback practices in a more comprehensive and explanatory way.

Purpose of the Study

The purpose of this study is to provide an explanatory model to understand doctoral students' perceptions and attitudes toward different types and sources of feedback, and how their revision decisions are influenced by these perceptions and attitudes and other potentially relevant factors in their feedback practices. The study further explores the relationship between all these factors (perceptions and attitudes toward different characteristics of written feedback and written feedback providers, students' revision decisions, and other potentially relevant factors in the feedback practices). To define the scope of this study, the following three delimitations should be considered.

\section{Delimitations of the Study}

1. This study focused on only written feedback for academic writing. Although some of the results of this study might be applicable to oral feedback as well, the findings and interpretations should be considered in the context of written feedback.

2. Because academic writing practices (Torrance et al., 1992) and the opportunities for academic and social interactions with the members of the academic community are mainly different in sciences and social sciences programs (Lovitts, 2001), this study only focused on the doctoral students in social sciences programs to provide more homogenous results. However, as presented in Chapter 5, replication studies need to be conducted for the science programs.

3. Considering the unclear boundary and definition of social sciences (Becher \& Trowler, 2001; MacDonald, 1994), this study considered the subject categories in the Social Science Citation Index of Thomson-Reuters (Thomson-Reuters, 2008) as social sciences. 


\section{Research Questions}

This study addresses the following questions:

1. What are the perceptions and attitudes of doctoral students in social science programs toward different characteristics of written feedback in regard to their academic writing?

2. What are the doctoral students' perceptions and attitudes toward different characteristics of written feedback providers with regard to their academic writing?

3. How are the doctoral students' revision decisions influenced by these perceptions, attitudes, and other relevant factors in their feedback practices?

4. What kind of other relationships do doctoral students' perceptions and attitudes toward different characteristics of written feedback and written feedback providers, their revision decisions, and other relevant factors in their feedback practices have?

\section{Definition of Terms}

\section{Doctoral Students}

In this study, the use of the term doctoral students is based on the "American Model” (Lovitts, 2001, p. 7). All the students admitted to a Ph.D. program are considered doctoral students.

\section{Feedback in Instruction, Written Feedback, Feedback Provider}

In this research, feedback is defined and used in the context of instruction. Gagné et al. (1992) described feedback as one of the nine events of instruction: "[feedback] provides the learner with information about performances and sets in motion the process of reinforcement” (p. 189). Feedback in instruction may serve a variety of purposes to facilitate learning based on its use in different learning environments and its examination in different learning paradigms (Mory, 2004).

Written feedback for academic writing is particularly focused within this research study. It can be described as one or a group(s) of comments, edits, marks, and so forth, written (handwritten or electronic) by someone who reviewed an academic paper. There may be a variety of types of written feedback with 
different functions, including their use in formative and summative evaluations. In this research study, no distinction is made between formative and summative written feedback; however, the feedback receivers' revision decisions and the power positions between the reviewer and the feedback receiver were considered.

In this study, the reviewers who give written feedback are defined as feedback providers or feedback sources. The characteristics of the feedback provider may include their knowledge and experience level, writing skills, and personality.

\section{Attitude and Perception}

Oppenheim (1966) defined and described attitude as follows:

...[A]n attitude is a state of readiness, a tendency to act or react in a certain manner when confronted with certain stimuli.... Attitudes are reinforced by beliefs (the cognitive component) and often attract strong feelings (the emotional component) that will lead to particular forms of behavior (the action tendency component). (pp. 105-106)

Perception, on the other hand, is defined as “ a) a result of perceiving: observation, b) a mental image: concept” (Merriam-Webster, 2003, p. 918).

\section{Academic Writing in Higher Education}

According to Coffin et al. (2003), there are three main approaches to writing in higher education: writing as text, writing as process, and writing as a social practice (pp. 9-10). Kamler and Thomson (2006) similarly presented approaches to academic writing in doctoral education as academic writing as research and academic writing as the social practice of the academic community. Coffin et al. further listed the stages that the academic writing process may involve as prewriting, planning, drafting, reflection, peer/tutor review, revision, additional research or idea generation, editing and proofreading.

The main purposes of academic writing in higher education include assessing students' content knowledge and writing skills, improving content knowledge and thinking skills, and participating in the communication of the academic communities (Coffin et al., 2003). Academic writing in doctoral education can be in the form of essays, manuscripts, articles, reports, journals, and so forth. 
Social Science Programs

MacDonald (1994) stated that "if academic writing is a form of knowledge making, then differences in knowledge problems or ways of addressing such problems should account for much of the variation among the disciplines” (p. 21). She suggested that disciplinary fields can be placed on a conceptual continuum with science fields at one end to humanities fields at the other, and social science fields in between. There are no strict boundaries between these three main groups and many fields may fall in between groups on the continuum. Similarly, Becher and Trowler (2001) stated that the disciplinary boundaries are not clear, and they grouped social sciences with humanities in the following categorization of disciplines: pure sciences (hard-pure), humanities and pure social sciences (soft-pure), technologies (hard-applied), and applied social sciences (soft-applied) (p. 36). Because of these indistinct boundaries, this study considered the fields listed in the Social Science Citation Index Categories (Thomson-Reuters, 2008) as social science fields.

\section{Summary}

Considering the centrality of feedback for doctoral students' academic writing practices and the deficiency of research studies that explored doctoral students' perceptions and attitudes toward different types and sources of feedback and their revision decisions, this study aimed to provide an explanatory model to represent their perceptions and attitudes toward different types and sources of written feedback, their revision decisions, and the relationship among these factors and other potentially relevant factors in the feedback practices of the doctoral students. The following chapter further describes the conceptual framework and background of the study, followed by the detailed presentation of the methodology and results in Chapter 3 and 4, respectively. The results are discussed and the conclusions are drawn in Chapter 5. 
CHAPTER 2

\section{LITERATURE REVIEW}

In this section, the conceptual framework of this study is provided as a theoretical background to be used as a lens while examining this study and other studies in the literature. Relevant research studies, which also addressed similar research questions in the literature, are then described and their results are discussed along with their limitations.

\section{Conceptual Framework}

The conceptual framework of this study is based on two different theoretical approaches in a complementary way. In the first approach, feedback is described as an "external learning condition” to improve the effectiveness of learning (Gagné, 1985; Gagné et al., 1992). In the second approach, feedback represents the dialogue between the members of “communities of practice” that conveys the community’s criteria, conventions, language, and so forth (Lave \& Wenger, 1991). After a brief description of these two theoretical approaches, the context of doctoral students’ perceptions and attitudes toward feedback for academic writing are presented in relation to these approaches.

\section{Feedback in Instruction}

According to Gagné et al. (1992), instruction is defined as “a deliberately arranged set of external events designed to support internal learning processes” (p. 11). Conditions, both external and internal, that affect individuals’ learning should be considered in the design of instruction (Gagné, 1985). External learning conditions are related to “the stimuli that are external to the learner” (Gagné et al., p. 9), such as

display of an instructional material. The internal learning conditions, on the other hand, are "states of mind that the learner brings to the learning task” (p. 9), such as the attitudes of the learner.

Gagné (1985) suggested nine events of instruction based on internal processes of learners (e.g. selective perception, rehearsal, semantic encoding, and retrieval) as: gaining attention, informing learners of the objective, stimulating recall of prior learning, presenting the stimulus, providing learning guidance, eliciting performance, providing feedback, assessing performance, and enhancing retention and transfer. 
Therefore, providing feedback is considered as an external learning condition designed to support learning (Gagné; Gagné et al., 1992). Since learners’ performance after instruction is not always perfect, providing feedback is an essential component of the instructional process (Gagné et al.).

During instructional planning, external learning conditions should be designed by taking into consideration the internal learning conditions (Gagné et al., 1992). This is due to the effectiveness of the design of instruction and feedback depending on their compliance with learners' individual characteristics, including their attitudes (Gagné et al.). Therefore, it is crucial to understand how internal and external learning conditions influence each other.

Similarly, in the context of this research, the design of feedback provided to doctoral students for their academic writing practices requires the understanding of these students' internal learning conditions; specifically, their perceptions and attitudes toward the feedback and other external conditions related to the feedback process. This individualized design of feedback can help doctoral students improve their writing performance according to the academic writing standards and criteria.

However, the examination of doctoral students’ perceptions and attitudes toward feedback practices for their academic writing should not be limited to individuals' learning point of view. Learning is a social process as well as a cognitive one (Vygotsky, 1978), and academic writing is a social practice as well as an individual one (Kamler \& Thomson, 2006). In the following section, this social perspective is described in detail, and doctoral students' academic writing and feedback practices are discussed in the context of communities of practice (Lave \& Wenger, 1991).

Communities of Practice, Doctoral Education, Academic Writing, and Feedback

Description of Situated Learning and Communities of Practice

In the framework of a social practice theory, Lave and Wenger (1991) argued that learning is not the result of the internalization of transferred, decontextualized knowledge by an individual learner. In systems of relationships between the person, activity, and the social world, learning is defined as "increasing participation in communities of practice" (p. 49). According to this theory, learning is situated in social practice and is an integral part of it. By involving and participating in the practices of a 
community and thus gaining necessary knowledge and skills in situated learning activities, learners gradually become "full participants" (p. 53).

Engagement in social practices of a community is described by the term "legitimate peripheral participation” (Lave \& Wenger, 1991, p. 35). There can be different types and levels of participation and membership in a community of practice. The identities are dynamic and based on the nature or level of participation. As the members or their identities change, the communities of practice transform or reproduce themselves. The reproduction of communities of practice requires newcomers to have access to "a wide range of ongoing activity, old-timers, and other members of the community; and to information, resources, and opportunities for participation” (p. 101). When there are opportunities for participation and access to the practice, the apprentices contribute to the actual products at varying degrees. This way, they improve their knowledge and skills.

The nature of the relationship between master and apprentice, the role of the master in an apprentice's participation and learning, and the power and authority relations between them vary in different communities of practice. Furthermore, the relationships among apprentices are also part of these interactions. Different from conventional views of the master-apprentice relationship, Lave and Wenger (1991) viewed that “...mastery resides not in the master but in the organization of the community of practice of which the master is part” (p. 94).

In the process of becoming full members, newcomers learn the conventions of the language and terminology in their particular communities of practice. Moreover, they develop and share an understanding of the practice in their community. As their identity, participation, or community of practice changes, they revise or improve their understanding. While trying to understand and learn how to participate in the existing communities of practice, they also try to develop their own identities. However, conflicting viewpoints may emerge between the newcomers and oldtimers about the practice. Power issues become important with reference to allowing newcomers to participate in the practices with their own perspectives. Regarding the dynamic nature of communities of practice, oldtimers also change their identity (Lave \& Wenger, 1991).

The main intrinsic motivation of the apprentices is to become full participants and adept 
practitioners in the communities of practice. However, especially in school systems, newcomers might be motivated by the system to learn in order to prove their knowledge and skills for their formal evaluation in the institutions (Lave \& Wenger, 1991).

Academic Communities of Practice, Doctoral Education, Academic Writing, and Feedback

Academic Communities of Practice, Doctoral Education, and Apprenticeship

Based on the ideas of Lave and Wenger (1991), it can be suggested that doctoral education is an important part of the academic communities of practice's reproduction. Similarly, within the framework of apprenticeship and intellectual communities, the following was stated:

What accounts for the mystique of the PhD? It is the academy's own means of reproduction. In a Darwinian sense, the academy invests most heavily in its own means of reproduction and sustainability....[T]he academic profession bridges past and future in the context of each individual doctoral program. The doctorate as an institution provides the stability and tradition that renders scholarship a human activity that transcends generations, cultures, and contexts. It is both a paragon of innovation and a defender of the faith. (Walker et al., 2008, p. xi)

Apprenticeship is considered the "signature pedagogy" for doctoral education (Walker et al., 2008, p. 89). Although apprenticeship relationships between masters and apprentices in communities of practice is not always hierarchical, in doctoral education practices, there are power differences between doctoral students and their supervisors due to the institutional context and faculty's gatekeeping role (Kamler \& Thomson, 2006). Kamler and Thomson stated that "relationships between doctoral candidates and examiners are culturally constrained as unequal. They are not yet 'accepted' in their scholarly communities and are seeking entry through the writing of the dissertation itself” (p. 79).

Walker et al. (2008) pointed out the problems in the classic one-on-one master-apprentice relationships in doctoral education and provided suggestions for improvement. They stated that the effectiveness of students' development depends on the working relationship and mutual efforts of both faculty and students. They listed the essential characteristics of apprenticeship in doctoral education as follows: (a) Intentionality: Faculty providing students opportunities to practice the activities with gradual levels of scaffolding; (b) Multiple relationships: Students' apprenticeship with several mentors and peers (c) Collective responsibility: Faculty having the collective responsibility to ensure all students' access to 
the mentors and apprenticeship experiences; (d) Recognition: Recognizing and rewarding the faculty's effective apprenticeship with students; and (e) Respect, Trust, Reciprocity: Relationships should be founded on mutual respect, trust, and reciprocity.

In order for the faculty to cultivate mutual respect, trust, and reciprocity with the students, it is crucial to provide individualized instruction to doctoral students considering their variety of backgrounds, motivations, needs, and attitudes; communicate their needs and expectations to the students; provide regular feedback about students’ progress; and invest time for students’ development. Similarly, students need to understand the individual working styles of their mentors, communicate their needs and expectations to the faculty, develop self-regularity for their own learning with the help of regular feedback, and devote time for the apprenticeship relationship with faculty and the activities of the departmental community (Walker et al., 2008).

In the larger perspective, students' engagement in the practices of the departmental or disciplinary community is crucial for their development (Walker et al., 2008). As Walker et al. stated, doctoral students want to be part of the intellectual community; when this fails, it might lead students to attrition (Lovitts, 2001).

It is essential that departments provide opportunities for students to integrate into the departmental community. This integration constitutes both “academic and social integration” (Lovitts, 2001, p. 42).

Lovitts defined these two types of integration as follows:

Academic integration develops through task integration, working together on the intellectual and professional tasks of graduate education: learning, teaching, researching, and publishing....Social integration is brought about through socioemotional integration, supportive interactions inside and outside the department with members of the departmental community. (p. 42)

While academic integration is essential in graduate education, the social integration is not a necessary but an influential factor in degree completion (Lovitts, 2001).

Compared to the students in sciences who usually work on research projects in teams starting early in their program, the students in social sciences and humanities usually carry out their research individually, starting much later in their program (Lovitts, 2001). Therefore, the students in social sciences have fewer opportunities for academic and social integration than the students in sciences. Lovitts stated:

The more structures and opportunities a community provides its members to interact and engage 
in the professional tasks of the discipline, the more bonds the members will have with each other and with the community, and less likely its members will be to leave. (p. 49)

Some of these structures and opportunities that help students toward more academic and social interactions can be in the form of research and teaching assistantships; sharing an office space; dissertation groups; brown bag sessions; professional meetings; and other formal and informal, academic and social departmental activities (Lovitts).

Doctoral supervisors or faculty have the pivotal role of helping students develop identities in the academic community by their acquisition and access in the social practice of the community (Eyres et al., 2001; Kamler \& Thomson, 2006; Lovitts, 2001). Therefore, it is suggested that the faculty invite students to participate in the practices of the community (Walker et al., 2008). As stated by Lave and Wenger (1991), “...[I]n shaping the relation of masters to apprentices, the issue of conferring legitimacy is more important than the issue of providing teaching” (p. 92). Four aspects of interaction with the faculty were found as “frequency, location, content, and accessibility” (Lovitts, p. 119).

Doctoral students have a variety of experiences, motivations, expectations, and skills (Eyres et al., 2001; Kamler \& Thomson, 2006; Lovitts, 2001; Walker et al., 2008). Faculty feedback considering doctoral students' different backgrounds, therefore, can help students access the academic community and its practices (Eyres et al.). Doctoral students' giving and receiving of feedback is considered one of the activities of the departmental community (Walker et al.). Their colleague-to-colleague approach toward the doctoral students reflects on their feedback to students (Kumar \& Stracke, 2007).

Doctoral students can also integrate into the "graduate student subculture” (Lovitts, 2001, p. 79). During this integration, they do not only learn tacit knowledge or conventions reside in the practices of the academic culture, but they also support each other. Lovitts stated, “strong, bonded graduate communities are characterized by the existence of numerous opportunities for supportive academic and social interactions between and among their members- faculty and graduate students” (pp. 107-108). Several researchers also suggested such groups for doctoral students, most of which focus on supporting the academic writing practices of these students (e.g. Biklen \& Casella, 2007; Bolker, 1998; Kamler \& Thomson, 2006; Pageadams et al., 1995; Phelps et al., 2007; Wilkinson, 2005). 
Doctoral Students' Academic Writing and Feedback

Practices in the Academic Communities of Practice

Although doctoral graduates might have different career plans, such as having a position in an academy, industry, government, and so forth (Walker et al., 2008), an important part of the doctoral education's practice involves academic writing. In institutionalized settings, faculty and students participate in academic writing practices that consider the communities’ needs, standards, language, and conventions. Academic writing in doctoral education is similar to other types of academic writing; however, it is influenced by the institutional requirements of degree completion and conventions of the particular disciplines (Kamler \& Thomson, 2006). Moreover, since most doctoral students do not have enough experience or expertise regarding the use of their discipline’s particular discourse (Torrance et al., 1992), their academic writing might be different from those of experienced academics.

In their perspectives on doctoral students' development and academic writing practices, Kamler and Thomson (2006) stated that academic writing is not a set of general, decontextualized skills; rather it is situated in the social practice of the academic community. Therefore, the writing instructors' assistance is not comparable to the help provided in a particular discipline for doctoral students' understanding and practicing the conventions of that discipline (Eyres et al., 2001). In student communities, doctoral students may also assist each other's development regarding their academic writing practices. For example, in dissertation writing groups or publication groups, doctoral students may provide feedback regarding the writing of their peers and support each other during their writing process as presented in the previous section.

Dialogue and feedback between the newcomers, oldtimers, and other members in the community is essential for members' learning and is important for the transformation of practices in the community. In doctoral education, the supervisors provide "advanced academic training” and express their ideas through their feedback (Kumar \& Stracke, 2007, p. 462). Furthermore, through the discourse of the academic community, a supervisor, as a full participant of the community, “...mediates cultural, institutional and disciplinary rules, conventions and mores in order to support the doctoral researcher to produce an acceptable text” (Kamler \& Thomson, 2006, p. 15). Therefore, students' learning and their written products are influenced by this dialogue with the members in the practices of the academic community both at the 
institutional level and the wider sociocultural level (Kamler \& Thomson).

Two other issues that affect doctoral students’ academic writing practices after receiving feedback are their reactions toward feedback and their revision decisions. These can be grouped under three categories: (1) emotions regarding the evaluation of their written products; (2) perceived understanding of the feedback, its purpose, and the criteria of evaluation; and (3) attitudes and perceptions toward the feedback provider.

Emotions. Feedback may have an emotional effect on doctoral students, considering that their degree completion (Caffarella \& Barnett, 2000) and, therefore, their further access to the community's practice depend on the assessment of their written products. As apprentices they may view the critiques of their papers as an attack on their skills or abilities as academicians (Caffarella \& Barnett).

Perceived feedback. Doctoral students' revision decisions after receiving feedback may depend on not only their shared understanding with the feedback provider, but also on the perceived purposes of the feedback and perceived criteria for the evaluation of the written product (Kim, 2004).

Feedback provider. Based on the theories provided by O’Keefe (1990) and Cialdini (1993), Kim (2004) further presented that the "persuasiveness" of the response given by a feedback provider is affected by the perceptions and attitudes toward the feedback provider's characteristics. These were the providers' perceived credibility, which constitutes competence and trustworthiness; and liking, which constitutes physical attractiveness, similarity, praise, level of familiarity, and association (Kim, p. 307). The following characteristics are included in both of these main categories: “friendly-unfriendly,” "pleasant-unpleasant,” “nice-not nice,” and “valuable-worthless” (p. 307).

Self help books that provide guidelines to doctoral students for their academic writing in doctoral education would also be considered potential sources that contribute to this theoretical perspective of the academic writing and feedback practices of the doctoral students. However, there are several limitations to these resources. Although they are numerous in number (e.g. Biklen \& Casella, 2007; Bolker, 1998; Foss \& Waters, 2007; Gosling \& Noordam, 2006; Madsen, 1992; Mauch \& Birch, 1998; Newman, Benz, Weis, \& McNeil, 1997; Peters, 1992; Phelps et al., 2007; Rossman, 2002; Rudestam \& Newton, 2001; Thomas \& Brubaker, 2000; Wilkinson, 2005), and even though several of them stressed the importance of the revision 
process (e.g. Biklen \& Casella; Bolker; Foss \& Waters; Gosling \& Noordam; Mauch \& Birch; Peters; Rudestam \& Newton), only a few of them referred to the feedback process for academic writing and how to revise with feedback (e.g. Biklen \& Casella; Foss \& Waters; Mauch \& Birch; Rudestam \& Newton). Moreover, the authors' suggestions are usually based on their experiences rather than on research findings or their students' opinions because of the lack of research in this area. Furthermore, in these resources, giving and receiving peer feedback for academic writing is hardly discussed and sometimes only mentioned (e.g. Biklen \& Casella; Bolker; Foss \& Waters; Gosling \& Noordam; Mauch \& Birch; Peters; Phelps et al.; Thomas \& Brubaker).

Similarly, the suggestions presented in few available self help books for doctoral supervisors (e.g. Bartlett \& Mercer, 2001; Bolker, 1998; Delamont, Atkinson, \& Parry, 2004; Kamler \& Thomson, 2006; Piantanida \& Garman, 1999; Taylor \& Beasley, 2005; Wisker, 2005) are also primarily based on personal experiences of the authors without much empirical support. Although some of these books included extensive information on supporting doctoral students in their socialization into the academic community, they do not inform about the students' preferred types of feedback or how different factors affect students' revision decisions. These limitations in theoretical or practical resources relevant to this topic show the necessity for empirical research that provides information from the students’ point of view.

\section{Conclusion}

Considering feedback both as a part of instruction and as a dialogue between the members of the academic community extends the understanding of feedback potential in the writing practices of doctoral students. This view further helps the understanding of the academic writing environment as not a neutral, but influential factor for students’ academic writing, feedback, and revision practices.

Few available research studies in the literature about doctoral students' perceptions and attitudes toward feedback also inclined to view the feedback process in a larger perspective rather than view it as a simple process of giving instructions after the assessment based on defined criteria. In the following section, the results of these research studies are presented. 
Relevant Research Studies

In this section, a brief description of the differences between undergraduate and doctoral students' perceptions and attitudes toward the feedback practices is given, followed by an outline of doctoral students' writing and revision approaches. Subsequently, the few research studies found that explored research questions relevant to this study are presented.

\section{Undergraduate Students vs. Doctoral Students}

Several studies examined the perceptions and attitudes of undergraduate students toward different feedback types provided by the instructors for students’ writing (Straub, 1997). Although few in numbers, some of them also mentioned students' attitudes and perceptions toward different feedback providers (e.g. Cho, Schunn, \& Charney, 2006). These studies developed their own feedback categorizations to examine students’ reactions toward them.

As an example of some of these recent research studies, Cho et al. (2006) explored 116 undergraduate students’ perceived helpfulness of instructor versus peer comments provided in two psychology courses. They also examined the students' perceived helpfulness of different peer feedback

types categorized as directive, nondirective, praise, criticism, off-task, and summary feedback in relation to prose flow, argument, and insight dimensions of writing. Regarding the modality of feedback, Kim (2004) explored 39 first year undergraduate students' preferences of voice versus written feedback and their ratings on the persuasiveness of feedback provided by the instructors in a composition course. Similarly, Carless (2006) explored how 1,740 undergraduate students perceived the feedback process for their assignments and how their perceptions differed from those of the faculty.

Some studies claimed that the result of the studies conducted with undergraduate students can be generalized to the doctoral students (e.g. Eyres et al., 2001). However, the doctoral students’ academic writing practices and products (Caffarella \& Barnett, 2000; Torrance \& Thomas, 1994; Torrance et al., 1992), conceptions of academic writing (Torrance \& Thomas), writing strategies or approaches (Lavelle \& Bushrow, 2007; Torrance et al.), expected level of using conventions of the academic discipline's discourse (Torrance \& Thomas; Torrance et al.), types of feedback given (Cho et al., 2006), expectations of them 
(Torrance \& Thomas; Torrance et al.), evaluation criteria (Lavelle \& Bushrow), revision behaviors (Torrance et al.), and motivations are different from those of undergraduate students. Therefore, the results of these studies on undergraduate students cannot be generalized to doctoral students.

\section{Approaches of Doctoral Students Toward Academic Writing and Revision}

As presented above, doctoral students have different academic writing approaches and revision behaviors than undergraduate students. Torrance and Thomas (1994) also explained that experienced writers' perceptions toward academic writing and attitudes toward revision are very different from those of inexperienced writers. While inexperienced writers present their ideas through writing, produce a finished draft, and perceive revision as a polishing stage, experienced writers develop their ideas while writing and revising, and they revise extensively and repeatedly. For experienced writers, revision is part of the writing process. Lavelle and Bushrow (2007) also expressed that writers' approaches and strategies on writing differ based on their expertise in writing and their native language as well as the writing tasks, assessments, and objectives.

Aside from experience, native language, and other issues related to the writing task and environment, the individual differences in students' writing strategies also need to be considered. In their research on 110 social science doctoral students in the UK, Torrance, Thomas, and Robinson (1994) identified three groups of students who used different writing and revising strategies. While planners define and plan their content before starting to write and then produce few drafts, revisers develop the content during writing and revise more. Mixed strategy writers plan their content before writing, but they revise the content and produce many drafts. Mixed strategy writers expressed writing difficulties and anxieties more than the other two groups.

Similarly, Lavelle and Bushrow (2007) conducted a factor analysis to categorize 421 master students' writing beliefs and approaches and found seven factors based on the data gathered through a questionnaire: Elaborative, low self-efficacy, no revision, intuitive, scientist, task-oriented, and sculptor. Two of these factors were specifically related to the present research. The low self-efficacy factor represented items related to students' low self confidence and anxieties while writing, revising, and while 
their writing is being evaluated. The no-revision factor represented students' limited degree and frequency of revisions on their draft and their perceptions and attitudes towards the function of the revision process in a narrow perspective. Both of these writing approaches were identified as "surface factors" that are mostly similar to novice writers’ approaches (Lavelle \& Bushrow, p. 808).

Doctoral students' purposes for revising their papers were also categorized by Torrance et al. (1992) as follows, starting with the most preferred: (a) "improving clarity, cohesion, or to 'check that I have said what I mean;”” (b) “improving the style, flow or tone of the text;” (c) “developing or changing facts and/or ideas;” (d) “correcting errors in spelling and grammar;” (e) "reordering or restructuring the text;” and (f) “to reduce redundancy, repetition and length” (p. 160). On the other hand, Lavelle and Bushrow (2007) suggested that the doctoral students' reasons for not revising their papers might be related to their limited time and problems with planning.

\section{Description of Similar Research Studies}

The electronic database Science Citation Index (SCI) was utilized to search similar research studies in the literature. The following terms were used: Doctoral, doctorate, college, masters, higher education, graduate students, doctoral students; feedback, comment*, assess*, evaluat*, review*, respon*, information, interact*, communicat*, improve*, advice, suggest*, criticism, correction*, editing; writ*; perception*, attitude*, belief*, preference*, feeling*, approach*, conception*.

The abstracts of the resulting 1,385 articles were reviewed, and only 4 articles were identified that investigated or partially presented the doctoral students’ perceptions and attitudes toward feedback characteristics, feedback providers, and their revision decisions. Although these studies mostly addressed

written feedback for students' academic writing, they usually used the term “feedback” rather than "written feedback". Therefore, while discussing these studies, the term "feedback" is used in this chapter. Their results were categorized and presented in the following section. In this section, the purposes, data collection and analysis methods, and limitations of the articles are described.

One of the four relevant research studies was conducted by Eyres et al. (2001). They investigated doctoral students' perceived helpfulness of different oral and written feedback characteristics provided by 
the faculty in the nursing program. In this study, unstructured interviews were conducted with 15 female participants (27\% participation rate) who had different levels of writing experience. Qualitative data analysis was conducted by three researchers separately, comparisons were made, and the member-check method was used to reach the final interpretation. They framed their interpretation regarding socialization in the academic community and writing as a process. The main limitation of this research study concerns the generalizability of the results. Aside from the fact that the results represent doctoral students' perceptions and attitudes only toward faculty feedback, their data collection methods, especially regarding low diversity in their participants' characteristics and program, further limits the comprehensiveness of the results.

Another research study that utilized qualitative data collection and analysis methods was conducted by Kumar and Stracke (2007). They developed a typology of written feedback based on the feedback given by a supervisor to a doctoral student in an Applied Linguistics program for a completed $\mathrm{PhD}$ dissertation draft. They examined the helpfulness of different feedback types in relation to the student's revision decisions. Different aspects of the relationship between the supervisor and the student were also discussed. Even though their qualitative research study results were useful in facilitating further research and dialogue in this area, they are based on the attitudes and perceptions of only one doctoral student toward the feedback given by only one supervisor in a specific program.

Neither of these two research studies involved any writing course intervention. Cafarella and Barnett (2000), on the other hand, developed a writing project in a required doctoral level course in an Educational Leadership program and collected data from 45 students. The students were asked to prepare two drafts and revise their drafts after receiving written feedback from a peer and faculty member. They were also asked to write a response to the feedback providers regarding their revision decisions based on the feedback received. The data were collected through focus group interviews and written and oral reports from students who had taken this course within five years prior to the research study. An important limitation of this study was that focus group interview participants who took this course a few years ago may not have clearly remembered their perceptions and emotions when asked to describe them during the interviews. 
Although limited, some of the results of Lavelle and Bushrow’s (2007) study were also relevant to this research study. They investigated graduate students' writing processes and beliefs about writing. Four hundred and twenty-one graduate students who were enrolled in a master's level course in the Education program completed a questionnaire using Likert scales. Their results regarding revision and self efficacy issues were presented.

In the following section, the results of the aforementioned relevant research studies are presented in a categorized way in relation to the research questions of the present research study as: (a) perceptions and attitudes toward different characteristics of feedback; (b) perceptions and attitudes toward different characteristics of feedback providers; (c) how revision decisions are influenced by these perceptions and attitudes, and other relevant factors in students' feedback practices; and (d) other relationships between students' perceptions and attitudes toward different characteristics of feedback and feedback providers, their revision decisions, and other relevant issues in their feedback practices.

\section{Results of the Relevant Research Studies}

Perceptions and Attitudes Toward Different

Characteristics of Feedback

\section{Positive and Critical Feedback}

Positive feedback gave the feeling of encouragement, confidence, and acceptance of the students' writing (Kumar \& Stracke, 2007). Eyres et al. (2001) found that participants, especially those who had limited academic writing experience, reported their preference of receiving positive and encouraging feedback along with critical comments. However, it was not helpful to receive general positive feedback comments without a specific explanation for students' written work.

Regarding critical feedback, Caffarella and Barnett (2000) reported that as doctoral students engaged in giving and receiving critical feedback, their anxiety about the feedback process diminished relatively over time and their self confidence was improved as academic writers. For some students, however, the degree of negative emotional effects from receiving critical feedback was very strong, even after a great deal of time had passed since they had received the feedback. 
Internal Quality of Feedback

The doctoral students expressed that they appreciated in-depth feedback that stimulated their thinking, improved their arguments, and helped them to connect ideas. They considered this kind of feedback as good quality feedback (Eyres et al., 2001).

Amount and Frequency of Feedback and

Face-to-Face Support

Eyres et al. (2001) reported doctoral students’ negative attitudes toward receiving a limited amount of critical feedback. Regarding the frequency of feedback occasions, students perceived that receiving ongoing feedback helped build their confidence in writing academic papers (Caffarella \& Barnett, 2000). Moreover, personalized face-to-face feedback was found to be very helpful to students in improving their confidence as academic writers (Caffarella \& Barnett).

Aspects of Writing

One of the foremost preferences of the students was to receive feedback about the clarity of their writing, especially regarding the language and conventions used in a specific discipline (Eyres et al., 2001). Moreover, feedback regarding conceptualization was found to be the most helpful for the participants (Pageadams et al., 1995). Problems with conceptualization were related to theory bases, assumptions, and implications. Regarding editing, punctuation, grammar, syntax, and organization aspects of writing, most of the students in the research study perceived having editorial feedback in their first draft as irrelevant or offensive (Eyres et al.). However, this kind of feedback was perceived as the easiest type for revisions (Kumar \& Stracke, 2007).

Dialogue

Kumar and Stracke (2007) stated that expressed opinions in the form of dialogue from different perspectives in written feedback were perceived as very helpful for doctoral students to build their confidence as members in the academic community and develop necessary skills. Furthermore, doctoral students presented their appreciation for questions in feedback that stimulate their thinking (Eyres et al., 2001). 
Conflicting Feedback from Different Feedback Providers

Caffarella and Barnett (2000) reported students’ negative reactions toward conflicting feedback from different providers. Participants reported their discomfort in addressing these kinds of feedback in their revisions.

Perceptions and Attitudes Toward Different

Characteristics of Feedback Providers

Perceived Motivation of the Feedback Provider

Eyres et al. (2001) reported that the participating doctoral students thought about possible motivations of the feedback provider when examining the feedback. Students valued feedback when they perceived that the feedback providers believed in their potential, cared about their improvement of skills, and tried to be helpful.

\section{Valuing and Respecting Students' Voice and Ideas}

Students presented positive attitudes toward feedback providers who listened and respected students' ideas and tried to help them improve. However, they did not like feedback providers who criticized and corrected their writings without carefully examining the ideas that the students were trying to present (Eyres et al., 2001). The feedback provider who acknowledged and respected the opinions of the student while presenting their own opinions from a different perspective was found to be the most helpful regarding students’ revisions and improvement (Kumar \& Stracke, 2007).

\section{Interpersonal Relationship and Power Differences}

Eyres et al. (2001) presented that feedback characteristics and students' reactions toward them are related to the relationship with the feedback provider. Students found it helpful when they felt less power difference and more dialogue toward making decisions about the paper (Eyres et al.; Kumar \& Stracke, 2007).

\section{Clear Expectations and Criteria}

Considering writing assignments, doctoral students preferred to know clearly the criteria of 
evaluation and their instructors’ expectations from their assignments (Eyres et al., 2001). However, they preferred the instructors to be more flexible about the topic of the assignments.

Attitudes Toward Feedback Providers Based on Their Feedback Characteristics

A limited amount of critical feedback leads to the perception that feedback providers do not care about them. This is also perceived as the professors do not read their students' writings or they do not have time to give feedback (Eyres et al., 2001).

How Revision Decisions Are Influenced by These Perceptions and Attitudes, and Other Relevant Factors in Students’ Feedback Practices

Doctoral students reported that their decisions regarding the incorporation of feedback in their revisions were difficult when feedback from different faculty conflicted (Caffarella \& Barnett, 2000). However, written feedback in the form of dialogue was perceived as most helpful compared to other feedback forms in the revision process. Its effect on the improvement of skills and confidence of the receiver as an academician was also mentioned (Kumar \& Stracke, 2007).

Another issue that affects revision decisions and behaviors was the students' attitudes toward the critical feedback. Kumar and Stracke (2007) reported that the doctoral student who had positive attitudes toward critical feedback had a considerable amount of revisions in the draft, examined the draft with a new perspective, and developed a more critical stance for future writings.

Other Relationships Between Students’ Perceptions and Attitudes Toward Different Characteristics of Feedback and Feedback Providers, Their Revision Decisions, and Other Relevant Issues in Their Feedback Practices

\section{Goals or Motivations of Students}

Eyres et al. (2001) found that there is a relationship between students’ long term goals toward improving themselves as scholars and their level of interest and investment in different written assignments. The more relevant the assignments are to their goals, the more value they give to them. 


\section{Emotional Effect of Written Feedback Process}

Doctoral students found that the feedback process and receiving of critical comments negatively affected their emotional state. Receiving low quality or contradictory feedback also led to negative emotions such as frustration and anger. However, they felt that receiving ongoing, personalized feedback increased their confidence regarding academic writing (Caffarella \& Barnett, 2000).

\section{Self efficacy}

During their factor analysis, one of the factors that Lavelle and Bushrow (2007) found regarding graduate students' writing approaches was low self efficacy. They suggested several feedback providing strategies for students who have low self efficacy concerning their writing, which implies that these students need different types of feedback.

\section{Confidence in Writing Ability}

Cafarella and Barnett (2000) found that students' lack of confidence in their writing ability made it harder to make revision decisions and explain these decisions to the feedback providers. This was especially the case when there was conflicting feedback from different faculty.

\section{Time}

The study conducted by Lavelle and Bushrow (2007) also resulted in another factor regarding graduate students' writing approaches as not revising. They interpreted the reason for students' not revising as graduate students' busy schedules.

\section{Conclusion}

Few discrete studies questioned doctoral students' perceptions and attitudes toward factors in the feedback process. Considering students' perceptions and attitudes toward different feedback characteristics, these studies mostly focused on attitudes toward positive and critical feedback. They did not characterize these feedback types further to explore participants' perceptions and attitudes toward feedback in more detailed categorizations.

In regards to students' perceptions and attitudes toward different feedback providers, the studies 
almost exclusively examined perceptions and attitudes toward faculty or supervisor feedback while largely ignoring other feedback sources such as peers and professional reviewers. Moreover, as can be seen in Table 4-1, interview participants in this current study referred to a variety of characteristics of feedback providers other than merely describing them as being an instructor, advisor, or peer. For example, they considered issues such as feedback providers' experience level or power position as important factors that affect their decision to ask for their feedback. Therefore, it is possible that categorizing feedback providers only according to their positions in the institution might produce conflicting results, and could mislead to wrong conclusions.

Another limitation of these studies is that they hardly provided any information about how these perceptions and attitudes of students toward different feedback types and different feedback providers affect students' revision decisions. Although their questions are framed in a broader context of doctoral students' academic writing and feedback practices, their results did not provide an explanatory framework of the relationships between these factors in the feedback practices of the doctoral students.

In addition to these problems, the results of these studies might not be representative of the perceptions and attitudes of other doctoral students in different disciplines. Different disciplines have different writing conventions (Coffin et al., 2003; Hyland, 2004), but the boundaries of these disciplines are not clear (Becher \& Trowler, 2001; MacDonald, 1994). These studies collected data only from students in a few particular programs. Although collecting detailed data from only one program might provide extensive information about that program's writing practices, a wider sampling from similar programs would have provided more representative results because communities of practice also have indistinct boundaries (Wenger, 1998; Wenger, McDermott, \& Snyder, 2002).

Considering the importance of feedback in doctoral students' academic writing practices, it is crucial to provide a comprehensive, representative, and explanatory framework about how different factors in feedback practices are interrelated. This includes the students' perceptions and attitudes toward different characteristics of feedback and feedback providers and their revision decisions. Therefore, the purpose of this study is to provide a comprehensive, representative, explanatory model that portrays the doctoral students’ perceptions and attitudes regarding their feedback practices. 
CHAPTER 3

METHODOLOGY

Research Questions

This study addresses four main questions:

1. What are the perceptions and attitudes of doctoral students in social science programs toward different characteristics of written feedback in regard to their academic writing?

2. What are the doctoral students' perceptions and attitudes toward different characteristics of written feedback providers with regard to their academic writing?

3. How are the doctoral students' revision decisions influenced by these perceptions, attitudes, and other relevant factors in their feedback practices?

4. What kind of other relationships do doctoral students' perceptions and attitudes toward different characteristics of written feedback and written feedback providers, their revision decisions, and other relevant factors in their feedback practices have?

\section{Research Design}

\section{Mixed Methods Approach}

As presented in Chapter 2, there are a limited number of research studies found that have addressed research questions relevant to the questions posed in this study. Furthermore, these studies were limited in the scope and generalizability of their results. Compared to them, the current study aimed to not only explore the phenomena under investigation in a wider scope, but also to have some degree of generalizability to a larger group of doctoral students.

In this study, using only qualitative methods would be useful to reach an in-depth understanding of the phenomena; however, the generalizability of the findings would have been limited. Similarly, starting this study with quantitative methods would not have been possible due to a limited research background in the literature that defines the constructs or hypothesizes the relationships among them. Therefore, this study required the use of both qualitative and quantitative research methods. It required the 
use of qualitative methods to first discover the constructs and their relationships; later, the quantitative methods were used to confirm the relationships between these constructs with a larger sample in order to reach some degree of generalizability.

Accordingly, the mixed methods approach, which is relatively new compared to the qualitative and quantitative methods approaches, was utilized in this study. It can be defined as follows:

A mixed methods study involves the collection or analysis of both quantitative and/or qualitative data in a single study in which the data are collected concurrently or sequentially, are given a priority, and involve the integration of the data at one or more stages in the process of research. (Creswell, Clark, Gutmann, \& Hanson, 2003, p. 212)

The main objectives of qualitative data collection were to discover constructs, themes, and their relationships regarding participants' reactions toward a phenomenon. On the other hand, the main objectives of the quantitative data collection were to confirm these relationships with a larger sample, reach some degree of generalization, and identify complex relationship patterns that are hard to discover with a qualitative analysis of data.

Considering the need to use the qualitative methods before the quantitative methods, "Sequential Exploratory Strategy" which is one of the inquiry strategies in mixed methods was used (Creswell, 2003, p. 215) (see Figure 3-1). According to this strategy, the qualitative data collection and analysis is followed by quantitative data collection and analysis. The qualitative analysis results informed and affected the quantitative phase, however the priority was given to the quantitative data collection and analysis in this study.

\section{Epistemological Assumptions of the Study}

The main epistemological assumptions of this study are as follows:

1. Although social reality can be diverse and situational for different individuals, the frequent relationships between constructs about a phenomenon in a similar group of people helps one understand the general patterns. Therefore, some degree of generalization about these relationships is possible.

2. The patterns of relationships between constructs do not necessarily mean there is causality between them (Campbell \& Stanley, 1963). The exploration of these relationship patterns, however, helps toward the discovery of possible causal patterns. 


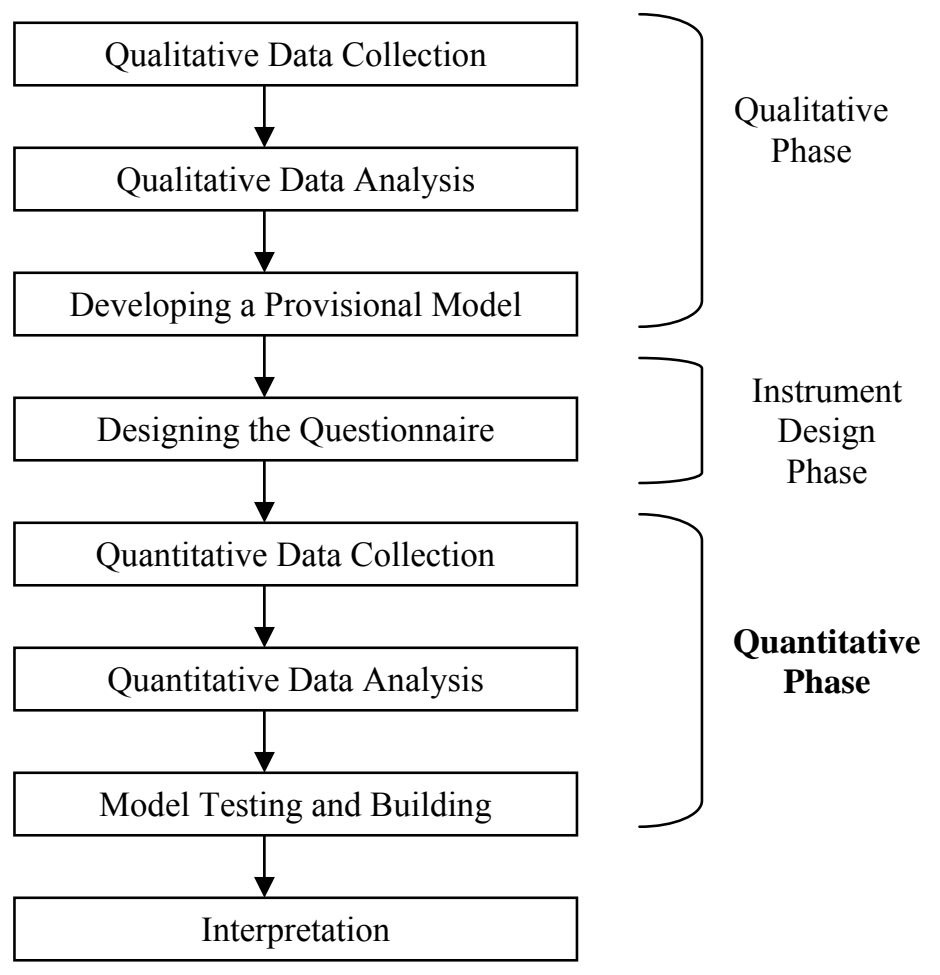

Figure 3-1. The design of the study.

3. The intensity and nature of attitudes may be represented on a linear and numerical scale for the purpose of measurement (Oppenheim, 1966).

\section{Other Methodological Assumptions}

Since interviews were conducted with participants who had previously received feedback and since the questionnaires were administered toward the end of the semester in both universities, the participants were assumed to have some feedback experience before answering the questionnaires. Another assumption made was that the participants were honest in their answers.

\section{Research Method}

This study was conducted in two main phases. In the first phase, qualitative data were collected with the interviews, and in the second phase, quantitative data were collected with a questionnaire. 


\section{Qualitative Phase}

The main purpose of this phase of the study was to develop a background to build a questionnaire and a provisional model to be used in the quantitative phase. Therefore this stage was designed to generate in-depth and rich descriptions about doctoral students' perceptions and attitudes toward different characteristics of written feedback and written feedback providers, how their revision decisions are influenced by these two issues (perceptions and attitudes toward different characteristics of written feedback and written feedback providers), and other potentially relevant factors in the feedback practices. This phase further explored the relationship between all these factors (perceptions and attitudes toward different characteristics of written feedback and written feedback providers, revision decisions, and other potentially relevant factors in the feedback practices of doctoral students).

\section{Qualitative Data Collection}

\section{Interview Guide}

Three common interview formats in qualitative research were suggested: The informal conversational interview, the general interview guide approach, and the standardized open-ended interview (Gall, Gall, \& Borg, 2003). Since there is limited information in the literature about the feedback practices of doctoral students, open-ended questions were asked in order to explore the participants' perceptions and attitudes extensively. Since the interviews were conducted with several participants, the phrasing and sequence of these open-ended questions was determined in advance to reduce bias. Therefore, the format of the interviews can be best categorized as a standardized open-ended interview. The questions were loosely structured to allow participants to express their opinions and experiences freely.

There were three main sections in the interview guide (see Appendix C). The first set of questions was about participants' perceptions toward the definition and purpose of academic writing and the criteria for good academic writing. These were used as opening questions to understand participants' frame of reference regarding the concept of academic writing which was used extensively in the interview guide. A few other questions regarding their general academic writing experiences were also asked. The second set of questions was about the participants' experiences with and preferences for different written feedback 
types and providers. Their revision behaviors were also inquired. These questions informed all four research questions of this study. Finally, a third set of questions covered the participants' specific experiences with written feedback, which also informed all of the research questions. There were a total of 28 main questions in the interview guide. Subquestions and probes were used to request further elaboration on the answers.

To ensure the content validity of the instrument, two researchers who had expertise in interviewing reviewed the interview guide. Pilot tests were also conducted with two doctoral students from the defined population of this research study. Revisions were made after each reviewing occasion.

\section{Participant Selection}

Since the intent of this phase was to reach a comprehensive understanding of the phenomenon in a wide scope, the purposeful sampling method was used for participant selection. The participants who had more academic writing experience compared to other doctoral students in their programs were invited. Moreover, to widen the scope, the participants in a variety of social science programs in a large public university were invited.

First, departments that best represent being social science departments with doctoral programs at Utah State University (USU) were selected considering the subject categories in the Social Science Citation Index (Thomson-Reuters, 2008). Next, e-mails were sent to department heads and/or several faculty members in these eight social science departments requesting references of doctoral students who were (a) at later stages of their program and (b) actively engaged in academic writing activities (see Appendix D). The suggested doctoral students were then sent e-mails requesting an interview along with consent forms (see Appendices A and D). From the 28 e-mail recipients, 7 did not respond, 5 declined because they were out of town, and 1 declined due to a busy schedule. Interviews were conducted with 15 volunteer participants from eight different social science departments at USU (see Table 3-1 for list of departments). The remaining 15 participants' characteristics were still suitable for the initial participant selection criteria.

\section{Interview Participants}

The interview participants were doctoral students, including eight women (53\%) and seven men 
(47\%) from eight different departments at USU (see Table 3-1). Their ages ranged between 29 and 62, and averaged about 35 . Twelve of them $(80 \%)$ were native English speakers. One of the participants had recently graduated and all of the remaining participants were working as graduate assistants.

Four participants were at the end of their coursework or at the comprehensive exam stage. Eight of the participants were writing their dissertation proposal or preparing for their proposal defense. Three participants had completed their proposal stage and were writing or revising their dissertations. As a group, students generally wrote or participated in writing several articles $(M=3.87)$ although there was quite a bit of variation $(S D=2.77)$ with responses as low as 1 and as high as 10 (see Table 3-1).

\section{Interview Process}

Guidelines provided by Holstein and Gubrium (2003) were considered during the planning of the interview process. All the interviews were conducted face to face, one participant at a time, in quiet and isolated rooms, such as in classrooms, conference rooms, or participants' offices, between 8 am and 5pm within a month's time. Mean duration of the interviews was 51.67 minutes (range: 30-67 minutes). A high quality digital audio recorder was used during all of the interviews.

The researcher, a doctoral student, conducted all of the interviews. The researcher had previous experience with conducting standardized open-ended interviews for educational research purposes. Moreover, having a doctoral student conducting the interviews was important considering the absence of power differences, which has a potential affect on participants' responses.

The first contact was through e-mails. In an e-mail, the researcher introduced herself and the research study. Before starting the interviews, the researcher initiated an informal conversation with the participants about nonresearch topics to establish rapport. During the interviews, the participants seemed to be comfortable with the process.

Before starting the interview, the researcher explained the study, the contents of the consent form, and the group of questions in the interview guide. Confidentiality was assured. After the consent forms were signed, the participants were asked questions about their age, occupation, stage of degree completion, and number of publications.

Since the researcher was also a doctoral student in a social science program and also engaged in 
Table 3-1

Interview Participants

\begin{tabular}{lcc}
\hline \multicolumn{1}{c}{ Departments } & $f$ & Mean no. of articles \\
\hline Instructional Technology & 5 & 4.60 \\
Psychology & 3 & 3.00 \\
Special Education and Rehabilitation & 2 & 8.00 \\
Elementary Education & 1 & 3.00 \\
Sociology & 1 & 3.00 \\
Theory and Practice of Professional Communication & 1 & 2.00 \\
Secondary Education & 1 & 1.00 \\
Family, Consumer and Human Development & 1 & 1.00 \\
Total & 15 & 3.87 \\
\hline
\end{tabular}

academic writing activities, there was little problem with understanding the terminology used by the participants. Occasionally, the researcher asked participants to clarify some phrases or idioms used by the participants.

The sequence and the order of the questions were almost the same for each participant. However, the researcher skipped questions if they were already sufficiently answered, jumped to a different question and returned back to the original sequence when the conversation was closely related that different question, or asked extra clarification questions or probes that were not in the interview guide when the answer was not sufficient.

\section{Reaching Saturation}

Between the interviews, the researcher examined the audio recordings and started to detect the main categories and some subthemes in the interviews. After the ninth interview, the main themes and most of the subthemes were roughly clear, and replications of these themes increased. However, the researcher continued to interview until she had reached 15 participants. 


\section{Transcription Process}

The transcription of the interview recordings and the reviewing process of the transcription quality were conducted according to the suggestions provided by Poland (2003). The transcriptions were written by the researcher, who had prior experience performing this task.

To ensure quality, each interview transcript was reviewed at least 4 times and the participants' statements were examined for coherence and consistency by comparing them to the rest of the interview statements. To further enhance trustworthiness two strategies were used:

1. Among all 15 audio recordings, the researcher located the parts in which she experienced the most problems during transcription. Samples of 5 to 6 minutes were extracted from 5 interview recordings and presented to a native English speaker in the Writing Center at USU who had prior transcription experience. Revisions were made.

2. The researcher asked the same Writing Center personnel to randomly select two 10-minute interview recordings from any of the 15 audio recordings that had no identifying information. Thirteen word corrections were made out of 2,992 words (transcription was $99.56 \%$ correct). The mistakes also did not change the content of the sentences, such as "it" vs. "that", or "he would" vs. "he'd."

\section{Human Rights and IRB}

This study was approved by the Utah State University Institutional Review Board (IRB). The identifying information in the recordings was covered with noise in the audio. A code list was prepared that matches the interview recordings and the participants' identifying information, and it was only available to the researcher. The audio recordings and the coded list were destroyed at the end of the study.

The interview participants were given \$20 gift cards as a token of appreciation. As explained in the previous section, the researcher had help from Writing Center at USU for the clarification of some sentences in the recordings. Prior approval for transcription assistance was obtained under the condition that no identifying information was present in the audio recordings. 
Qualitative Data Analysis

Grounded Theory data analysis methods provided by Strauss and Corbin (1998) were adapted in the qualitative analysis of the data. The aim of qualitative data analysis was to discover common themes, constructs, concepts, and dimensions; explore the relationships between these constructs; build a hypothetical theoretical model; and build the foundation for designing the questionnaire items. The qualitative analysis was conducted in three phases: open coding, axial coding, and selective coding (Strauss \& Corbin).

Open coding is defined as "the analytic process through which concepts are identified and their properties and dimensions are discovered in data" (Strauss \& Corbin, 1998, p. 101). The purpose of axial coding is "to begin the process of reassembling data that were fractured during open coding" (p. 124). In axial coding, the categories are linked with subcategories. Selective coding, on the other hand, is "the process of integrating and refining the theory" (p. 143). In this study, diagrams were used as an integration technique. The categories were further revised, some of the infrequent concepts were eliminated, and the consistency between the theory and the data were checked. For more information and examples of these phases, see Chapter 4.

Evaluation Criteria for Qualitative Research Regarding Data, Research Process, and Conclusions

Quantitative research, which assumes objectivity, is usually evaluated considering some agreed and defined criteria, such as validity and reliability. It also focuses on eliminating researcher bias. Although, for qualitative research, adherence to these criteria are usually not appropriate for evaluation (Auerbach \& Silverstein, 2003; Coyle, 2007; Lincoln \& Guba, 1985; Strauss \& Corbin, 1998), some researchers adopted similar criteria that are more suitable for evaluating qualitative research. One of these methods is suggested by Miles and Huberman (1994) which includes processes of data reduction, data display, and conclusion drawing/verification. They stated that “...the meanings emerging from the data have to be tested for their plausibility, their sturdiness, their 'confirmability'- that is, their validity" (p. 11). This study used data reduction methods during open and axial coding stages and data display methods to outline clearly the reduced data in the form of tables and figures during all three coding stages for 
reference. The provisional model was also tested with a larger sample during the quantitative data analysis stage. This relates to the conclusion drawing/verification process.

There are also other criteria suggested only for the evaluation of qualitative research (Coyle, 2007). One of these criterion in naturalistic inquiry is "trustworthiness," which constitutes credibility, transferability, dependability, and confirmability (Lincoln \& Guba, 1985). In terms of the terminology commonly used in quantitative research, the term credibility is defined in relation to internal validity; transferability to external validity; dependability to reliability; and confirmability to objectivity (p. 300). Lincoln and Guba also informed that “...naturalistic criteria of trustworthiness are open-ended; they can never be satisfied to such an extent that the trustworthiness of the inquiry could be labeled as unassailable" (p. 329).

Among several techniques suggested by Lincoln and Guba (1985), the following were used in this study to increase the credibility of the findings. First, they stated that it is important for the researcher to spend enough time to learn the culture and examine the most relevant issues to the research questions thoroughly (p. 302). However, they also warned that, as researchers spend more time in the field their judgments are more likely to be influenced. They continued that "there are no techniques that will provide a guarantee against such influence either unconsciously or consciously; awareness is, however, a great step toward prevention" (p. 304). In this study, since the researcher was also a doctoral student in a social science program for several years, she was familiar with the culture of doctoral students, doctoral education, and academic writing and feedback practices. Paying special attention to any possible detrimental influence, during the interviews the researcher used standardized open-ended interview questions for all participants. Moreover, during the data analysis process she tried to uncover participants' variety of perspectives by being as open minded as possible and examined the transcripts in detail in view of the research questions.

Second, it is stated that the credibility of the results can be further improved by "using different sources, different methods, and sometimes multiple investigators"; in other words, with the techniques of triangulation (Lincoln \& Guba, 1985, p. 307). In this study, during the data collection, multiple participants were interviewed by using multiple and a variety of open-ended questions. During the data analysis, the 
researcher checked the consistency of participants' answers in the transcripts at different levels (paragraph, page, whole transcript). Different data collection methods were also utilized (interview and questionnaire).

Third, archiving raw data is suggested for future analyses and for replication analyses to test the findings. In this study, raw data were obtained, prepared, and archived in the form of transcripts, which allows future references to data and replication studies in line with Human Rights and IRB.

Regarding transferability criteria, it is suggested that the researcher provides thick descriptions from the data for readers to allow them to make their own "transferability judgments" (Lincoln \& Guba, 1985, p. 316). In Chapter 5, the conclusions and interpretations were illustrated by such thick descriptions from the participants' actual interview recordings.

For dependability and confirmability criteria, the process and the product of the inquiry are suggested to be audited. Therefore, a variety of materials should be available for these audits including data analysis findings, explanation of methodological decisions, and interpretations. These materials were prepared in the form of this document and evaluated by the dissertation committee.

Furthermore, since this study adapted grounded theory data analysis methods, some of the criteria related to grounded theory might also be applicable for the evaluation of the data analysis methods. Strauss and Corbin (1998) suggested researchers present detailed information about the coding process. They also outlined several criteria as guidelines to examine the empirical grounding of a research. In the following, these criteria were addressed in relation to this research study.

Are concepts generated? The concepts were generated by the researcher, directly drawn from the interview participants' transcripts, or used same as their common usage. These concepts were categorized and presented in tables in Chapter 4.

Are the concepts systematically related? During axial coding, the concepts in the form of categories were associated with their main and subcategories. Moreover, during the selective coding process, these concepts further linked to each other. In Chapter 4, the relationships between these concepts were analyzed.

Are there many conceptual linkages, and are the categories well developed? Do Categories have conceptual density? As presented in Table 4-1 and Table 4-2 in Chapter 4, main and subcategories were 
developed. Although not presented in this document due to space limitations, several properties and dimensions of these categories were also drawn from the data. Moreover, as can be seen in Figure 4-1, many of these main and subcategories were linked to each other during the selective coding analysis process.

Is variation built into the theory? Are the conditions under which variation can be found built into the study and explained? Has process been taken into account? Concepts were examined in relation to different conditions, action/interactions, and their different dimensions.

Do the theoretical findings seem significant, and to what extent? The model was tested using quantitative methods, and significance of the findings was discussed.

Does the theory stand the test of time and become part of the discussions and ideas exchanged among relevant social and professional groups? Relevant research studies that would test and/or extend the findings of this study were suggested in Chapter 5 .

\section{Instrument Design Phase}

Collection of Participants' Actual Writings and Feedback

To obtain examples of written feedback statements from doctoral students' actual writings to be used in the questionnaire, interview participants were requested to bring or send one of their previous academic papers that had written feedback on it. They were also requested to bring or send the revised version of the same paper. In the consent form, the confidentiality of these documents was assured (see Appendix A). Four participants' documents were received. Two of the academic papers were in the form of journal articles, one was in the form of a dissertation proposal, and the other was a completed dissertation. Most of the feedback comments were from the participants' dissertation committee chairs or members. In total, 319 pages were received and examined. Example feedback statements from these documents were quoted and used in a group of questions in the questionnaire.

Questionnaire Design and Development

The questionnaire was designed based on the qualitative data analysis results using the guidelines for survey research and questionnaire design (Bradburn, Sudman, \& Wansink, 2004; Dillman, 2007; 
Oppenheim, 1966; Rea \& Parker, 2005) (see Appendix G). The researcher prepared a pool of 343 items, 331 of which were in the 4-point Likert scale. Most of the items were directly quoted from the interview transcripts. Iterative pilot tests were conducted with ten doctoral students. For the final questionnaire, 155 items were determined based on the feedback obtained from pilot tests and the consideration of the questions as being the best representatives of the variables they measure.

During the pilot tests, the participants answered the questions, rated the Pilot Test Review Sheets (see Appendix F), and provided feedback about the quality of the questions. The researcher was present at three of these pilot tests and identified the questions that have problems mostly regarding clarity, comprehensiveness, and acceptability (Rea \& Parker, 2005, pp. 31-32). In seven of these pilot tests, the participants completed the questionnaire and the Pilot Test Review Sheet, provided feedback for the questionnaire items, and sent the documents electronically to the researcher. Revisions to the questionnaire were made after each pilot test occasion. Therefore, each subsequent participant received an improved version of the questionnaire. Pilot test data were examined regarding the frequency and variation of responses on the scale and consistency of the responses for each participant.

To ensure the content validity of the questionnaire, two instructors who specialize in Technical Writing reviewed the questionnaire. Content validity testing sheets (see Appendix E) were provided to them. The questionnaire was revised according to their suggestions.

The final questionnaire was converted into an online form and hosted by a professional website that specializes in psychological research (PsychData, 2008). A total of 13 pages and 155 items were included in the final online version of the questionnaire (see Appendix G). The questions were grouped under the following headings: general information, academic writing, program, requesting written feedback, written feedback preferences, critical/negative written feedback, feedback providers, revision decisions, and feedback process in general.

\section{Quantitative Phase}

The purpose of this phase of the study was to identify complex relationship patterns, test the 
strength of the relationships between categories, and reach some degree of generalization with a larger sample.

Quantitative Data Collection

\section{Participant Selection}

A convenience sampling method was used and the doctoral students in social science programs in Utah were recruited. Two universities that provide doctoral programs in Utah were the University of Utah ( $\mathrm{U}$ of $\mathrm{U}$ ) and Utah State University (USU). The decision of which subject categories are regarded as social science, Social Science Citation Index Subject Categories were considered (Thomson-Reuters, 2008). At the University of Utah 22 social science departments and in Utah State University 10 social science departments were identified to have doctoral programs. Their department heads were sent e-mails requesting that they forward the invitation letter to their current and recently graduated doctoral students (see Appendix H). The number of recipient doctoral students is unknown. At University of Utah, 20 of 22 selected departments (91\%) participated in the research, and all of the selected departments at Utah State University (100\%) participated.

\section{Questionnaire Administration}

The questionnaire was administered completely online. The data were collected in one-month duration towards the end of the spring 2008 semester. After the initial notice and data collection, second notices were sent to departments and data were collected again. For some departments, three notices were sent due to lack of participation. It is possible that interview and pilot test participants also completed the questionnaire.

\section{Human Rights and IRB}

No identifying information was asked in the questionnaire. Participants were asked to read the consent form and proceed to the questionnaire only if they agreed (see Appendix B). The data were secured in a password protected survey website, which uses Secure Sockets Layer (SSL) technology. Four participants were selected after a computerized drawing and were given $\$ 100$ gift cards. 


\section{Participants}

The sample consisted of 276 participants, 116 from Utah State University (42\%) and 160 from the University of Utah (58\%). Most of the participants were in the second, third, and fourth years of their doctoral programs (see Table 3-2).

The participants' ages ranged from 22 to $83, M=37(S D=10.17$, Median $=34$, Mode $=29)$. As shown in Table 3-2, $60 \%$ of the participants were women $(n=165)$ while $40 \%$ of them were men $(n=110)$. Most of the participants $(87 \%, n=239)$ reported that they consider English their native language. Eightyone percent $(n=223)$ of the participants were employed but only $56 \%(n=124$ out of 223$)$ of these participants' jobs required them to engage in academic writing.

Almost half of the data (47\%) were collected from doctoral students in Education programs in two universities (see Table 3-3). Table 3-4 shows the participation rate from different colleges. Across both universities, most of the participants were from the following programs: USU Instructional Technology ( $n$ $=27,10 \%)$, USU Psychology $(n=24,9 \%)$, USU Curriculum and Instruction $(n=22,8 \%)$, and UofU Psychology $(n=20,7 \%)$ (see Table 3-5).

Quantitative Data Analysis

Descriptive and multivariate correlational data analyses were conducted. The multivariate correlational analysis was conducted in three main steps: Exploratory Factor Analysis (EFA), Confirmatory Factor Analysis (CFA), and Structural Equation Modeling (SEM). Structural Equation modeling (SEM) is a method for multivariate correlational analysis. It is the most suitable method of analysis for the quantitative phase of this study because SEM can be used to analyze and test theoretical models (Schumacker \& Lomax, 2004). Since this study required testing the theoretical model developed in the qualitative phase, the use of SEM in the quantitative phase was essential. There were several other reasons for using SEM rather than alternative statistical approaches such as multiple regression or path analysis:

a. SEM analysis allows for issues related to prediction as well as measurement (Kelloway, 1998).

b. With SEM, multiple observed variables can be examined compared to some other statistical methods that can only use a limited numbers of variables (Schumacker \& Lomax, 2004).

c. In SEM analyses, measurement error is taken into account (Schumacker \& Lomax, 2004). 
Table 3-2

Participants' Demographic and General Characteristics: Frequencies and Percentages

\begin{tabular}{|c|c|c|c|c|}
\hline Participants' characteristics & UofU- $f$ & USU- $f$ & Total $f$ & $P$ \\
\hline \multicolumn{5}{|l|}{ Gender } \\
\hline Male & 58 & 52 & 110 & $40 \%$ \\
\hline Female & 102 & 63 & 165 & $60 \%$ \\
\hline Missing & & & 1 & $0 \%$ \\
\hline \multicolumn{5}{|l|}{ Language (English) } \\
\hline Native & 137 & 102 & 239 & $87 \%$ \\
\hline Not native & 23 & 13 & 36 & $13 \%$ \\
\hline Missing & & & 1 & $0 \%$ \\
\hline \multicolumn{5}{|l|}{ Employment } \\
\hline Employed & 127 & 96 & 223 & $81 \%$ \\
\hline Not employed & 33 & 20 & 53 & $19 \%$ \\
\hline \multicolumn{5}{|l|}{ Job requires academic writing } \\
\hline Yes & 74 & 50 & 124 & $45 \%$ \\
\hline No & 53 & 45 & 98 & $36 \%$ \\
\hline Not applicable & 33 & 20 & 53 & $19 \%$ \\
\hline Missing & & & 1 & $0 \%$ \\
\hline \multicolumn{5}{|l|}{ Year in the Doc. program } \\
\hline Less than a year & 9 & 10 & 19 & $7 \%$ \\
\hline 1 year & 15 & 9 & 24 & $9 \%$ \\
\hline 2 years & 32 & 31 & 63 & $23 \%$ \\
\hline 3 years & 34 & 21 & 55 & $20 \%$ \\
\hline 4 years & 31 & 22 & 53 & $19 \%$ \\
\hline 5 or more years & 33 & 11 & 44 & $16 \%$ \\
\hline Graduated & 6 & 12 & 18 & $7 \%$ \\
\hline
\end{tabular}


Table 3-3

Frequencies and Percentages of Participants from Different Colleges or Schools

\begin{tabular}{lcccc}
\hline \multicolumn{1}{c}{ Colleges/schools } & UofU $f$ & USU $f$ & Total $f$ & $P$ \\
\hline Education & 29 & 101 & 130 & $47 \%$ \\
Social Sciences and Humanities & 76 & 6 & 82 & $30 \%$ \\
Health Related & 46 & - & 46 & $17 \%$ \\
Business and Economics & 9 & 8 & 17 & $6 \%$ \\
Missing & - & 1 & 1 & $0 \%$ \\
Total & 160 & 116 & 276 & $100 \%$ \\
\hline
\end{tabular}

d. Compared to other methods, it is more powerful and provides more valid and reliable measures

(Gall et al., 2003).

e. Compared to multiple regression, it can have more than one dependent variable and a variable can be both a dependent and independent variable (Norman \& Streiner, 2003), which is more rational in the natural setting for this research for which variables were neither manipulated nor controlled.

f. With SEM analysis, both "direct" and "indirect" effects of the variables can be examined (Raykov \& Marcoulides, 2000, p. 7).

g. Compared to Path Analysis, it can have latent variables, which are theoretical constructs not directly observed (Norman \& Streiner, 2003).

In order to conduct SEM, a theoretical model with latent variables and observed variables were needed. Exploratory Factor Analysis (EFA) was initially conducted to find out the latent constructs underlying the group of measured variables based on the data. Confirmatory Factor Analysis (CFA), which is another type of SEM analysis, was conducted after EFA for establishing the "construct validity" of the factors (Brown, 2006, p. 2) and as an a priori step for SEM analysis. Brown (2006) has said:

The results of CFA can provide compelling evidence of the convergent and discriminant validity of theoretical constructs. Convergent validity is indicated by evidence that different indicators of theoretically similar or overlapping constructs are strongly interrelated.... Discriminant validity is indicated by results showing that indicators of theoretically distinct constructs are not highly intercorrelated. (pp. 2-3) 
Table 3-4

Percentages of Participation from Two Universities

\begin{tabular}{lccc}
\hline \multicolumn{1}{c}{ Colleges/schools } & $\begin{array}{c}\text { No. of enrolled } \\
\text { doctoral students } \\
\text { who participated }\end{array}$ & $\begin{array}{c}\text { No. of enrolled } \\
\text { doctoral students at } \\
\text { UofU and USU }\end{array}$ & $\begin{array}{c}\text { P participation/ } \\
\text { participation rate }\end{array}$ \\
\hline Education & 26 & UofU & $15 \%$ \\
Social Sciences and Humanities & 74 & 175 & $28 \%$ \\
Health Related & 45 & 265 & $24 \%$ \\
Business and Economics & 9 & 185 & $8 \%$ \\
Total & 154 & 118 & $21 \%$ \\
\hline & & 743 & $34 \%$ \\
Education & 90 & USU & $29 \%$ \\
Social Sciences and Humanities & 6 & 265 & NA \\
Health Related & NA & 21 & $54 \%$ \\
Business and Economics & 7 & NA & $34 \%$ \\
Total & 104 & 13 & \\
\hline
\end{tabular}

Note. USU data is based on the School of Graduate Studies information and University of Utah data is based on the University of Utah's 2007-2008 Office of Budget and Institutional Analysis (OBIA, 2008)

report. For two departments that do not have information in the OBIA report, the data were gathered from department secretaries. One USU participant had a missing datum about the program. 
Table 3-5

Frequencies and Percentages of Participants from Different Programs

\begin{tabular}{lll}
\hline Colleges/schools and programs & $f$ & $P$ \\
\hline UNIVERSITY OF UTAH &
\end{tabular}

Education

Educational Leadership and Policy

Education, Culture and Society

Special Education

Educational Psychology

Teaching and Learning

Total

Social Sciences and Humanities

Psychology

Social Work

Anthropology

History

Linguistics

Geography

Political Science

Sociology

Total

Health Related Departments

Nursing

Public Health

Health Promotion and Education

Parks, Recreation, and Tourism
11

9

4

3

2

29

20

11

9

9

9

8

7

3

76

15

11

3
$28 \%$

$4 \%$

$3 \%$

$1 \%$

$1 \%$

$1 \%$

$10 \%$

$7 \%$

$4 \%$

$3 \%$

$3 \%$

$3 \%$

$3 \%$

$3 \%$

$1 \%$

$5 \%$

$5 \%$

$4 \%$

$1 \%$ 


\begin{tabular}{lcc}
\hline \multicolumn{1}{c}{ Colleges/schools and programs } & $f$ & $P$ \\
\hline Speech-Language Pathology and Audiology & 2 & $1 \%$ \\
Total & 46 & $17 \%$ \\
Business \& Economics & & \\
Economics & 7 & $3 \%$ \\
Business Administration & 2 & $1 \%$ \\
Total & 9 & $3 \%$ \\
\hline
\end{tabular}

Education

$\begin{array}{lcc}\text { Instructional Technology } & 27 & 10 \% \\ \text { Psychology } & 26 & 9 \% \\ \text { Curriculum \& Instruction }^{\text {a }} & 22 & 8 \% \\ \text { Special Education and Rehabilitation } & 12 & 4 \% \\ \text { Education }^{\text {a }} & 8 & 3 \% \\ \text { Elementary/Early Childhood Education } & 3 & 0 \% \\ \text { Research \& Evaluation }^{\text {a }} & 1 & 0 \% \\ \text { Secondary Education }^{\text {Family, Consumer and Human Development }} & 1 & 0 \% \\ \text { Total } & 1 & 37 \%\end{array}$

Social Sciences and Humanities

Sociology

$41 \%$

Theory and Practice of Professional Communication $\quad 2 \quad 1 \%$

$\begin{array}{lll}\text { Total } & 6 & 2 \%\end{array}$

Business \& Economics

Business/Management Information Systems ${ }^{\text {a }} \quad 4 \quad 1 \%$

$\begin{array}{lrl}\text { Economics } & 4 & 1 \%\end{array}$

(table continues) 


\begin{tabular}{|c|c|c|}
\hline Colleges/schools and programs & $f$ & $P$ \\
\hline Total & 8 & $3 \%$ \\
\hline Missing & 1 & $0 \%$ \\
\hline Total & 276 & $100 \%$ \\
\hline
\end{tabular}

${ }^{\mathrm{a}}$ Interdepartmental programs are Curriculum and Instruction, Education, Research and Evaluation, and Management Information Systems. Some of the participants preferred to indicate their programs only according to interdepartmental programs.

After these analyses, based on the provisional model, a hypothetical model was developed by specifying the relationships between the factors resulted from EFA. Later, this model was tested using SEM analysis to "determine the extent to which the theoretical model is supported by sample data" (Schumacker \& Lomax, 2004, p. 2). The hypothetical model was modified several times; but the modified models were never departed far from the hypothetical model. During this process, the significance values and fit indexes were considered and some of the factors were dropped from the model considering their weak association with other factors. A modified model with satisfactory indexes and significant relationships between its constructs were identified.

Model fit is defined as follows: "model fit determines the degree to which the sample variancecovariance data fit the structural equation model" (Schumacker \& Lomax, 2004, p. 100). One criterion to examine for model fit is "the statistical significance of individual parameter estimates for the paths in the model," which is usually evaluated with .05 level of significance (Schumacker \& Lomax, p. 81). Other criteria to consider are the fit indexes. Although there is not an agreed and strict list of fit indexes to be examined and criteria to be met while evaluating the model fit (Hu \& Bentler, 1999), the researchers usually consider the following conventional fit indexes: Chi-square $\left(\chi^{2}\right)$, Comparative Fit Index (CFI), Tucker Lewis Index (TLI), and Root Mean Square Error of Approximation (RMSEA).

The cutoff criteria for fit-indexes vary in different publications. Hu and Bentler (1999) stated that “...it is difficult to designate a specific cutoff value for each fit index because it does not work equally well with various conditions" (p. 27). Similarly Schumaker and Lomax (2004) stated “...there has been much controversy and discussion on their subjective interpretation and appropriateness under specific modeling 
conditions" (p. 106). The conventional criteria consider "any model with a fit index above .9 as acceptable" (Hu \& Bentler, p. 5). However, Hu and Bentler suggested cutoff criteria for fit indexes as .95 (see Table 36). For chi-square criteria a nonsignificant value is suggested (Schumacker \& Lomax). However it is warned that this value is affected by sample size. When sample size is larger than 200 , it tends to result in significant values. Alternative criterion is suggested by Hatcher (1994). Regarding RMSEA index, Browne and Cudeck (1993) suggested the cut-off values presented in Table 3-6.

Several post analyses were conducted to extend the findings of this research study. Since students' general characteristics have the potential to influence all of their perceptions and attitudes, and since it was not feasible to include and test all of these relationships in SEM analysis, these analyses were conducted after testing the model. The relation of the tested model to the students' general characteristics, such as age, gender, year in the program, employment, native language, perceived writing ability, and so forth were examined. For variables with continuous metrics, bivariate correlational analysis was conducted, and for variables with categorical metrics, independent samples $t$ test was conducted.

In the quantitative data analysis and postanalysis phases SPSS v15 software was used in the analysis of most of the data, including EFA. In the case of CFA and SEM, Mplus v5 software, which is a statistical modeling program, was used. 
Table 3-6

Criteria for Model Fit

\begin{tabular}{|c|c|c|}
\hline $\begin{array}{l}\text { Model fit } \\
\text { criterion }\end{array}$ & Description & Suggested criteria \\
\hline Chi-square $\left(\chi^{2}\right)$ & $\begin{array}{l}\text { "The } \chi^{2} \text { goodness-of-fit statistic assesses the magnitude } \\
\text { of discrepancy between the sample and fitted } \\
\text { covariance matrices, and it is the product of the sample } \\
\text { size minus one and the minimum fitting function" (Hu } \\
\& \text { Bentler, 1999, p. 2). } \\
\text { Note: This statistic is affected by sample size. When } \\
\text { sample size is more than } 200, \chi^{2} \text { tends to result in a } \\
\text { significant value. Therefore conclusions based on this } \\
\text { value may be erroneous (Schumacker \& Lomax, 2004). }\end{array}$ & $\begin{array}{l}\text { a. Chi-square }\left(\chi^{2}\right) \text { statistic to } \\
\text { degrees of freedom }(\mathrm{df}) \\
\text { ratio } \leq 2 \text { (Hatcher, 1994) } \\
\text { b. Non-significant value of } \\
\chi^{2} \text { (Schumacker \& Lomax, } \\
2004)\end{array}$ \\
\hline $\begin{array}{l}\text { Comparative } \\
\text { Fit Index (CFI) }\end{array}$ & $\begin{array}{l}\text { "The CFI is defined as the ratio of improvement in } \\
\text { noncentrality (moving from the null to the proposed } \\
\text { model) to the noncentrality of the null model" } \\
\text { (Raykov \& Marcoulides, 2000, p. 41) }\end{array}$ & $\begin{array}{l}\text { CFI } \geq .95 \\
(\mathrm{Hu} \& \text { Bentler, 1999) }\end{array}$ \\
\hline $\begin{array}{l}\text { Tucker Lewis } \\
\text { Index (TLI) }\end{array}$ & $\begin{array}{l}\text { "The measure can be used to compare alternative } \\
\text { models or a proposed model against a null model" } \\
\text { (Schumacker \& Lomax, 2004, p. 103) }\end{array}$ & $\begin{array}{l}\text { TLI } \geq .95 \\
(\mathrm{Hu} \& \text { Bentler, 1999) }\end{array}$ \\
\hline $\begin{array}{l}\text { Root Mean } \\
\text { Square Error } \\
\text { of } \\
\text { Approximation } \\
\text { (RMSEA) }\end{array}$ & $\begin{array}{l}\text { "The RMSEA is a population-based index that relies } \\
\text { on the noncentral } \chi^{2} \text { distribution, which is the } \\
\text { distribution of the fitting function... when the fit of the } \\
\text { model is not perfect....The RMSEA is an "error of } \\
\text { approximation' index because it assesses the extent to } \\
\text { which a model fits reasonably well in the population } \\
\text { (as opposed to testing whether the model holds exactly } \\
\left.\text { in the population; cf. } \chi^{2}\right) \text { " (Brown, 2006, p. 83). }\end{array}$ & $\begin{array}{l}\text { a. RMSEA } \leq .06 \\
\text { (Hu \& Bentler, 1999) } \\
\\
\text { b. RMSEA } \leq .05: \text { Close fit } \\
.05 \leq \text { RMSEA } \leq .08: \text { Fair } \\
\text { fit } \\
\text { RMSEA } \geq .10: \text { Poor fit } \\
\text { (Browne \& Cudeck, 1993) }\end{array}$ \\
\hline
\end{tabular}




\section{CHAPTER 4}

\section{RESULTS}

In this chapter, the results of the qualitative and quantitative data analyses are presented.

Qualitative data analysis was conducted according to the guidelines provided by Strauss and Corbin (1998). It included three main stages: open coding, axial coding, and selective coding. Quantitative data analysis was also conducted in three main stages: (1) Descriptive data analyses, (2) Multivariate correlational data analysis including Exploratory Factor Analysis (EFA), Confirmatory Factor Analysis (CFA), and Structural Equation Modeling (SEM), and (3) Post analyses.

\section{Qualitative Data Analysis}

\section{Open Coding and Axial Coding Results}

During open and axial coding stages, the data were closely examined, main categories and their subcategories were developed, the properties and dimensions were explored, and patterns were examined. During these analyses, analytic techniques which were suggested by Strauss and Corbin were used (1998).

The main unit of analysis for open and axial coding was concepts. As presented in Chapter 3, during the detailed analysis, the concepts were generated by the researcher, directly drawn from the interview participants' transcripts, or used according to their common usage.

The transcripts were examined to systematically find main categories, subcategories, and properties and dimensions of these categories. Strauss and Corbin (1998) defined these as follows: Concepts are "the building blocks of theory,” categories are "concepts that stand for phenomena," subcategories are "concepts that pertain to a category, giving it further clarification and specification," properties are "characteristics of a category, the delineation of which defines and gives it meaning," and dimensions are "the range along which general properties of a category vary, giving specification to a category and variation to the theory” (Strauss \& Corbin, p. 101)

Regarding the guidelines provided by Strauss and Corbin (1998) about conducting open and axial coding, first the transcript data were analyzed at the paragraph level. Answers to each main question in the 
interview were examined and temporary main categories were labeled. Next, the data were analyzed at the sentence level, temporary subcategories were discovered, and main categories were further developed.

One sentence was sometimes related to more than one concept.

Finally, the transcripts were further examined and analyzed in detail more than ten times to reach reasonable saturation for main categories, subcategories, and their dimensions. This process was iterative. The borders of each main and subcategories were not determined at the beginning of the analysis. These categories were revised throughout the analysis. The open and axial coding analyses were stopped when (a) a meaningful categorization was developed after many iterative examinations of the transcripts; (b) subcategories, properties, and dimensions were repeated; (c) not much relevant and new information was coming from the transcripts and even though some new information was found, it fits the existing categorization.

Table 4-1 and Table 4-2 present the final categorization. These categories should not be considered definite ones or have strict boundaries. However, they can be considered as adequate for the subsequent data analysis stages and designing the questionnaire.

The following example may illustrate the open and axial coding processes: In line with the research questions, several questions were asked of the participants during the interviews regarding feedback providers, such as "whom do you mostly get feedback from?," "what are the important characteristics of this person that lead you to ask for feedback?," "what do you think are his/her motivations or reasons to give you feedback?," and "what kind of feedback do they give to you?”. The participants answered these questions with variety of responses. Through iterative examination of transcripts, subcategories started to emerge such as feedback providers' willingness to help, personality, writing style, and so forth. After several thorough examinations of the transcripts at paragraph, sentence, and idea level, repetitive occurrences of these subcategories were observed. Moreover, not much new information was coming from the transcripts. Even when new information was found, it fit these subcategories.

To further illustrate, the following information was drawn from the data: several participants explained that some of their professors have very high expectations or very low expectations from them; 
sometimes they ask too much from the participants than they are able to do; they expect participants to adapt one's work to their own preferences; or expect participants to revise their papers if the participants were the ones who asked for feedback. They further explained that some reviewers have high or low expectations about the quality of the participants' paper to begin with before they start reading and reviewing their papers. All of these and several other ideas were related to feedback providers' expectations from the participants. Therefore, this subcategory was generated and named as 'feedback providers' expectations from the author”. The transcripts were examined several times and some other relevant ideas were found to increase the saturation of this subcategory. Other subcategories were also developed in the same way.

The identified 12 main categories and their subcategories are listed in Table 4-1. The properties and dimensions of the subcategories were also categorized; however they are not presented in this document due to space limitations. During the questionnaire design, except for specific academic writing instances category, all other main categories, most of their subcategories, and some of their properties and dimensions were represented in the questionnaire.

Considering the first research question of this study, different feedback characteristics were also analyzed and outlined during the qualitative data analysis (see Table 4-2). These categories were also represented in the questionnaire in the form of attitude statements and in the form of actual written feedback examples.

Four main written feedback categories were defined after the analysis: (a) external qualities, (b) internal qualities, (c) content, and (d) groups of written feedback. External qualities of written feedback category represents the characteristics of written feedback related to its delivery, location, amount, format, and provider. On the other hand, internal qualities of written feedback category represents issues such as the clarity, relevance, justification, specificity, and tone of written feedback. Content category stands for the written feedback provided regarding certain matters in a paper, such as content and arguments, organization and flow, and mechanical issues, and so forth. Finally, groups of written feedback represents several feedback occasions which can be complementary, contradictory, and follow-up. 
Table 4-1

Open and Axial Coding Results: Main and Subcategories

\begin{tabular}{ll}
\hline \multicolumn{1}{c}{ Main categories } & \multicolumn{1}{c}{ Subcategories } \\
\hline 1. Author's characteristics & $\begin{array}{l}\text { a. General information and demographics } \\
\text { b. Interests, goals, self-confidence level, and other personality traits } \\
\text { c. Characteristics regarding academic writing (previous experiences, } \\
\text { general academic writing ability, confidence in writing academic } \\
\text { papers, academic writing style, attitudes toward writing academic } \\
\text { papers etc.) }\end{array}$ \\
$\begin{array}{l}\text { d. Characteristics regarding written feedback (expectation levels, the } \\
\text { level of emotional control after receiving negative feedback, need for } \\
\text { certain types of feedback, etc.) }\end{array}$ \\
$\begin{array}{l}\text { a. Perceptions of the purposes and functions of academic writing } \\
\text { toward academic writing }\end{array}$ \\
$\begin{array}{l}\text { b. Perceptions of the defining characteristics of academic writing } \\
\text { c. Perceptions of criteria for good academic writing }\end{array}$ \\
$\begin{array}{l}\text { d. Perceptions of the audience of academic writing } \\
\text { e. Attitudes toward writing academic papers and academic writing } \\
\text { process }\end{array}$
\end{tabular}

f. Attitudes toward learning academic writing

3. Motivations for academic writing

4. Types of academic writing a. Motivations related to personal goals

b. Motivations related to the field

a. Perceptions and attitudes toward different types of academic writing

b. Attitudes toward turning one type into another

c. Different categorizations

a. Perceptions toward the discipline regarding academic writing

b. Perceptions toward the program/department regarding academic writing

c. Perceptions toward available opportunities in the program to engage in academic writing 


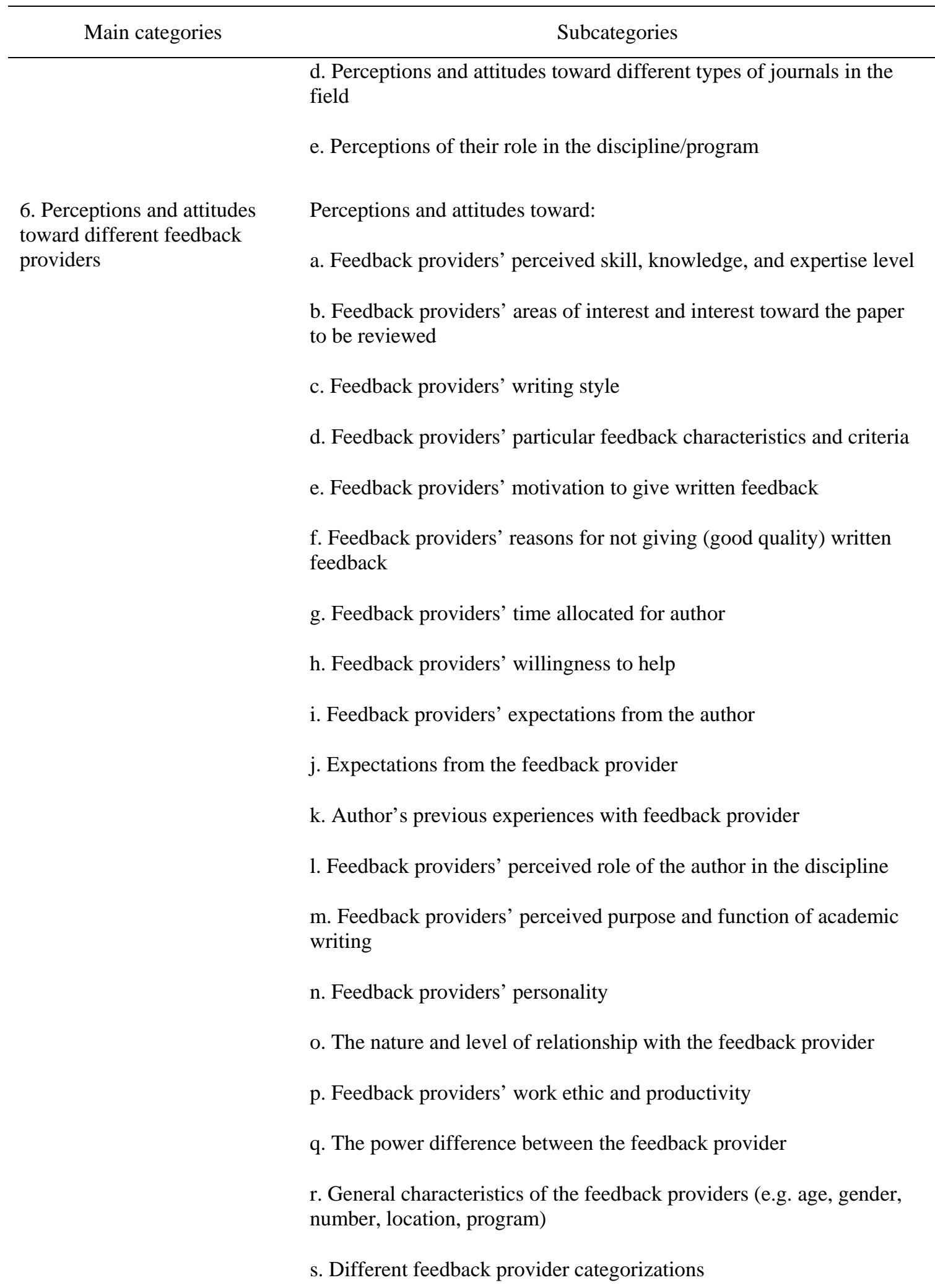




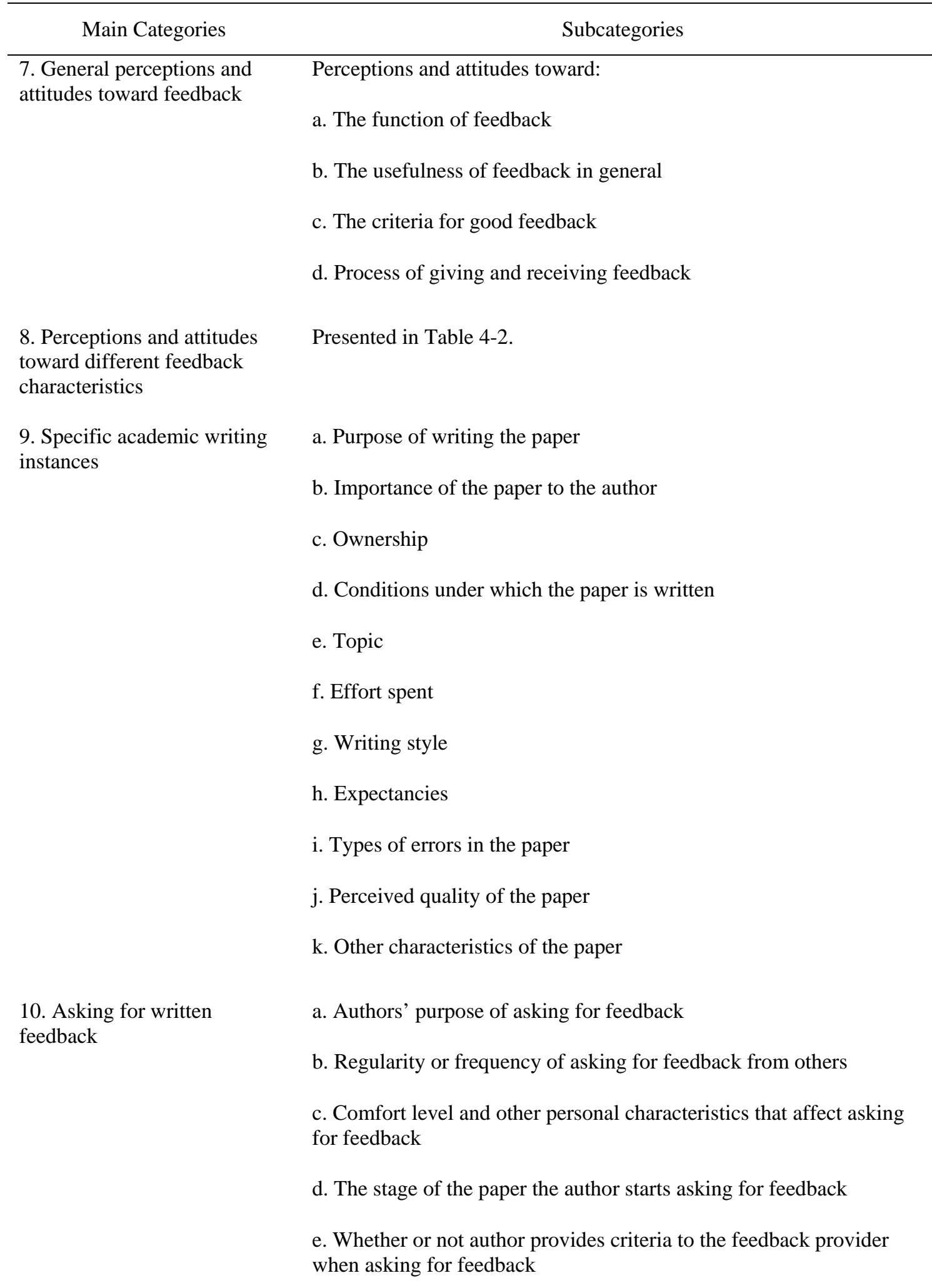




\begin{tabular}{ll}
\hline \multicolumn{1}{c}{ Main Categories } & \multicolumn{1}{c}{ Subcategories } \\
\hline $\begin{array}{l}\text { 11. Examination of written } \\
\text { feedback }\end{array}$ & a. Comparing comments with author's knowledge or ideas \\
b. Checking the justification and the correctness of feedback \\
c. Decision making after expectancy conflict \\
d. Decision making about rewriting or not \\
e. Decision making about revising according to the comment or not \\
f. Decision making about revising according to required effort and time \\
g. Examining contradictory feedback from different people \\
h. Emotional effect of the written feedback \\
a. Personal characteristics that affect the revision behavior \\
b. Motivations or reasons for making the revisions, punishment-reward \\
issues \\
c. Decisions to follow-up or not with the feedback provider \\
d. Timing of the revisions \\
Acception-Rejection decisions based on: \\
e. Feedback provider \\
f. Feedback characteristics \\
i. Effort and skill needed to revise, feasibility of making the revisions \\
\hline
\end{tabular}


Table 4-2

Identified Different Feedback Characteristics

\begin{tabular}{cll}
\hline Main categories & Subcategories & Further subcategories/ properties/ dimensions \\
\hline
\end{tabular}

A. External qualities

1. Written feedback delivery

b. Handwritten vs. electronic written feedback

c. Media/technology used

d. Timing based on the draft progress

e. Turnaround duration

f. Frequency and regularity of feedback
-Written feedback only

-Combination of written and oral feedback

-Handwritten feedback

-Electronic written feedback

-For sending the paper

-For receiving the paper with feedback

-Feedback during the writing process

-Feedback after the significant part of the paper is written

-Late feedback

-Same day

-Two weeks

-One month

-One feedback occasion for a paper

-Regular feedback occasions from one feedback provider

-Several feedback occasions from one feedback provider for a paper

-Several feedback occasions from different feedback providers at the same time for a paper

-Several feedback occasions from different feedback providers at different times for a paper

(table continues) 


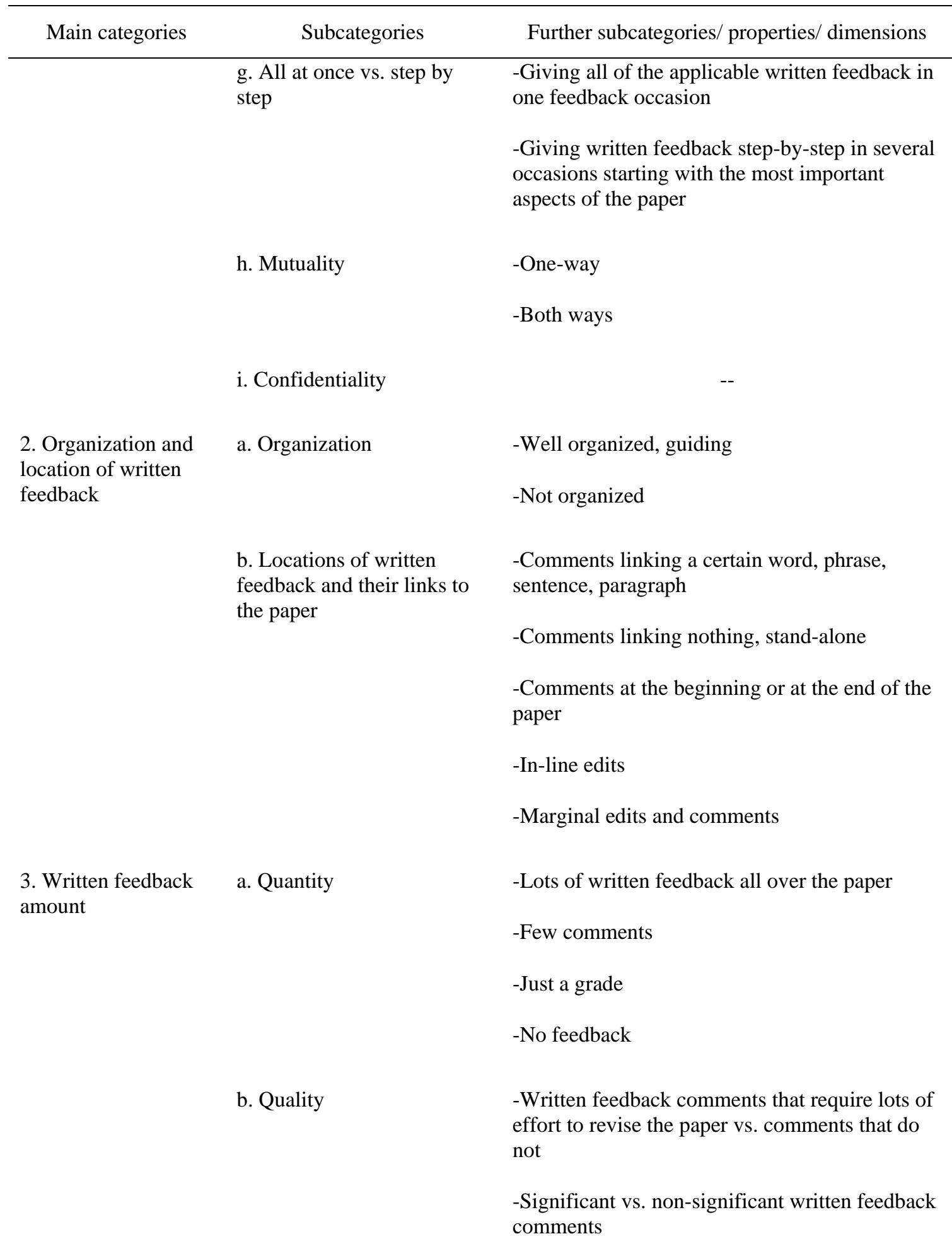

(table continues) 


\begin{tabular}{|c|c|c|}
\hline Main categories & Subcategories & Further subcategories/ properties/ dimensions \\
\hline \multirow{10}{*}{$\begin{array}{l}\text { 4. Written feedback } \\
\text { format }\end{array}$} & a. Color & -Red \\
\hline & & -Blue \\
\hline & & -Pencil \\
\hline & b. Marks & -Question mark \\
\hline & & -Exclamation mark \\
\hline & & -Underline \\
\hline & & -Parenthesis around a sentence \\
\hline & & -Circle \\
\hline & & -Strikethrough \\
\hline & c. Comments & -- \\
\hline $\begin{array}{l}\text { 5. Written feedback } \\
\text { provider }\end{array}$ & -- & -- \\
\hline
\end{tabular}

1. Clarity of written feedback

\section{B. Internal qualities}

2. Relevance of written feedback

3. Feasibility and applicability of written feedback in revisions

4. Correctness or sensibility of written feedback

5. Importance of written feedback 


\begin{tabular}{|c|c|c|}
\hline Main categories & Subcategories & Further subcategories/ properties/ dimensions \\
\hline $\begin{array}{l}\text { 6. Flexibility of } \\
\text { written feedback for } \\
\text { revisions }\end{array}$ & -- & -- \\
\hline $\begin{array}{l}\text { 7. Depth and scope of } \\
\text { written feedback }\end{array}$ & -- & -- \\
\hline $\begin{array}{l}\text { 8. Justification of } \\
\text { written feedback }\end{array}$ & -- & -- \\
\hline \multirow[t]{4}{*}{$\begin{array}{l}\text { 9. Specificity of } \\
\text { written feedback }\end{array}$} & a. General feedback & $\begin{array}{l}\text {-General and superficial written feedback about } \\
\text { the overall quality of the paper }\end{array}$ \\
\hline & & $\begin{array}{l}\text {-General written feedback that evaluates the } \\
\text { paper conceptually in a holistic view, detects } \\
\text { patterns of errors }\end{array}$ \\
\hline & b. Specific feedback & $\begin{array}{l}\text {-Specific written feedback that focus on very } \\
\text { small, unimportant corrections }\end{array}$ \\
\hline & & $\begin{array}{l}\text {-Specific written feedback indicates sentences or } \\
\text { paragraphs of the paper, detailed, and significant }\end{array}$ \\
\hline \multirow{8}{*}{$\begin{array}{l}\text { 10. Positive/ } \\
\text { negative, \& } \\
\text { suggestions }\end{array}$} & $\begin{array}{l}\text { a. Positive with or without } \\
\text { suggestions }\end{array}$ & $\begin{array}{l}\text {-Mostly positive, supportive, praise, no } \\
\text { suggestion }\end{array}$ \\
\hline & & -Mostly positive with suggestions \\
\hline & & -Balanced positive and negative \\
\hline & $\begin{array}{l}\text { b. Negative with or without } \\
\text { suggestions }\end{array}$ & -Mostly negative, critical with suggestions \\
\hline & & -Mostly negative, overly critical, no suggestions \\
\hline & & $\begin{array}{l}\text {-Mostly negative, focus on unimportant small } \\
\text { details }\end{array}$ \\
\hline & $\begin{array}{l}\text { c. The sequence of positive } \\
\text { and negative comments }\end{array}$ & -Starting with positive comments \\
\hline & & -Starting with negative comments \\
\hline $\begin{array}{l}\text { 11. Scaffolding } \\
\text { degree of written } \\
\text { feedback }\end{array}$ & Low vs. High & $\begin{array}{l}\text {-General advice and strategies } \\
\text {-Shows general problems, gives hints, asks } \\
\text { questions }\end{array}$ \\
\hline
\end{tabular}




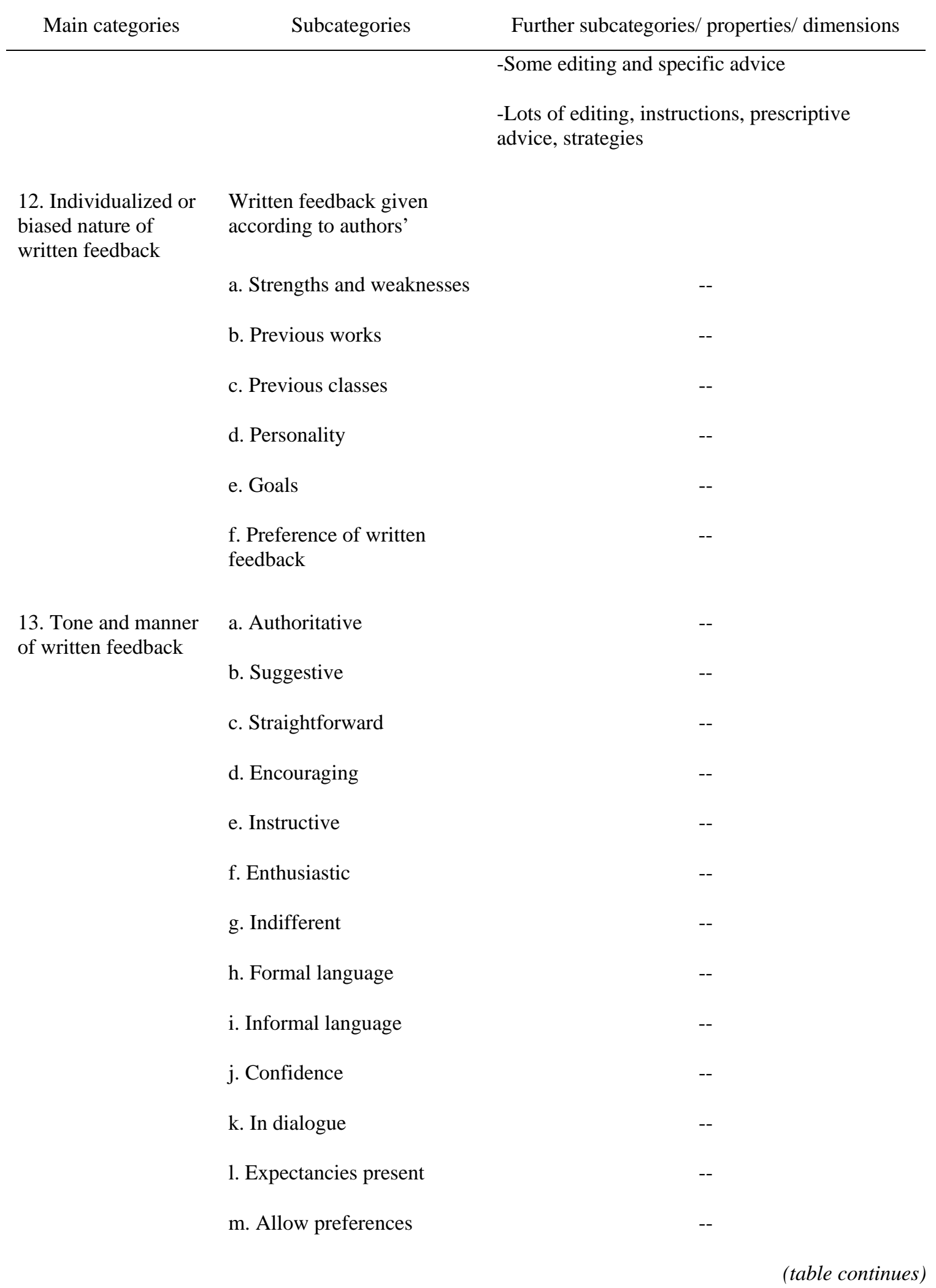




\begin{tabular}{|c|c|c|}
\hline Main categories & Subcategories & Further subcategories/ properties/ dimensions \\
\hline & n. Direct or in-direct & -Direct negative/critical feedback \\
\hline & & $\begin{array}{l}\text {-Giving negative/critical feedback in a more } \\
\text { gentle way }\end{array}$ \\
\hline & o. Insult/attack & $\begin{array}{l}\text {-Insulting, sarcastic, offensive, snotty, rude, } \\
\text { harsh, humiliating }\end{array}$ \\
\hline & & -Personal attack toward the person, not the paper \\
\hline & & -Biased and prejudiced \\
\hline $\begin{array}{l}\text { 14. The Level of } \\
\text { technical language } \\
\text { and terminology used }\end{array}$ & -- & -- \\
\hline
\end{tabular}

\section{Content}

1. Content and arguments in the paper a. Content and arguments

b. Coverage

c. Reader consideration
-Accuracy/sensibility

-Clarity and understandability

-Obsoleteness

-Concepts and categorizations

-Adding or removing information and explanations

-Adding or removing a section

-Adding or removing a paragraph, sentence, word

-Adding or removing references and literature

-Removing a research question and reducing the extent of the research

-Interestingness of the topic

-Timeliness of the topic

-Revisions needed regarding the audience 


\begin{tabular}{|c|c|c|}
\hline Main categories & Subcategories & Further subcategories/ properties/ dimensions \\
\hline \multirow{9}{*}{$\begin{array}{l}\text { 2. Direction of the } \\
\text { paper }\end{array}$} & d. Parts of the paper & $\begin{array}{l}\text {-Significance and the strength of the research } \\
\text { study }\end{array}$ \\
\hline & & -Research Questions \\
\hline & & -Methodology \\
\hline & & -Statistics \\
\hline & & -Inferences and conclusions \\
\hline & a. Strengthens & -Strengthen the direction of the paper \\
\hline & & -Questioning the direction \\
\hline & & $\begin{array}{l}\text {-Giving a direction if the paper does not have } \\
\text { one }\end{array}$ \\
\hline & & -Change the direction of the paper overall \\
\hline \multirow[t]{5}{*}{ 3. Mechanical Issues } & a. Grammar & -- \\
\hline & b. Punctuation & -- \\
\hline & c. Sentence structure & -- \\
\hline & d. Formatting & -- \\
\hline & e. References \& citations & -- \\
\hline \multirow[t]{4}{*}{$\begin{array}{l}\text { 4. Organization and } \\
\text { flow of the paper }\end{array}$} & $\begin{array}{l}\text { a. Organization and location } \\
\text { of things in the paper }\end{array}$ & -- \\
\hline & b. Logical order of ideas & -- \\
\hline & c. Transitions and flow & -- \\
\hline & d. Consistency in the paper & -- \\
\hline \multicolumn{3}{|c|}{ D. Groups of written feedback } \\
\hline \multirow{2}{*}{$\begin{array}{l}\text { 1. Complementary } \\
\text { vs. contradictory } \\
\text { written feedback }\end{array}$} & a. Complementary feedback & -- \\
\hline & $\begin{array}{l}\text { b. Contradictory feedback } \\
\text { from the same person }\end{array}$ & -- \\
\hline
\end{tabular}




\begin{tabular}{lcc}
\hline \multicolumn{1}{c}{ Main categories } & Subcategories & Further subcategories/ properties/ dimensions \\
\hline & $\begin{array}{l}\text { c. Contradictory feedback } \\
\text { from different people }\end{array}$ & -- \\
& -- & -- \\
2. Follow-up written & & \\
feedback & &
\end{tabular}

Note. Some of the main categories do not include any subcategories, properties, or dimensions. These empty cells are represented by (--) symbol.

\section{Selective Coding Results}

During the selective coding and integration processes, the interview transcripts were reviewed again and the sentences or idea units representing relationships between both main categories and subcategories were located. Each of these sentences or units was numbered on the transcripts. For example, one participant stated: "I think the more, the better relationship you have, then more closely you work with those people and that is just kind of sets in motion that cycle of going to those people for more feedback and more feedback and you forge those relationships”. This part of the transcript was labeled as \#337 on the transcript document. Similarly, sentences or units representing a relationship between main and subcategories were labeled with numbers on the transcript document.

Then, using IHMC CmapTools Software (2008), these categories and subcategories were visually linked (see Figure 4-1). The numbers located between each main or subcategory represent the idea units which were numbered on the transcript documents. For example, \#337 represents the relationship between the subcategory "regularity or frequency of asking for feedback from others" and another subcategory "perceptions and attitudes toward: the nature and level of relationship with the feedback provider". While the former subcategory related to the main category "asking for written feedback", the latter was the subcategory of main category "perceptions and attitudes toward different feedback providers”.

To obtain further information about these relationships, the frequencies of relationships in the data were also calculated by counting the number of such sentences or idea units in the transcripts. For example, as can be seen in Figure 4-1, there is only one idea unit (\#337) between aforementioned subcategories. However, some other relationships include several transcript numbers, which means there were more 
frequent references to these relationships in the interviews. As presented in Table 4-3, these numbers were counted for each main category. This table shows the relationships with frequencies of 10 and more. The influence directions were suggested based on the qualitative data analysis to be used for the provisional model.

As relationship frequency column of Table 4-3 shows, the interview transcripts included frequent reference to relationships between perceptions and attitudes toward the feedback providers, perceptions and attitudes toward the feedback characteristics, issues related to participants' asking for written feedback, and their revision decisions.

Based on these analyses results, the following provisional model was developed (see Figure 4-2). Author characteristics category had the potential to influence many other categories. Therefore, this category was not included in the model. Instead, the relationship of this category with other categories were examined in the post analyses. Specific writing instances included situational contexts and therefore this category was not included in the model either. However, these instances were referred to during the design of the questionnaire. Types of academic writing, perceptions and attitudes toward academic writing, and general perceptions and attitudes toward feedback categories were not included in the provisional model either because of their low frequency of relationships with other categories. However, all of these categories were represented in the questionnaire.

The provisional model represents frequent relationships between main categories that were found during the qualitative analysis. According to this model, doctoral students' motivations for academic writing are influenced by their perceptions and attitudes toward their discipline or program. In turn, their motivations affect issues related to students' asking for written feedback and also their revision decisions after receiving written feedback. Students’ perceptions and attitudes toward the feedback provider influence students' revision decisions and their perceptions and attitudes toward the characteristics of feedback given by these individuals. Moreover, students' perceptions and attitudes toward the different feedback characteristics affect their revision decisions as well. 


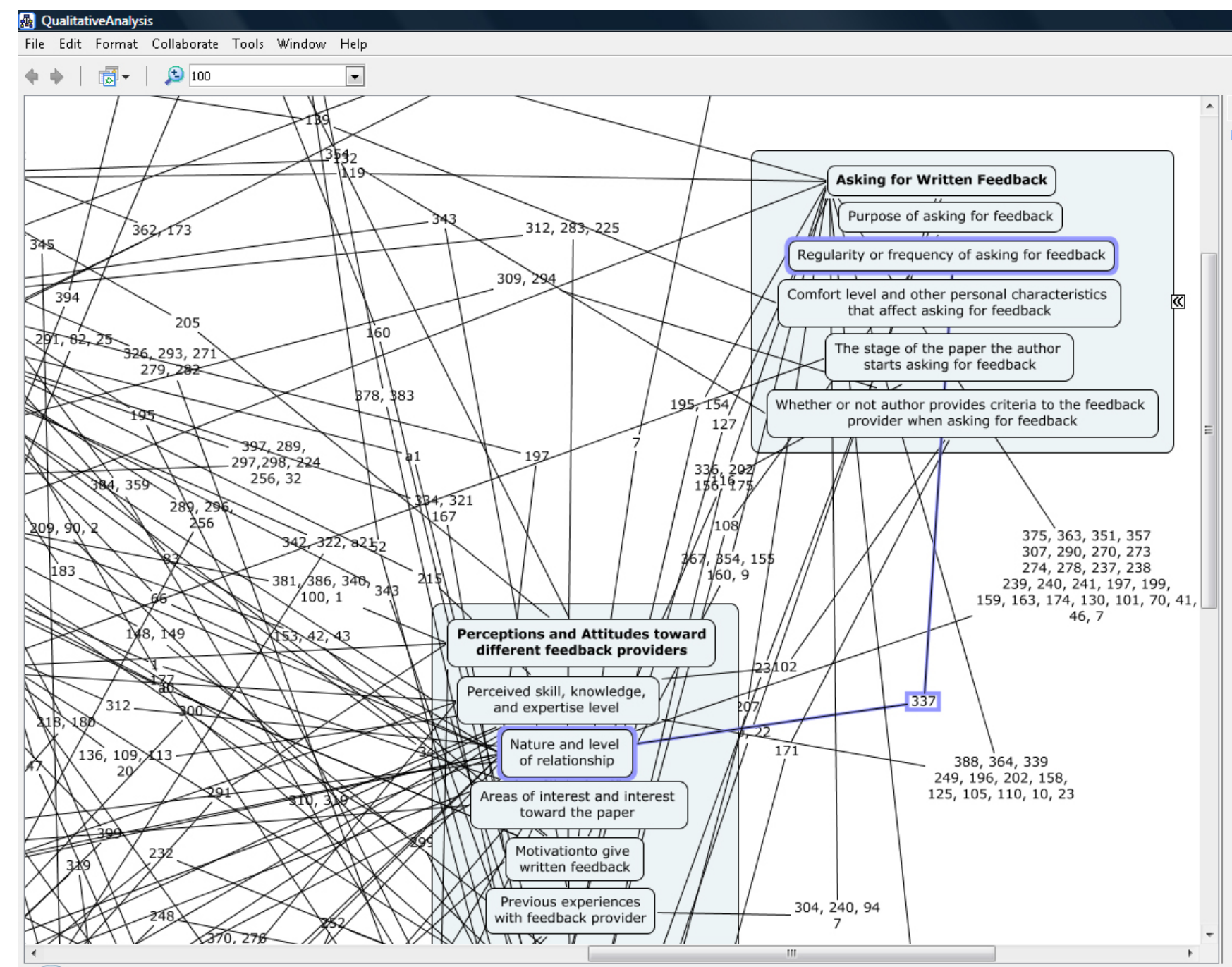

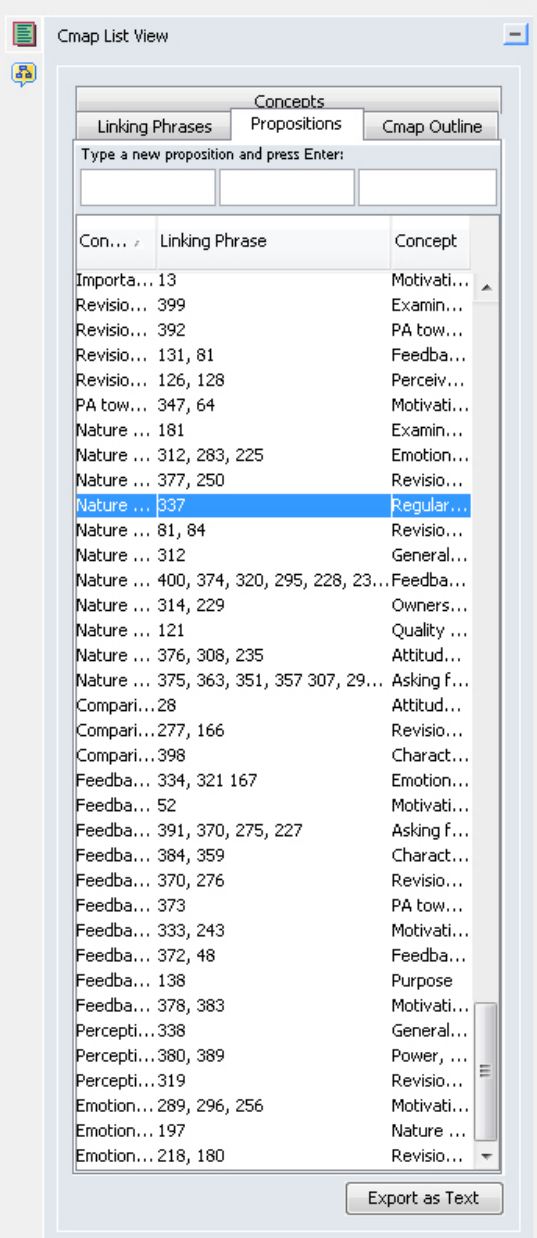

Figure 4-1. Qualitative, selective coding analysis using IHMC CMAP Tool. 
Table 4-3

The Most Frequent Relationships Between Main Categories

\begin{tabular}{|c|c|c|c|}
\hline Main category & $\begin{array}{l}\text { Influence } \\
\text { direction }\end{array}$ & Main category & $\begin{array}{l}\text { Relationship } \\
\text { frequency }\end{array}$ \\
\hline $\begin{array}{l}\text { Perceptions and attitudes toward } \\
\text { different feedback providers }\end{array}$ & $\longrightarrow$ & Asking for written feedback & 67 \\
\hline $\begin{array}{l}\text { Perceptions and attitudes toward } \\
\text { different feedback characteristics }\end{array}$ & & $\begin{array}{l}\text { Perceptions and attitudes toward } \\
\text { different feedback providers }\end{array}$ & 63 \\
\hline $\begin{array}{l}\text { Perceptions and attitudes toward } \\
\text { different feedback providers }\end{array}$ & & Revision decisions & 41 \\
\hline $\begin{array}{l}\text { Perceptions and attitudes toward } \\
\text { different feedback providers }\end{array}$ & -- & $\begin{array}{l}\text { Specific academic writing } \\
\text { instances }\end{array}$ & 24 \\
\hline $\begin{array}{l}\text { Perceptions and attitudes toward } \\
\text { different feedback characteristics }\end{array}$ & -- & Author's characteristics & 23 \\
\hline $\begin{array}{l}\text { Perceptions and attitudes toward } \\
\text { different feedback providers }\end{array}$ & 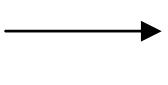 & Examination of written feedback & 20 \\
\hline $\begin{array}{l}\text { Perceptions and attitudes toward } \\
\text { different feedback characteristics }\end{array}$ & - & Revision decisions & 20 \\
\hline Revision decisions & -- & $\begin{array}{l}\text { Specific academic writing } \\
\text { instances }\end{array}$ & 15 \\
\hline Revision decisions & -- & Examination of written feedback & 15 \\
\hline $\begin{array}{l}\text { Perceptions and attitudes toward } \\
\text { different feedback providers }\end{array}$ & -- & Author's characteristics & 13 \\
\hline $\begin{array}{l}\text { Perceptions and attitudes toward } \\
\text { different feedback characteristics }\end{array}$ & & Examination of written feedback & 12 \\
\hline $\begin{array}{l}\text { Perceptions and attitudes toward } \\
\text { their discipline/program }\end{array}$ & & $\begin{array}{l}\text { Motivations for academic } \\
\text { writing }\end{array}$ & 10 \\
\hline
\end{tabular}




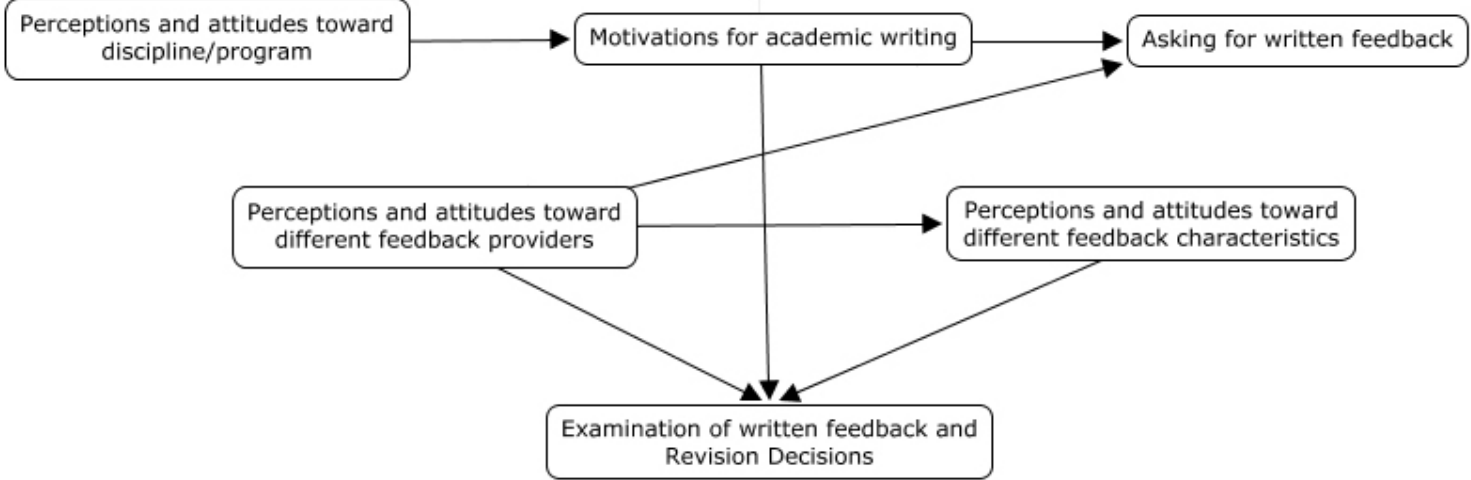

Figure 4-2. Provisional model.

\section{Instrument Design}

As presented in detail in Chapter 3, a questionnaire was developed and used in an effort to validate and refine the provisional model using quantitative data from a wider sample (see Appendix G). A pool of 343 items were prepared, 331 of them were in 4-point Likert scale. During item selection, several representative items were selected considering each category and subcategory and also considering the relationships between these categories. Most of the items were directly quoted from the interview transcripts. After pilot tests, 155 items were determined to be included in the final questionnaire. Several issues were considered during the selection of the final items: (a) pilot test participants' feedback, (b) research questions of this study, (c) whether or not there were enough items to represent the categories in the provisional model, and (d) whether or not the items were best representatives of the variables they measure. For more information about the questionnaire design, please see Chapter 3.

As an example, considering the main category "perceptions and attitudes toward different feedback providers", a question was developed for the questionnaire "How important are the following characteristics of a person to you when deciding whether or not to ask for their written feedback?” Example items were listed as follows: "his/her publication experience, his/her writing skills, his/her writing style". The scale included four levels: unimportant, somewhat important, important, and very important. 
Quantitative Data Analysis

After the basic steps of data screening, recoding, and handling missing values, the quantitative data analysis was conducted mainly in three stages: (1) descriptive data analyses, (2) multivariate correlational data analysis including Exploratory Factor Analysis (EFA), Confirmatory Factor Analysis (CFA), and Structural Equation Modeling (SEM), and (3) post analyses.

\section{Data Screening, Recoding, Missing Values}

Although a total of 297 participants started filling the questionnaire, 17 participants’ data were not complete (6\%). Moreover, four participants did not fit the initial criteria for participants. Therefore, only 276 participants’ data were used in the quantitative data analyses.

Regarding the academic writing experience question (Question A8), participants’ responses such as "more than 10 ” or " $10+$ " were replaced with the quantity plus 1 . Total of 32 of 108 questions that were included in the multivariate correlational data analysis were reverse scaled. There were a total of 120 missing cells out of 45,816 cells in the data of 276 participants $(\sim 0 \%)$. They were not replaced in the case of descriptive data analysis results and reported in the tables. However, the missing data in the questions that were included in the multivariate correlational data analysis were replaced by the mode of that item.

\section{Descriptive Data Analysis}

The results of the descriptive data analysis regarding the research questions of this study are presented below. It should be noted that descriptive data analysis methods were limited in answering the last two research questions. These questions were addressed using the multivariate correlational data analysis methods in the next section.

Research Question 1: Perceptions and Attitudes Toward Different Written Feedback Characteristics

Participants’ preferences for different feedback characteristics were asked in the questionnaire in five main question groups. The first group of questions addressed the participants' need for written feedback for different aspects of their paper. The second group questioned their preferences for the delivery 
of the written feedback. In the third and fourth group of questions, the participants were asked to rate their preferred types of written feedback among a variety of choices. Finally in the fifth group, the participants were asked to rate attitude statements regarding critical/negative written feedback.

\section{Perceived Need for Written Feedback Regarding}

Different Aspects of Academic Writing

Participants rated the answer choices for the question "When writing academic papers, how frequently do you feel that you need written feedback for the following aspects of your papers?" in a 4point frequency scale (1-Never, 2-Seldom, 3-Sometimes, 4-Often). Based on the mean scores and frequencies in Table 4-4 and 4-5, the participants rated that they need written feedback most frequently for arguments and justifications in their paper, clarity and understandability of the statements, inclusion and exclusion of information, introduction, and conclusion parts of their papers. Technical aspects such as grammar and sentence structure, formatting, and references and literature decisions were rated the lowest.

\section{Delivery Preferences}

Most of the participants rated that they prefer sending their paper and receiving written feedback electronically (112 participants, $41 \%)$. Seventy-four participants (27\%) had no preference in either method. Twenty five participants (9\%) preferred to hand their paper personally and receive handwritten comments (see Tables 4-6 and 4-7).

\section{General Feedback Preferences}

On a 4-point agreement scale (1- Strongly Disagree, 2- Disagree, 3- Agree, 4- Strongly Agree), the participants rated their preferences for different feedback types in general. When arranged according to their means (see Table 4-8) and the number of participants who agreed with the statements (see Table 4-9), it has been found that participants mostly rated their appreciation of written feedback which is straightforward (98\%), gives clear instructions for how to revise their paper (97\%), and directs them to

other related resources (97\%). Other mostly preferred feedback types were written feedback about grammar (88\%), balanced positive and negative written feedback (86\%), detailed and specific written feedback (85\%) and not-individualized or biased written feedback (83\%). 
Table 4-4

Perceived Need for Written Feedback Regarding Different Aspects of Academic Writing: Descriptive Statistics (1-Never, 2-Seldom, 3-Sometimes, 4-Often)

\begin{tabular}{|c|c|c|c|c|c|c|c|c|}
\hline Aspects of academic writing & $M$ & $M d n$ & Mode & $S D$ & Var & Ran & Skew & Kur \\
\hline $\begin{array}{l}\text { Arguments and justifications in my } \\
\text { paper }\end{array}$ & 3.16 & 3 & 3 & .69 & .48 & 3 & -.43 & -.13 \\
\hline $\begin{array}{l}\text { Clarity and understandability of the } \\
\text { statements }\end{array}$ & 3.11 & 3 & 3 & .75 & .56 & 3 & -.33 & -.68 \\
\hline Conclusion & 3.11 & 3 & 3 & .80 & .64 & 3 & -.50 & -.46 \\
\hline $\begin{array}{l}\text { Inclusion or exclusion of } \\
\text { information }\end{array}$ & 3.08 & 3 & 3 & .73 & .53 & 3 & -.35 & -.36 \\
\hline $\begin{array}{l}\text { Introduction, purpose and } \\
\text { significance of the paper }\end{array}$ & 3.05 & 3 & 3 & .79 & .62 & 3 & -.40 & -.51 \\
\hline Consistency in the overall paper & 2.99 & 3 & 3 & .74 & .54 & 3 & -.21 & -.57 \\
\hline $\begin{array}{l}\text { Logical order and organization of } \\
\text { information and ideas }\end{array}$ & 2.90 & 3 & 3 & .78 & .60 & 3 & -.29 & -.34 \\
\hline $\begin{array}{l}\text { Transition and flow between } \\
\text { sentences, paragraphs, or sections }\end{array}$ & 2.79 & 3 & 3 & .82 & .68 & 3 & -.07 & -.72 \\
\hline Grammar and sentence structure & 2.52 & 2 & 2 & .96 & .91 & 3 & .20 & -.95 \\
\hline $\begin{array}{l}\text { Formatting (tables, figures, page } \\
\text { design, fitting APA style, giving } \\
\text { citations, etc.) }\end{array}$ & 2.51 & 2 & 2 & .90 & .82 & 3 & .07 & -.77 \\
\hline References and literature decisions & 2.45 & 2 & 2 & .82 & .67 & 3 & -.02 & -.52 \\
\hline
\end{tabular}


Table 4-5

Perceived Need for Written Feedback Regarding Different Aspects of Academic Writing: Frequencies and Percentages

\begin{tabular}{|c|c|c|c|c|c|}
\hline Aspects of academic writing & $\begin{array}{l}\text { Never } \\
f(P)\end{array}$ & $\begin{array}{l}\text { Seldom } \\
f(P)\end{array}$ & $\begin{array}{l}\text { Sometimes } \\
\qquad f(P)\end{array}$ & $\begin{array}{l}\text { Often } \\
f(P)\end{array}$ & $\begin{array}{l}\text { Missing } \\
f(P)\end{array}$ \\
\hline $\begin{array}{l}\text { Arguments and justifications in my } \\
\text { paper }\end{array}$ & $3(1 \%)$ & $38(14 \%)$ & $146(53 \%)$ & $89(32 \%)$ & 0 \\
\hline $\begin{array}{l}\text { Clarity and understandability of the } \\
\text { statements }\end{array}$ & $3(1 \%)$ & $55(20 \%)$ & $127(46 \%)$ & $90(33 \%)$ & $1(0 \%)$ \\
\hline Conclusion & $7(3 \%)$ & $53(19 \%)$ & $119(43 \%)$ & $97(35 \%)$ & 0 \\
\hline $\begin{array}{l}\text { Inclusion or exclusion of } \\
\text { information }\end{array}$ & $4(1 \%)$ & $51(19 \%)$ & $141(51 \%)$ & $80(29 \%)$ & 0 \\
\hline $\begin{array}{l}\text { Introduction, purpose and } \\
\text { significance of the paper }\end{array}$ & $7(3 \%)$ & $58(21 \%)$ & $124(45 \%)$ & $86(31 \%)$ & $1(0 \%)$ \\
\hline Consistency in the overall paper & $4(1 \%)$ & $64(23 \%)$ & $138(50 \%)$ & $70(25 \%)$ & 0 \\
\hline $\begin{array}{l}\text { Logical order and organization of } \\
\text { information and ideas }\end{array}$ & $10(4 \%)$ & $68(25 \%)$ & $137(50 \%)$ & $60(22 \%)$ & $1(0 \%)$ \\
\hline $\begin{array}{l}\text { Transition and flow between } \\
\text { sentences, paragraphs, or sections }\end{array}$ & $12(4 \%)$ & $91(33 \%)$ & $113(41 \%)$ & $57(21 \%)$ & $3(1 \%)$ \\
\hline Grammar and sentence structure & $35(13 \%)$ & $118(43 \%)$ & $67(24 \%)$ & $56(20 \%)$ & 0 \\
\hline $\begin{array}{l}\text { Formatting (tables, figures, page } \\
\text { design, fitting APA style, giving } \\
\text { citations, etc.) }\end{array}$ & $36(13 \%)$ & $106(38 \%)$ & $92(33 \%)$ & $42(15 \%)$ & 0 \\
\hline References and literature decisions & $34(12 \%)$ & $109(40 \%)$ & $109(40 \%)$ & $24(9 \%)$ & 0 \\
\hline
\end{tabular}

Note. Percentages may not add to 100 or exceed 100 due to rounding. This is applicable to all the tables in this document that include frequencies. 
Table 4-6

Delivery Preferences: Frequencies and Percentages

\begin{tabular}{lcc}
\hline \multicolumn{1}{c}{ Method of giving/sending paper to feedback providers } & $f$ & $P$ \\
\hline I prefer sending my paper electronically, such as through email & 149 & $54 \%$ \\
I prefer handing in my paper personally, face-to-face & 30 & $11 \%$ \\
I have no preference & 96 & $35 \%$ \\
Missing & 1 & $0 \%$ \\
Total & 276 & $100 \%$ \\
\hline \multicolumn{1}{c}{ Method of receiving feedback from feedback providers } & 124 & \\
\hline $\begin{array}{l}\text { I prefer receiving written feedback electronically, such as track-changes } \\
\text { in Word, comments, edits on the computer }\end{array}$ & 48 & $17 \%$ \\
$\begin{array}{l}\text { I prefer receiving handwritten feedback, such as comments handwritten } \\
\text { on my paper }\end{array}$ & 103 & $37 \%$ \\
I have no preference & 1 & $0 \%$ \\
Missing & 276 & $100 \%$ \\
Total & & \\
\hline
\end{tabular}

\section{Table 4-7}

Cross-tabular Presentation of Delivery Preferences

\begin{tabular}{|c|c|c|c|c|}
\hline \multirow[t]{2}{*}{ Method of giving/sending paper } & \multicolumn{3}{|c|}{ Method of receiving feedback $f(P)$} & \multirow[t]{2}{*}{ Total $f(P)$} \\
\hline & Electronically & Handwritten & No preference & \\
\hline Sending electronically & 112 & 11 & 26 & $149(54 \%)$ \\
\hline Handing personally & 2 & 25 & 3 & $30(11 \%)$ \\
\hline No preference & 10 & 12 & 74 & $96(35 \%)$ \\
\hline Total $f(P)$ & $124(45 \%)$ & $48(17 \%)$ & $103(37 \%)$ & $275(100 \%)$ \\
\hline
\end{tabular}


Table 4-8

General Feedback Preferences: Descriptive Statistics (1- Strongly Disagree, 2- Disagree, 3- Agree, 4Strongly Agree)

\begin{tabular}{|c|c|c|c|c|c|c|c|c|}
\hline Preferences: Positive statements & $M$ & $M d n$ & Mode & $S D$ & Var & Ran & Skew & Kur \\
\hline $\begin{array}{l}\text { I appreciate straightforward } \\
\text { written feedback }\end{array}$ & 3.51 & 4 & 4 & .54 & .29 & 2 & -.41 & -1.09 \\
\hline $\begin{array}{l}\text { I appreciate written feedback } \\
\text { that gives me clear instructions } \\
\text { for how to revise my paper }\end{array}$ & 3.49 & 4 & 4 & .58 & .33 & 3 & -.81 & .98 \\
\hline $\begin{array}{l}\text { I appreciate written feedback that } \\
\text { directs me to other related } \\
\text { resources }\end{array}$ & 3.39 & 3 & 3 & .54 & .30 & 3 & -.23 & -.05 \\
\hline $\begin{array}{l}\text { I appreciate detailed/specific } \\
\text { comments more than } \\
\text { overall/general comments }\end{array}$ & 3.29 & 3 & 4 & .72 & .52 & 3 & -.55 & -.69 \\
\hline $\begin{array}{l}\text { I appreciate written feedback } \\
\text { about grammar }\end{array}$ & 3.16 & 3 & 3 & .65 & .42 & 3 & -.49 & .71 \\
\hline $\begin{array}{l}\text { I appreciate written feedback } \\
\text { which is given based on only } \\
\text { what is on the paper, not based } \\
\text { on my previous papers }\end{array}$ & 3.16 & 3 & 3 & .70 & .50 & 3 & -.37 & -.49 \\
\hline $\begin{array}{l}\text { I appreciate balanced positive } \\
\text { and critical/negative written } \\
\text { feedback }\end{array}$ & 3.12 & 3 & 3 & .65 & .42 & 3 & -.28 & -.04 \\
\hline $\begin{array}{l}\text { I appreciate written feedback in } \\
\text { which negative things are said in } \\
\text { a more positive way }\end{array}$ & 3.08 & 3 & 3 & .66 & .43 & 3 & -.17 & -.41 \\
\hline $\begin{array}{l}\text { I appreciate written feedback that } \\
\text { revises or edits my paper for me }\end{array}$ & 2.71 & 3 & 3 & .78 & .60 & 3 & .04 & -.56 \\
\hline $\begin{array}{l}\text { I appreciate critical/negative } \\
\text { written feedback more than } \\
\text { positive written feedback }\end{array}$ & 2.58 & 3 & 2 & .69 & .48 & 3 & .31 & -.37 \\
\hline
\end{tabular}

Preferences: Negative statements

\begin{tabular}{lllllllll}
\hline I don't appreciate written & 3.02 & 3 & 3 & .74 & .54 & 3 & -.36 & -.19
\end{tabular}
feedback that is given because of a personal preference 


\begin{tabular}{|c|c|c|c|c|c|c|c|c|}
\hline Preferences: Negative statements & $M$ & $M d n$ & Mode & $S D$ & Var & Ran & Skew & Kur \\
\hline $\begin{array}{l}\text { I don't appreciate suggestions in } \\
\text { written feedback that are hard for } \\
\text { me to use while revising my } \\
\text { paper }\end{array}$ & 2.80 & 3 & 3 & .77 & .59 & 3 & -.36 & -.10 \\
\hline $\begin{array}{l}\text { I don't appreciate marks without } \\
\text { text in feedback (such as } \\
\text { underlined sentences, circle } \\
\text { around a word, question mark, } \\
\text { etc.) }\end{array}$ & 2.79 & 3 & 3 & .82 & .67 & 3 & -.20 & -.52 \\
\hline $\begin{array}{l}\text { I don't appreciate written } \\
\text { feedback that tries to change my } \\
\text { writing style }\end{array}$ & 2.70 & 3 & 3 & .74 & .55 & 3 & .10 & -.52 \\
\hline $\begin{array}{l}\text { I don't appreciate written } \\
\text { feedback that tries to change the } \\
\text { direction of my paper }\end{array}$ & 2.69 & 3 & 3 & .75 & .56 & 3 & .05 & -.47 \\
\hline $\begin{array}{l}\text { I don't appreciate receiving } \\
\text { contradictory feedback from } \\
\text { different people }\end{array}$ & 2.58 & 2.5 & 2 & .84 & .70 & 3 & .16 & -.66 \\
\hline
\end{tabular}

The least preferred feedback characteristics were written feedback that is given because of a personal preference (77\%), suggestions that are hard for them to use while revising their paper (69\%), and marks without text in feedback (64\%). Regarding the categorization made in the first phase (Table 4-2), participants' ratings were related written feedback about the content and the grammar of the paper as well as the tone, clarity, applicability, relevance, importance, specificity, individualization or bias, and positive or negative nature of written feedback.

\section{Specific Feedback Preferences}

On a 4-point agreement scale (1-Strongly Disagree, 2-Disagree, 3-Agree, 4-Strongly Agree) the participants answered a question by rating a series of examples according to their preferences. Table 4-10 was prepared to categorize these feedback examples by referring to some of the characteristics of written feedback categorized in Table 4-2. They were grouped regarding four dimensions: tone of the written feedback, their being positive or critical, what they are about, and their specificity. It should be noted that this categorization was made only to facilitate the understanding of the participants' preferred types of 
Table 4-9

General Feedback Preferences: Frequencies and Percentages (SD- Strongly Disagree, D- Disagree, A- Agree, SA-Strongly Agree)

\begin{tabular}{|c|c|c|c|c|c|c|c|}
\hline \multirow[b]{2}{*}{ Preferences: Positive statements } & \multirow[b]{2}{*}{$\begin{array}{c}\mathrm{SD} \\
f(P)\end{array}$} & \multirow[b]{2}{*}{$\begin{array}{c}\mathrm{D} \\
f(P)\end{array}$} & \multirow[b]{2}{*}{$\begin{array}{c}\text { A } \\
f(P)\end{array}$} & \multirow[b]{2}{*}{$\begin{array}{c}\text { SA } \\
f(P)\end{array}$} & \multicolumn{2}{|c|}{ Total } & \multirow[b]{2}{*}{$\begin{array}{l}\text { Missing } \\
\quad f(P)\end{array}$} \\
\hline & & & & & $\begin{array}{l}\text { Disagree } \\
f(P)\end{array}$ & $\begin{array}{l}\text { Agree } \\
f(P)\end{array}$ & \\
\hline I appreciate straightforward written feedback & 0 & $\begin{array}{c}5 \\
(2 \%)\end{array}$ & $\begin{array}{c}124 \\
(45 \%)\end{array}$ & $\begin{array}{c}146 \\
(53 \%)\end{array}$ & $\begin{array}{c}5 \\
(2 \%)\end{array}$ & $\begin{array}{c}270 \\
(98 \%)\end{array}$ & $\begin{array}{c}1 \\
(0 \%)\end{array}$ \\
\hline $\begin{array}{l}\text { I appreciate written feedback that directs me to other related } \\
\text { resources }\end{array}$ & $\begin{array}{c}1 \\
(0 \%)\end{array}$ & $\begin{array}{c}5 \\
(2 \%)\end{array}$ & $\begin{array}{c}155 \\
(56 \%)\end{array}$ & $\begin{array}{c}114 \\
(41 \%)\end{array}$ & $\begin{array}{c}6 \\
(2 \%)\end{array}$ & $\begin{array}{c}269 \\
(97 \%)\end{array}$ & $\begin{array}{c}1 \\
(0 \%)\end{array}$ \\
\hline $\begin{array}{l}\text { I appreciate written feedback that gives me clear instructions for } \\
\text { how to revise my paper }\end{array}$ & $\begin{array}{c}2 \\
(1 \%)\end{array}$ & $\begin{array}{c}5 \\
(2 \%)\end{array}$ & $\begin{array}{c}125 \\
(45 \%)\end{array}$ & $\begin{array}{c}142 \\
(51 \%)\end{array}$ & $\begin{array}{c}7 \\
(2 \%)\end{array}$ & $\begin{array}{l}267 \\
(97 \%)\end{array}$ & $\begin{array}{c}2 \\
(1 \%)\end{array}$ \\
\hline I appreciate written feedback about grammar & $\begin{array}{c}4 \\
(1 \%)\end{array}$ & $\begin{array}{c}27 \\
(10 \%)\end{array}$ & $\begin{array}{c}166 \\
(60 \%)\end{array}$ & $\begin{array}{c}78 \\
(28 \%)\end{array}$ & $\begin{array}{c}31 \\
(11 \%)\end{array}$ & $\begin{array}{l}244 \\
(88 \%)\end{array}$ & $\begin{array}{c}1 \\
(0 \%)\end{array}$ \\
\hline $\begin{array}{l}\text { I appreciate balanced positive and critical/negative written } \\
\text { feedback }\end{array}$ & $\begin{array}{c}2 \\
(1 \%)\end{array}$ & $\begin{array}{c}38 \\
(14 \%)\end{array}$ & $\begin{array}{c}162 \\
(59 \%)\end{array}$ & $\begin{array}{c}74 \\
(27 \%)\end{array}$ & $\begin{array}{c}40 \\
(14 \%)\end{array}$ & $\begin{array}{l}236 \\
(86 \%)\end{array}$ & 0 \\
\hline $\begin{array}{l}\text { I appreciate detailed/specific comments more than overall/general } \\
\text { comments }\end{array}$ & $\begin{array}{c}1 \\
(0 \%)\end{array}$ & $\begin{array}{c}40 \\
(14 \%)\end{array}$ & $\begin{array}{c}113 \\
(41 \%)\end{array}$ & $\begin{array}{l}121 \\
(44 \%)\end{array}$ & $\begin{array}{c}41 \\
(15 \%)\end{array}$ & $\begin{array}{c}234 \\
(85 \%)\end{array}$ & $\begin{array}{c}1 \\
(0 \%)\end{array}$ \\
\hline $\begin{array}{l}\text { I appreciate written feedback which is given based on only what is } \\
\text { on the paper, not based on my previous papers }\end{array}$ & $\begin{array}{c}2 \\
(1 \%)\end{array}$ & $\begin{array}{c}43 \\
(16 \%)\end{array}$ & $\begin{array}{c}137 \\
(50 \%)\end{array}$ & $\begin{array}{c}92 \\
(33 \%)\end{array}$ & $\begin{array}{c}45 \\
(16 \%)\end{array}$ & $\begin{array}{c}229 \\
(83 \%)\end{array}$ & $\begin{array}{c}2 \\
(1 \%)\end{array}$ \\
\hline $\begin{array}{l}\text { I appreciate written feedback in which negative things are said in a } \\
\text { more positive way }\end{array}$ & $\begin{array}{c}1 \\
(0 \%)\end{array}$ & $\begin{array}{c}46 \\
(17 \%)\end{array}$ & $\begin{array}{c}158 \\
(57 \%)\end{array}$ & $\begin{array}{c}71 \\
(26 \%)\end{array}$ & $\begin{array}{c}47 \\
(17 \%)\end{array}$ & $\begin{array}{c}229 \\
(83 \%)\end{array}$ & 0 \\
\hline
\end{tabular}




\begin{tabular}{|c|c|c|c|c|c|c|c|}
\hline \multirow[b]{2}{*}{ Preferences: Positive statements } & \multirow[b]{2}{*}{$\begin{array}{c}\mathrm{SD} \\
f(P)\end{array}$} & \multirow[b]{2}{*}{$\begin{array}{c}\mathrm{D} \\
f(P)\end{array}$} & \multirow[b]{2}{*}{$\begin{array}{c}\text { A } \\
f(P)\end{array}$} & \multirow[b]{2}{*}{$\begin{array}{c}\text { SA } \\
f(P)\end{array}$} & \multicolumn{2}{|c|}{ Total } & \multirow[b]{2}{*}{$\begin{array}{l}\text { Missing } \\
\quad f(P)\end{array}$} \\
\hline & & & & & $\begin{array}{l}\text { Disagree } \\
\quad f(P)\end{array}$ & $\begin{array}{l}\text { Agree } \\
f(P)\end{array}$ & \\
\hline I appreciate written feedback that revises or edits my paper for me & $\begin{array}{c}11 \\
(4 \%)\end{array}$ & $\begin{array}{c}102 \\
(37 \%)\end{array}$ & $\begin{array}{c}120 \\
(43 \%)\end{array}$ & $\begin{array}{c}43 \\
(16 \%)\end{array}$ & $\begin{array}{c}113 \\
(41 \%)\end{array}$ & $\begin{array}{c}163 \\
(59 \%)\end{array}$ & 0 \\
\hline $\begin{array}{l}\text { I appreciate critical/negative written feedback more than positive } \\
\text { written feedback }\end{array}$ & $\begin{array}{c}7 \\
(3 \%)\end{array}$ & $\begin{array}{c}127 \\
(46 \%)\end{array}$ & $\begin{array}{c}117 \\
(42 \%)\end{array}$ & $\begin{array}{l}25 \\
(9 \%)\end{array}$ & $\begin{array}{c}134 \\
(49 \%)\end{array}$ & $\begin{array}{c}142 \\
(51 \%)\end{array}$ & 0 \\
\hline \multicolumn{8}{|l|}{ Preferences: Negative statements } \\
\hline $\begin{array}{l}\text { I don't appreciate written feedback that is given because of a } \\
\text { personal preference }\end{array}$ & $\begin{array}{c}6 \\
(2 \%)\end{array}$ & $\begin{array}{c}53 \\
(19 \%)\end{array}$ & $\begin{array}{c}143 \\
(52 \%)\end{array}$ & $\begin{array}{c}70 \\
(25 \%)\end{array}$ & $\begin{array}{c}59 \\
(21 \%)\end{array}$ & $\begin{array}{l}213 \\
(77 \%)\end{array}$ & $\begin{array}{c}4 \\
(1 \%)\end{array}$ \\
\hline $\begin{array}{l}\text { I don't appreciate suggestions in written feedback that are hard for } \\
\text { me to use while revising my paper }\end{array}$ & $\begin{array}{c}15 \\
(5 \%)\end{array}$ & $\begin{array}{c}70 \\
(25 \%)\end{array}$ & $\begin{array}{l}146 \\
(53 \%)\end{array}$ & $\begin{array}{c}44 \\
(16 \%)\end{array}$ & $\begin{array}{c}85 \\
(31 \%)\end{array}$ & $\begin{array}{c}190 \\
(69 \%)\end{array}$ & $\begin{array}{c}1 \\
(0 \%)\end{array}$ \\
\hline $\begin{array}{l}\text { I don't appreciate marks without text in feedback (such as } \\
\text { underlined sentences, circle around a word, question mark, etc) }\end{array}$ & $\begin{array}{c}15 \\
(5 \%)\end{array}$ & $\begin{array}{c}81 \\
(29 \%)\end{array}$ & $\begin{array}{c}124 \\
(45 \%)\end{array}$ & $\begin{array}{c}54 \\
(20 \%)\end{array}$ & $\begin{array}{c}96 \\
(35 \%)\end{array}$ & $\begin{array}{l}178 \\
(64 \%)\end{array}$ & $\begin{array}{c}2 \\
(1 \%)\end{array}$ \\
\hline $\begin{array}{l}\text { I don't appreciate written feedback that tries to change the } \\
\text { direction of my paper }\end{array}$ & $\begin{array}{c}10 \\
(4 \%)\end{array}$ & $\begin{array}{c}102 \\
(37 \%)\end{array}$ & $\begin{array}{l}125 \\
(45 \%)\end{array}$ & $\begin{array}{c}38 \\
(14 \%)\end{array}$ & $\begin{array}{c}112 \\
(41 \%)\end{array}$ & $\begin{array}{c}163 \\
(59 \%)\end{array}$ & $\begin{array}{l}1 \\
(0 \%)\end{array}$ \\
\hline $\begin{array}{l}\text { I don't appreciate written feedback that tries change my writing } \\
\text { style }\end{array}$ & $\begin{array}{c}8 \\
(3 \%)\end{array}$ & $\begin{array}{c}103 \\
(37 \%)\end{array}$ & $\begin{array}{c}124 \\
(45 \%)\end{array}$ & $\begin{array}{c}38 \\
(14 \%)\end{array}$ & $\begin{array}{c}111 \\
(40 \%)\end{array}$ & $\begin{array}{c}162 \\
(59 \%)\end{array}$ & $\begin{array}{c}3 \\
(1 \%)\end{array}$ \\
\hline $\begin{array}{l}\text { I don't appreciate receiving contradictory feedback from different } \\
\text { people }\end{array}$ & $\begin{array}{c}20 \\
(7 \%)\end{array}$ & $\begin{array}{c}117 \\
(42 \%)\end{array}$ & $\begin{array}{c}94 \\
(34 \%)\end{array}$ & $\begin{array}{c}43 \\
(16 \%)\end{array}$ & $\begin{array}{c}137 \\
(50 \%)\end{array}$ & $\begin{array}{c}137 \\
(50 \%)\end{array}$ & $\begin{array}{c}2 \\
(1 \%)\end{array}$ \\
\hline
\end{tabular}


written feedback in Table 4-11 and Table 4-12.

Table 4-11 and 4-12 show the mean scores and frequencies respectively. After the examination of the mostly preferred written feedback statements, certain similarities were found between the results of the general preferences and these specific preferences.

The participants rated that they prefer receiving written feedback that provides them content related resources that support the direction of their papers $(100 \%)$ instead of written feedback that tries to change the direction of their paper (48\%). Similar to the general preferences, the participants preferred written feedback examples that are both positive and critical, but mostly the ones with suggestive tones. Their preference of written feedback content was all in three areas of content and arguments, organization and flow, and mechanical issues. Regarding the scope of the written feedback, their preferences were varied as well.

Attitudes Toward Critical/Negative Written Feedback

On a 4-point agreement scale (1-Strongly Disagree, 2-Disagree, 3-Agree, 4-Strongly Agree) the participants rated a series of attitude statements regarding critical/negative written feedback. Table 4-13 and Table 4-14 show the mean scores and frequencies respectively. As seen in Table 4-14, most participants were more open to rewriting their paper, rather than abandoning their paper when they receive very critical/negative written feedback from someone with more knowledge and experience than they have. Although more than half of the participants rated that critical/negative written feedback affects them emotionally, most participants disagreed with the statements about losing their self confidence or motivation when they receive critical/negative written feedback.

Research Question 2: Perceptions and Attitudes Toward Different Characteristics of Written Feedback Providers

Participants' perceptions and attitudes toward the characteristics of feedback providers were examined under two main question groups. In the first group, the importance of the feedback provider characteristics was questioned regarding the participants' decision to ask for their written feedback. While 
Table 4-10

Categorization of Questionnaire Items Regarding Specific Feedback Preferences

\begin{tabular}{|c|c|c|c|c|}
\hline $\begin{array}{l}\text { Specific feedback } \\
\text { preferences }\end{array}$ & Tone & $\begin{array}{l}\text { Positive/ } \\
\text { critical }\end{array}$ & About & $\begin{array}{l}\text { Specificity } \\
\text { regarding } \\
\text { scope }\end{array}$ \\
\hline $\begin{array}{l}\text { Here is an article that } \\
\text { supports what you're saying } \\
\text { here. }\end{array}$ & Suggestive & -- & $\begin{array}{l}\text { Content and arguments } \\
\text { (coverage) }\end{array}$ & Narrow \\
\hline $\begin{array}{l}\text { Maybe you need a table } \\
\text { here, listing X with each } \\
\text { column showing Y. Just an } \\
\text { idea. }\end{array}$ & Suggestive & Critical & $\begin{array}{l}\text { Content and arguments } \\
\text { (coverage) } \\
\text { Mechanical issues } \\
\text { (formatting) }\end{array}$ & Narrow \\
\hline $\begin{array}{l}\text { I think this sentence should } \\
\text { be said much earlier. It is } \\
\text { important. }\end{array}$ & Suggestive & Critical & $\begin{array}{l}\text { Organization and flow } \\
\text { (logical order) }\end{array}$ & Narrow \\
\hline $\begin{array}{l}\text { Have you thought about } \\
\text { adding one more section to } \\
\text { your paper about } X \\
\text { literature? }\end{array}$ & Suggestive & Critical & $\begin{array}{c}\text { Content and arguments } \\
\text { (coverage) }\end{array}$ & Wide \\
\hline $\begin{array}{l}\text { Break this into smaller, } \\
\text { more focused paragraphs. }\end{array}$ & Authoritative & Critical & $\begin{array}{l}\text { Organization and flow } \\
\text { (organization) }\end{array}$ & Narrow \\
\hline $\begin{array}{l}\text { This argument is } \\
\text { unsupported. You need to } \\
\text { cite more references. }\end{array}$ & $\begin{array}{l}\text { Suggestive/ } \\
\text { Authoritative }\end{array}$ & Critical & $\begin{array}{l}\text { Mechanical issues } \\
\text { (References and } \\
\text { citations) }\end{array}$ & Narrow/Wide \\
\hline $\begin{array}{l}\text { You're on the right track, } \\
\text { this is a well-organized } \\
\text { paper. }\end{array}$ & Encouraging & Positive & Organization and flow & Wide \\
\hline This section is really strong. & Encouraging & Positive & Content and arguments & Narrow \\
\hline $\begin{array}{l}\text { It is not clear how this } \\
\text { paragraph addresses your } \\
\text { research question. You need } \\
\text { to show links to the research } \\
\text { question. }\end{array}$ & $\begin{array}{l}\text { Suggestive/ } \\
\text { Authoritative }\end{array}$ & Critical & $\begin{array}{l}\text { Organization and flow } \\
\text { (consistency) }\end{array}$ & Narrow \\
\hline $\begin{array}{l}\text { Explain why you're } \\
\text { focusing on these } \\
\text { dimensions. Not clear to the } \\
\text { reader. }\end{array}$ & Authoritative & Critical & $\begin{array}{l}\text { Content and arguments } \\
\text { (coverage, reader } \\
\text { consideration) }\end{array}$ & Narrow \\
\hline
\end{tabular}




\begin{tabular}{|c|c|c|c|c|}
\hline $\begin{array}{l}\text { Specific feedback } \\
\text { preferences }\end{array}$ & Tone & $\begin{array}{l}\text { Positive/ } \\
\text { critical }\end{array}$ & About & $\begin{array}{l}\text { Specificity } \\
\text { regarding } \\
\text { scope }\end{array}$ \\
\hline $\begin{array}{l}\text { This section is a bit dense, } \\
\text { with lots of details. Are they } \\
\text { all necessary? }\end{array}$ & Suggestive & Critical & $\begin{array}{l}\text { Content and arguments } \\
\text { (coverage) }\end{array}$ & Narrow \\
\hline $\begin{array}{l}\text { Check the APA manual for } \\
\text { this citation. }\end{array}$ & Authoritative & Critical & $\begin{array}{l}\text { Mechanical issues } \\
\text { (references and } \\
\text { citations) }\end{array}$ & Narrow \\
\hline $\begin{array}{l}\text { A bit of wavering focus } \\
\text { from this paragraph to this } \\
\text { paragraph. Check for } \\
\text { consistency throughout. }\end{array}$ & Authoritative & Critical & $\begin{array}{l}\text { Organization and flow } \\
\text { (consistency) }\end{array}$ & Narrow/Wide \\
\hline $\begin{array}{l}\text { I don't agree with this } \\
\text { paragraph. I think, ...... }\end{array}$ & -- & Critical & $\begin{array}{l}\text { Content and arguments } \\
\text { (accuracy/sensibility) }\end{array}$ & Narrow \\
\hline $\begin{array}{l}\text { I have a hard time following } \\
\text { this section. }\end{array}$ & -- & Critical & $\begin{array}{l}\text { Content and arguments } \\
\text { (clarity and } \\
\text { understandability) }\end{array}$ & Narrow \\
\hline $\begin{array}{l}\text { I'd like you to go in a little } \\
\text { different direction, like } \\
\text { this.... }\end{array}$ & Authoritative & Critical & Direction (Changes) & Wide \\
\hline
\end{tabular}

in the second group, participants rated their perceptions of the feedback providers in relation to the types of feedback they give.

Perceptions and Attitudes Toward Different Written Feedback Providers

The participants were asked the question "How important are the following characteristics of a person to you when deciding whether or not to ask for their written feedback?" The participants rated 24 written feedback provider characteristics on a 4-point importance scale (1- Unimportant, 2- Somewhat Important, 3- Important, 4- Very Important).

They rated that the feedback providers' willingness to help, and their thinking, organizing, analyzing, and writing skills are important when deciding to ask for their feedback (see Table 4-15 and Table 4-16). Age and the location of the feedback providers were rated to have the least importance when participants deciding to ask for their written feedback. 
Table 4-11

Specific Feedback Preferences: Descriptive Statistics (1- Strongly Disagree, 2- Disagree, 3- Agree, 4Strongly Agree)

\begin{tabular}{|c|c|c|c|c|c|c|c|c|}
\hline $\begin{array}{l}\text { Specific feedback } \\
\text { preferences }\end{array}$ & $M$ & $M d n$ & Mode & $S D$ & Var & Ran & Skew & Kur \\
\hline \multicolumn{9}{|l|}{$\begin{array}{l}\text { I appreciate written } \\
\text { feedback comments similar } \\
\text { to this:.... }\end{array}$} \\
\hline $\begin{array}{l}\text { Here is an article that } \\
\text { supports what you're saying } \\
\text { here. }\end{array}$ & 3.59 & 4 & 4 & .49 & .24 & 1 & -.36 & -1.88 \\
\hline $\begin{array}{l}\text { I think this sentence should } \\
\text { be said much earlier. It is } \\
\text { important. }\end{array}$ & 3.35 & 3 & 3 & .54 & .29 & 2 & .01 & -.82 \\
\hline $\begin{array}{l}\text { Maybe you need a table } \\
\text { here, listing X with each } \\
\text { column showing Y. Just an } \\
\text { idea. }\end{array}$ & 3.35 & 3 & 3 & .57 & .32 & 3 & -.41 & .74 \\
\hline This section is really strong. & 3.27 & 3 & 3 & .59 & .35 & 3 & -.27 & .02 \\
\hline $\begin{array}{l}\text { This argument is } \\
\text { unsupported. You need to } \\
\text { cite more references. }\end{array}$ & 3.25 & 3 & 3 & .57 & .32 & 3 & -.27 & .91 \\
\hline $\begin{array}{l}\text { Have you thought about } \\
\text { adding one more section to } \\
\text { your paper about X } \\
\text { literature? }\end{array}$ & 3.25 & 3 & 3 & .53 & .28 & 2 & .16 & -.32 \\
\hline $\begin{array}{l}\text { You're on the right track, } \\
\text { this is a well-organized } \\
\text { paper. }\end{array}$ & 3.22 & 3 & 3 & .56 & .31 & 2 & .02 & -.28 \\
\hline $\begin{array}{l}\text { It is not clear how this } \\
\text { paragraph addresses your } \\
\text { research question. You need } \\
\text { to show links to the research } \\
\text { question. }\end{array}$ & 3.21 & 3 & 3 & .58 & .33 & 3 & -.16 & .24 \\
\hline $\begin{array}{l}\text { Break this into smaller, } \\
\text { more focused paragraphs. }\end{array}$ & 3.17 & 3 & 3 & .51 & .26 & 3 & .07 & 1.16 \\
\hline
\end{tabular}




\begin{tabular}{|c|c|c|c|c|c|c|c|c|}
\hline $\begin{array}{l}\text { Specific feedback } \\
\text { preferences }\end{array}$ & $M$ & $M d n$ & Mode & $S D$ & Var & Ran & Skew & Kur \\
\hline $\begin{array}{l}\text { Explain why you're } \\
\text { focusing on these } \\
\text { dimensions. Not clear to the } \\
\text { reader. }\end{array}$ & 3.10 & 3 & 3 & .55 & .30 & 3 & -.07 & .86 \\
\hline $\begin{array}{l}\text { This section is a bit dense, } \\
\text { with lots of details. Are they } \\
\text { all necessary? }\end{array}$ & 3.01 & 3 & 3 & .61 & .38 & 3 & -.38 & .94 \\
\hline $\begin{array}{l}\text { Check the APA manual for } \\
\text { this citation. }\end{array}$ & 3.00 & 3 & 3 & .75 & .56 & 3 & -.74 & .79 \\
\hline $\begin{array}{l}\text { A bit of wavering focus } \\
\text { from this paragraph to this } \\
\text { paragraph. Check for } \\
\text { consistency throughout. }\end{array}$ & 2.91 & 3 & 3 & .71 & .51 & 3 & -.36 & .12 \\
\hline $\begin{array}{l}\text { I have a hard time following } \\
\text { this section. }\end{array}$ & 2.70 & 3 & 3 & .76 & .58 & 3 & -.11 & -.36 \\
\hline $\begin{array}{l}\text { I don't agree with this } \\
\text { paragraph. I think, ...... }\end{array}$ & 2.69 & 3 & 3 & .76 & .58 & 3 & -.44 & -.01 \\
\hline $\begin{array}{l}\text { I'd like you to go in a little } \\
\text { different direction, like } \\
\text { this.... }\end{array}$ & 2.47 & 2 & 2 & .74 & .55 & 3 & .03 & -.29 \\
\hline
\end{tabular}


Table 4-12

Specific Feedback Preferences: Frequencies and Percentages (SD- Strongly Disagree, D-Disagree, A- Agree, SA-Strongly Agree)

\begin{tabular}{|c|c|c|c|c|c|c|c|}
\hline \multirow[b]{2}{*}{ Specific feedback preferences } & \multirow[b]{2}{*}{$\begin{array}{c}\text { SD } \\
f(P)\end{array}$} & \multirow[b]{2}{*}{$\begin{array}{c}\mathrm{D} \\
f(P)\end{array}$} & \multirow[b]{2}{*}{$\begin{array}{c}\mathrm{A} \\
f(P)\end{array}$} & \multirow[b]{2}{*}{$\begin{array}{l}\text { SA } \\
f(P)\end{array}$} & \multicolumn{2}{|c|}{ Total } & \multirow[b]{2}{*}{$\begin{array}{c}\text { Missing } \\
f(P)\end{array}$} \\
\hline & & & & & $\begin{array}{c}\text { Disagree } \\
f(P)\end{array}$ & $\begin{array}{l}\text { Agree } \\
f(P)\end{array}$ & \\
\hline I appreciate written feedback comments similar to this:...... & & & & & & & \\
\hline Here is an article that supports what you're saying here. & 0 & 0 & $\begin{array}{c}113 \\
(41 \%)\end{array}$ & $\begin{array}{c}162 \\
(59 \%)\end{array}$ & 0 & $\begin{array}{c}275 \\
(100 \%)\end{array}$ & $\begin{array}{c}1 \\
(0 \%)\end{array}$ \\
\hline $\begin{array}{l}\text { Maybe you need a table here, listing } \mathrm{X} \text { with each column showing } \\
\text { Y. Just an idea. }\end{array}$ & $\begin{array}{c}2 \\
(1 \%)\end{array}$ & $\begin{array}{c}7 \\
(2 \%)\end{array}$ & $\begin{array}{c}159 \\
(58 \%)\end{array}$ & $\begin{array}{l}108 \\
(39 \%)\end{array}$ & $\begin{array}{c}9 \\
(3 \%)\end{array}$ & $\begin{array}{l}267 \\
(97 \%)\end{array}$ & 0 \\
\hline I think this sentence should be said much earlier. It is important. & 0 & $\begin{array}{c}9 \\
(3 \%)\end{array}$ & $\begin{array}{c}162 \\
(59 \%)\end{array}$ & $\begin{array}{c}105 \\
(38 \%)\end{array}$ & $\begin{array}{c}9 \\
(3 \%)\end{array}$ & $\begin{array}{l}267 \\
(97 \%)\end{array}$ & 0 \\
\hline $\begin{array}{l}\text { Have you thought about adding one more section to your paper } \\
\text { about X literature? }\end{array}$ & 0 & $\begin{array}{c}13 \\
(5 \%)\end{array}$ & $\begin{array}{c}181 \\
(66 \%)\end{array}$ & $\begin{array}{c}82 \\
(30 \%)\end{array}$ & $\begin{array}{c}13 \\
(5 \%)\end{array}$ & $\begin{array}{l}263 \\
(95 \%)\end{array}$ & 0 \\
\hline Break this into smaller, more focused paragraphs. & $\begin{array}{c}1 \\
(0 \%)\end{array}$ & $\begin{array}{c}14 \\
(5 \%)\end{array}$ & $\begin{array}{c}199 \\
(72 \%)\end{array}$ & $\begin{array}{c}62 \\
(23 \%)\end{array}$ & $\begin{array}{c}15 \\
(5 \%)\end{array}$ & $\begin{array}{c}261 \\
(95 \%)\end{array}$ & 0 \\
\hline This argument is unsupported. You need to cite more references. & $\begin{array}{c}2 \\
(1 \%)\end{array}$ & $\begin{array}{c}12 \\
(4 \%)\end{array}$ & $\begin{array}{c}176 \\
(64 \%)\end{array}$ & $\begin{array}{c}85 \\
(31 \%)\end{array}$ & $\begin{array}{c}14 \\
(5 \%)\end{array}$ & $\begin{array}{c}261 \\
(95 \%)\end{array}$ & $\begin{array}{c}1 \\
(0 \%)\end{array}$ \\
\hline You're on the right track, this is a well-organized paper. & 0 & $\begin{array}{c}19 \\
(7 \%)\end{array}$ & $\begin{array}{c}176 \\
(64 \%)\end{array}$ & $\begin{array}{c}81 \\
(29 \%)\end{array}$ & $\begin{array}{c}19 \\
(7 \%)\end{array}$ & $\begin{array}{c}257 \\
(93 \%)\end{array}$ & 0 \\
\hline
\end{tabular}




\begin{tabular}{|c|c|c|c|c|c|c|c|}
\hline \multirow[b]{2}{*}{ Specific feedback preferences } & \multirow[b]{2}{*}{$\begin{array}{c}\text { SD } \\
f(P)\end{array}$} & \multirow[b]{2}{*}{$\begin{array}{c}\mathrm{D} \\
f(P)\end{array}$} & \multirow[b]{2}{*}{$\begin{array}{c}\text { A } \\
f(P)\end{array}$} & \multirow[b]{2}{*}{$\begin{array}{l}\text { SA } \\
f(P)\end{array}$} & \multicolumn{2}{|c|}{ Total } & \multirow[b]{2}{*}{$\begin{array}{c}\text { Missing } \\
f(P)\end{array}$} \\
\hline & & & & & $\begin{array}{c}\text { Disagree } \\
f(P)\end{array}$ & $\begin{array}{c}\text { Agree } \\
f(P)\end{array}$ & \\
\hline This section is really strong. & $\begin{array}{c}1 \\
(0 \%)\end{array}$ & $\begin{array}{l}18 \\
(6 \%)\end{array}$ & $\begin{array}{c}162 \\
(59 \%)\end{array}$ & $\begin{array}{c}95 \\
(34 \%)\end{array}$ & $\begin{array}{c}19 \\
(7 \%)\end{array}$ & $\begin{array}{c}257 \\
(93 \%)\end{array}$ & 0 \\
\hline $\begin{array}{l}\text { It is not clear how this paragraph addresses your research question. } \\
\text { You need to show links to the research question. }\end{array}$ & $\begin{array}{c}1 \\
(0 \%)\end{array}$ & $\begin{array}{c}20 \\
(7 \%)\end{array}$ & $\begin{array}{l}175 \\
(63 \%)\end{array}$ & $\begin{array}{c}80 \\
(29 \%)\end{array}$ & $\begin{array}{c}21 \\
(8 \%)\end{array}$ & $\begin{array}{l}255 \\
(92 \%)\end{array}$ & 0 \\
\hline $\begin{array}{l}\text { Explain why you're focusing on these dimensions. Not clear to the } \\
\text { reader. }\end{array}$ & $\begin{array}{c}1 \\
(0 \%)\end{array}$ & $\begin{array}{l}25 \\
(9 \%)\end{array}$ & $\begin{array}{c}192 \\
(70 \%)\end{array}$ & $\begin{array}{c}55 \\
(20 \%)\end{array}$ & $\begin{array}{c}26 \\
(9 \%)\end{array}$ & $\begin{array}{c}247 \\
(89 \%)\end{array}$ & $\begin{array}{c}3 \\
(1 \%)\end{array}$ \\
\hline $\begin{array}{l}\text { This section is a bit dense, with lots of details. Are they all } \\
\text { necessary? }\end{array}$ & $\begin{array}{c}4 \\
(1 \%)\end{array}$ & $\begin{array}{c}39 \\
(14 \%)\end{array}$ & $\begin{array}{c}184 \\
(67 \%)\end{array}$ & $\begin{array}{c}49 \\
(18 \%)\end{array}$ & $\begin{array}{c}43 \\
(16 \%)\end{array}$ & $\begin{array}{l}233 \\
(84 \%)\end{array}$ & 0 \\
\hline Check the APA manual for this citation. & $\begin{array}{c}14 \\
(5 \%)\end{array}$ & $\begin{array}{c}34 \\
(12 \%)\end{array}$ & $\begin{array}{c}162 \\
(59 \%)\end{array}$ & $\begin{array}{c}63 \\
(23 \%)\end{array}$ & $\begin{array}{c}48 \\
(17 \%)\end{array}$ & $\begin{array}{c}225 \\
(82 \%)\end{array}$ & $\begin{array}{c}3 \\
(1 \%)\end{array}$ \\
\hline $\begin{array}{l}\text { A bit of wavering focus from this paragraph to this paragraph. } \\
\text { Check for consistency throughout. }\end{array}$ & $\begin{array}{c}8 \\
(3 \%)\end{array}$ & $\begin{array}{c}59 \\
(21 \%)\end{array}$ & $\begin{array}{l}157 \\
(57 \%)\end{array}$ & $\begin{array}{c}50 \\
(18 \%)\end{array}$ & $\begin{array}{c}67 \\
(24 \%)\end{array}$ & $\begin{array}{c}207 \\
(75 \%)\end{array}$ & $\begin{array}{c}2 \\
(1 \%)\end{array}$ \\
\hline I don't agree with this paragraph. I think, ....... & $\begin{array}{c}21 \\
(8 \%)\end{array}$ & $\begin{array}{c}73 \\
(26 \%)\end{array}$ & $\begin{array}{c}152 \\
(55 \%)\end{array}$ & $\begin{array}{c}30 \\
(11 \%)\end{array}$ & $\begin{array}{c}94 \\
(34 \%)\end{array}$ & $\begin{array}{c}182 \\
(66 \%)\end{array}$ & 0 \\
\hline I have a hard time following this section. & $\begin{array}{c}14 \\
(5 \%)\end{array}$ & $\begin{array}{c}93 \\
(34 \%)\end{array}$ & $\begin{array}{c}131 \\
(48 \%)\end{array}$ & $\begin{array}{c}37 \\
(13 \%)\end{array}$ & $\begin{array}{c}107 \\
(39 \%)\end{array}$ & $\begin{array}{c}168 \\
(61 \%)\end{array}$ & $\begin{array}{c}1 \\
(0 \%)\end{array}$ \\
\hline I'd like you to go in a little different direction, like this.... & $\begin{array}{c}22 \\
(8 \%)\end{array}$ & $\begin{array}{c}121 \\
(44 \%)\end{array}$ & $\begin{array}{c}113 \\
(41 \%)\end{array}$ & $\begin{array}{c}19 \\
(7 \%)\end{array}$ & $\begin{array}{c}143 \\
(52 \%)\end{array}$ & $\begin{array}{c}132 \\
(48 \%)\end{array}$ & $\begin{array}{c}1 \\
(0 \%)\end{array}$ \\
\hline
\end{tabular}


Table 4-13

Attitudes Toward Critical/Negative Written Feedback: Descriptive Statistics (1- Strongly Disagree, 2- Disagree, 3- Agree, 4- Strongly Agree)

\begin{tabular}{|c|c|c|c|c|c|c|c|c|}
\hline Statements about critical/negative written feedback & $M$ & $M d n$ & Mode & $S D$ & Var & Ran & Skew & Kur \\
\hline $\begin{array}{l}\text { I re-write my paper if I receive very critical/negative written feedback } \\
\text { from someone with more knowledge and experience than I have }\end{array}$ & 2.82 & 3 & 3 & .75 & .56 & 3 & -.52 & .26 \\
\hline Critical/negative written feedback affects me emotionally & 2.61 & 3 & 3 & .70 & .49 & 3 & -.47 & .07 \\
\hline Having critical/negative written feedback makes me feel embarrassed & 2.29 & 2 & 2 & .75 & .56 & 3 & .10 & -.32 \\
\hline I lose self-confidence when I receive critical/negative written feedback & 2.24 & 2 & 2 & .72 & .52 & 3 & .12 & -.26 \\
\hline I am scared to get critical/negative written feedback & 2.06 & 2 & 2 & .71 & .51 & 3 & .22 & -.24 \\
\hline $\begin{array}{l}\text { I lose my motivation to work on my paper further when I receive } \\
\text { critical/negative written feedback }\end{array}$ & 2.04 & 2 & 2 & .74 & .54 & 3 & .37 & -.05 \\
\hline $\begin{array}{l}\text { I feel that it is a personal attack when I receive critical/negative written } \\
\text { feedback without suggestions }\end{array}$ & 1.99 & 2 & 2 & .81 & .66 & 3 & .39 & -.53 \\
\hline $\begin{array}{l}\text { I give up on my paper if I receive very critical/negative written } \\
\text { feedback from someone with more knowledge and experience than I } \\
\text { have }\end{array}$ & 1.72 & 2 & 2 & .61 & .38 & 3 & .44 & .37 \\
\hline
\end{tabular}


Table 4-14

Attitudes Toward Critical/Negative Written Feedback: Frequencies and Percentages (SD-Strongly Disagree, D-Disagree, A-Agree, SA-Strongly Agree)

\begin{tabular}{|c|c|c|c|c|c|c|}
\hline \multirow[b]{2}{*}{ Statements about critical/negative written feedback } & \multirow[b]{2}{*}{$\begin{array}{l}\mathrm{SD} \\
f(P)\end{array}$} & \multirow[b]{2}{*}{$\begin{array}{c}\mathrm{D} \\
f(P)\end{array}$} & \multirow[b]{2}{*}{$\begin{array}{c}\text { A } \\
f(P)\end{array}$} & \multirow[b]{2}{*}{$\begin{array}{l}\text { SA } \\
f(P)\end{array}$} & \multicolumn{2}{|c|}{ Total } \\
\hline & & & & & $\begin{array}{l}\text { Disagree } \\
\qquad f(P)\end{array}$ & $\begin{array}{l}\text { Agree } \\
f(P)\end{array}$ \\
\hline $\begin{array}{l}\text { I re-write my paper if I receive very critical/negative written feedback } \\
\text { from someone with more knowledge and experience than I have }\end{array}$ & $16(6 \%)$ & $59(21 \%)$ & $160(58 \%)$ & $41(15 \%)$ & $75(27 \%)$ & $201(73 \%)$ \\
\hline Critical/negative written feedback affects me emotionally & $18(6 \%)$ & $87(32 \%)$ & $155(56 \%)$ & $16(6 \%)$ & $105(38 \%)$ & $171(62 \%)$ \\
\hline Having critical/negative written feedback makes me feel embarrassed & $36(13 \%)$ & $135(49 \%)$ & $93(34 \%)$ & $12(4 \%)$ & $171(62 \%)$ & $105(38 \%)$ \\
\hline I lose self-confidence when I receive critical/negative written feedback & $38(14 \%)$ & $143(52 \%)$ & $86(31 \%)$ & $9(3 \%)$ & $181(66 \%)$ & $95(34 \%)$ \\
\hline I am scared to get critical/negative written feedback & $57(21 \%)$ & $151(55 \%)$ & $63(23 \%)$ & $5(2 \%)$ & $208(75 \%)$ & $68(25 \%)$ \\
\hline $\begin{array}{l}\text { I lose my motivation to work on my paper further when I receive } \\
\text { critical/negative written feedback }\end{array}$ & $61(22 \%)$ & $150(54 \%)$ & $57(21 \%)$ & $8(3 \%)$ & $211(76 \%)$ & $65(24 \%)$ \\
\hline $\begin{array}{l}\text { I feel that it is a personal attack when I receive critical/negative written } \\
\text { feedback without suggestions }\end{array}$ & $83(30 \%)$ & $122(44 \%)$ & $62(22 \%)$ & $9(3 \%)$ & $205(74 \%)$ & $71(26 \%)$ \\
\hline $\begin{array}{l}\text { I give up on my paper if I receive very critical/negative written } \\
\text { feedback from someone with more knowledge and experience than I } \\
\text { have }\end{array}$ & $99(36 \%)$ & $157(57 \%)$ & $18(7 \%)$ & $2(1 \%)$ & $256(93 \%)$ & $20(7 \%)$ \\
\hline
\end{tabular}


Table 4-15

Perceptions and Attitudes Toward Different Written Feedback Providers: Descriptive Statistics (1- Unimportant, 2- Somewhat Important, 3- Important, 4- Very Important)

\begin{tabular}{|c|c|c|c|c|c|c|c|c|}
\hline Characteristics of feedback providers & $M$ & $M d n$ & Mode & $S D$ & Var & Range & Skew & Kur \\
\hline Whether I feel that he/she will be willing to help & 3.25 & 3 & 3 & .69 & .47 & 3 & -.51 & -.27 \\
\hline His/her thinking, organizing, and analyzing skills & 3.16 & 3 & 3 & .80 & .64 & 3 & -.78 & .22 \\
\hline His/her writing skills & 3.16 & 3 & 3 & .80 & .64 & 3 & -.77 & .22 \\
\hline Whether I trust him/her as a person & 3.11 & 3 & 3 & .79 & .62 & 3 & -.60 & -.10 \\
\hline Whether I feel that I won't be a burden to him/her & 3.04 & 3 & 3 & .80 & .63 & 3 & -.68 & .26 \\
\hline Whether I think they have time to give me feedback & 3.03 & 3 & 3 & .74 & .54 & 3 & -.54 & .28 \\
\hline My previous experiences with his/her feedback & 3.01 & 3 & 3 & .81 & .66 & 3 & -.52 & -.19 \\
\hline Whether he/she is a responsible person & 2.90 & 3 & 3 & .80 & .64 & 3 & -.42 & -.21 \\
\hline His/her knowledge level in the content area that my paper is about & 2.81 & 3 & 3 & .85 & .72 & 3 & -.34 & -.46 \\
\hline His/her interest level in the content area that my paper is about & 2.63 & 3 & 3 & .85 & .73 & 3 & -.21 & -.54 \\
\hline His/her writing style & 2.65 & 3 & 3 & .92 & .85 & 3 & -.13 & -.82 \\
\hline Whether I think he/she will give feedback quickly & 2.59 & 3 & 3 & .81 & .65 & 3 & -.26 & -.38 \\
\hline
\end{tabular}




\begin{tabular}{|c|c|c|c|c|c|c|c|c|}
\hline Characteristics of feedback providers & $M$ & $M d n$ & Mode & $S D$ & Var & Range & Skew & Kur \\
\hline His/her publication experience & 2.56 & 3 & 3 & .95 & .90 & 3 & -.21 & -.86 \\
\hline His/her being in the same discipline or not & 2.56 & 3 & 3 & .87 & .75 & 3 & -.22 & -.60 \\
\hline His/her expectations of the quality of my paper & 2.45 & 3 & 3 & .87 & .76 & 3 & -.13 & -.71 \\
\hline Others' previous experiences with his/her feedback & 2.40 & 2 & 3 & .85 & .72 & 3 & -.12 & -.69 \\
\hline Whether we have a good social relationship & 2.39 & 2 & 3 & .94 & .88 & 3 & .02 & -.90 \\
\hline Whether I like his/her personality & 2.26 & 2 & 3 & .94 & .88 & 3 & .13 & -.96 \\
\hline Whether I have a mutual feedback relationship with him/her & 2.24 & 2 & 2 & .87 & .76 & 3 & .10 & -.79 \\
\hline Whether he/she thinks my paper is important & 2.19 & 2 & 2 & .86 & .74 & 3 & .12 & -.82 \\
\hline His/her reasons/incentives for giving me feedback & 2.14 & 2 & 2 & .84 & .71 & 3 & .25 & -.63 \\
\hline $\begin{array}{l}\text { Whether he/she has a decisive role in my degree completion or } \\
\text { publication }\end{array}$ & 2.13 & 2 & 1 & 1.07 & 1.14 & 3 & .39 & -1.17 \\
\hline $\begin{array}{l}\text { Whether the person lives/works/studies close to me in terms of } \\
\text { location }\end{array}$ & 1.58 & 1 & 1 & .77 & .59 & 3 & .93 & -.51 \\
\hline Whether the person is younger or older than I am & 1.25 & 1 & 1 & .56 & .32 & 3 & 2.42 & 5.73 \\
\hline
\end{tabular}


Table 4-16

Perceptions and Attitudes Toward Different Written Feedback Providers: Frequencies and Percentages

\begin{tabular}{|c|c|c|c|c|c|}
\hline $\begin{array}{l}\text { Characteristics of feedback } \\
\text { providers }\end{array}$ & $\begin{array}{c}\text { Unimportant } \\
\qquad f(P)\end{array}$ & $\begin{array}{c}\text { Somewhat } \\
\text { important } \\
f(P)\end{array}$ & $\begin{array}{c}\text { Important } \\
f(P)\end{array}$ & $\begin{array}{c}\text { Very } \\
\text { important } \\
f(P)\end{array}$ & $\begin{array}{c}\text { Missing } \\
f(P)\end{array}$ \\
\hline $\begin{array}{l}\text { Whether I feel that he/she will be } \\
\text { willing to help }\end{array}$ & $2(1 \%)$ & $33(12 \%)$ & $134(49 \%)$ & $107(39 \%)$ & 0 \\
\hline $\begin{array}{l}\text { His/her thinking, organizing, and } \\
\text { analyzing skills }\end{array}$ & $11(4 \%)$ & $36(13 \%)$ & $126(46 \%)$ & $103(37 \%)$ & 0 \\
\hline His/her writing skills & $11(4 \%)$ & $36(13 \%)$ & $126(46 \%)$ & $101(37 \%)$ & $2(1 \%)$ \\
\hline Whether I trust him/her as a person & $9(3 \%)$ & $45(16 \%)$ & $129(47 \%)$ & $93(34 \%)$ & 0 \\
\hline $\begin{array}{l}\text { Whether I feel that I won't be a } \\
\text { burden to him/her }\end{array}$ & $14(5 \%)$ & $40(14 \%)$ & $143(52 \%)$ & $78(28 \%)$ & $1(0 \%)$ \\
\hline $\begin{array}{l}\text { Whether I think they have time to } \\
\text { give me feedback }\end{array}$ & $9(3 \%)$ & $44(16 \%)$ & $153(55 \%)$ & $69(25 \%)$ & $1(0 \%)$ \\
\hline $\begin{array}{l}\text { My previous experiences with } \\
\text { his/her feedback }\end{array}$ & $12(4 \%)$ & $52(19 \%)$ & $131(48 \%)$ & $80(29 \%)$ & $1(0 \%)$ \\
\hline $\begin{array}{l}\text { Whether he/she is a responsible } \\
\text { person }\end{array}$ & $14(5 \%)$ & $61(22 \%)$ & $138(50 \%)$ & $62(22 \%)$ & $1(0 \%)$ \\
\hline $\begin{array}{l}\text { His/her knowledge level in the } \\
\text { content area that my paper is about }\end{array}$ & $20(7 \%)$ & $70(25 \%)$ & $127(46 \%)$ & $58(21 \%)$ & $1(0 \%)$ \\
\hline $\begin{array}{l}\text { His/her interest level in the content } \\
\text { area that my paper is about }\end{array}$ & $28(10 \%)$ & $85(31 \%)$ & $123(45 \%)$ & $40(14 \%)$ & 0 \\
\hline His/her writing style & $31(11 \%)$ & $88(32 \%)$ & $102(37 \%)$ & $54(20 \%)$ & $1(0 \%)$ \\
\hline $\begin{array}{l}\text { Whether I think he/she will give } \\
\text { feedback quickly }\end{array}$ & $27(10 \%)$ & $87(32 \%)$ & $132(48 \%)$ & $29(10 \%)$ & $1(0 \%)$ \\
\hline His/her publication experience & $46(17 \%)$ & $73(26 \%)$ & $114(41 \%)$ & $43(16 \%)$ & 0 \\
\hline $\begin{array}{l}\text { His/her being in the same discipline } \\
\text { or not }\end{array}$ & $35(13 \%)$ & $84(30 \%)$ & $122(44 \%)$ & $34(12 \%)$ & $1(0 \%)$ \\
\hline $\begin{array}{l}\text { His/her expectations of the quality } \\
\text { of my paper }\end{array}$ & $44(16 \%)$ & $91(33 \%)$ & $115(42 \%)$ & $26(9 \%)$ & 0 \\
\hline $\begin{array}{l}\text { Others' previous experiences with } \\
\text { his/her feedback }\end{array}$ & $45(16 \%)$ & $96(35 \%)$ & $114(41 \%)$ & $21(8 \%)$ & 0 \\
\hline
\end{tabular}




\begin{tabular}{|c|c|c|c|c|c|}
\hline $\begin{array}{l}\text { Characteristics of feedback } \\
\text { providers }\end{array}$ & $\begin{array}{l}\text { Unimportant } \\
\qquad f(P)\end{array}$ & $\begin{array}{c}\text { Somewhat } \\
\text { important } \\
f(P)\end{array}$ & $\begin{array}{l}\text { Important } \\
\qquad f(P)\end{array}$ & $\begin{array}{c}\text { Very } \\
\text { important } \\
f(P)\end{array}$ & $\begin{array}{l}\text { Missing } \\
f(P)\end{array}$ \\
\hline $\begin{array}{l}\text { Whether we have a good social } \\
\text { relationship }\end{array}$ & $55(20 \%)$ & $90(33 \%)$ & $97(35 \%)$ & $32(12 \%)$ & $2(1 \%)$ \\
\hline Whether I like his/her personality & $70(25 \%)$ & $90(33 \%)$ & $91(33 \%)$ & $25(9 \%)$ & 0 \\
\hline $\begin{array}{l}\text { Whether I have a mutual feedback } \\
\text { relationship with him/her }\end{array}$ & $61(22 \%)$ & $105(38 \%)$ & $92(33 \%)$ & $18(6 \%)$ & 0 \\
\hline $\begin{array}{l}\text { Whether he/she thinks my paper is } \\
\text { important }\end{array}$ & $66(24 \%)$ & $106(38 \%)$ & $90(33 \%)$ & $14(5 \%)$ & 0 \\
\hline $\begin{array}{l}\text { His/her reasons/incentives for giving } \\
\text { me feedback }\end{array}$ & $66(24 \%)$ & $117(42 \%)$ & $76(28 \%)$ & $14(5 \%)$ & $3(1 \%)$ \\
\hline $\begin{array}{l}\text { Whether he/she has a decisive role } \\
\text { in my degree completion or } \\
\text { publication }\end{array}$ & $105(38 \%)$ & $66(24 \%)$ & $68(25 \%)$ & $37(13 \%)$ & 0 \\
\hline $\begin{array}{l}\text { Whether the person lives/works/ } \\
\text { studies close to me in terms of } \\
\text { location }\end{array}$ & $162(59 \%)$ & $69(25 \%)$ & $44(16 \%)$ & $1(0 \%)$ & 0 \\
\hline $\begin{array}{l}\text { Whether the person is younger or } \\
\text { older than I am }\end{array}$ & $223(81 \%)$ & $39(14 \%)$ & $12(4 \%)$ & $2(1 \%)$ & 0 \\
\hline
\end{tabular}


Perceptions Toward Feedback Providers Regarding

the Types of Feedback They Give

Participants were also asked a short series of questions about their perceptions toward the feedback providers in relation to the types of feedback they give, especially critical/negative written feedback and written feedback about mechanical issues in the paper, on a 4-point agreement scale (1Strongly Disagree, 2-Disagree, 3-Agree, 4-Strongly Agree). As seen in Table 4-17 and 4-18, 88\% of the participants agreed with the statement that written feedback is influenced by the personality of the feedback provider. Most of them (80\%) also perceived that the feedback providers have high expectations of the participants when they give critical/negative written feedback. Considering the feedback providers who give written feedback mostly about mechanical issues, the participants perceived that this is not because they are not knowledgeable about their paper or not because they are not interested in their paper.

Research Question 3: Relationships with the Revision Decisions

In this part, participants' attitudes regarding their revision decisions were presented in relation to some of their perceptions and attitudes toward different characteristics of written feedback and written feedback providers.

Revision Decisions in the Case of Disagreement with the Written Feedback

The participants were asked to complete the statement "If I don't agree with a written feedback comment, before deciding to ignore or use that comment for my revisions I ask myself:" with a series of questions in 4-point frequency scale (1- Never, 2- Seldom, 3- Sometimes, 4- Often). In the case of such conflicts, the participants most frequently examine the justification of the written feedback and the need for the revision (see Table 4-19 and Table 4-20). They also question their confidence in what they wrote and how much that revision will affect the direction of their paper. Questions regarding the feedback providers' characteristics such as knowledge and experience of the person, authority-power relationships, and their motivations were questioned less frequently compared to the first group of questions. Questions regarding the punishment and reward for revising as asked or suggested in the written feedback rated as the least frequently asked questions on the list. 
Table 4-17

Perceptions Toward Feedback Providers Regarding the Types of Feedback They Give: Descriptive Statistics (1-Strongly Disagree, 2-Disagree, 3-Agree, 4-

Strongly Agree)

\begin{tabular}{|c|c|c|c|c|c|c|c|c|}
\hline Statements about feedback providers and their feedback & $M$ & $M d n$ & Mode & $S D$ & Var & Ran & Skew & Kur \\
\hline $\begin{array}{l}\text { I think that written feedback is influenced by the personality of the } \\
\text { feedback provider }\end{array}$ & 3.03 & 3 & 3 & .60 & .36 & 3 & -.63 & 2.08 \\
\hline $\begin{array}{l}\text { I think that feedback providers have high expectations of me when } \\
\text { they give me critical/negative written feedback }\end{array}$ & 2.95 & 3 & 3 & .66 & .43 & 3 & -.42 & .64 \\
\hline $\begin{array}{l}\text { I think that people I have a close relationship with (e.g family, good } \\
\text { friends) avoid giving me critical/negative written feedback }\end{array}$ & 2.40 & 2 & 2 & .74 & .55 & 3 & .35 & -.12 \\
\hline $\begin{array}{l}\text { When feedback providers give me written feedback mostly about } \\
\text { grammar, sentence structure, format, etc. I think that they are not } \\
\text { knowledgeable about the content topic of my paper }\end{array}$ & 2.13 & 2 & 2 & .70 & .49 & 3 & .26 & .02 \\
\hline $\begin{array}{l}\text { When feedback providers give me written feedback mostly about } \\
\text { grammar, sentence structure, format, etc. I think that they are not } \\
\text { interested in my paper }\end{array}$ & 2.10 & 2 & 2 & .71 & .51 & 3 & .40 & .21 \\
\hline
\end{tabular}


Table 4-18

Perceptions Toward Feedback Providers Regarding the Types of Feedback They Give: Frequencies and Percentages (SD- Strongly Disagree, D- Disagree, A-

Agree, SA-Strongly Agree)

\begin{tabular}{|c|c|c|c|c|c|c|}
\hline \multirow[b]{2}{*}{ Statements about feedback providers and their feedback } & \multirow[b]{2}{*}{$\begin{array}{l}\mathrm{SD} \\
f(P)\end{array}$} & \multirow[b]{2}{*}{$f(P)$} & \multirow[b]{2}{*}{$\begin{array}{c}\text { A } \\
f(P)\end{array}$} & \multirow[b]{2}{*}{$\begin{array}{l}\text { SA } \\
f(P)\end{array}$} & \multicolumn{2}{|c|}{ Total } \\
\hline & & & & & $\begin{array}{l}\text { Disagree } \\
\qquad f(P)\end{array}$ & $\begin{array}{l}\text { Agree } \\
f(P)\end{array}$ \\
\hline $\begin{array}{l}\text { I think that written feedback is influenced by the personality of the } \\
\text { feedback provider }\end{array}$ & $6(2 \%)$ & $27(10 \%)$ & $196(71 \%)$ & $47(17 \%)$ & $33(12 \%)$ & $243(88 \%)$ \\
\hline $\begin{array}{l}\text { I think that feedback providers have high expectations of me when } \\
\text { they give me critical/negative written feedback }\end{array}$ & $6(2 \%)$ & $48(17 \%)$ & $175(63 \%)$ & $47(17 \%)$ & $54(20 \%)$ & $222(80 \%)$ \\
\hline $\begin{array}{l}\text { I think that people I have a close relationship with (e.g family, good } \\
\text { friends) avoid giving me critical/negative written feedback }\end{array}$ & $21(8 \%)$ & $145(52 \%)$ & $89(32 \%)$ & $21(8 \%)$ & $166(60 \%)$ & $110(40 \%)$ \\
\hline $\begin{array}{l}\text { When feedback providers give me written feedback mostly about } \\
\text { grammar, sentence structure, format, etc. I think that they are not } \\
\text { knowledgeable about the content topic of my paper }\end{array}$ & $44(16 \%)$ & $158(57 \%)$ & $67(24 \%)$ & $7(2 \%)$ & $202(73 \%)$ & $74(27 \%)$ \\
\hline $\begin{array}{l}\text { When feedback providers give me written feedback mostly about } \\
\text { grammar, sentence structure, format, etc. I think that they are not } \\
\text { interested in my paper }\end{array}$ & $49(18 \%)$ & $160(58 \%)$ & $58(21 \%)$ & $9(3 \%)$ & $209(76 \%)$ & $67(24 \%)$ \\
\hline
\end{tabular}


Table 4-19

Revision Decisions In the Case of Disagreement with the Written Feedback: Descriptive Statistics (1- Never, 2- Seldom, 3- Sometimes, 4- Often)

\begin{tabular}{|c|c|c|c|c|c|c|c|c|}
\hline Revision decision questions & $M$ & $M d n$ & Mode & $S D$ & Var & Ran & Skew & Kur \\
\hline \multicolumn{9}{|l|}{$\begin{array}{l}\text { If I don't agree with a written feedback comment, before } \\
\text { deciding to ignore or use that comment for my revisions I ask } \\
\text { myself:... }\end{array}$} \\
\hline Is there any justification for that feedback? & 3.64 & 4 & 4 & .62 & .38 & 3 & -1.91 & 3.99 \\
\hline Is there really a need to make the change? & 3.64 & 4 & 4 & .56 & .31 & 2 & -1.25 & .61 \\
\hline Am I confident in what I wrote? & 3.33 & 3 & 4 & .80 & .64 & 3 & -1.17 & 1.01 \\
\hline How much will this revision affect my paper's direction? & 3.33 & 3 & 4 & .74 & .55 & 3 & -.95 & .53 \\
\hline $\begin{array}{l}\text { What is the knowledge and experience level of the person who } \\
\text { gave me this feedback? }\end{array}$ & 3.26 & 3 & 4 & .82 & .67 & 3 & -.88 & .06 \\
\hline Should I ask that person about the feedback? & 3.17 & 3 & 3 & .68 & .47 & 3 & -.57 & .51 \\
\hline Is it hard or easy for me to make the revision? & 3.04 & 3 & 3 & .89 & .80 & 3 & -.64 & -.37 \\
\hline Did the person really understand what I wrote? & 2.98 & 3 & 3 & .79 & .62 & 3 & -.50 & -.04 \\
\hline $\begin{array}{l}\text { What kind of authority-power relationship do I have with the } \\
\text { person who gave me this feedback? }\end{array}$ & 2.79 & 3 & 3 & .96 & .93 & 3 & -.31 & -.88 \\
\hline Will I lose my voice and writing style if I accept this change? & 2.66 & 3 & 3 & .95 & .90 & 3 & -.18 & -.88 \\
\hline
\end{tabular}




\begin{tabular}{|c|c|c|c|c|c|c|c|c|}
\hline Revision decision questions & $M$ & $M d n$ & Mode & $S D$ & Var & Ran & Skew & Kur \\
\hline $\begin{array}{l}\text { What kind of motivation or agenda might this person have for } \\
\text { giving me this feedback? }\end{array}$ & 2.49 & 3 & 3 & .99 & .98 & 3 & -.02 & -1.04 \\
\hline $\begin{array}{l}\text { Will there be some kind of punishment for not revising this } \\
\text { way? }\end{array}$ & 2.34 & 2 & 2 & .99 & .98 & 3 & .27 & -.95 \\
\hline Will there be some kind of reward for revising this way? & 2.28 & 2 & 2 & .96 & .93 & 3 & .21 & -.94 \\
\hline
\end{tabular}


Table 4-20

Revision Decisions in the Case of Disagreement with the Written Feedback: Frequencies and Percentages

\begin{tabular}{|c|c|c|c|c|}
\hline Revision decision questions & $\begin{array}{l}\text { Never } \\
f(P)\end{array}$ & $\begin{array}{l}\text { Seldom } \\
\qquad f(P)\end{array}$ & $\begin{array}{l}\text { Sometimes } \\
\qquad f(P)\end{array}$ & $\begin{array}{l}\text { Often } \\
f(P)\end{array}$ \\
\hline \multicolumn{5}{|l|}{$\begin{array}{l}\text { If I don't agree with a written feedback } \\
\text { comment, before deciding to ignore or use } \\
\text { that comment for my revisions I ask } \\
\text { myself:... }\end{array}$} \\
\hline $\begin{array}{l}\text { Is there any justification for that } \\
\text { feedback? }\end{array}$ & $4(1 \%)$ & $9(3 \%)$ & $68(25 \%)$ & $195(71 \%)$ \\
\hline Is there really a need to make the change? & 0 & $11(4 \%)$ & $78(28 \%)$ & $187(68 \%)$ \\
\hline Am I confident in what I wrote? & $12(4 \%)$ & $22(8 \%)$ & $106(38 \%)$ & $136(49 \%)$ \\
\hline $\begin{array}{l}\text { How much will this revision affect my } \\
\text { paper's direction? }\end{array}$ & $6(2 \%)$ & $27(10 \%)$ & $112(41 \%)$ & $131(48 \%)$ \\
\hline $\begin{array}{l}\text { What is the knowledge and experience } \\
\text { level of the person who gave me this } \\
\text { feedback? }\end{array}$ & $9(3 \%)$ & $38(14 \%)$ & $101(37 \%)$ & $128(46 \%)$ \\
\hline $\begin{array}{l}\text { Should I ask that person about the } \\
\text { feedback? }\end{array}$ & $5(2 \%)$ & $30(11 \%)$ & $155(56 \%)$ & $86(31 \%)$ \\
\hline $\begin{array}{l}\text { Is it hard or easy for me to make the } \\
\text { revision? }\end{array}$ & $18(6 \%)$ & $50(18 \%)$ & $111(40 \%)$ & $97(35 \%)$ \\
\hline $\begin{array}{l}\text { Did the person really understand what I } \\
\text { wrote? }\end{array}$ & $12(4 \%)$ & $52(19 \%)$ & $142(51 \%)$ & $70(25 \%)$ \\
\hline $\begin{array}{l}\text { What kind of authority-power relationship } \\
\text { do I have with the person who gave me } \\
\text { this feedback? }\end{array}$ & $30(11 \%)$ & $72(26 \%)$ & $99(36 \%)$ & $75(27 \%)$ \\
\hline $\begin{array}{l}\text { Will I lose my voice and writing style if I } \\
\text { accept this change? }\end{array}$ & $35(13 \%)$ & $81(29 \%)$ & $102(37 \%)$ & $58(21 \%)$ \\
\hline $\begin{array}{l}\text { What kind of motivation or agenda might } \\
\text { this person have for giving me this } \\
\text { feedback? }\end{array}$ & $53(19 \%)$ & $84(30 \%)$ & $91(33 \%)$ & $48(17 \%)$ \\
\hline $\begin{array}{l}\text { Will there be some kind of punishment for } \\
\text { not revising this way? }\end{array}$ & $60(22 \%)$ & $106(38 \%)$ & $66(24 \%)$ & $44(16 \%)$ \\
\hline $\begin{array}{l}\text { Will there be some kind of reward for } \\
\text { revising this way? }\end{array}$ & $68(25 \%)$ & $96(35 \%)$ & $80(29 \%)$ & $32(12 \%)$ \\
\hline
\end{tabular}


Other Revision Decisions in Relation to the

Feedback Types and Feedback Providers

The participants rated the statements related to their revision decisions on a 4-point agreement scale (1-Strongly Disagree, 2-Disagree, 3-Agree, 4-Strongly Agree). The statements were about the resistance for the revision in the case of start-up critical comments, perceived authoritative tone of the comments, perceived incorrect feedback, and the perceived personality of the feedback provider. As seen in Table 4-21 and Table 4-22, most participants disagreed with all of these statements. Only around $30 \%$ of the participants agreed that these issues may cause resistance for revision.

Research Question 4: Other Potentially Relevant Factors

As presented in Chapter 2, examining doctoral students' perceptions and attitudes toward different characteristics of written feedback and written feedback providers, and their revision decisions without any relation to other aspects relevant to the academic writing practice of the community would be insufficient to understand the phenomenon under investigation. Consequently, during the qualitative analysis of the interviews, several categories were developed such as: author's characteristics, perceptions and attitudes toward academic writing, motivations for academic writing, perceptions and attitudes toward their discipline or program, general perceptions and attitudes toward feedback, and asking for written feedback. Some of them were included in the provisional model as well.

These issues were represented in the questionnaire so that corresponding quantitative data could be collected. Descriptive and multivariate correlational analyses were conducted about these factors to understand their possible relationships with three main categories (perceptions and attitudes toward different characteristics of written feedback and written feedback providers, and revision decisions). In this part, the descriptive analyses of these relevant factors were presented in six main headings: (a) perceptions toward the program, (b) academic writing experiences, (c) perceptions of overall academic writing ability, (d) motivations for academic writing, (e) attitudes toward academic writing, (f) attitudes toward asking for written feedback, and $(\mathrm{g})$ attitudes toward the feedback process in general. Most of these factors were included in the further analyses. 
Table 4-21

Other Revision Decisions in Relation to the Feedback Providers and the Feedback Types: Descriptive Statistics (1-Strongly Disagree, 2-Disagree, 3-Agree, 4-

Strongly Agree)

\begin{tabular}{|c|c|c|c|c|c|c|c|c|}
\hline Statements about revision decisions & $M$ & $M d n$ & Mode & $S D$ & Var & Ran & Skew & Kur \\
\hline $\begin{array}{l}\text { If feedback providers start their written feedback with critical/negative } \\
\text { comments, I feel less open to the rest of the comments }\end{array}$ & 2.28 & 2 & 2 & .76 & .58 & 3 & .14 & -.33 \\
\hline $\begin{array}{l}\text { If I sense an authoritative tone in the written feedback, I feel resistant to } \\
\text { use that feedback in my revisions }\end{array}$ & 2.27 & 2 & 2 & .75 & .56 & 3 & .36 & -.02 \\
\hline $\begin{array}{l}\text { If I catch a big mistake among the written feedback, I tend to disregard the } \\
\text { other feedback comments that person gives }\end{array}$ & 2.19 & 2 & 2 & .67 & .45 & 3 & .56 & .69 \\
\hline $\begin{array}{l}\text { If I dislike the personality of a feedback provider, I tend to disregard } \\
\text { his/her written feedback }\end{array}$ & 2.16 & 2 & 2 & .69 & .48 & 3 & .52 & .58 \\
\hline
\end{tabular}


Table 4-22

Other Revision Decisions in Relation to the Feedback Providers and the Feedback Types: Frequencies and Percentages (SD- Strongly Disagree, D- Disagree, AAgree, SA-Strongly Agree)

\begin{tabular}{|c|c|c|c|c|c|c|}
\hline \multirow[b]{2}{*}{ Statements about revision decisions } & \multirow[b]{2}{*}{$\begin{array}{l}\text { SD } \\
f(P)\end{array}$} & \multirow[b]{2}{*}{$\begin{array}{c}\mathrm{D} \\
f(P)\end{array}$} & \multirow[b]{2}{*}{$\begin{array}{c}\text { A } \\
f(P)\end{array}$} & \multirow[b]{2}{*}{$\begin{array}{l}\text { SA } \\
f(P)\end{array}$} & \multicolumn{2}{|c|}{ Total } \\
\hline & & & & & $\begin{array}{c}\text { Disagree } \\
\qquad f(P)\end{array}$ & $\begin{array}{l}\text { Agree } \\
f(P)\end{array}$ \\
\hline $\begin{array}{l}\text { If feedback providers start their written feedback with critical/negative } \\
\text { comments, I feel less open to the rest of the comments }\end{array}$ & $39(14 \%)$ & $135(49 \%)$ & $89(32 \%)$ & $13(5 \%)$ & $174(63 \%)$ & $102(37 \%)$ \\
\hline $\begin{array}{l}\text { If I sense an authoritative tone in the written feedback, I feel resistant to use } \\
\text { that feedback in my revisions }\end{array}$ & $34(12 \%)$ & $150(54 \%)$ & $76(28 \%)$ & $16(6 \%)$ & $184(67 \%)$ & $92(33 \%)$ \\
\hline $\begin{array}{l}\text { If I catch a big mistake among the written feedback, I tend to disregard the } \\
\text { other feedback comments that person gives }\end{array}$ & $30(11 \%)$ & $175(63 \%)$ & $60(22 \%)$ & $11(4 \%)$ & $205(74 \%)$ & $71(26 \%)$ \\
\hline $\begin{array}{l}\text { If I dislike the personality of a feedback provider, I tend to disregard his/her } \\
\text { written feedback }\end{array}$ & $36(13 \%)$ & $171(62 \%)$ & $58(21 \%)$ & $11(4 \%)$ & $207(75 \%)$ & $69(25 \%)$ \\
\hline
\end{tabular}




\section{Perceptions Toward the Program}

Participants were asked to complete the sentence "In my program..." with choices in 4-point agreement scale (1- Strongly Disagree, 2- Disagree, 3- Agree, 4- Strongly Agree). More than $80 \%$ of the participants think that the faculty members in their program are very productive regarding the publications (see Table 4-23 and Table 4-24). Fifty-eight percent agreed that they often write academic papers with their students and $45 \%$ agreed that they invite students to write academic papers with them. However, $61 \%$ of the participants rated that there are not a lot of opportunities to write with the faculty members and only $34 \%$ agreed that they ask faculty members to write together with them.

\section{Participants’ Academic Writing Experiences}

Table 4-25 shows the frequency of participants who had written or participated in writing (including the ones that they were currently writing) different types of academic writing. Moreover, Table 4-26 shows the number of occasions for each academic writing type that the participants had written or participated in writing. The main academic writing types that participants engaged in writing were conference proposal-poster-proceedings $(M=5.01)$, journal articles $(M=2.43)$, and grant proposals $(M=$ 2.06). Twenty-nine percent of the participants were currently writing their dissertation.

\section{Perceptions of Overall Academic Writing Ability}

The participants rated their overall academic writing ability for the question:

“How do you rate your overall academic writing ability?” in a 5-point scale (1-Very poor, 2-poor, 3average, 4-good, 5-very good). Most of the participants (83\%) rated their academic writing abilities as good or very good (see Table 4-27 and Table 4-28).

During the interviews, some of the non-native English speaker doctoral students expressed that their writing ability was related to being a native English speaker or not. Considering this issue, a two-way contingency table analysis was conducted to evaluate how doctoral students who consider English their native language or not perceive their overall academic writing ability (see Table 4-29).

Two variables for this analysis were native language and perceived academic writing ability. These two variables were found to be significantly related, Pearson $\chi^{2}(4, n=275)=16.52, p=.00$, 
Cramer's $V=.25$. However, since three cells in contingency table have expected count less than five (30\%), the test was conducted again after dropping the 'very poor' level for academic writing ability.

After the second test, only one cell had expected count less than five (12\%), which is acceptable according to Green and Salkind (2005, p. 368). Again two variables were found to be significantly related, Pearson $\chi^{2}(3, n=274)=10.01, p=.02$, Cramer's $V=0.19$. Therefore, it can be concluded that there is a significant relationship between perceived overall academic writing ability and the participants' being native English speakers or not.

\section{Motivations for Academic Writing}

The participants completed the phrase "My motivation for academic writing is..." by their ratings of different types of motivations in a 4-point agreement scale: 1- Strongly Disagree, 2- Disagree, 3- Agree, 4- Strongly Agree. Their main motivations for academic writing were more related to contributing to the field and sharing their ideas and findings than motivations such as building up their vita or gaining recognition in the field (see Table 4-30 and Table 4-31).

\section{Attitudes Toward Academic Writing}

Questions for another possibly relevant construct, attitudes toward academic writing, were also included in the questionnaire based on the interview transcripts. On a 4-point agreement scale (1- Strongly Disagree, 2- Disagree, 3- Agree, 4- Strongly Agree) the participants were asked four questions about their attitudes toward academic writing. As seen in Table 4-32 and 4-33, most participants agreed with positive statements; while around $20 \%$ of the participants rated that they do not enjoy writing academic papers or they do not have confidence in writing them.

\section{Attitudes Toward Asking for Written Feedback}

Another closely related issue to the participants' perceptions and attitudes toward different feedback providers and feedback types is who to ask for feedback, when they ask for feedback, and the way they ask for feedback. Eleven questions were asked in the questionnaire in the form of 4-point agreement scale (1- Strongly Disagree, 2- Disagree, 3- Agree, 4- Strongly Agree).

Although $91 \%$ of the participants rated that they ask others for written feedback for their academic 
Table 4-23

Perceptions Toward the Program: Descriptive Statistics (1- Strongly Disagree, 2- Disagree, 3- Agree, 4- Strongly Agree)

\begin{tabular}{|c|c|c|c|c|c|c|c|c|}
\hline Statements about the program and academic writing & $M$ & $M d n$ & Mode & $S D$ & Var & Ran & Skew & Kur \\
\hline \multicolumn{9}{|l|}{ In my program... } \\
\hline The faculty members' academic writing standards are very high & 3.13 & 3 & 3 & .63 & .40 & 3 & -.20 & -.20 \\
\hline The faculty members are very productive in terms of the quantity of publications & 3.03 & 3 & 3 & .69 & .47 & 3 & -.44 & .40 \\
\hline I feel like I am treated as a peer and a colleague here by the faculty members & 2.84 & 3 & 3 & .73 & .53 & 3 & -.26 & -.09 \\
\hline The faculty members often write academic papers with their students & 2.63 & 3 & 3 & .79 & .62 & 3 & -.10 & -.40 \\
\hline The faculty members push doctoral students to write and publish a lot & 2.42 & 2 & 2 & .75 & .56 & 3 & -.03 & -.33 \\
\hline The faculty members invite me to write academic papers together with them & 2.37 & 2 & 2 & .87 & .76 & 3 & .04 & -.70 \\
\hline There are a lot of opportunities to write academic papers with faculty members & 2.26 & 2 & 2 & .82 & .68 & 3 & .11 & -.59 \\
\hline I ask faculty members to write academic papers together with me & 2.22 & 2 & 2 & .74 & .55 & 3 & .16 & -.26 \\
\hline
\end{tabular}


Table 4-24

Perceptions Toward the Program: Frequencies and Percentages (SD- Strongly Disagree, D- Disagree, A- Agree, SA-Strongly Agree)

\begin{tabular}{|c|c|c|c|c|c|c|}
\hline \multirow[b]{2}{*}{ Statements about the program and academic writing } & \multirow[b]{2}{*}{$\begin{array}{c}\mathrm{SD} \\
f(P)\end{array}$} & \multirow[b]{2}{*}{$\begin{array}{c}\mathrm{D} \\
f(P)\end{array}$} & \multirow[b]{2}{*}{$\begin{array}{c}\text { A } \\
f(P)\end{array}$} & \multirow[b]{2}{*}{$\begin{array}{c}\text { SA } \\
f(P)\end{array}$} & \multicolumn{2}{|c|}{ Total } \\
\hline & & & & & $\begin{array}{c}\text { Disagree } \\
\qquad f(P)\end{array}$ & $\begin{array}{l}\text { Agree } \\
f(P)\end{array}$ \\
\hline \multicolumn{7}{|l|}{ In my program... } \\
\hline The faculty members' academic writing standards are very high & $1(0 \%)$ & $37(13 \%)$ & $164(59 \%)$ & $74(27 \%)$ & $38(14 \%)$ & $238(86 \%)$ \\
\hline $\begin{array}{l}\text { The faculty members are very productive in terms of the quantity of } \\
\text { publications }\end{array}$ & $6(2 \%)$ & $43(16 \%)$ & $164(59 \%)$ & $63(23 \%)$ & $49(18 \%)$ & $227(82 \%)$ \\
\hline $\begin{array}{l}\text { I feel like I am treated as a peer and a colleague here by the faculty } \\
\text { members }\end{array}$ & $9(3 \%)$ & $71(26 \%)$ & $151(55 \%)$ & $45(16 \%)$ & $80(29 \%)$ & $196(71 \%)$ \\
\hline The faculty members often write academic papers with their students & $19(7 \%)$ & $98(36 \%)$ & $125(45 \%)$ & $34(12 \%)$ & $117(42 \%)$ & $159(58 \%)$ \\
\hline The faculty members push doctoral students to write and publish a lot & $27(10 \%)$ & $121(44 \%)$ & $112(41 \%)$ & $16(6 \%)$ & $148(54 \%)$ & $128(46 \%)$ \\
\hline $\begin{array}{l}\text { The faculty members invite me to write academic papers together with } \\
\text { them }\end{array}$ & $47(17 \%)$ & $105(38 \%)$ & $99(36 \%)$ & $25(9 \%)$ & $152(55 \%)$ & $124(45 \%)$ \\
\hline $\begin{array}{l}\text { There are a lot of opportunities to write academic papers with faculty } \\
\text { members }\end{array}$ & $50(18 \%)$ & $119(43 \%)$ & $91(33 \%)$ & $16(6 \%)$ & $169(61 \%)$ & $107(39 \%)$ \\
\hline I ask faculty members to write academic papers together with me & $41(15 \%)$ & $142(51 \%)$ & $83(30 \%)$ & $10(4 \%)$ & $183(66 \%)$ & $93(34 \%)$ \\
\hline
\end{tabular}


Table 4-25

Participants' Engagement in Different Types of Academic Writing: Frequencies and Percentages

\begin{tabular}{lcccc}
\hline \multicolumn{1}{c}{ Types of academic writing } & No $f$ & No $P$ & Yes $f$ & Yes $P$ \\
\hline Conference proposal, poster, proceeding & 41 & $15 \%$ & 235 & $85 \%$ \\
Journal article & 73 & $26 \%$ & 203 & $74 \%$ \\
Masters thesis & 95 & $34 \%$ & 181 & $66 \%$ \\
Grant proposal & 116 & $42 \%$ & 160 & $58 \%$ \\
Dissertation proposal & 134 & $49 \%$ & 142 & $51 \%$ \\
Doctoral comprehensive exam & 147 & $53 \%$ & 129 & $47 \%$ \\
Book chapter or book & & & & \\
Dissertation & 193 & $70 \%$ & 83 & $30 \%$ \\
\hline
\end{tabular}

${ }^{a}$ Outlier eliminated: Number of book chapters $=54$.

Table 4-26

Participants’ Academic Writing Experiences: Descriptive Statistics

\begin{tabular}{|c|c|c|c|c|c|c|c|c|c|}
\hline $\begin{array}{c}\text { Types of academic } \\
\text { writing }\end{array}$ & $M$ & $M d n$ & Mode & $S D$ & Min & Max & Ran & Skew & Kur \\
\hline $\begin{array}{l}\text { Conference proposal, } \\
\text { poster, proceeding }\end{array}$ & 5.01 & 3 & 2 & 6.40 & 0 & 50 & 50 & 3.09 & 13.78 \\
\hline Journal article & 2.43 & 2 & 0 & 3.15 & 0 & 21 & 21 & 2.84 & 10.79 \\
\hline Grant proposal & 2.06 & 1 & 0 & 3.70 & 0 & 30 & 30 & 3.78 & 19.29 \\
\hline Masters thesis & .68 & 1 & 1 & .53 & 0 & 3 & 3 & -.01 & .20 \\
\hline $\begin{array}{l}\text { Doctoral comprehensive } \\
\text { exam }\end{array}$ & .63 & 0 & 0 & .90 & 0 & 6 & 6 & 2.33 & 7.96 \\
\hline Dissertation proposal & .55 & 1 & 1 & .60 & 0 & 5 & 5 & 1.60 & 9.16 \\
\hline Book chapter or book ${ }^{a}$ & .42 & 0 & 0 & .84 & 0 & 6 & 6 & 3.33 & 15.13 \\
\hline Dissertation & .29 & 0 & 0 & .46 & 0 & 2 & 2 & 1.02 & -.66 \\
\hline
\end{tabular}

${ }^{\mathrm{a}}$ Outlier eliminated: Number of book chapters $=54$. 
Table 4-27

Perceived Academic Writing Ability: Descriptive Statistics (1-very poor, 2-poor, 3-average, 4-good, 5-very good)

\begin{tabular}{ccccccccc}
\hline Writing ability & $M$ & $M d n$ & Mode & $S D$ & Var & Ran & Skew & Kur \\
\hline & 4.10 & 4 & 4 & .75 & .56 & 4 & -.68 & .78 \\
\hline
\end{tabular}

Table 4-28

Perceived Overall Academic Writing Ability: Frequencies and Percentages

\begin{tabular}{lcc}
\hline \multicolumn{1}{r}{ Writing ability } & $f$ & $P$ \\
\hline 1. Very poor & 1 & $0 \%$ \\
2. Poor & 6 & $2 \%$ \\
3. Average & 41 & $15 \%$ \\
4. Good & 145 & $53 \%$ \\
5. Very good & 83 & $30 \%$ \\
Total & 276 & $100 \%$ \\
\hline
\end{tabular}

Table 4-29

Cross-tabular Presentation of the Participants' Native Language and Perceived Overall Academic Writing Ability

\begin{tabular}{|c|c|c|c|c|c|c|}
\hline \multirow[t]{2}{*}{ Language } & \multicolumn{5}{|c|}{ Writing ability } & \multirow{2}{*}{$\begin{array}{l}\text { Total } \\
f(P)\end{array}$} \\
\hline & $\begin{array}{c}\text { 1-Very poor } \\
f(P)\end{array}$ & $\begin{array}{l}\text { 2-Poor } \\
\qquad f(P)\end{array}$ & $\begin{array}{c}\text { 3-Average } \\
f(P)\end{array}$ & $\begin{array}{c}\text { 4-Good } \\
f(P)\end{array}$ & $\begin{array}{c}\text { 5-Very good } \\
f(P)\end{array}$ & \\
\hline $\begin{array}{l}\text { Native English } \\
\text { speaker }\end{array}$ & 0 & $3(1 \%)$ & $34(14 \%)$ & $125(52 \%)$ & $77(32 \%)$ & $239(100 \%)$ \\
\hline $\begin{array}{l}\text { Non-native } \\
\text { English speaker }\end{array}$ & $1(3 \%)$ & $3(8 \%)$ & $6(17 \%)$ & $20(56 \%)$ & $6(17 \%)$ & $36(100 \%)$ \\
\hline Total & $1(0 \%)$ & $6(2 \%)$ & $40(15 \%)$ & $145(53 \%)$ & $83(30 \%)$ & $275(100 \%)$ \\
\hline
\end{tabular}

Note. The data that has one missing value in native language variable was eliminated. 
Table 4-30

Motivations for Academic Writing: Descriptive Statistics (1- Strongly Disagree, 2- Disagree, 3- Agree, 4Strongly Agree)

\begin{tabular}{|c|c|c|c|c|c|c|c|c|}
\hline Motivations & $M$ & $M d n$ & Mode & $S D$ & Var & Ran & Skew & Kur \\
\hline \multicolumn{9}{|l|}{$\begin{array}{l}\text { My motivation for } \\
\text { academic writing is... }\end{array}$} \\
\hline $\begin{array}{l}\text { To contribute knowledge } \\
\text { to the field }\end{array}$ & 3.41 & 3 & 3 & .59 & .35 & 3 & -.53 & -.02 \\
\hline $\begin{array}{l}\text { To share my ideas or } \\
\text { findings with others }\end{array}$ & 3.33 & 3 & 3 & .62 & .38 & 3 & -.44 & -.15 \\
\hline $\begin{array}{l}\text { To gain experiences, } \\
\text { skills, and knowledge as } \\
\text { an academician }\end{array}$ & 3.26 & 3 & 3 & .66 & .44 & 3 & -.57 & .28 \\
\hline $\begin{array}{l}\text { To meet graduation or } \\
\text { occupation requirements } \\
\text { and expectations }\end{array}$ & 3.23 & 3 & 3 & .67 & .45 & 3 & -.59 & .52 \\
\hline To build up my vita & 3.05 & 3 & 3 & .73 & .53 & 3 & -.48 & .12 \\
\hline $\begin{array}{l}\text { To gain a promotion or } \\
\text { get into a good job in the } \\
\text { future }\end{array}$ & 3.05 & 3 & 3 & .74 & .55 & 3 & -.40 & -.23 \\
\hline $\begin{array}{l}\text { To have recognition in } \\
\text { the field }\end{array}$ & 2.90 & 3 & 3 & .79 & .63 & 3 & -.21 & -.58 \\
\hline
\end{tabular}


Table 4-31

Motivations for Academic Writing: Frequencies and Percentages (SD-Strongly Disagree, D- Disagree, AAgree, SA-Strongly Agree)

\begin{tabular}{|c|c|c|c|c|c|c|c|}
\hline \multirow[b]{2}{*}{ Motivations } & \multirow[b]{2}{*}{$\begin{array}{l}\text { SD } \\
f(P)\end{array}$} & \multirow[b]{2}{*}{$\begin{array}{c}\mathrm{D} \\
f(P)\end{array}$} & \multirow[b]{2}{*}{$\begin{array}{c}\mathrm{A} \\
f(P)\end{array}$} & \multirow[b]{2}{*}{$\begin{array}{c}\text { SA } \\
f(P)\end{array}$} & \multicolumn{2}{|c|}{ Total } & \multirow[b]{2}{*}{$\begin{array}{l}\text { Missing } \\
f(P)\end{array}$} \\
\hline & & & & & $\begin{array}{l}\text { Disagree } \\
\qquad f(P)\end{array}$ & $\begin{array}{l}\text { Agree } \\
f(P)\end{array}$ & \\
\hline \multicolumn{8}{|l|}{$\begin{array}{l}\text { My motivation for } \\
\text { academic writing is... }\end{array}$} \\
\hline $\begin{array}{l}\text { To contribute knowledge } \\
\text { to the field }\end{array}$ & $\begin{array}{c}1 \\
(0 \%)\end{array}$ & $\begin{array}{c}12 \\
(4 \%)\end{array}$ & $\begin{array}{c}137 \\
(50 \%)\end{array}$ & $\begin{array}{c}126 \\
(46 \%)\end{array}$ & $\begin{array}{c}13 \\
(5 \%)\end{array}$ & $\begin{array}{c}263 \\
(95 \%)\end{array}$ & 0 \\
\hline $\begin{array}{l}\text { To share my ideas or } \\
\text { findings with others }\end{array}$ & $\begin{array}{c}1 \\
(0 \%)\end{array}$ & $\begin{array}{c}19 \\
(7 \%)\end{array}$ & $\begin{array}{c}144 \\
(52 \%)\end{array}$ & $\begin{array}{c}111 \\
(40 \%)\end{array}$ & $\begin{array}{c}20 \\
(72 \%)\end{array}$ & $\begin{array}{c}255 \\
(92 \%)\end{array}$ & $\begin{array}{c}1 \\
(0 \%)\end{array}$ \\
\hline $\begin{array}{l}\text { To gain experiences, } \\
\text { skills, and knowledge as } \\
\text { an academician }\end{array}$ & $\begin{array}{c}3 \\
(1 \%)\end{array}$ & $\begin{array}{l}25 \\
(9 \%)\end{array}$ & $\begin{array}{c}145 \\
(53 \%)\end{array}$ & $\begin{array}{c}103 \\
(37 \%)\end{array}$ & $\begin{array}{c}28 \\
(10 \%)\end{array}$ & $\begin{array}{c}248 \\
(90 \%)\end{array}$ & 0 \\
\hline $\begin{array}{l}\text { To meet graduation or } \\
\text { occupation requirements } \\
\text { and expectations }\end{array}$ & $\begin{array}{c}4 \\
(1 \%)\end{array}$ & $\begin{array}{c}25 \\
(9 \%)\end{array}$ & $\begin{array}{c}151 \\
(55 \%)\end{array}$ & $\begin{array}{c}96 \\
(35 \%)\end{array}$ & $\begin{array}{c}29 \\
(11 \%)\end{array}$ & $\begin{array}{c}247 \\
(89 \%)\end{array}$ & 0 \\
\hline To build up my vita & $\begin{array}{c}7 \\
(3 \%)\end{array}$ & $\begin{array}{c}45 \\
(16 \%)\end{array}$ & $\begin{array}{l}150 \\
(54 \%)\end{array}$ & $\begin{array}{c}73 \\
(26 \%)\end{array}$ & $\begin{array}{c}52 \\
(19 \%)\end{array}$ & $\begin{array}{c}223 \\
(81 \%)\end{array}$ & $\begin{array}{c}1 \\
(0 \%)\end{array}$ \\
\hline $\begin{array}{l}\text { To gain a promotion or get } \\
\text { into a good job in the } \\
\text { future }\end{array}$ & $\begin{array}{c}6 \\
(2 \%)\end{array}$ & $\begin{array}{c}52 \\
(19 \%)\end{array}$ & $\begin{array}{c}141 \\
(51 \%)\end{array}$ & $\begin{array}{c}77 \\
(28 \%)\end{array}$ & $\begin{array}{c}58 \\
(21 \%)\end{array}$ & $\begin{array}{c}218 \\
(79 \%)\end{array}$ & 0 \\
\hline $\begin{array}{l}\text { To have recognition in the } \\
\text { field }\end{array}$ & $\begin{array}{c}9 \\
(3 \%)\end{array}$ & $\begin{array}{c}75 \\
(27 \%)\end{array}$ & $\begin{array}{c}127 \\
(46 \%)\end{array}$ & $\begin{array}{c}65 \\
(24 \%)\end{array}$ & $\begin{array}{c}84 \\
(30 \%)\end{array}$ & $\begin{array}{c}192 \\
(70 \%)\end{array}$ & 0 \\
\hline
\end{tabular}


Table 4-32

Attitudes Toward Academic Writing: Descriptive Statistics (1- Strongly Disagree, 2- Disagree, 3- Agree, 4Strongly Agree)

\begin{tabular}{lcccccccc}
\hline \multicolumn{1}{c}{ Statements } & $M$ & Mdn & Mode & SD & Var & Ran & Skew & Kur \\
\hline $\begin{array}{l}\text { I enjoy writing academic } \\
\text { papers }\end{array}$ & 3 & 3 & 3 & .68 & .46 & 3 & -.42 & .47 \\
$\begin{array}{l}\text { I have confidence in } \\
\text { writing academic papers }\end{array}$ & 2.98 & 3 & 3 & .67 & .45 & 3 & -.35 & .33 \\
$\begin{array}{l}\text { I enjoy writing academic } \\
\text { papers with others }\end{array}$ & 2.90 & 3 & 3 & .72 & .52 & 3 & -.26 & -.15 \\
$\begin{array}{l}\text { I need someone to push } \\
\text { me to write academic } \\
\text { papers }\end{array}$ & 2.41 & 2 & 2 & .81 & .66 & 3 & .14 & -.45 \\
\hline
\end{tabular}

Table 4-33

Attitudes Toward Academic Writing: Frequencies and Percentages (SD- Strongly Disagree, D-Disagree, A- Agree, SA-Strongly Agree)

\begin{tabular}{|c|c|c|c|c|c|c|}
\hline \multirow[b]{2}{*}{ Statements } & \multirow[b]{2}{*}{$\begin{array}{c}\text { SD } \\
f(P)\end{array}$} & \multirow[b]{2}{*}{$\begin{array}{c}\mathrm{D} \\
f(P)\end{array}$} & \multirow[b]{2}{*}{$\begin{array}{c}\mathrm{A} \\
f(P)\end{array}$} & \multirow[b]{2}{*}{$\begin{array}{c}\text { SA } \\
f(P)\end{array}$} & \multicolumn{2}{|c|}{ Total } \\
\hline & & & & & $\begin{array}{c}\text { Disagree } \\
f(P)\end{array}$ & $\begin{array}{l}\text { Agree } \\
f(P)\end{array}$ \\
\hline $\begin{array}{l}\text { I enjoy writing academic } \\
\text { papers }\end{array}$ & $\begin{array}{c}6 \\
(2 \%)\end{array}$ & $\begin{array}{c}45 \\
(16 \%)\end{array}$ & $\begin{array}{c}168 \\
(61 \%)\end{array}$ & $\begin{array}{c}57 \\
(21 \%)\end{array}$ & $\begin{array}{c}51 \\
(18 \%)\end{array}$ & $\begin{array}{c}225 \\
(82 \%)\end{array}$ \\
\hline $\begin{array}{l}\text { I have confidence in writing } \\
\text { academic papers }\end{array}$ & $\begin{array}{c}5 \\
(2 \%)\end{array}$ & $\begin{array}{c}49 \\
(18 \%)\end{array}$ & $\begin{array}{c}168 \\
(61 \%)\end{array}$ & $\begin{array}{c}54 \\
(20 \%)\end{array}$ & $\begin{array}{c}54 \\
(20 \%)\end{array}$ & $\begin{array}{c}222 \\
(80 \%)\end{array}$ \\
\hline $\begin{array}{l}\text { I enjoy writing academic } \\
\text { papers with others }\end{array}$ & $\begin{array}{c}7 \\
(3 \%)\end{array}$ & $\begin{array}{c}66 \\
(24 \%)\end{array}$ & $\begin{array}{c}151 \\
(55 \%)\end{array}$ & $\begin{array}{c}52 \\
(19 \%)\end{array}$ & $\begin{array}{c}73 \\
(26 \%)\end{array}$ & $\begin{array}{c}203 \\
(74 \%)\end{array}$ \\
\hline $\begin{array}{l}\text { I need someone to push me } \\
\text { to write academic papers }\end{array}$ & $\begin{array}{c}32 \\
(12 \%)\end{array}$ & $\begin{array}{c}123 \\
(45 \%)\end{array}$ & $\begin{array}{c}96 \\
(35 \%)\end{array}$ & $\begin{array}{c}25 \\
(9 \%)\end{array}$ & $\begin{array}{c}155 \\
(56 \%)\end{array}$ & $\begin{array}{c}121 \\
(44 \%)\end{array}$ \\
\hline
\end{tabular}


papers, $9 \%$ (26 participants) rated that they do not. Regarding whom to ask for written feedback, it has been found that most participants feel more comfortable asking for feedback from their professors in their committee (91\%), and other doctoral students (75\%) (See Table 4-34 and Table 4-35). Comparably, only $63 \%$ rated that they feel comfortable asking feedback from professors outside of their committee. Also $72 \%$ of the participants rated that they look for several people to give them written feedback.

As for when they ask for written feedback, $65 \%$ of the participants rated their preference that they look for several feedback occasions at different stages of their papers and only $37 \%$ of the participants choose that they ask for written feedback only when they can not improve their paper any further by themselves. Twenty-two percent of the participants rated that they do not ask for written feedback when they are confident with their paper, and similarly $21 \%$ rated that they do not ask for written feedback when they are not confident with their paper.

Considering the way they ask for written feedback, the participants were asked if they tell the feedback providers what aspects of their paper they want them to look at. Sixty-nine percent of the participants rated that they inform the feedback providers about the aspects when they ask for their written feedback.

\section{Attitudes Toward the Feedback Process in General}

In the questionnaire several other issues that emerged during the interview were asked in the form of attitude statements in 4-point agreement scale (1- Strongly Disagree, 2- Disagree, 3- Agree, 4- Strongly Agree), mostly regarding the participants' general perceptions and attitudes toward the feedback process. While four participants disagreed, all other participants agreed with the statement that feedback process is a good learning experience. Only $9 \%$ rated that the feedback process keeps them from progressing. Around $60 \%$ of the participants agreed that feedback process affects them emotionally and they get upset when they wait for written feedback for more than two weeks and when they are not given another opportunity to submit their paper after receiving written feedback. 
Table 4-34

Attitudes Toward Asking for Written Feedback: Descriptive Statistics (1- Strongly Disagree, 2- Disagree, 3- Agree, 4- Strongly Agree)

\begin{tabular}{|c|c|c|c|c|c|c|c|c|}
\hline Statements about asking for written feedback & $M$ & $M d n$ & Mode & $S D$ & Var & Ran & Skew & Kur \\
\hline I ask others for written feedback on my academic papers & 3.26 & 3 & 3 & .63 & .40 & 3 & -.35 & -.21 \\
\hline $\begin{array}{l}\text { I feel comfortable asking for written feedback from professors on my } \\
\text { committee }\end{array}$ & 3.25 & 3 & 3 & .66 & .43 & 3 & -.63 & .71 \\
\hline I look for several people to give me written feedback for my papers & 2.98 & 3 & 3 & .78 & .60 & 3 & -.20 & -.75 \\
\hline I feel comfortable asking for written feedback from other doctoral students & 2.97 & 3 & 3 & .75 & .56 & 3 & -.28 & -.37 \\
\hline $\begin{array}{l}\text { When asking for written feedback from others, I tell them what aspects of } \\
\text { the paper I want them to look at }\end{array}$ & 2.80 & 3 & 3 & .68 & .47 & 3 & -.24 & .05 \\
\hline $\begin{array}{l}\text { I look for several written feedback occasions at different stages of my } \\
\text { papers }\end{array}$ & 2.80 & 3 & 3 & .76 & .58 & 3 & -.04 & -.55 \\
\hline $\begin{array}{l}\text { I feel comfortable asking for written feedback from professors outside of } \\
\text { my committee }\end{array}$ & 2.75 & 3 & 3 & .77 & .60 & 3 & -.10 & -.44 \\
\hline $\begin{array}{l}\text { I ask for written feedback only when I come to a point where I can't } \\
\text { improve my paper any further }\end{array}$ & 2.32 & 2 & 2 & .68 & .46 & 3 & .21 & -.03 \\
\hline I don't ask for written feedback if I am confident with my paper's quality & 2.03 & 2 & 2 & .70 & .49 & 3 & .28 & -.08 \\
\hline $\begin{array}{l}\text { I don't want to expose myself to others by asking them to give me written } \\
\text { feedback if I am not confident in my paper's quality }\end{array}$ & 1.92 & 2 & 2 & .75 & .56 & 3 & .35 & -.52 \\
\hline My pride has a lot to do with my decisions to not ask for written feedback & 1.79 & 2 & 2 & .72 & .52 & 3 & .57 & -.06 \\
\hline
\end{tabular}


Table 4-35

Attitudes Toward Asking for Written Feedback: Frequencies and Percentages (SD- Strongly Disagree, D- Disagree, A- Agree, SA-Strongly Agree)

\begin{tabular}{|c|c|c|c|c|c|c|}
\hline \multirow[b]{2}{*}{ Statements about asking for written feedback } & \multirow[b]{2}{*}{$\begin{array}{c}\mathrm{SD} \\
f(P)\end{array}$} & \multirow[b]{2}{*}{$\begin{array}{c}\mathrm{D} \\
f(P)\end{array}$} & \multirow[b]{2}{*}{$\begin{array}{c}\text { A } \\
f(P)\end{array}$} & \multirow[b]{2}{*}{$\begin{array}{l}\text { SA } \\
f(P)\end{array}$} & \multicolumn{2}{|c|}{ Total } \\
\hline & & & & & $\begin{array}{c}\text { Disagree } \\
\qquad f(P)\end{array}$ & $\begin{array}{l}\text { Agree } \\
f(P)\end{array}$ \\
\hline I ask others for written feedback on my academic papers & $1(0 \%)$ & $25(9 \%)$ & $152(55 \%)$ & $98(36 \%)$ & $26(9 \%)$ & $250(91 \%)$ \\
\hline $\begin{array}{l}\text { I feel comfortable asking for written feedback from professors on } \\
\text { my committee }\end{array}$ & $4(1 \%)$ & $21(8 \%)$ & $152(55 \%)$ & $99(36 \%)$ & $25(9 \%)$ & $251(91 \%)$ \\
\hline $\begin{array}{l}\text { I look for several people to give me written feedback for my } \\
\text { papers }\end{array}$ & $5(2 \%)$ & $71(26 \%)$ & $125(45 \%)$ & $75(27 \%)$ & $76(28 \%)$ & $200(72 \%)$ \\
\hline $\begin{array}{l}\text { I feel comfortable asking for written feedback from other doctoral } \\
\text { students }\end{array}$ & $6(2 \%)$ & $62(22 \%)$ & $141(51 \%)$ & $67(24 \%)$ & $68(25 \%)$ & $208(75 \%)$ \\
\hline $\begin{array}{l}\text { When asking for written feedback from others, I tell them what } \\
\text { aspects of the paper I want them to look at }\end{array}$ & $8(3 \%)$ & $78(28 \%)$ & $158(57 \%)$ & $32(12 \%)$ & $86(31 \%)$ & $190(69 \%)$ \\
\hline $\begin{array}{l}\text { I look for several written feedback occasions at different stages of } \\
\text { my papers }\end{array}$ & $8(3 \%)$ & $89(32 \%)$ & $130(47 \%)$ & $49(18 \%)$ & $97(35 \%)$ & $179(65 \%)$ \\
\hline $\begin{array}{l}\text { I feel comfortable asking for written feedback from professors } \\
\text { outside of my committee }\end{array}$ & $12(4 \%)$ & $90(33 \%)$ & $130(47 \%)$ & $44(16 \%)$ & $102(37 \%)$ & $174(63 \%)$ \\
\hline $\begin{array}{l}\text { I ask for written feedback only when I come to a point where I } \\
\text { can't improve my paper any further }\end{array}$ & $23(8 \%)$ & $151(55 \%)$ & $92(33 \%)$ & $10(4 \%)$ & $174(63 \%)$ & $102(37 \%)$ \\
\hline
\end{tabular}

(table continues) 


\begin{tabular}{|c|c|c|c|c|c|c|}
\hline \multirow[b]{2}{*}{ Statements about asking for written feedback } & \multirow[b]{2}{*}{$\begin{array}{l}\mathrm{SD} \\
f(P)\end{array}$} & \multirow[b]{2}{*}{$\begin{array}{c}\mathrm{D} \\
f(P)\end{array}$} & \multirow[b]{2}{*}{$\begin{array}{c}\text { A } \\
f(P)\end{array}$} & \multirow[b]{2}{*}{$\begin{array}{l}\text { SA } \\
f(P)\end{array}$} & \multicolumn{2}{|c|}{ Total } \\
\hline & & & & & $\begin{array}{c}\text { Disagree } \\
f(P)\end{array}$ & $\begin{array}{l}\text { Agree } \\
f(P)\end{array}$ \\
\hline $\begin{array}{l}\text { I don't ask for written feedback if I am confident with my paper's } \\
\text { quality }\end{array}$ & $58(21 \%)$ & $156(57 \%)$ & $57(21 \%)$ & $5(2 \%)$ & $214(78 \%)$ & $62(22 \%)$ \\
\hline $\begin{array}{l}\text { I don't want to expose myself to others by asking them to give me } \\
\text { written feedback if I am not confident in my paper's quality }\end{array}$ & $85(31 \%)$ & $133(48 \%)$ & $54(20 \%)$ & $4(1 \%)$ & $218(79 \%)$ & $58(21 \%)$ \\
\hline $\begin{array}{l}\text { My pride has a lot to do with my decisions to not ask for written } \\
\text { feedback }\end{array}$ & $102(37 \%)$ & $134(49 \%)$ & $36(13 \%)$ & $4(1 \%)$ & $236(86 \%)$ & $40(14 \%)$ \\
\hline
\end{tabular}


Table 4-36

Attitudes Toward the Feedback Process in General: Descriptive Statistics (1- Strongly Disagree, 2- Disagree, 3- Agree, 4- Strongly Agree)

\begin{tabular}{|c|c|c|c|c|c|c|c|c|}
\hline Statements & $M$ & $M d n$ & Mode & $S D$ & Var & Ran & Skew & Kur \\
\hline The feedback process is a good learning experience & 3.47 & 3 & 3 & .53 & .28 & 2 & -.18 & -.132 \\
\hline I rarely get surprised with the written feedback on my papers & 2.72 & 3 & 3 & .62 & .38 & 3 & -.10 & -.09 \\
\hline I get upset if I wait for written feedback for more than two weeks & 2.71 & 3 & 3 & .80 & .64 & 3 & -.20 & -.38 \\
\hline The feedback process affects me emotionally & 2.60 & 3 & 3 & .71 & .51 & 3 & -.50 & .02 \\
\hline $\begin{array}{l}\text { I get upset when I am not given another opportunity to submit my } \\
\text { paper after receiving written feedback }\end{array}$ & 2.58 & 3 & 3 & .73 & .54 & 3 & -.07 & -.26 \\
\hline $\begin{array}{l}\text { I feel that feedback providers' opinions of me will be affected based on } \\
\text { whether I make the revisions they suggest or not }\end{array}$ & 2.41 & 2 & 2 & .71 & .51 & 3 & .12 & -.20 \\
\hline It is hard for me to get others' written feedback & 2.28 & 2 & 2 & .76 & .58 & 3 & .53 & .13 \\
\hline The feedback process keeps me from progressing & 1.84 & 2 & 2 & .66 & .44 & 3 & .87 & 1.99 \\
\hline
\end{tabular}


Table 4-37

Attitudes Toward the Feedback Process in General: Frequencies and Percentages (SD-Strongly Disagree, D- Disagree, A- Agree, SA-Strongly Agree)

\begin{tabular}{|c|c|c|c|c|c|c|}
\hline \multirow[b]{2}{*}{ Statements } & \multirow[b]{2}{*}{$\begin{array}{c}\text { SD } \\
f(P)\end{array}$} & \multirow[b]{2}{*}{$\begin{array}{c}\mathrm{D} \\
f(P)\end{array}$} & \multirow[b]{2}{*}{$\begin{array}{c}\text { A } \\
f(P)\end{array}$} & \multirow[b]{2}{*}{$\begin{array}{c}\mathrm{SA} \\
f(P)\end{array}$} & \multicolumn{2}{|c|}{ Total } \\
\hline & & & & & $\begin{array}{c}\text { Disagree } \\
\qquad f(P)\end{array}$ & $\begin{array}{l}\text { Agree } \\
f(P)\end{array}$ \\
\hline The feedback process is a good learning experience & 0 & $4(1 \%)$ & $138(50 \%)$ & $134(49 \%)$ & $4(1 \%)$ & $272(99 \%)$ \\
\hline I rarely get surprised with the written feedback on my papers & $4(1 \%)$ & $90(33 \%)$ & $161(58 \%)$ & $21(8 \%)$ & $94(34 \%)$ & $182(66 \%)$ \\
\hline I get upset if I wait for written feedback for more than two weeks & $18(6 \%)$ & $86(31 \%)$ & $131(48 \%)$ & $41(15 \%)$ & $104(38 \%)$ & $172(62 \%)$ \\
\hline The feedback process affects me emotionally & $21(8 \%)$ & $85(31 \%)$ & $154(56 \%)$ & $16(6 \%)$ & $106(38 \%)$ & $170(62 \%)$ \\
\hline $\begin{array}{l}\text { I get upset when I am not given another opportunity to submit my paper } \\
\text { after receiving written feedback }\end{array}$ & $16(6 \%)$ & $107(39 \%)$ & $129(47 \%)$ & $24(9 \%)$ & $123(45 \%)$ & $153(55 \%)$ \\
\hline $\begin{array}{l}\text { I feel that feedback providers' opinions of me will be affected based on } \\
\text { whether I make the revisions they suggest or not }\end{array}$ & $22(8 \%)$ & $135(49 \%)$ & $104(38 \%)$ & $15(5 \%)$ & $157(57 \%)$ & $119(43 \%)$ \\
\hline It is hard for me to get others' written feedback & $31(11 \%)$ & $158(57 \%)$ & $66(24 \%)$ & $21(8 \%)$ & $189(68 \%)$ & $87(32 \%)$ \\
\hline The feedback process keeps me from progressing & $77(28 \%)$ & $175(63 \%)$ & $15(5 \%)$ & $9(3 \%)$ & $252(91 \%)$ & $24(9 \%)$ \\
\hline
\end{tabular}




\section{Multivariate Correlational Data Analysis}

Multivariate correlational data analysis was conducted in three main phases. During the first phase, Exploratory Factor Analysis (EFA) was conducted to identify factors representing doctoral students' perceptions and attitudes toward different characteristics of written feedback and written feedback providers, their revision decisions, and other potentially relevant factors in the feedback practices of the doctoral students. In the second phase, Confirmatory Factor Analysis (CFA) was conducted before SEM as a priori step to establish the construct validity of the factors. Finally in the third phase, the hypothetical relationships between these factors were tested with Structural-Equation Modeling (SEM). Please see Chapter 3 for the explanations and the justification of using these analysis methods.

A total of 108 items included at the beginning of data analysis, 32 of them were reverse-scaled. Questions regarding participants' general information (Section A, nine questions: total of 17 response items) were not included in this part of the analysis because they were examined during the post-analyses instead. Also, some items regarding the participants' written feedback preferences (Section E, questions 1, 2, 3, and 5: total of 29 items) were not included in this part of the analysis either because these items were too specific individually to form meaningful factors by themselves or to form a meaningful factor item under other resulting factors. These were confirmed by conducting several pre-analyses. Finally, the screening question (Section H, question 1) was not included in the analysis.

Examination and Preparation of Data for Analysis

\section{Meeting Multivariate Normality Assumption for Maximum Likelihood Method}

According to West, Finch, and Curran (1995, p. 68) an important benchmark includes multivariate normality for variables. Values exceeding a skewness of 2 or a kurtosis of 7 indicate that normality assumption may be violated. Across all 108 items, only one was severely non-normal (skewness $=2.42$, kurtosis $=5.73$ ) and it was excluded from further analyses. This item was an attitude statement in 4-point importance scale and answered the question "how important are the following characteristics of a person to you when deciding whether or not to ask for their written feedback?" as "whether the person is younger or 
older than I am" $(M=1.25, S D=0.56)$.

\section{Reliability Analysis}

Internal estimates of reliability were computed for the remaining 107 standardized items, all of which had 4-point scales. Cronbach's alpha level based on standardized scores was found as 0.83 , indicating satisfactory reliability. However, it is possible that the alpha level might be overestimated due to large number of items (Schmitt, 1996).

\section{Item Reliability and Commonality Analyses}

Item analysis using reliability procedure was conducted with 107 standardized items according to the guidelines of Green and Salkind (2005). Cronbach's alpha if item deleted values ranged from 0.83 to 0.84, and Corrected Item Total Correlations values ranged from -1.46 to 0.43 . Items with lowest Corrected Item Total Correlations were detected.

Commonalities of 107 standardized items were examined. When the principal components method was used, the commonalities ranged from 0.57 to 0.83 with a mean value of 0.71 . When Maximum Likelihood method was used, the commonalities ranged from 0.22 to 1 , with a mean value of 0.58 . Items with commonality scores lower than 0.4 were detected.

Based on these analyses results it has been found that 16 items affect the internal reliability and commonality scores negatively. These items were marked for further examination in the next analysis phase (see Appendix I, Table I-1).

\section{Exploratory Factor Analysis (EFA)}

There were three different scales in the questionnaire (agreement, frequency, and importance scales). Although all of them were 4-point Likert scales, they had different metrics (agreement scale: strongly disagree, disagree, agree, strongly agree; frequency scale: never, seldom, sometimes, often; importance scale: unimportant, somewhat important, important, very important). For example, while an item score of 2 in agreement scale means "disagree," same item score means "somewhat important" in the importance scale. This problem required separate exploratory factor analyses to assure that the derived factors are internally consistent. 
Factor Extraction and the Number of Factors

Principal components method was used for factor extraction with total of 107 items. Total variance explained for each factor is presented in Table 4-38. Commonality mean scores were higher than 0.4 .

As suggested by Fabrigar, Wegener, MacCallum, and Strahan (1999) multiple criteria, specifically Scree test and parallel analysis were used to determine the number of factors to rotate for each group of items. Scree test was conducted according to Catell (1966). Ten factors from agreement scale (Figure 4-3), four from importance scale (Figure 4-4), and three from frequency scale (Figure 4-5) were detected.

Parallel Analysis, the second analysis method to determine the number of factors in this study, was conducted according to O'Connor (O'Connor, 2000, 2008) with 276 cases, 99\% percentile for the analysis, and 1000 data sets. Principal components method was used while performing parallel analysis. In this analysis, Eigenvalues obtained from random data were compared to the Eigenvalues obtained from the actual data (see Table 4-39). As shown in Table 4-38, Scree test and parallel analysis results matched.

Table 4-38

Results of Factor Extraction

\begin{tabular}{lccc}
\hline & Agreement scale & Importance scale & Frequency scale \\
\hline Number of items & 71 & 23 & 13 \\
Number of components Eigenvalues $>1$ & 22 & 6 & 3 \\
Total variance explained & $69 \%$ & $60 \%$ & $58 \%$ \\
Commonality values range & $0.54-0.84$ & $0.39-0.80$ & $0.38-0.75$ \\
Commonality values mean & 0.69 & 0.60 & 0.58 \\
Number of factors according to Scree test & 10 & 4 & 3 \\
$\begin{array}{l}\text { Number of factors according to Parallel } \\
\text { Analysis }\end{array}$ & 10 & 4 & 3 \\
\hline
\end{tabular}




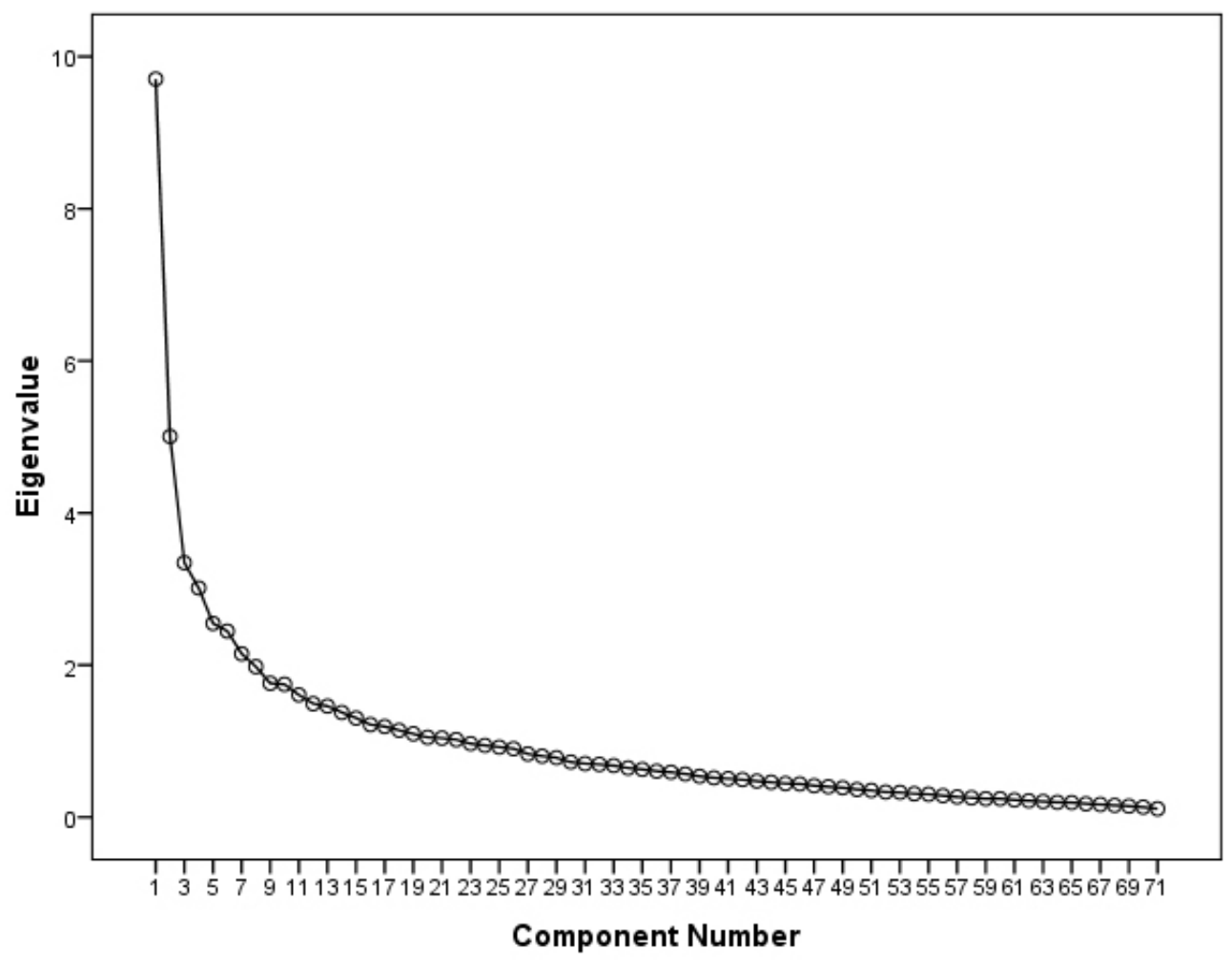

Figure 4-3. Agreement scale Scree plot.

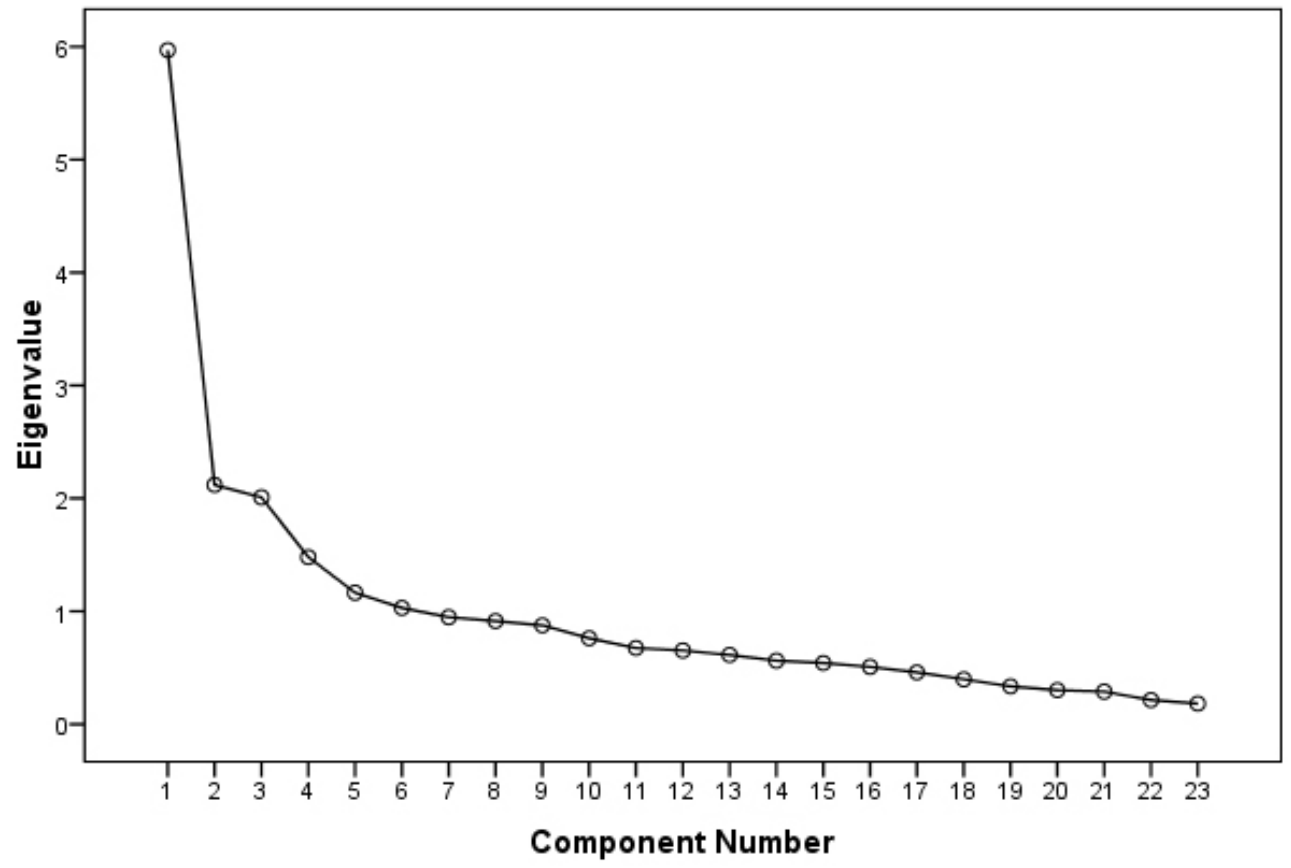

Figure 4-4. Importance scale Scree plot. 


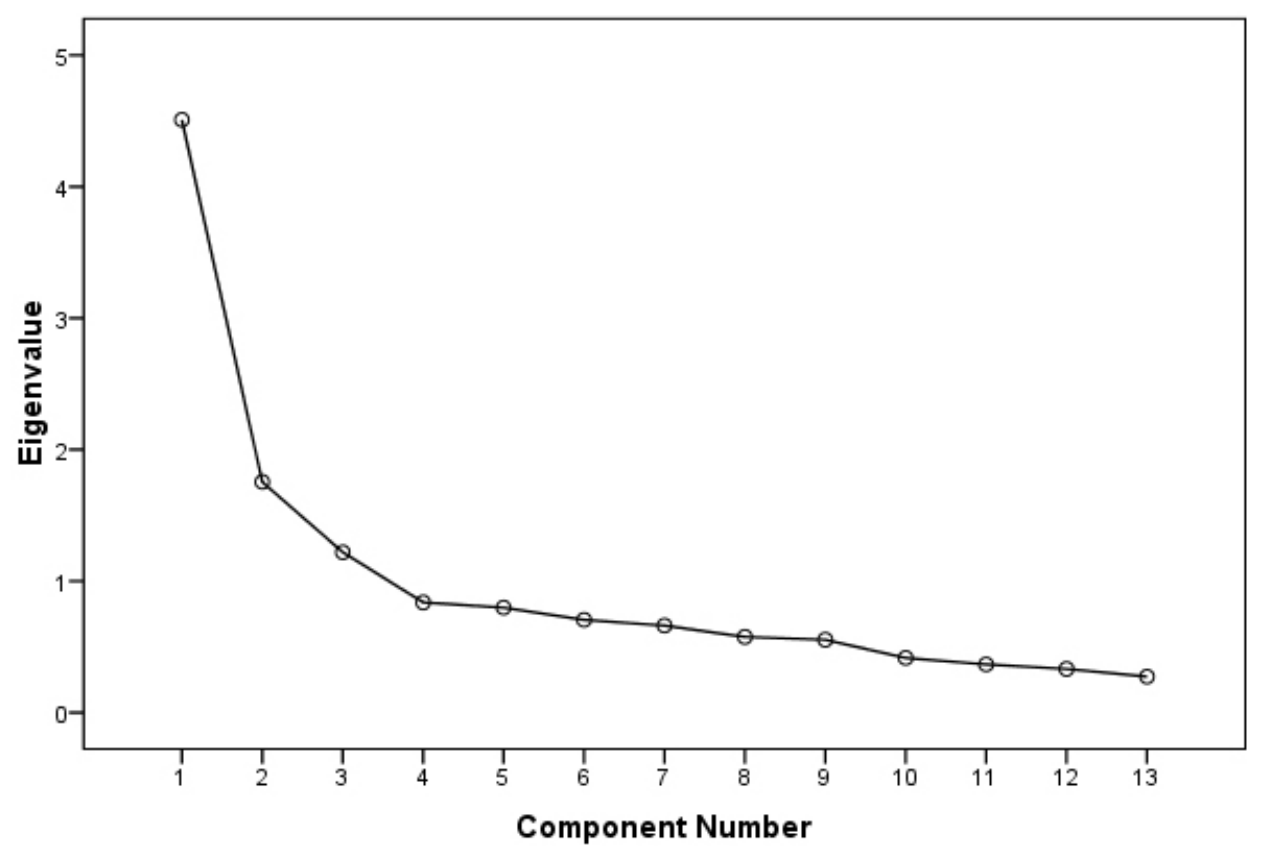

Figure 4-5. Frequency scale Scree plot.

\section{Factor Rotation}

Based on the Scree test and Parallel analysis results, 10 factors for the agreement scale, 4 factors for the importance scale, and 3 factors for the frequency scale were rotated using an oblique rotation procedure which is suggested by Fabrigar et al. (1999) (see Table 4-40). Factor extraction incorporated the Maximum Likelihood method and rotation employed Direct Oblimin with Delta $=0$.

After the rotation, the factors were examined according to their items' factor loadings, number of items, and plausibility and interpretability (Brown, 2006). Also item analysis results, commonalities, and cross-loadings among factors were considered. Some of the factors were eliminated, the rationale of which is explained below. Remaining factors were further examined and their best representative items were selected. As recommended by MacCallum, Widaman, Zhang, and Hong (1999), at least three representative items for each factor were selected. In total, 107 items were retained. Seventy-one of these items accounted for $47 \%, 23$ of them $50 \%$, and 13 of them $58 \%$ of the variance.

Examination of pattern matrix and factor loadings showed that there were some factors that have only two items with factor loadings more than 0.4 . For example, two reverse scaled items "I don't want to expose myself to others by asking them to give me written feedback if I am not confident in my paper's 
Table 4-39

Parallel Test Results to Determine the Number of Factors in EFA

\begin{tabular}{ccccccc}
\hline $\begin{array}{c}\text { \# of } \\
\text { factors }\end{array}$ & $\begin{array}{c}\text { Random data } \\
\text { agreement } \\
\text { scale }\end{array}$ & $\begin{array}{c}\text { Agreement } \\
\text { scale real } \\
\text { Eigenvalues }\end{array}$ & $\begin{array}{c}\text { Random data } \\
\text { Eigenvalues } \\
\text { importance } \\
\text { scale }\end{array}$ & $\begin{array}{c}\text { Importance } \\
\text { scale real } \\
\text { Eigenvalues }\end{array}$ & $\begin{array}{c}\text { Random data } \\
\text { Eigenvalues } \\
\text { frequency } \\
\text { scale }\end{array}$ & $\begin{array}{c}\text { Frequency } \\
\text { scale real } \\
\text { Eigenvalues }\end{array}$ \\
\hline 1 & 2.177017 & 9.705 & 1.560018 & 5.971 & 1.373556 & 4.509 \\
2 & 2.077276 & 5.006 & 1.467205 & 2.119 & 1.281489 & 1.754 \\
3 & 2.001351 & 3.345 & 1.395550 & 2.009 & 1.208577 & 1.220 \\
4 & 1.938839 & 3.015 & 1.334576 & 1.480 & 1.144801 & 0.838 \\
5 & 1.882293 & 2.548 & 1.280136 & 1.164 & & \\
6 & 1.830637 & 2.447 & & & & \\
7 & 1.782395 & 2.149 & & & & \\
8 & 1.737162 & 1.979 & & & & \\
9 & 1.695512 & 1.761 & & & & \\
10 & 1.654563 & 1.748 & & & & \\
11 & 1.616400 & 1.609 & & & & \\
Result & & 10 Factors & & & & \\
\hline
\end{tabular}

Table 4-40

Factor Rotation Results

\begin{tabular}{lcccc}
\hline \multicolumn{1}{c}{ Scales } & $\begin{array}{c}\text { Number of } \\
\text { items }\end{array}$ & $\begin{array}{c}\text { Number of } \\
\text { factors rotated }\end{array}$ & $\begin{array}{c}\text { Total variance } \\
\text { explained }\end{array}$ & Goodness of fit \\
\hline Agreement scale & 71 & 10 & $47 \%$ & $\chi^{2}=2695.18, d f=1820, p=.00$ \\
Importance scale & 23 & 4 & $50 \%$ & $\chi^{2}=394.96, d f=167, p=.00$ \\
Frequency scale & 13 & 3 & $58 \%$ & $\chi^{2}=84.72, d f=42, p=.00$ \\
\hline
\end{tabular}


quality: and "my pride has a lot to do with my decisions to not ask for written feedback" were grouped together as a factor; however this factor was eliminated due to having only two items.

Moreover some factors' items were cross-loaded with other factors. For example, item "if feedback providers start their written feedback with critical/negative comments, I feel less open to the rest of the comments" cross-loaded on two factors with factor loadings of 0.38 and 0.50 on each. This item was eliminated.

Furthermore, when the meaning of the factors was examined, some factors' interpretation was not meaningful and their item loadings were low. As an example, the following items were grouped together in one factor: "If I catch a big mistake among the written feedback, I tend to disregard the other feedback comments that person gives" (factor loading: 0.47), "I don't appreciate written feedback that tries change my writing style" (factor loading: 0.46), "I don't appreciate written feedback that tries to change the direction of my paper" (factor loading: 0.42 ). All of these items' factor loadings were close to 0.4 . Moreover, while the first item was related to their revision decisions especially considering the feedback provider, the other two items were related to their feedback preferences. This factor was also eliminated.

When these factors were excluded, in agreement scale total of four strong and meaningful factors were decided to be included in the SEM analysis. As for importance scale items, all four factors were included in the next stage. For frequency scale, one factor was eliminated and items that best represent the remaining two factors were selected. Table 4-41 shows the selected factors and their representative items that were included in the SEM analysis.

\section{Criteria Check for Sample Size and Number of Measured Variables}

One criterion to determine the required sample size is to calculate the ratio of sample size to number of measured variables. The suggested ratio is about 5-10 and sample size should be 100 or more (Fabrigar et al., 1999). In this study, the ratio is $276 / 35=7.8$, meets these criteria. However the nature of the data also determines the required sample size (Fabrigar et al., 1999).

According to Fabrigar et al. (1999) and MacCallum et al. (1999) when factors are "overdetermined" (when there are at least three or more measured variables for each factor) with moderate 
Table 4-41

Main Factors and Variables That Best Represent 10 Factors

\begin{tabular}{|c|c|}
\hline Factors & Descriptions, scale information, and items \\
\hline \multirow{9}{*}{$\begin{array}{l}\text { 1: Attitudes-critical } \\
\text { feedback } \\
\text { Attitudes toward } \\
\text { critical/negative written } \\
\text { feedback }\end{array}$} & $\begin{array}{l}\text { a. Description: This factor represents attitudes toward critical/negative written } \\
\text { feedback, specifically the negative effect of critical/negative written feedback } \\
\text { on doctoral students' emotions, self-confidence, and motivation. }\end{array}$ \\
\hline & $\begin{array}{l}\text { b. Scale: Reversed scaled } 6 \text { items, 4-point Agreement scale (strongly } \\
\text { disagree, disagree, agree, strongly agree) }\end{array}$ \\
\hline & c. Items: \\
\hline & 117. Critical/negative written feedback affects me emotionally \\
\hline & 119. Having critical/negative written feedback makes me feel embarrassed \\
\hline & 120. I lose self-confidence when I receive critical/negative written feedback \\
\hline & 118. I am scared to get critical/negative written feedback \\
\hline & 148. The feedback process affects me emotionally \\
\hline & $\begin{array}{l}\text { 121. I lose my motivation to work on my paper further when I receive } \\
\text { critical/negative written feedback }\end{array}$ \\
\hline \multirow{9}{*}{$\begin{array}{l}\text { 2: Motivations } \\
\text { Motivations for } \\
\text { academic writing }\end{array}$} & $\begin{array}{l}\text { a. Description: This factor represents the doctoral students' motivations for } \\
\text { engaging in academic writing specifically their motivations related to }\end{array}$ \\
\hline & $\begin{array}{l}\text { improving and contributing to the field, and improving themselves as } \\
\text { academicians. }\end{array}$ \\
\hline & $\begin{array}{l}\text { b. Scale: } 4 \text { items, 4-point Agreement scale (strongly disagree, disagree, agree, } \\
\text { strongly agree) }\end{array}$ \\
\hline & c. Items: \\
\hline & Main Phrase: My motivation for academic writing is: \\
\hline & 28: To contribute knowledge to the field \\
\hline & 27: To share my ideas or findings with others \\
\hline & 25: To gain experiences, skills, and knowledge as an academician \\
\hline & 26: To have recognition in the field \\
\hline
\end{tabular}




\begin{tabular}{l} 
Factors \\
\hline 3: Department \\
Perceptions of \\
opportunities to write \\
academic papers with \\
faculty members in the \\
department
\end{tabular}

4: Asking for feedback

Attitudes toward asking and searching for written feedback for academic papers a. Description: This factor represents doctoral students' perceptions about the opportunities that doctoral students have regarding writing academic papers with the faculty members in their department.

b. Scale: 3 items, 4-point Agreement scale (strongly disagree, disagree, agree, strongly agree)

c. Items:

Main Phrase: In my program:

36: There are a lot of opportunities to write academic papers with faculty members

33: The faculty members often write academic papers with their students

34: The faculty members invite me to write academic papers together with them

a. Description: This factor represents doctoral students' behaviors in asking for written feedback, specifically regarding the number of feedback providers and the number of feedback occasions.

b. Scale: 3 items, 4-point Agreement scale (strongly disagree, disagree, agree, strongly agree)

c. Items:

38: I look for several people to give me written feedback for my papers

39: I look for several written feedback occasions at different stages of my papers

37: I ask others for written feedback on my academic papers

a. Description: This factor represents doctoral students' attitudes toward the feedback providers' allocated time and willingness to help the students, when they consider asking for their written feedback.

b. Scale: 3 items, 4-point Importance scale (unimportant, somewhat important, important, very important)

c. Items:

Main Question: How important are the following characteristics of a person to you when deciding whether or not to ask for their written feedback?

66: Whether I think they have time to give me feedback 
65: Whether I feel that I won't be a burden to him/her

64: Whether I feel that he/she will be willing to help

6: Provider-knowledge

Attitudes toward feedback providers' knowledge level in the content area of the paper when asking for written feedback

Attitudes toward feedback providers' skills and style when asking for written feedback a. Description: This factor represents doctoral students' attitudes toward the feedback providers' knowledge level, department, perception toward the importance of the students' paper, when students consider asking for their feedback.

b. Scale: 3 items, 4-point Importance Scale (unimportant, somewhat important, important, very important)

c. Items:

Main Question: How important are the following characteristics of a person to you when deciding whether or not to ask for their written feedback?

51: His/her knowledge level in the content area that my paper is about

50: His/her being in the same discipline or not

53: Whether he/she thinks my paper is important

a. Description: This factor represents doctoral students' attitudes toward the feedback providers' writing style and writing, thinking, organizing, analyzing skills, when they consider asking for their feedback.

b. Scale: 3 items, 4-point Importance Scale (unimportant, somewhat important, important, very important)

c. Items:

Main Question: How important are the following characteristics of a person to you when deciding whether or not to ask for their written feedback?

\section{7: His/her writing style}

56: His/her writing skills

58: His/her thinking, organizing, and analyzing skills

8: Provider- personality

Attitudes toward feedback providers' personality when asking for written feedback a. Description: This factor represents doctoral students' attitudes toward the feedback providers' personality, specifically whether or not they like them, trust them, and perceive them as responsible, when they consider asking for their feedback.

b. Scale: 3 items, 4-point Importance Scale (unimportant, somewhat important, important, very important) 


\begin{tabular}{|c|c|}
\hline Factors & Descriptions, scale information, and items \\
\hline \multirow{14}{*}{$\begin{array}{l}\text { 9: Revision decision- } \\
\text { external } \\
\text { Revision decisions } \\
\text { considering the external } \\
\text { issues while examining } \\
\text { the written feedback }\end{array}$} & c. Items: \\
\hline & $\begin{array}{l}\text { Main Question: How important are the following characteristics of a person } \\
\text { to you when deciding whether or not to ask for their written feedback? }\end{array}$ \\
\hline & 59: Whether I like his/her personality \\
\hline & 61: Whether I trust him/her as a person \\
\hline & 60: Whether he/she is a responsible person \\
\hline & $\begin{array}{l}\text { a. Description: This factor represents doctoral students' attitudes regarding } \\
\text { their revision decisions when they do not agree with a feedback comment, } \\
\text { specifically the frequency in the consideration of the punishment-reward }\end{array}$ \\
\hline & $\begin{array}{l}\text { issues, authority-power issues, and the underlying motivation issues in the } \\
\text { feedback. }\end{array}$ \\
\hline & b. Scale: 4 items, 4-point Frequency Scale (never, seldom, sometimes, often) \\
\hline & c. Items: \\
\hline & $\begin{array}{l}\text { Main Phrase: If I don't agree with a written feedback comment, before } \\
\text { deciding to ignore or use that comment for my revisions I ask myself: }\end{array}$ \\
\hline & 134: Will there be some kind of punishment for not revising this way? \\
\hline & 135: Will there be some kind of reward for revising this way? \\
\hline & $\begin{array}{l}\text { 140: What kind of authority-power relationship do I have with the person } \\
\text { who gave me this feedback? }\end{array}$ \\
\hline & $\begin{array}{l}\text { 141: What kind of motivation or agenda might this person have for giving me } \\
\text { this feedback? }\end{array}$ \\
\hline \multirow{6}{*}{$\begin{array}{l}\text { 10: Revision decision- } \\
\text { justification } \\
\text { Revision decisions } \\
\text { considering the } \\
\text { feedback } \\
\text { characteristics and the } \\
\text { need for the revisions } \\
\text { while examining the } \\
\text { written feedback }\end{array}$} & $\begin{array}{l}\text { a. Description: This factor represents doctoral students' attitudes regarding } \\
\text { their revision decisions when they do not agree with a feedback comment, } \\
\text { specifically the frequency in the consideration of the justification in the }\end{array}$ \\
\hline & feedback, the need for revision, and their confidence level in what they wrote. \\
\hline & b. Scale: 3 items, 4-point Frequency Scale (never, seldom, sometimes, often) \\
\hline & c. Items: \\
\hline & $\begin{array}{l}\text { Main Phrase: If I don't agree with a written feedback comment, before } \\
\text { deciding to ignore or use that comment for my revisions I ask myself: }\end{array}$ \\
\hline & 132 : Is there any justification for that feedback? \\
\hline
\end{tabular}




Factors
$\begin{aligned} & \text { 133: Is there really a need to make the change? } \\ & \text { 131: Am I confident in what I wrote? }\end{aligned}$
Note. Factor 1 (Attitudes- critical feedback) items were reverse-scaled. The items were sequenced in an
order of having the highest factor loadings in that factor. The item codes represent their item number in the
questionnaire.

commonalities (around .5), sample size of 100-200 is needed. Considering this study, the ratio of measured variables to number of factors is $35 / 10=3.5$. Therefore the factors are overdetermined. Regarding the commonalities, they ranged from 0.45 to 0.81 with mean value of 0.69 with principal components analysis; and they ranged from 0.09 to 1 , with a mean value of 0.57 with maximum likelihood method. Therefore a sample size of 276 meets this criterion.

Confirmatory Factor Analysis (CFA)

As an a priori step for SEM, CFA was conducted to establish the construct validity of the factors, both regarding convergent and discriminant validity (Brown, 2006). Based on the results of the EFA, a 10factor model (4 agreement scale factors, 4 importance scale factors, and 2 frequency scale factors) was specified and 35 measured variables were included in the CFA. Because ordinal, noncontinuous indicator variables were included in the model, Weighted Least Squares (WLS) estimator with theta parameterization was specified during both CFA and SEM analyses.

Table 4-42 presents CFA results compared to specified criteria. Please see Chapter 3 for explanations of these criteria. According to these results it can be suggested that the factors found in the EFA may exist.

Factor Loadings and Correlations

In Table 4-43 standardized parameter estimates are presented. Model parameters were all significant $(p<.01)$ and explained substantial amounts of item variance ( $R^{2}$ ranged from 0.36 to 0.94$)$. Composite reliability of a factor, which is the measurement of reliability of a group of similar items that 
measure a construct, ranged from 0.69 to 0.93 . Except for Factor 6, all other factors had composite reliability higher than 0.7 as recommended by Hair, Anderson, Tatham, and Black (1998).

As in the correlation matrix presented in Table 4-44, the factors had low correlations. The highest correlations were between Provider- personality and Provider- help (0.45), Provider- knowledge (0.44), and Provider- skill (0.44). The high correlations between the factors do not necessarily mean that they are similar factors.

Structural Equation Modeling (SEM)

Based on the provisional model and the factors resulted from EFA, a hypothetical model was developed, direct and mediating relationships between factors were identified (see Figure 4-6). Compared to provisional model's factors which included several subcategories, the factors of the hypothetical model were composed of specific and a few number of questionnaire items. Therefore, the hypothetical model can be considered as a subset of the provisional model.

The hypothetical model was tested with Structural Equation Modeling (SEM) analysis. The estimations, direct and indirect effects of factors on each other in the hypothetical model were also presented in Figure 4-6. Only seven of the hypothesized direct effects were found to be significant. Several other connections were not statistically significant. The results were compared to the model fit criteria described in Chapter 3. CFI and TLI indexes satisfied the criteria, and according to RMSEA indexes, this model has a fair fit (see Table 4-45). Chi-square criterion was not satisfied. It has been concluded that although the model has a fair fit, it can be improved.

As explained by Schumacker and Lomax (2004), during the model specification, the researcher specifies the variables to include in the model and their relationships based on theory or research. However errors of inclusion or exclusion of variables in the model are possible. They stated "if the fit of the implied theoretical model is not as strong as one would like (which is typically the case with an initial model), then the next step is to modify the model and subsequently evaluate the new modified model" (p. 70).

Considering the provisional model, the model was modified several times by deleting weak connections between factors and by observing the effect of the changes on the model modification indices and statistical significance of the parameter estimations. Among several versions of this model, the 
Table 4-42

Confirmatory Factor Analysis Results

\begin{tabular}{|c|c|c|c|}
\hline Model fit criterion & Results & Criteria & Satisfaction \\
\hline $\begin{array}{l}\text { Chi-square test of } \\
\text { model fit value }\end{array}$ & $\begin{array}{c}\chi^{2}=214.822 \\
d f=108 \\
p=.00 \\
\chi^{2} / d f=1.99\end{array}$ & $\begin{array}{l}\text { a. Chi-square }\left(\chi^{2}\right) \text { statistic to degrees of } \\
\text { freedom }(d f) \text { ratio } \leq 2 \\
\text { b. Non-significant value of } \chi^{2}\end{array}$ & $\begin{array}{l}\text { a. Satisfies } \\
\text { b. Does not satisfy }\end{array}$ \\
\hline $\begin{array}{l}\text { Comparative Fit } \\
\text { Index (CFI) }\end{array}$ & 0.97 & $\mathrm{CFI} \geq .95$ & Satisfies \\
\hline $\begin{array}{l}\text { Tucker Lewis Index } \\
\text { (TLI) }\end{array}$ & 0.97 & $\mathrm{TLI} \geq .95$ & Satisfies \\
\hline $\begin{array}{l}\text { Root Mean Square } \\
\text { Error of } \\
\text { Approximation } \\
\text { (RMSEA) }\end{array}$ & 0.06 & $\begin{array}{l}\text { a. RMSEA } \leq .06 \\
\text { b. RMSEA } \leq .05: \text { Close fit } \\
.05 \leq \text { RMSEA } \leq .08: \text { Fair fit } \\
\text { RMSEA } \geq .10 \text { : Poor fit }\end{array}$ & $\begin{array}{l}\text { a. Satisfies } \\
\text { b. Satisfies: Fair fit }\end{array}$ \\
\hline
\end{tabular}


Table 4-43

Standardized Paramater Estimates for 10 Factors- Estimates (standard errors) - STDYX Standardization

\begin{tabular}{|c|c|c|c|}
\hline $\begin{array}{c}\text { Factors and items in the questionnaire that } \\
\text { represent the factors }\end{array}$ & $\begin{array}{c}\text { Loadings } \\
\text { (standard errors) }\end{array}$ & $\begin{array}{l}\text { Composite } \\
\text { reliability }\end{array}$ & $R^{2}$ \\
\hline Factor1: Attitudes- critical feedback & & 0.93 & \\
\hline Item 120 - reverse scaled & $0.87(0.02)$ & & 0.75 \\
\hline Item 148- reverse scaled & $0.85(0.03)$ & & 0.72 \\
\hline Item 118- reverse scaled & $0.84(0.02)$ & & 0.71 \\
\hline Item 119- reverse scaled & $0.84(0.02)$ & & 0.71 \\
\hline Item 117 - reverse scaled & $0.82(0.02)$ & & 0.67 \\
\hline Item 121 - reverse scaled & $0.74(0.03)$ & & 0.54 \\
\hline Factor2: Motivations & & 0.89 & \\
\hline Item 28 & $0.96(0.02)$ & & 0.93 \\
\hline Item 27 & $0.94(0.02)$ & & 0.87 \\
\hline Item 25 & $0.69(0.04)$ & & 0.48 \\
\hline Item 26 & $0.630 .04)$ & & 0.39 \\
\hline Factor3: Department & & 0.92 & \\
\hline Item 34 & $0.90(0.02)$ & & 0.82 \\
\hline Item 33 & $0.90(0.02)$ & & 0.81 \\
\hline Item 36 & $0.87(0.02)$ & & 0.76 \\
\hline Factor4: Asking for feedback & & 0.88 & \\
\hline Item 38 & $0.92(0.02)$ & & 0.85 \\
\hline Item 37 & $0.86(0.03)$ & & 0.74 \\
\hline Item 39 & $0.75(0.04)$ & & 0.56 \\
\hline Factor5: Provider-help & & 0.88 & \\
\hline Item 65 & $0.97(0.02)$ & & 0.94 \\
\hline
\end{tabular}




\begin{tabular}{|c|c|c|c|}
\hline $\begin{array}{c}\text { Factors and items in the questionnaire that } \\
\text { represent the factors }\end{array}$ & $\begin{array}{c}\text { Loadings } \\
\text { (standard errors) }\end{array}$ & $\begin{array}{l}\text { Composite } \\
\text { reliability }\end{array}$ & $R^{2}$ \\
\hline Item 66 & $0.86(0.03)$ & & 0.74 \\
\hline Item 64 & $0.68(0.04)$ & & 0.47 \\
\hline Factor6: Provider-knowledge & & 0.69 & \\
\hline Item 53 & $0.68(0.07)$ & & 0.46 \\
\hline Item 51 & $0.67(0.06)$ & & 0.45 \\
\hline Item 50 & $0.60(0.06)$ & & 0.36 \\
\hline Factor7: Provider-skill & & 0.85 & \\
\hline Item 56 & $0.86(0.04)$ & & 0.74 \\
\hline Item 57 & $0.82(0.03)$ & & 0.66 \\
\hline Item 58 & $0.75(0.04)$ & & 0.57 \\
\hline Factor8: Provider- personality & & 0.81 & \\
\hline Item 60 & $0.83(0.04)$ & & 0.69 \\
\hline Item 61 & $0.83(0.03)$ & & 0.68 \\
\hline Item 59 & $0.64(0.04)$ & & 0.41 \\
\hline Factor9: Revision decision- external & & 0.88 & \\
\hline Item 134 & $0.87(0.02)$ & & 0.75 \\
\hline Item 140 & $0.82(0.03)$ & & 0.67 \\
\hline Item 135 & $0.79(0.03)$ & & 0.62 \\
\hline Item 141 & $0.72(0.04)$ & & 0.51 \\
\hline Factor 10: Revision decision- justification & & 0.86 & \\
\hline Item 132 & $0.89(0.04)$ & & 0.80 \\
\hline Item 133 & $0.85(0.04)$ & & 0.72 \\
\hline Item 131 & $0.70(0.05)$ & & 0.49 \\
\hline
\end{tabular}


Table 4-44

Inter-factor Correlations

\begin{tabular}{|c|c|c|c|c|c|c|c|c|c|c|}
\hline & $\begin{array}{c}1 . \\
\text { Attit/crit. }\end{array}$ & $\begin{array}{c}2 . \\
\text { Motivat. }\end{array}$ & $\begin{array}{c}3 . \\
\text { Depart. }\end{array}$ & $\begin{array}{c}4 . \\
\text { Asking }\end{array}$ & $\begin{array}{c}5 . \\
\text { Pro-help }\end{array}$ & $\begin{array}{c}6 . \\
\text { Pro-know }\end{array}$ & $\begin{array}{c}7 . \\
\text { Pro-skill }\end{array}$ & $\begin{array}{c}8 . \\
\text { Pro-pers }\end{array}$ & $\begin{array}{c}9 . \\
\text { Rev-ext }\end{array}$ & $\begin{array}{c}10 . \\
\text { Rev-just }\end{array}$ \\
\hline 1. Attitudes- critical feedback & 1 & & & & & & & & & \\
\hline 2. Motivations & .05 & 1 & & & & & & & & \\
\hline 3. Department & $.15^{*}$ & $.24 * *$ & 1 & & & & & & & \\
\hline 4. Asking for feedback & $.23 * *$ & $.15^{*}$ & $.23 * *$ & 1 & & & & & & \\
\hline 5. Provider- help & $-.19 * *$ & .11 & -.12 & -.12 & 1 & & & & & \\
\hline 6. Provider- knowledge & -.12 & .11 & .01 & -.07 & $.26^{* *}$ & 1 & & & & \\
\hline 7. Provider- skill & .01 & $.15^{*}$ & $.14 *$ & .13 & $.25 * *$ & $.18 *$ & 1 & & & \\
\hline 8. Provider- personality & $-.19 * *$ & .05 & $-.13 *$ & -.09 & $.45^{* *}$ & $.44 * *$ & $.44^{* *}$ & 1 & & \\
\hline 9. Revision decision- external & $-.39 * *$ & .06 & .05 & -.03 & $.15^{*}$ & .10 & $.15^{*}$ & $.20 * *$ & 1 & \\
\hline 10. Revision decision- justification & -.08 & $.17 *$ & .04 & $.21 * *$ & -.07 & .03 & .10 & .08 & $.32 * *$ & 1 \\
\hline
\end{tabular}

Note: Significant at $* p<.05, * * p<.01$, two-tailed. 


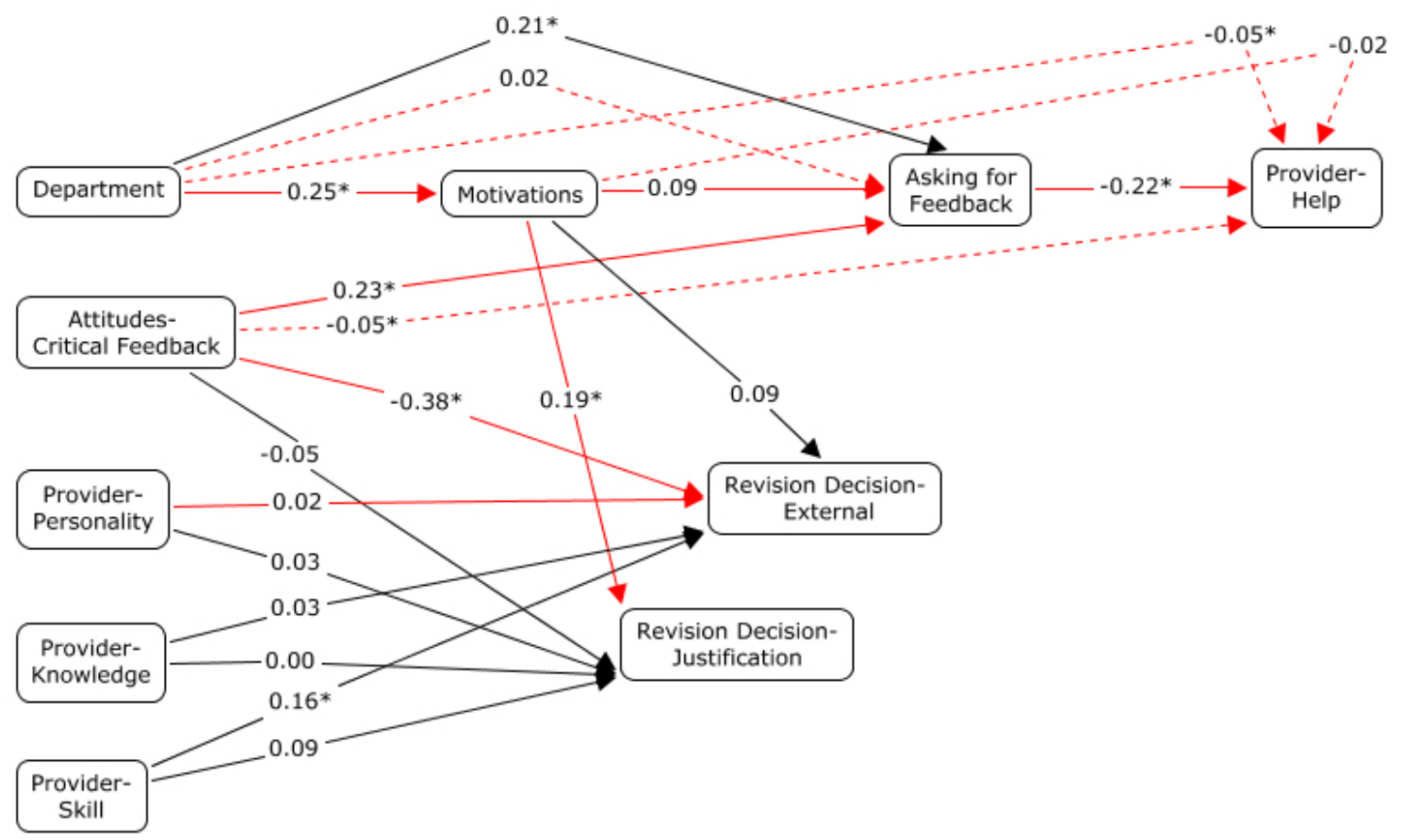

Figure 4-6. Hypothetical model.

Note. Solid lines: direct effect; dashed lines: indirect effect; red lines: final model; numbers: estimations based on STDYX standardization values (larger values indicates larger influence); * significant at $p<.05$. Attitudes-critical feedback items were reverse-scaled. 
Table 4-45

SEM Results of the Hypothetical Model

\begin{tabular}{|c|c|c|c|}
\hline Model fit criterion & Results & Criteria & Satisfaction \\
\hline \multirow[t]{3}{*}{$\begin{array}{l}\text { Chi-square test of } \\
\text { model fit value }\end{array}$} & $\begin{array}{c}\chi^{2}=258.122 \\
d f=91\end{array}$ & $\begin{array}{l}\text { a. Chi-square }\left(\chi^{2}\right) \text { statistic to degrees of } \\
\text { freedom }(d f) \text { ratio } \leq 2\end{array}$ & a. Does not satisfy \\
\hline & $p=.00$ & b. Nonsignificant value of $\chi^{2}$ & b. Does not satisfy \\
\hline & $\chi^{2} / d f=2.84$ & & \\
\hline $\begin{array}{l}\text { Comparative Fit } \\
\text { Index (CFI) }\end{array}$ & 0.95 & $\mathrm{CFI} \geq .95$ & Satisfies \\
\hline $\begin{array}{l}\text { Tucker Lewis Index } \\
\text { (TLI) }\end{array}$ & 0.95 & $\mathrm{TLI} \geq .95$ & Satisfies \\
\hline \multirow{4}{*}{$\begin{array}{l}\text { Root Mean Square } \\
\text { Error of } \\
\text { Approximation } \\
\text { (RMSEA) }\end{array}$} & 0.08 & a. $\mathrm{RMSEA} \leq .06$ & a. Does not satisfy \\
\hline & & b. RMSEA $\leq .05:$ Close fit & b. Satisfies: Fair Fit \\
\hline & & $.05 \leq$ RMSEA $\leq .08:$ Fair fit & \\
\hline & & RMSEA $\geq .10:$ Poor fit & \\
\hline
\end{tabular}

following model was decided to represent the data (see Figure 4-7) due to its compliance with qualitative data analysis, provisional, and hypothetical model; satisfaction of some of the model fit criteria; and statistical significance of the estimates. Although it was not the only model that fit the data, CFI, TLI, RMSEA indexes and the significance values of the estimates showed that the model has an acceptable/fair fit (see Table 4-46).

Exogenous variables or factors are similar to independent variables. They originate paths but they do not receive them. Endogenous variables or factors on the other hand are similar to dependent variables. They receive paths but they may also originate paths to other variables and factors (Raykov \& Marcoulides, 2000). In this study, the exogenous factors were Department, Attitudes- critical feedback, Providerpersonality. Endogenous factors were Motivations, Asking for feedback, Provider- help, Revision Decision- justification, Revision Decision- external. 


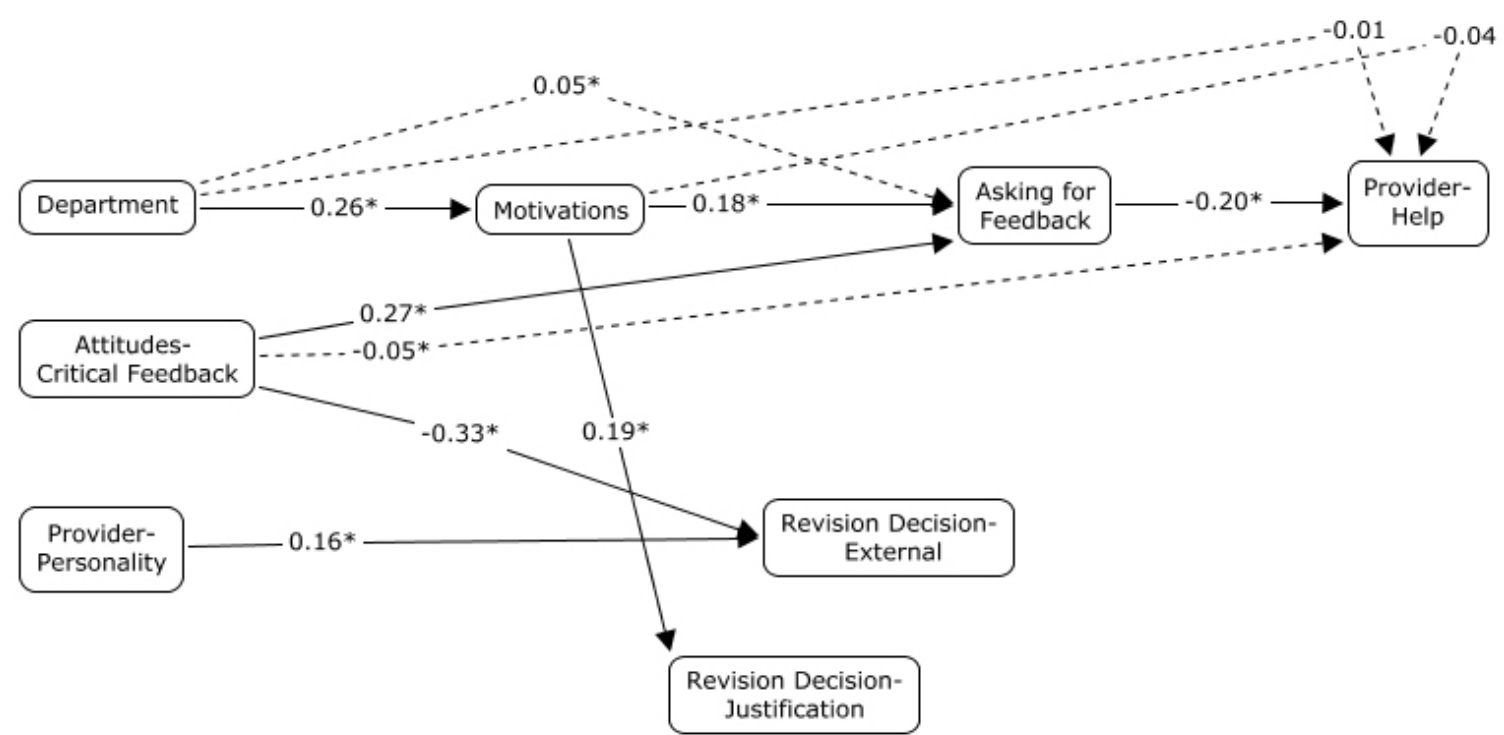

Figure 4-7. Modified model.

Note. Solid lines: direct effect; dashed lines: indirect effect; red lines: final model; numbers: estimations based on STDYX standardization values (larger values indicates larger influence); * significant at $p<.05$. Attitudes-critical feedback items were reverse-scaled.

The model is recursive, which means the arrows lead to one direction. There is a mediated relation between Department, Motivations, Asking for feedback, and Provider-help, in which Motivations modifies the effect of Department on Asking for feedback, and Asking for feedback modifies the effect of Motivations on Provider-help. Therefore, Motivations and Asking for feedback are mediating factors. The indirect effect of Department on Asking for feedback is also significant.

\section{Description of the Modified Model- Results}

According to this model, participants' perceptions toward the opportunities to write academic papers with faculty members in their departments directly and positively influence their motivations for academic writing, specifically regarding improving and contributing to the field and improving themselves as academicians. Moreover, it positively and indirectly influences participants' attitudes toward asking for written feedback for their academic papers from several people and several times, which is also positively affected by their described motivations. 
Table 4-46

SEM Results of the Modified Model

\begin{tabular}{|c|c|c|c|}
\hline Model fit criterion & Results & Criteria & Satisfaction \\
\hline $\begin{array}{l}\text { Chi-square Test of } \\
\text { Model Fit Value }\end{array}$ & $\begin{array}{c}\chi^{2}=1345.002 \\
d f=448 \\
p=.00 \\
\chi^{2} / d f=3.00\end{array}$ & $\begin{array}{l}\text { a. Chi-square }\left(\chi^{2}\right) \text { statistic to degrees of } \\
\text { freedom }(d f) \text { ratio } \leq 2 \\
\text { b. Non-significant value of } \chi^{2}\end{array}$ & $\begin{array}{l}\text { a. Does not satisfy } \\
\text { b. Does not satisfy }\end{array}$ \\
\hline $\begin{array}{l}\text { Comparative Fit } \\
\text { Index (CFI) }\end{array}$ & 0.96 & $\mathrm{CFI} \geq .95$ & Satisfies \\
\hline $\begin{array}{l}\text { Tucker Lewis Index } \\
\text { (TLI) }\end{array}$ & 0.96 & $\mathrm{TLI} \geq .95$ & Satisfies \\
\hline $\begin{array}{l}\text { Root Mean Square } \\
\text { Error of } \\
\text { Approximation } \\
\text { (RMSEA) }\end{array}$ & 0.08 & $\begin{array}{l}\text { a. RMSEA } \leq .06 \\
\text { b. RMSEA } \leq .05: \text { Close fit } \\
.05 \leq \text { RMSEA } \leq .08: \text { Fair fit } \\
\text { RMSEA } \geq .10 \text { : Poor fit }\end{array}$ & $\begin{array}{l}\text { a. Does not satisfy } \\
\text { b. Satisfies: Fair } \\
\text { Fit }\end{array}$ \\
\hline
\end{tabular}

Participants' attitudes toward critical/negative written feedback, especially the negative effect of the critical/negative feedback on their emotions, self-confidence, and motivation negatively influence their attitudes toward asking for feedback. Moreover, it positively influences their revision decisions related to the frequency of their consideration of punishment-reward issues, authority-power issues, and the underlying motivation issues in the feedback; which are also influenced by the participants' attitudes toward the feedback providers' personality when considering asking for their feedback.

Furthermore, doctoral students' attitudes toward asking for more written feedback negatively influence their attitudes toward the feedback providers' allocated time and willingness to help the students, when students consider asking for their feedback. The latter is also indirectly influenced by participants' attitudes toward critical/negative written feedback. Also, participants' revision decisions, specifically the frequency in their consideration of the justification in the feedback, the need for revision, and their 
confidence level in what they wrote when they do not agree with the feedback, is positively influenced by their motivations in improving the field and improving themselves as academicians.

\section{Post Analyses}

During the qualitative data analyses, it has been found that the main category author characteristics have the potential to influence several other categories. Including this category and all the relationship paths toward other categories in the provisional model would have made the model too complex. Since it was not feasible to include all of these relationships in SEM analysis, two post analyses were conducted based on the results of the SEM analyses: Correlational analysis for the variables with continuous metrics and t-test for variables with categorical metrics.

\section{Data Screening, Recoding, Missing Values}

In order to meet the normality assumption of the correlation and t-test analyses, the skewness and kurtosis values of the variables were examined and no extreme values were detected. Therefore, it is assumed that the variables are normally distributed. One missing value in each of the following variables was excluded pair-wise during the analyses: age, gender, and language. Moreover, the variable that represents the participants' number of written journal articles were recoded in a way that 10 or more articles were recoded as 10. The items of the factor "Attitudes- Critical Feedback" were not reverse-scaled in these analyses.

For each factor in the model, a variable was created by summing the scores of their individual items. This way, eight variables were created to represent eight factors: Attitude-critical feedback, motivations, department, asking for feedback, provider-help, provider-personality, revision decisionexternal, and revision decision-justification.

\section{Correlational Data Analysis}

Correlational data analysis was conducted between two sets of variables: eight variables that represent the total score of their individual items and the variables of student characteristics which have continuous metrics (i.e. age, year in the program, perceived writing ability, and number of written journal 
articles). Correlations were computed between variables from these two different sets rather than within each set. Total of 32 correlations were computed (see Table 4-47).

Using the Bonferroni approach, when the corrected significance level is considered $(0.05 / 32=$ $0.0016), p$ value of less than 0.0016 was required. Students' written number of journal articles $(M=2.27$, $S D=2.49$ ) was found to be significantly and positively correlated to their perceived opportunities to write academic papers with faculty members in their department $(M=7.26, S D=2.22), r(274)=.20, p<.0016$. As students have more positive perceptions toward the opportunities to write academic papers with the faculty members in their department the number of journal articles they write increases, and/or as they write more journal articles their perceptions toward the opportunities to write academic papers with faculty members in their department become more positive.

There is also a significant but negative relationship found between students' written number of journal articles and students' attitudes toward feedback providers' personality when asking for feedback ( $M$ $=8.27, S D=2.05), r(274)=-.22, p<.0016$. This can be interpreted that, as students write more journal articles they consider less about the issues of the personality of the feedback provider when asking for feedback, such as whether or not they like the personality of the feedback provider, trust them, find them responsible when deciding to ask for their feedback. It is also possible to interpret that the students who consider less about the issues of the feedback providers' personality when deciding to ask for their feedback write more journal articles, or vice versa.

\section{Independent Samples $t$ Test}

For student characteristics variables which have bi-nominal metrics (i.e. gender, language, university, employment, and being at the dissertation stage or not), an independent samples $t$ tests was conducted to evaluate the relationship of these variables to the factor variables. The test was significant for six of the relationships (see Table 4-48). In all of the results equal variances were assumed based on the $F$ test results.

According to the results, female doctoral students $(n=165, M=9.55, S D=1.86)$ considered more about the feedback providers' willingness and time to give feedback when deciding to ask for their feedback than male doctoral students $(n=110, M=8.96, S D=1.90), t(273)=-2.55, p=.01$. The students 
from the two universities also differed in their mean scores of their perceptions toward the opportunities to write academic papers with the faculty members in their department. The participants from the Utah State University ( $n=116, M=7.76, S D=2.21)$ rated the perception items more positively than the participants from the University of Utah $(n=160, M=6.91, S D=2.16), t(274)=3.20, p=.00$. This reinforces the need to conduct this study in multiple institutions.

Significant mean differences were found between the scores of the students who are writing, started writing, or finished writing their dissertation $(n=80)$ and who do not $(n=196)$ regarding four of the factor variables: Motivations $t(274)=2.48, p=.01$, asking for feedback $t(274)=-3.38, p=.00$, feedback provider- help $t(274)=2.57, p=.01$, and revision decision-justification $t(274)=-2.11, p=.04$. The students who were not at the dissertation stage $(M=13.09, S D=2.09)$ had significantly higher mean scores on their motivations to contribute to the field and improve themselves as academicians compared to the students who were at the dissertation stage $(M=12.40, S D=2.14)$. Moreover, they also considered the issues of feedback providers' willingness and time to give feedback when deciding to ask for their feedback $(M=9.50, S D=1.87)$ more than the students who were at the dissertation stage $(M=8.86, S D=1.87)$.

The student at the dissertation stage $(M=9.61, S D=1.63)$ had higher mean scores on actively asking for written feedback than students who were not $(M=8.80, S D=1.89)$, and they considered the issues of justification in feedback, need to make the change, and confidence in what they wrote when they do not agree with the feedback during their revision decisions $(M=10.92, S D=1.48)$ more than the students who were not at the dissertation stage $(M=10.48, S D=1.64)$.

In the following chapter the interpretations based on these results were presented. Furthermore, recommendations for further research and implications of the study were listed. 
Table 4-47

Correlations Between Factor Variables and Students' General Characteristics

\begin{tabular}{|c|c|c|c|c|c|c|c|c|c|}
\hline & & $\begin{array}{l}\text { Attitudes } \\
\text { critical } \\
\text { feedback }\end{array}$ & Motivations & Department & $\begin{array}{l}\text { Asking for } \\
\text { feedback }\end{array}$ & $\begin{array}{l}\text { Feedback } \\
\text { provider- } \\
\text { personality }\end{array}$ & $\begin{array}{c}\text { Feedback } \\
\text { provider- help }\end{array}$ & $\begin{array}{c}\text { Revision } \\
\text { decision- } \\
\text { justification }\end{array}$ & $\begin{array}{c}\text { Revision } \\
\text { decision- } \\
\text { external }\end{array}$ \\
\hline \multirow[t]{3}{*}{ Age } & $\begin{array}{l}\text { Pearson } \\
\text { Correlation }\end{array}$ & -.01 & -.07 & -.10 & -.02 & .08 & -.02 & .08 & .08 \\
\hline & Sig. (2-tailed) & .928 & .225 & .084 & .788 & .161 & .675 & .158 & .163 \\
\hline & $N$ & 275 & 275 & 275 & 275 & 275 & 275 & 275 & 275 \\
\hline \multirow{3}{*}{$\begin{array}{l}\text { Year in } \\
\text { the } \\
\text { program }\end{array}$} & $\begin{array}{l}\text { Pearson } \\
\text { Correlation }\end{array}$ & -.02 & $-.14^{*}$ & -.04 & .10 & -.04 & $-.18^{* *}$ & .04 & -.03 \\
\hline & Sig. (2-tailed) & .762 & .024 & .533 & .084 & .464 & .002 & .478 & .668 \\
\hline & $N$ & 276 & 276 & 276 & 276 & 276 & 276 & 276 & 276 \\
\hline \multirow[t]{3}{*}{$\begin{array}{l}\text { Perceived } \\
\text { writing } \\
\text { ability }\end{array}$} & $\begin{array}{l}\text { Pearson } \\
\text { Correlation }\end{array}$ & $-.13^{*}$ & $.15^{*}$ & -.04 & -.05 & .000 & -.05 & $.13^{*}$ & .01 \\
\hline & Sig. (2-tailed) & .026 & .011 & .559 & .439 & .993 & .431 & .032 & .881 \\
\hline & $N$ & 276 & 276 & 276 & 276 & 276 & 276 & 276 & 276 \\
\hline
\end{tabular}




\begin{tabular}{|c|c|c|c|c|c|c|c|c|c|}
\hline & & $\begin{array}{l}\text { Attitudes } \\
\text { critical } \\
\text { feedback }\end{array}$ & Motivations & Department & $\begin{array}{l}\text { Asking for } \\
\text { feedback }\end{array}$ & $\begin{array}{l}\text { Feedback } \\
\text { provider- } \\
\text { personality }\end{array}$ & $\begin{array}{c}\text { Feedback } \\
\text { provider- help }\end{array}$ & $\begin{array}{c}\text { Revision } \\
\text { decision- } \\
\text { justification }\end{array}$ & $\begin{array}{c}\text { Revision } \\
\text { decision- } \\
\text { external }\end{array}$ \\
\hline \multirow{4}{*}{$\begin{array}{l}\text { Number } \\
\text { of journal } \\
\text { articles }\end{array}$} & Pearson & -.07 & .10 & $.20^{* *}$ & $.15^{*}$ & $-.22^{* *}$ & -.10 & .06 & -.05 \\
\hline & Correlation & & & & & & & & \\
\hline & Sig. (2-tailed) & .243 & .103 & .001 & .014 & .000 & .096 & .303 & .436 \\
\hline & $N$ & 276 & 276 & 276 & 276 & 276 & 276 & 276 & 276 \\
\hline
\end{tabular}

Note. ${ }^{*}$ Correlation is significant at the 0.05 level (2-tailed). ${ }^{* *}$ Correlation is significant at the 0.01 level (2-tailed). 
Table 4-48

t Test Results

\begin{tabular}{|c|c|c|c|c|c|c|c|}
\hline \multirow[b]{2}{*}{ Students' characteristics } & \multirow[b]{2}{*}{ Factors } & \multirow[b]{2}{*}{$t$} & \multirow[b]{2}{*}{$d f$} & \multirow[b]{2}{*}{$\begin{array}{l}\text { Sig } \\
\text { 2-tailed }\end{array}$} & \multirow[b]{2}{*}{$\begin{array}{l}\text { Mean } \\
\text { difference }\end{array}$} & \multicolumn{2}{|c|}{$\begin{array}{l}95 \% \text { confidence interval of } \\
\text { the difference }\end{array}$} \\
\hline & & & & & & Lower & Upper \\
\hline Gender (Male vs. Female) & Feedback Provider- Help & -2.55 & 273 & .01 & -0.59 & -1.04 & -.13 \\
\hline University (USU vs. UofU) & Department & 3.20 & 274 & .00 & .85 & .33 & 1.38 \\
\hline $\begin{array}{l}\text { Dissertation (Not at Dissertation } \\
\text { Stage vs. Dissertation stage) }\end{array}$ & Motivations & 2.48 & 274 & .01 & .69 & .14 & 1.24 \\
\hline $\begin{array}{l}\text { Dissertation (Not at Dissertation } \\
\text { Stage vs. Dissertation stage) }\end{array}$ & Asking for Feedback & -3.38 & 274 & .00 & -.82 & -1.29 & -.34 \\
\hline $\begin{array}{l}\text { Dissertation (Not at Dissertation } \\
\text { Stage vs. Dissertation stage) }\end{array}$ & Feedback Provider- Help & 2.57 & 274 & .01 & .64 & .15 & 1.13 \\
\hline $\begin{array}{l}\text { Dissertation (Not at Dissertation } \\
\text { Stage vs. Dissertation stage) }\end{array}$ & $\begin{array}{l}\text { Revision Decision- } \\
\text { Justification }\end{array}$ & -2.11 & 274 & .04 & -.45 & -.86 & -.03 \\
\hline
\end{tabular}


CHAPTER 5

\title{
DISCUSSION AND CONCLUSION
}

\author{
Summary
}

The purpose of this study was to provide an explanatory model to understand social science doctoral students' perceptions and attitudes toward different characteristics of written feedback and written feedback providers and how their revision decisions were affected by these and other factors in the feedback process. A mixed methods approach was used and data were collected in two stages from 276 doctoral students in two large midwestern universities. In the qualitative stage, interviews were conducted with 15 participants, and a questionnaire and provisional model were developed based on the qualitative data analysis results. In the quantitative stage, a) the data were analyzed by using basic statistical analyses to describe the participants’ responses to different questions in the questionnaire; (b) Exploratory and Confirmatory Factor Analyses and Structural Equation Modeling were used to explore the factors and their relationships in the written feedback process; (c) some post analyses were conducted by using correlational methods to investigate the relationship of the final factors to the participants' characteristics.

It should be noted that, in this research study the priority was given to the quantitative analysis results, as presented in Chapter 3. The role of qualitative data analysis was only to inform the quantitative phase of the study; specifically to develop a background for building a questionnaire and a hypothetical model to be used in the quantitative stage. Therefore, in this chapter, the discussions are based on the quantitative analysis results while direct quotes from interviews were used only to provide examples for readers to contextualize the quantitative results of the study. Before discussing the findings, the following limitations of this study should be considered.

\section{Limitations of the Study}

1. The use of convenience sampling procedure decreases the generalizability of the findings. The data were collected in only two large public universities of Utah, which were both research institutions with extensive social science graduate programs. 
2. The participation rates for the questionnaire are $21 \%$ for the University of Utah and $35 \%$ for the Utah State University. The participation rate for the interviews is 54\%. Some students may have chosen not to respond to the questionnaire. There is no information that the remaining doctoral students have the same perceptions and attitudes as the participants in this study.

3. The validity and reliability of the results of this study are limited to the honesty of the participants' responses to the interviews and the questionnaire.

4. Although the SEM analysis results indicated adequate fit, the final model is not the only model that fits the data. Chi-Square Test of Model Fit criterion was not satisfied although CFI and TLI indexes met the specified criteria. RMSEA value also showed that the model has a fair fit but not a close fit. Therefore, improvements can be made to the final model.

5. Because it limits the manageability of the task, interviews were not conducted within Business and Economics programs at USU.

Discussion of the Findings and Conclusions

\section{Doctoral Students’ Perceptions and Attitudes Toward Different Types of Written Feedback (Addresses Research Question 1)}

As presented in Chapter 4, according to the frequencies and percentages presented regarding descriptive data analysis results, the majority of the participants preferred sending their document and receiving written feedback electronically. They rated that they need written feedback most frequently for arguments and justifications in their paper; inclusion or exclusion of information; clarity and understandability of the statements; introduction, purpose and significance of the paper; conclusion; and consistency in the overall paper. Regarding other characteristics of written feedback, they rated that they preferred written feedback on content and arguments, organization and flow, and grammar. They liked to have written feedback which is straightforward; gives them clear instructions about how to revise their paper; provides suggestions for improvement; strengthens the direction of the paper; directs them to other related resources; is more detailed/specific than overall/general; is given based on only what is on the paper, not based on their previous papers; has balanced positive and critical/negative comments; has 
comments in which negative things are said in a more positive way; has a suggestive tone more than an authoritative tone; is not given because of a personal preference only.

Some of the results were parallel to the findings of Eyres et al. (2001). For example, most of the doctoral students participated in this study also preferred to have comments to strengthen their arguments, comments for clarity and understandability of statements, balanced positive and critical/negative comments, and specific comments more than overall praise comments.

While rating their preferences of written feedback, most of the doctoral students who participated in this study did not only consider the content of the written feedback relevant to their paper, but they also frequently considered the tone of the written feedback. Correspondingly, in her practical guide, Bolker (1998) suggested doctoral advisors be careful about the tone of the feedback, start their feedback with positive comments before the critical ones, and give very negative feedback in a gentle way. One of the reasons for these preferences can be explained by the description of Eyres et al. (2001) as follows:

There is a sense of vulnerability during the struggle to get beyond feeling like an outsider and novice. Because students perceive their writing as part of themselves, they can feel abused during this sensitive transition time if their written ideas are 'corrected' or are called 'incorrect' without the teacher first exploring with them the budding ideas behind the words on the paper. (p. 152)

Specifically regarding the participants’ attitudes toward critical/negative written feedback, 62\% of the participants rated that critical/negative written feedback affects them emotionally. However much fewer participants rated that these types of feedback negatively affect their self confidence or motivations. Thus, it is possible that most of the students in this $62 \%$ might be able to control their emotions in a way that they do not lose their self confidence or motivations when they receive critical/negative written feedback. Concerning this issue, Caffarella and Barnett (2000) found that as participants practice giving and receiving critiques and also as time passes, their anxieties diminished and self confidence in their writing improved. During the post analyses, however, no significant correlation was found between the students' year in the program and their attitudes toward critical/negative written feedback, especially regarding its affect on their emotions, self confidence, or motivations. This result might be related to students' different writing and feedback experiences. 


\section{Doctoral Students' Perceptions and Attitudes Toward Different Characteristics of Written Feedback Providers (Addresses Research Questions 2 and 4)}

The participants rated the characteristics of the feedback providers that they find important when deciding to ask for their written feedback. Descriptive data analysis results showed that, according to the majority of the participants it is important to feel comfortable while soliciting written feedback and not feeling like a burden to the feedback providers. They found it important that the potential written feedback provider is willing to help and has time for them. Similarly, the participants also reported that they feel most comfortable asking for written feedback from the professors in their committees, while they feel less comfortable asking for written feedback from other professors outside of their committees and other doctoral students. To understand the reasons behind this finding, additional research is needed. Two example speculations might be suggested beyond the data, regarding the reasons of doctoral students to feel more comfortable asking for written feedback from the professors on their committees: (a) the students might form their committees with professors who are already willing to help them and have time for them; and (b) the students think that it is part of the doctoral committee's role to assist in their academic writing. SEM analysis results showed that when students are active seekers of written feedback, this will influence them to be concerned less about the feedback providers' willingness or time to give feedback. Therefore, high percentages of ratings on the items related to comfort in asking for feedback might suggest that the participants in this study might not be very frequent written feedback seekers. The ratings on the items related to asking for written feedback are also parallel to this inference. While $91 \%$ of the participants rated that they ask for written feedback, only around $65 \%$ rated that they look for several written feedback occasions at different stages of their writing, and only $72 \%$ rated that they look for written feedback from several people.

In the literature, it has been found that doctoral students want feedback for multiple drafts (Eyres et al., 2001) and their confidence improves as they receive ongoing feedback (Caffarella \& Barnett, 2000). However, according to the findings of this current study, 28\% of the participants do not ask for written feedback from several people and 35\% of the participants do not ask for several written feedback occasions at different stages of their writings. Based on the SEM results, it can be suggested that perceived 
opportunities to write academic papers with faculty members might be one of the influential factors for not asking for ongoing feedback or feedback from multiple providers. As students perceive that there are few opportunities to engage in collaborative writing activities with faculty members, this might negatively affect their motivations for academic writing to contribute to the field, improve themselves as academicians, and have recognition in the field. This, in turn, negatively influences their feedback seeking attitudes. This relationship is further explained in detail in the following section.

Aside from these findings, possible speculative explanations beyond the data for $28-35 \%$ of the participants not asking for feedback frequently can be following: (a) the participant doctoral students might not need to ask for written feedback because they already receive ongoing written feedback and feedback from multiple feedback providers; (b) they do not request it although they want this kind of feedback; and (c) different from the literature findings, this large percentage of doctoral students actually do not prefer or need to have written feedback for multiple drafts or written feedback from multiple providers. This is another area for further research.

Another quite frequent consideration of the characteristics of the feedback providers that affect doctoral students' decisions regarding asking for written feedback is the feedback providers' skills, especially their thinking, organizing, analyzing, and writing skills based on the descriptive data analysis results. The participants found the feedback providers' thinking and writing skills are more important when deciding to ask for their written feedback compared to the feedback providers' knowledge level in the content area that their paper is about or whether or not the feedback providers are in the same discipline. As the types of written feedback listed in the previous section, it can be seen that not all of them require the content knowledge of the feedback provider, such as written feedback for the clarity and understandability of the statements, consistency in the overall paper, and organization and flow of the paper.

The Influence of Perceived Opportunities to Write Academic Papers with

Faculty Members on Doctoral Students' Motivations for Academic Writing (Addresses Research Question 4)

According to the SEM analysis results, the doctoral students' perceptions toward available 
opportunities to write academic papers with faculty members influence their motivations for academic writing to contribute to their field, improve themselves as academicians, and have recognition in the field. Moreover, during the post analyses, a positive significant correlation was found between these perceptions toward the available opportunities to write academic papers with faculty members and the students' number of written journal articles. These relationships can be explained in the framework of Situated Learning and Communities of Practice (Lave \& Wenger, 1991).

As presented in Chapter 2, participation in the actual practices and the activities of the full participants can help doctoral students to improve their knowledge and skills, learn the criteria and conventions of the discipline, and build their identity in the academic community. The available opportunities to write academic papers with faculty members imply the available opportunities to participate with the support of experienced community members to produce publishable products. Perceived availability of this support, therefore, might shift their motivations to write academic papers toward becoming a full participant by contributing knowledge to the field; sharing their ideas and findings with other members; gaining experiences, skills, and knowledge as academicians; and building recognition in the field. As stated by Walker et al. (2008), "doctoral students bring different motivations to their work, but for most of them passion for the field tops the list....[T]hey want and expect to be surrounded by others who share their passion; they long to be part of an intellectual community” (p. 121). Therefore, the collaboration with the members of the academic community would further increase their motivation to socialize and integrate within it.

Another relevant speculative interpretation of this result is that faculty members writing with their students might be perceived by doctoral students as faculty members acknowledging their skills and knowledge, treating them as colleagues, and accepting them as participants of the academic community. This acknowledgment, in turn, might shift and promote their motivation to contribute to the field and develop their skills more. Acknowledgement will also encourage them to increase their participation in the practices of the academic community with their academic writing.

Lovitts (2001) explained,

Professional socialization takes place most effectively through collaboration. When students apprentice to a master they learn the formal and informal art of the trade. Thus, advisers who work 
closely with their students not only will have a higher frequency of interaction with their students but also will facilitate their students' intellectual development and professional socialization to a greater degree than those who do not. (p. 146)

Peters (1992) also listed several advantages of graduate students coauthoring with their advisors. Aside from getting guidance from them to produce good quality papers, it may make it easier for their papers to be published and increases the students' reputations if their advisors are well-known in the field. However, when there are problems with students' integration into the academic communities, it becomes not only harder to obtain these outcomes, but this even leads to student' attrition (Lovitts, 2001).

The collaborative writing opportunities with faculty members can be in the form of research projects, grants, or individual papers of the faculty in which faculty need or want doctoral students' collaboration. As explained by one of the interview participants quoted below, these opportunities can be sought by students. Walker et al. (2008) stated that learners who are self regulated about their own learning and development proactively pursue their goals, look for learning opportunities to improve their learning, and have several mentors.

The following interview participant's opinions illustrate these relationship that the perceived available opportunities to write with faculty members shift their motivation more toward contributing to the field and improving their skills as academicians.

It's [academic writing] obviously enjoyable because I get to do the research that I want with certain faculty members, and then of course the products out of that are writing and publication and also presentations at conferences, so. You know it's part of the life of academia and if you want, in my opinion, to excel in the academic field, you know, the one way to do it is obviously publications, it's the gold standard. So. I think they really do a good job here preparing us for that mentality of, really, if you wanna academic position then, you need to publish, so, that's really what they push here....My motivations were really to get the experience, you know, they really train us here to be academicians and part of the academicians' position or job is to really provide outside funding and also write publications. So, having those skills is not something you just get automatically, it requires a lot of practice and exposure. And so, you know, having those opportunities, we're very productive department, so you know, everyone's always writing some sort of grant or some sort of publication, do some sort of research, and so, just asking to be part of that is really nice, everyone is really open here, so, I can go to see $<$ Instructor $X>$, and say "hey are you writing a X grant?”, he is like "yes”, “do you need help?”, he's like, "sure, and what section do you wanna write?", "I can write the significance section, I can write the introduction", whatever, so. You know, taking some of the initiative from the student side....I think that the more experience you have towards grant writing or publications, the easier comes you know, and is definitely a learning process (laughing) [Participant 12].

About colleague-to-colleague relationship that he has with his committee members, same participant stated: 
I look at him [one of the committee members] as you know, my superior and, but they [committee members] don't treat me as a you know as a student, they really treat me as a colleague and they help shape my writing and as very open here as, one of the reasons why I was attracted to this department was just the openness of the department, and everyone willing to help and no one makes you feel like you're stupid or anything like that, it's always a "oh well, like, this is one way to do it” you know, “try reading this section and doing this”, and it’s really helpful, I really enjoy that part [Participant 12].

In short, as illustrated in these quotations, in the process of developing their identity in the academic community, doctoral students can make use of the opportunities to write with more experienced writers and researchers who have similar motivations and interests. This will further increase their motivations to integrate into the academic communities of their disciplines.

The Influence of Perceived Opportunities to Write Academic Papers with Faculty Members and Doctoral Students' Motivations for Academic Writing on Their Attitudes of Actively Asking for Written Feedback (Addresses Research Question 4)

SEM analysis results also showed that doctoral students' motivations for engaging in academic writing activities to contribute to the field, improve themselves as academicians, and have recognition in the field positively influence their attitudes toward actively asking for written feedback. This relationship suggests that students might perceive feedback as a means to fulfill these motivations while writing academic papers. One participant explained his purpose of asking for written feedback from his committee members and chair as follows:

Maybe because I wanna get through like preliminary peer review. If my committee and mentors, if they like it and they stamp it and say "yep, this is good”, then when I submit it for publication, it has a better chance of being accepted or published [Participant 4].

Not only advisers and committee members, but the feedback from peers can also be useful for doctoral students to have, as "a rehearsal for the peer review that occurs in professional academic settings" (Coffin et al., 2003, p. 40). Efforts to increase the publishability of their products or to familiarize with the feedback process in academic settings are based on the students' motivations to integrate into the academic communities. Consequently, it is expected that the doctoral students ask for written feedback more frequently and actively as they are more motivated to become full participants.

The perceived opportunities to write academic papers with faculty members was also found to 
have a significant but indirect influence on the participants' attitudes of actively asking for written feedback. It can be suggested that faculty members' perceived attitudes toward doctoral students' participation in the academic practice collaboratively with them might also encourage students to ask for more help in the form of written feedback. One of the interview participants' quotes illustrates this relationship:

She's [course professor] fantastic, she has written a book, she is a guru in <discipline>, but she would came to me and say "ok, before I submit this article, give me your feedback on this article", kind of thing. So, and it's wonderful now, because, I am, I have two professors now that have said "we've got to write an article together as soon as you get this [dissertation] edited. And so, I am learning humility I think. I am learning from them how to say this "I really need feedback on it" and I am learning to when they say, when they start the crossing out and the revising in that, I am learning to think "wow, you really did make this better, this is really great!" kind of thing [Participant 13].

Another possible reason is that since collaborative writing requires a lot of communication between authors, it is expected that the doctoral students ask for more frequent feedback from their coauthors. Furthermore, these collaborative writing activities and feedback practices might help to build the collaborative relationship between the student and the faculty, and the student might feel comfortable asking for the faculty's feedback frequently, as one of the interview participants stated below.

I think the more, the better relationship you have, then the more closely you work with those people and that just kind of sets in motion that cycle of going to those people for more feedback and more feedback and then you forge those relationships [Participant 11].

Consequently, it is possible that developing a colleague-to-colleague relationship with the students, coauthoring academic papers with them, and giving and receiving feedback might encourage students to ask for written feedback more actively and frequently when students are motivated to contribute to the field, improve themselves as academicians, and develop their reputation in the field. As explained in the previous sections, in the reverse case, however, doctoral students might ask written feedback less frequently as explained in the previous section considering around 28-35\% of the participants.

\section{The Influence of Doctoral Students' Motivations for Academic Writing on}

Their Revision Decisions (Addresses Research Question 3)

Based on the descriptive data analysis results, in the case of disagreement with the written feedback comments, most of the participants rated that they consider the issues of justification in the 
feedback, the need for revision, their confidence in what they wrote, and how the revision will influence the direction of their paper. Also, according to the SEM analysis results, the participants' motivations for academic writing to contribute to the field and improve themselves as academicians positively and significantly influence some of their revision decisions when they do not agree with the feedback. When students' motivations for academic writing are focused on contributing to the field and improving themselves as academicians, this leads them to frequently question the justification in the feedback, the need for revision, and their confidence in what they wrote.

The following example illustrates this relationship. A participant whose motivations for academic writing are to share his ideas with others and to improve his vita for job applications described the issues that affect his decisions to accept or reject a feedback comment as follows:

Their justification. Do I agree with their justification, because if I do, then the cause is good, and then I’ll take a look at what their specific suggestion is, if they, cause they may say "revise this" and then they'll say, "and this is how". Well, those are two separate things. So, their justification will help me accept whether or not it needs revision, then I can evaluate their suggestion to see if I want to do it that way or not. So their justification plays a lot into determining [Participant 5].

Moreover, students' frequent questioning of the justification, need for making the change, or confidence in what they wrote shows that they might have confidence in their writings and/or they might feel less open to revise their papers when they do not agree with the feedback. This relationship can be further interpreted with another result of this study. During these conflicting situations, the participants who were at the dissertation stage considered the issues of justification in feedback, the need for change, and confidence in what they wrote significantly more often than the participants who had not started writing their dissertations. Therefore, it is possible to suggest that as students move toward the end of the program, they become more confident in their writing and become more resistive to revise their writings when they do not agree with the feedback. One interview participant explained her reasons based on her age and experience level.

I don't accept all of them. I think that partly has to do with my age. And this isn't my first career. I think if I were, you know, 22-23 I might just accept all of them, because I might accept on faith that the reviewers have more experience and more wisdom than me. I don't always believe that, so I think usually the feedback, even if I disagree with it, I can see the logic behind it, so, if I don't see the logic, or if something in my head is going “this guy's crack cocaine”, I don't accept it (laughing). Sometimes reviewers don't know what they're talking about. Especially, you know, my emphasis is in <discipline name>, sometimes it's hard for them to give me feedback on that, 
because they just have no idea. So, if it sounds intelligent and if it makes sense, I would change it [Participant 6].

Foss and Waters (2007) stated that how students manage feedback affects their professional images. They suggested doctoral students listen to critiques and suggestions and accept feedback; however, they also suggested students respond to these critiques and suggestions, defend their ideas, and negotiate for revisions when necessary. They described defending one’s ideas as "scholarly behavior” (p. 318). Accordingly, the result of this study can be interpreted in that as students are more motivated to develop their academic identity with their writings, they increase their competence to defend their ideas and thus engage in this scholarly behavior.

\section{The Influence of Doctoral Students' Attitudes Toward Critical/Negative Written}

\section{Feedback on Their Attitudes of Actively Asking for Written}

\section{Feedback (Addresses Research Question 4)}

Based on SEM analysis results, the participants' attitudes toward critical/negative written feedback regarding their emotions, self confidence, and motivations influence their attitudes of actively asking for written feedback. When there is less negative effect of critical/negative feedback, this leads to positive attitudes toward actively seeking for written feedback for their academic papers, from several people, and on several drafts. It can be suggested that when doctoral students are scared to have critical-negative feedback, and when they feel embarrassed, lose self confidence and motivation after receiving criticalnegative feedback, they refrain from actively asking for written feedback. The following two quotations from interview transcripts illustrate this interpretation.

When I was a new graduate student, yeah, I was scared to ask for feedback, cause I didn't want negative, I was scared about getting negative feedback. And most professors know and most peers know that a new graduate student, they're scared and they're nice, so they say nice feedback and things, unless it's gonna be published, then, they're really mean (laughing).... Now, I want it, "tell me what's bad, and what's bad, tell me”. But, cause I spent so much time writing and practicing and I didn't want negative, I just wanted you to tell me that it was a great paper. So, I didn't ask for feedback as much as I should've in my first or second year as a grad student. Where now, I, even if my papers are really bad...."here, give me feedback" [Participant 4].

Similarly, another participant explained his reason for not asking for written feedback for his writings until he is satisfied with the quality of his papers: 
For me, personally, I tend to not to show my work if I feel like it’s not ready. Which maybe a detriment because I am not inclined to take a real rough draft and share it with someone for review. Because I don't want to expose myself to that level. And maybe that's a detriment, maybe if I got more out to people, I would get some good criticism back and it will probably move along faster. But I would tend to avoid situations like that....I have an expectation, and if my paper has not reached my expectation, then I don't give it out for review of any kind....Because I don't want overly negative criticism. I wanna make sure it's to a level that I can have a pretty good expectation of the criticism that's gonna come back [Participant 5].

In the reverse case, when students feel that they are less affected by critical/negative written feedback they actively ask for written feedback to improve their writings. An interview participant who actively asked for written feedback from different people and several times at different stages of his writings explained the following:

I know that no one is perfect, and so, certainly I know my writing is not perfect and I know that I'm probably gonna learn throughout my entire career, how to write....[E]veryone gets criticized and you just need to learn to take it and say, "ok what can I take away from this, how can I improve?”...I think, as the more feedback I get the happier I am because...it’s just, it makes me a better writer and even if I reject some of the feedback, it's still useful, because, I can see where they're coming from, and I can see why they've said it [Participant 12].

\section{The Influence of Doctoral Students’ Attitudes of Actively Asking for Written \\ Feedback on Their Consideration of Feedback Providers' Helpfulness and Time (Addresses Research Question 4)}

Regarding the significant but negative influence of students' attitudes toward asking for written feedback on the students' attitudes toward the feedback providers' willingness and time to provide feedback (SEM analysis finding), it can be suggested that students' active feedback-pursuit attitude influences them to consider less about the potential feedback providers' willingness or time to give them feedback when they decide to ask for their feedback. Furthermore, during the post analyses, it has been found that the students who started writing their dissertations ask for feedback more actively and frequently than the students who are not at the dissertation stage, as also presented in the previous section by Participant 4. Moreover, these students are concerned less about the feedback providers' time or willingness to give them feedback compared to the latter group. It is possible that some of the students at the dissertation stage might be inclined to ask for feedback more actively and frequently, considering that they might not get enough feedback later when they graduate, as discussed by Participant 11. 
Part of my motivation was knowing that, if you really wanna be successful in our field, you have to be a good writer, you have to produce works and whether it's one format or another, you know, something you have to be competent in, and so, I feel like the more practice I get on all of these things the better because, very soon I'm going to be in a position where, I won't be able to get as much feedback from them....I would like more, I don't think there is ever enough feedback, and you know, if there is a way to get more, I would be open to it, but everybody gets really busy with their lives and I think in their eyes, we get to a point where you know, they wanna set us free and have us fly on our own eventually and so the feedback tends to, well actually to the dissertation process, it has been great. You know, but I know that that will end soon [Participant 11].

Walker et al. (2008) also stated that students and their mentors spend more time together in the students' last year in the program. They further reported that some of the faculty who participated in their study explained that they spend more time with students who are "proactive” (p. 107). In short, doctoral students who have attitudes of actively asking for written feedback and students who are writing their dissertation are less likely to be concerned about the feedback providers' willingness or time to give them feedback.

\author{
The Influence of Doctoral Students’ Attitudes Toward Critical/Negative Written \\ Feedback and their Attitudes of Actively Asking for Written Feedback \\ on Their Consideration of Feedback Providers' Helpfulness \\ and Time (Addresses Research Question 4)
}

The significant and indirect influence of students' attitudes toward critical-negative feedback on their attitudes toward feedback providers' willingness and time to provide feedback informs that the more the students are negatively affected by the critical/negative written feedback, the more they are concerned about the issues feedback providers' willingness and time to help them and they do not want to be a burden for them. One interpretation for this SEM analysis finding is that these students might not be used to asking for written feedback because they do not want to receive potential critical/negative written feedback. And because they are not used to asking for written feedback, they might not feel comfortable with the feedback providers and the feedback process.

As presented by Walker et al. (2008), in a good apprenticeship relationship, the mentor is willing to help the student and invest time in them. Also, the student is active and regulates his or her own learning. To cultivate this apprenticeship relationship, it is important for mentors to invest their time with students 
and provide regular feedback to them on their progress (Walker et al.). In this kind of reciprocal relationship, it is expected that the students would not be concerned with being a burden to their mentors when they ask for their feedback, or would not need to make sure their mentors are willing to give them feedback.

Most of the interview participants in Lovitts' study (2001) who did not complete their doctoral degree reported that they had limited academic and social interaction with the faculty and their advisors. Their interaction with other doctoral students also diminished over time. They found their faculty was not open to students and not interested in building relationships with them. They had bad experiences with faculty who they found cold and intimidating, and too busy, or not available for them. On the other hand, most of the participants reported good experiences with faculty with whom they had academic and social interactions, who were friendly and open, who were interested in students' progress and cared about them, and who were available and had time for the students. The degree completers found their advisor very helpful. Among their reasons of satisfaction with their advisors, some noted the useful and quick feedback they received from them.

Consequently, as some students whose emotions, self confidence, and motivations are negatively affected by the critical/negative written feedback, it is possible that they are also affected by the feedback providers' attitudes toward the students, especially their helpfulness or negligence. This, in turn, reflects on their decisions in whether to ask for their written feedback or not.

\section{Influence of Doctoral Students’ Attitudes toward Critical/Negative Written Feedback and Attitudes Toward the Feedback Providers' Personality on Their Revision Decisions (Addresses Research Question 3)}

The SEM analysis results showed that participants’ attitudes toward critical-negative written feedback, especially the effect of feedback on their emotions, self confidence, and motivations, influence their revision decisions when they do not agree with the feedback. When the negative effect of the criticalnegative feedback on their emotions, self confidence, and motivations is stronger and when they receive feedback that they do not agree with, this influences them to more frequently consider the issues of 
punishment-reward, authority-power relationships with the feedback provider and feedback providers' motivation for giving that feedback. This suggests that the negative emotional effect of feedback might lead students to think more about the conditions under which the feedback is given. A participant's following sentences illustrate this relationship:

Sometimes journal reviewers give you snotty feedback (laughing). It's very, kind of rude, kind of harsh, more putting you down and, you know, kind of makes you wonder if there is some other agenda [Participant 6].

Eyres et al. (2001) also reported that doctoral students considered the feedback providers' motivations while examining feedback. They appreciated feedback when they perceive that the feedback provider was trying to be helpful.

During the descriptive data analysis, the participants rated that it is important whether or not they trust the feedback provider as a person or whether or not he/she is a responsible person. Moreover, as SEM analysis results showed, doctoral students' consideration of whether or not they like the personality of the feedback provider, trust them, or find them responsible before asking for their feedback also influences them to consider punishment-reward, authority-power relationships, and the motivations of the feedback provider. In the following, an interview participant explained how the personality of the feedback provider affects her revision decisions and consideration of power relationships.

Actually I think the person who gave me feedback also determines whether I will revise it or not. For example, the person's characteristics, personality will affect what I will fix in the paper. And perhaps, sometimes I don't like some feedback because I don't like the person who gave me the feedback.... Those kind of persons I don't like, give me a lot of feedback. Like I just said, like those feedback, it's hard to improve. I think some persons, they just like to, because they are teachers, they just like to teach you.... [T] hey're like a commander, and they're higher level than you. And so they need to point out everything [Participant 2].

Similarly another participant stated the following:

There are some people that I have a hard time taking feedback from. And it’s probably my own personal-, personality problems with that person....Even if I don't have a good social relationship with them sometimes, I will often still revise. But I will be more-, but I'll look at their feedback more carefully to make sure they're giving me actual feedback for the article or jour- or piece that I am writing, instead of just giving me like personal feedback about my personality [Participant 3].

The following quote of an interview participant demonstrates the relationships among the factors of attitudes toward critical-negative feedback; attitudes toward the personality of the feedback provider; and revision decisions considering the issues of punishment-reward, authority-power relationships, and the 
motivation of the feedback provider.

Some of his [his chair] comments maybe, because of his personality I guess or I think more of his power position, sometimes become, sometimes are viewed by me at least, as being overly critical. And maybe, I think that's the power relation. I mean, I end up correcting everything probably because of that power relationship, because he is the department head, because he's the chair of my committee. Because he's extremely well known in the field, that, that power relationship does sometimes make it seem overly critical.... When I first got to know her [a committee member], I felt that she was being overly critical. Because, you know, I did not have the experience of getting a paper back and have it being just written all over everywhere, I mean comments everywhere. And the first that sort of, in terms of your self confidence that doesn't necessarily improve upon your self confidence (slightly laughing) when you get a paper with that many comments on it. But once you get to know her, once you understand her and once you sort of go through her comments systematically, you understand what she's doing. And then, once you get to know her on a personal level as well that that improves [Participant 14].

He also stated:

Being able to be approachable, I think is important. Feeling comfortable with that person is always, it's not mandatory, but I think it's helpful, to feel like that person is approachable and feel like you can go talk to them at any point in time, and you know, free manner....I think intimidation by that person causes you to be a little bit more defensive. And maybe that mentally affects how you consider fixing what they're telling you to fix. And if you feel more intimidated, or you feel like they're sort of trying to put you down, or put you in your place then, then maybe you become, you become more of a person, that's offended by that [Participant 14].

In short, the conditions under which the feedback is given, the feedback provider, and students'

attitudes affect the students' revision decisions. Foss and Waters (2007) similarly described this

relationship as follows:

Asking for and accepting feedback also involves professionalism. When you submit papers or program proposals for presentations at professional conventions, essays to journals, or proposals to book publishers, you will be receiving feedback. How you handle that feedback often determines how quickly you advance in your career. At the dissertation stage it can determine how quickly you progress on your dissertation and how much of a professional you appear to your advisor. There's no doubt about it: Accepting feedback is difficult, and it's especially so when it comes from someone you respect and really want to impress. (pp. 317-318)

\section{Conclusion}

This study provided descriptive information on doctoral students’ perceptions and attitudes toward different characteristics of written feedback and written feedback providers, and an explanatory model to portray the relationship of several factors in the feedback practices of the doctoral students. According to the results, most of the participants felt they need written feedback mostly for arguments and justifications, inclusion and exclusion of information, and clarity and understandability of the statements. They preferred 
written feedback that provides suggestions and clear instructions for revisions, strengthens the direction of their paper, and directs them to other related resources. The balanced positive and negative comments in the feedback were also preferred. Regarding the characteristics of the feedback providers that they find important when they decide whether or not to ask for their feedback, the majority of the participants rated the feedback providers' willingness and time to give feedback; thinking, organizing, analyzing, and writing skills; and trust and responsibility.

The doctoral students' perceived opportunities to write academic papers with faculty members influence them to become more motivated to contribute to the field and improve themselves as academicians, which, in turn, also leads them to ask for written feedback more actively to improve their writings. As they are more active feedback seekers, they tend to worry less about whether or not the feedback provider is willing to help them or have time for them. However, when students have negative attitudes toward critical/negative written feedback, this influences them to refrain from asking for written feedback.

The revision decisions of the doctoral students are affected by their motivations for academic writing, their attitudes toward critical/negative written feedback, and their attitudes toward feedback providers' personality, trust, and responsibility. The students' motivations for academic writing to contribute to the field and improve their academic skills affect them to check the justification in the written feedback more frequently while revising their writings. Moreover, their negative attitudes toward critical/negative written feedback and attitudes toward the personality, trust, and responsibility of the feedback provider lead them to frequently consider the issues punishment-reward, authority-power relationships, and underlying motivations of the feedback provider as well.

In short, there are several factors that affect doctoral students' written feedback practices, including their attitudes toward different types of feedback, their relationships with the feedback providers, and so forth. Some of these relationships were explored and discussed in this study. Further research would be useful to retest or extend the findings of this study as presented in the following section. 
Recommendations for Further Research

Several research studies could be conducted to further explore the questions addressed in this study. Some of the suggestions are provided below.

1. The second stage of the study can be repeated with a larger and more diverse sample of social science doctoral students in similar institutions to increase the generalizability of the results. Replication studies can be conducted with natural science and ESL doctoral students.

2. Doctoral students' written feedback practices particularly in virtual environments can be investigated.

3. The relationships between the main factors resulted in the final model can be further explored by developing and using a new questionnaire that includes more items relevant to each main factor.

4. Research studies can be conducted to explore each relationship in the final model individually.

5. Further interviews can be conducted to explore other important and relevant factors in the feedback process so that the model can be enhanced.

Implications

The results of this study have several implications. First, this study provided a model that can be used as a conceptual framework for doctoral students and feedback providers. They may compare the model to their own relevant experiences and opinions. This may facilitate inner and external dialogue of doctoral students and feedback providers about the written feedback practices of the doctoral students. This dialogue may help doctoral students to further question and recognize their own perceptions and attitudes regarding their written feedback practices. It may also stimulate feedback providers' consideration of different factors in the feedback process that affect the use of their feedback.

Second, individual feedback providers may consider this model and the opinions of the majority of the participants presented in this research study while they are giving feedback to doctoral students. Moreover, in line with the results of this study, social science programs might consider encouraging faculty members to write more with their doctoral students to help their integration into the academic communities of their disciplines. Also, academic writing groups could be formed and sustained by the departments to 
increase the feedback opportunities of doctoral students as well as peer support. Finally, this study might lead to similar research studies that may collectively provide a more extensive framework for understanding the students' attitudes and perceptions related to their feedback practices. 


\section{REFERENCES}

Auerbach, C. F., \& Silverstein, L. B. (2003). Qualitative data: An introduction to coding and analysis. New York: New York University Press.

Bartlett, A., \& Mercer, G. (Eds.). (2001). Postgraduate research supervision: Transforming (r)elations. New York: Peter Lang.

Becher, T., \& Trowler, P. R. (2001). Academic tribes and territories: Intellectual enquiry and the culture of disciplines (2nd ed.). Buckingham, UK: Open University Press/ SRHE.

Biklen, S. K., \& Casella, R. (2007). A practical guide to the qualitative dissertation. New York: Teachers College Press.

Bolker, J. (1998). Writing your dissertation in fifteen minutes a day: A guide to starting, revising, and finishing your doctoral thesis. New York: Henry Holt and Company.

Bradburn, N. M., Sudman, S., \& Wansink, B. (2004). Asking questions: The definitive guide to questionnaire design - For market research, political polls, and social and health questionnaires (Rev. ed.). San Francisco: Jossey-Bass.

Brown, T. A. (2006). Confirmatory factor analysis for applied research. New York: The Guilford Press.

Browne, M. W., \& Cudeck, R. (1993). Alternative ways of assessing model fit. In K. A. Bollen \& J. S. Long (Eds.), Testing structural equation models (pp. 136-162). Newbury Park, CA: Sage.

Caffarella, R. S., \& Barnett, B. G. (2000). Teaching doctoral students to become scholarly writers: The importance of giving and receiving critiques. Studies in Higher Education, 25(1), 39-52.

Campbell, D. T., \& Stanley, J. C. (1963). Experimental and quasi-experimental designs for research. Boston: Houghton Mifflin.

Carless, D. (2006). Differing perceptions in the feedback process. Studies in Higher Education, 31(2), 219233.

Cattell, R. (1966). The Scree test for the number of factors. Multivariate and Behavioral Research, 1, 245276. 
Cho, K., Schunn, C. D., \& Charney, D. (2006). Commenting on writing - Typology and perceived helpfulness of comments from novice peer reviewers and subject matter experts. Written Communication, 23(3), 260-294.

Cialdini, R. (1993). Influence: Science and practice (3rd ed.). New York: HarperCollins.

Coffin, C., Curry, M. J., Goodman, S., Hewings, A., Lillis, T. M., \& Swann, J. (2003). Teaching academic writing: A toolkit for higher education. New York: Routledge.

Coyle, A. (2007). Introduction to qualitative psychological research. In E. Lyons \& A. Coyle (Eds.), Analysing qualitative data in psychology (pp. 9-29). Thousand Oaks, CA: Sage.

Creswell, J. W. (2003). Research design: Qualitative, quantitative, and mixed methods approaches (2nd ed.). Thousand Oaks, CA: Sage.

Creswell, J. W., Clark, V. L. P., Gutmann, M. L., \& Hanson, W. E. (2003). Advanced mixed methods research designs. In A. Tashakkori \& C. Teddlie (Eds.), Handbook of mixed methods in social and behavioral research (pp. 209-240). Thousand Oaks, CA: Sage.

Delamont, S., Atkinson, P., \& Parry, O. (2004). Supervising the doctorate: A guide to success (2nd ed.). Berkshire, UK: Open University Press/ SRHE.

Dillman, D. A. (2007). Mail and Internet surveys: The tailored design method (2nd ed.). Hoboken, NJ: John Wiley \& Sons, Inc.

Eyres, S. J., Hatch, D. H., Turner, S. B., \& West, M. (2001). Doctoral students' responses to writing critique: Messages for teachers. Journal of Nursing Education, 40(4), 149-155.

Fabrigar, L. R., Wegener, D. T., MacCallum, R. C., \& Strahan, E. J. (1999). Evaluating the use of exploratory factor analysis in psychological research. Psychological Methods, 4(3), 272-299.

Foss, S. K., \& Waters, W. (2007). Destination dissertation: A traveler's guide to a done dissertation. Lanham, MD: Rowman \& Littlefield Publishers, Inc.

Gagné, R. M. (1985). The conditions of learning and theory of instruction (4th ed.). New York: Holt, Rinehart and Winston.

Gagné, R. M., Briggs, L. J., \& Wager, W. W. (1992). Principles of instructional design (4th ed.). Belmont, CA: Holt, Rinehart and Winston. 
Gall, M. D., Gall, J. P., \& Borg, W. R. (2003). Educational research: An introduction (7th ed.). Boston: Allyn and Bacon.

Gosling, P., \& Noordam, B. (2006). Mastering your PhD: Survival and success in the doctoral years and beyond. Germany: Springer.

Green, S. B., \& Salkind, N. J. (2005). Using SPSS for Windows and Macintosh: Analyzing and understanding data (4th ed.). Upper Saddle River, NJ: Pearson Prentice Hall.

Hair, J. F. J., Anderson, R. E., Tatham, R. L., \& Black, W. C. (1998). Multivariate data analysis (5th ed.). Upper Saddle River, NJ: Prentice Hall.

Hatcher, L. (1994). A step-by-step approach to using the SAS system for factor analysis and structural equation modeling. Cary, NC: SAS Institute Inc.

Holstein, J. A., \& Gubrium, J. F. (Eds.). (2003). Inside interviewing: New lenses, new concerns. Thousand Oaks, CA: Sage.

Hu, L., \& Bentler, P. M. (1999). Cutoff criteria for fit indices in covariance structure analysis:

Conventional criteria versus new alternatives. Structural Equation Modeling, 6, 1-55.

Hyland, K. (2004). Disciplinary discourses: Social interactions in academic writing. Ann Arbor, MI: The University of Michigan Press.

IHMC. (2008). Institute for Human and Machine Cognition Cmap Tools. Pensacola, FL.

Kamler, B., \& Thomson, P. (2006). Helping doctoral students write: Pedagogies for supervision. New York: Routledge.

Kelloway, E. K. (1998). Using LISREL for structural equation modeling: A researcher's guide. Thousand Oaks, CA: Sage.

Kim, L. (2004). Online technologies for teaching writing: Students react to teacher response in voice and written modalities. Research in the Teaching of English, 38(3), 304-337.

Kumar, V., \& Stracke, E. (2007). An analysis of written feedback on a PhD thesis. Teaching in Higher Education, 12(4), 461-470.

Lave, J., \& Wenger, E. (1991). Situated learning: Legitimate peripheral participation. New York: Cambridge University Press. 
Lavelle, E., \& Bushrow, K. (2007). Writing approaches of graduate students. Educational Psychology, 27(6), 807-822.

Lincoln, Y. S., \& Guba, E. G. (1985). Naturalistic inquiry. Beverly Hills, CA: Sage.

Lovitts, B. E. (2001). Leaving the ivory tower: The causes and consequences of departure from doctoral study. Lanham, MD: Rowman \& Littlefield.

MacCallum, R. C., Widaman, K. F., Zhang, S. B., \& Hong, S. H. (1999). Sample size in factor analysis. Psychological Methods, 4(1), 84-99.

MacDonald, S. P. (1994). Professional academic writing in the humanities and social sciences. Carbondale: Southern Illinois University Press.

Madsen, D. (1992). Successful dissertation and theses (2nd ed.). San Francisco: Jossey-Bass.

Mauch, J. E., \& Birch, J. W. (1998). Guide to the successful thesis and dissertation: A handbook for students and faculty (4th ed.). New York: Marcel Dekker.

Merriam-Webster. (Ed.) (2003). Merriam-Webster's collegiate dictionary (11th ed.). Springfield, MA: Merriam-Webster.

Miles, M. B., \& Huberman, A. M. (1994). Qualitative data analysis: An expanded sourcebook (2nd ed.). Thousand Oaks, CA: Sage.

Mory, E. H. (2004). Feedback research revisited. In D. H. Jonassen (Ed.), Handbook of research on educational communications and technology (pp. 745-783). Mahwah, NJ: Erlbaum.

Newman, I., Benz, C. R., Weis, D., \& McNeil, K. (1997). Theses and dissertations: A guide to writing in the social and physical sciences. Lanham, MD: University Press of America, Inc.

Norman, G. R., \& Streiner, D. L. (2003). Pdq statistics (3rd ed.). New York: BC Decker.

OBIA. (2008). Office of Budget and Institutional Analysis Datamarts. Retrieved March 1, 2008, from http://www.obia.utah.edu/

O’Connor, B. P. (2000). SPSS and SAS programs for determining the number of components using parallel analysis and Velicer's MAP test. Behavior Research Methods, Instrumentation, and Computers, 32(3), 396-402. 
O’Connor, B. P. (2008). SPSS, SAS, and MATLAB programs for determining the number of components and factors using parallel analysis and Velicer's MAP test. Retrieved September 1, 2008, from http://people.ok.ubc.ca/brioconn/nfactors/nfactors.html

O’Keefe, D. J. (1990). Persuasion: Theory and research. Newbury Park, CA: Sage.

Oppenheim, A. N. (1966). Questionnaire design and attitude measurement. New York: Basic Books, Inc.

Pageadams, D., Cheng, L. C., Gogineni, A., \& Shen, C. Y. (1995). Establishing a group to encourage writing for publication among doctoral students. Journal of Social Work Education, 31(3), 402407.

Peters, R. L. (1992). Getting what you came for: The smart student's guide to earning a Master's or a Ph.D. New York: Noonday.

Phelps, R., Fisher, K., \& Ellis, A. (2007). Organizing and managing your research: A practical guide for postgraduates. Thousand Oaks, CA: Sage.

Piantanida, M., \& Garman, N. B. (1999). The qualitative dissertation: A guide for students and faculty. Thousand Oaks, CA: Corwin Press.

Poland, B. D. (2003). Transcription quality. In J. A. Holstein \& J. F. Gubrium (Eds.), Inside interviewing: New lenses, new concerns (pp. 267- 287). Thousand Oaks, CA: Sage.

PsychData. (2008). PsychData online surveys. Retrieved March 1, 2008, from http://www.psychdata.com

Raykov, T., \& Marcoulides, G. A. (2000). A first course in structural equation modeling. Mahwah, NJ: Erlbaum.

Rea, L. M., \& Parker, R. A. (2005). Designing and conducting survey research: A comprehensive guide (3rd ed.). San Francisco: Jossey-Bass.

Rossman, M. H. (2002). Negotiating graduate school. Thousand Oaks, CA: Sage.

Rudestam, K. E., \& Newton, R. R. (2001). Surviving your dissertation: A comprehensive guide to content and process (2nd ed.). Thousand Oaks, CA: Sage.

Schmitt, N. (1996). Uses and abuses of coefficient alpha. Psychological Assessment, 8(4), 350-353.

Schumacker, R. E., \& Lomax, R. G. (2004). A beginner's guide to structural equation modeling (2nd ed.). Mahwah, NJ: Erlbaum. 
Straub, R. (1997). Students' reactions to teacher comments: An exploratory study. Research in the Teaching of English, 31(1), 91-119.

Strauss, A., \& Corbin, J. (1998). Basics of qualitative research: Techniques and procedures for developing grounded theory (2nd ed.). Thousand Oaks, CA: Sage.

Taylor, S., \& Beasley, N. (2005). A handbook for doctoral supervisors. New York: Routledge.

Thomas, R. M., \& Brubaker, D. L. (2000). Theses and dissertations: A guide to planning, research, and writing. Westport, CT: Bergin \& Garvey.

Thomson-Reuters. (2008). Social sciences citation index- subject categories. Retrieved March 1, 2008, from http://scientific.thomson.com/cgi-bin/jrnlst/jlsubcatg.cgi?PC=J

Torrance, M. S., \& Thomas, G. V. (1994). The development of writing skills in doctoral research students. In R. G. Burgess (Ed.), Postgraduate education and training in the social sciences (pp. 105-123). London: Jessica Kingsley.

Torrance, M. S., Thomas, G. V., \& Robinson, E. J. (1992). The writing experiences of social-science research students. Studies in Higher Education, 17(2), 155-167.

Torrance, M. S., Thomas, G. V., \& Robinson, E. J. (1994). The writing strategies of graduate research students in the social-sciences. Higher Education, 27(3), 379-392.

Vygotsky, L. S. (1978). Mind in society: The development of higher psychological processes. Cambridge, MA: Harvard University Press.

Walker, G. E., Golde, C. M., Jones, L., Bueschel, A. C., \& Hutchings, P. (2008). The formation of scholars: Rethinking doctoral education for the twenty-first century. San Francisco: Jossey-Bass.

Wenger, E. (1998). Communities of practice: Learning, meaning, and identity. Cambridge, United Kingdom: Cambridge University Press.

Wenger, E., McDermott, R., \& Snyder, W. M. (2002). Cultivating communities of practice: A guide to managing knowledge. Boston: Harvard Business School Press.

West, S. G., Finch, J. F., \& Curran, P. J. (1995). Structural equation models with nonnormal variables: Problems and remedies. In R. H. Hoyle (Ed.), Structural equation modeling: Concepts, issues and applications (pp. 56-75). Newbury Park, CA: Sage. 
Wilkinson, D. (2005). The essential guide to postgraduate study. Thousand Oaks, CA: Sage.

Wisker, G. (2005). The good supervisor: Supervising postgraduate and undergraduate research for doctoral theses and dissertations. Basingstoke, UK: Palgrave Macmillan. 
APPENDICES 
Appendix A. Informed Consent Form for Interviews 
USU IRB Original Approval 04/26/2007

\author{
Informed Consent \\ Perceptions and Attitudes of Doctoral Students toward Different Sources and \\ Characteristics of Written Feedback
}

Introduction/ Purpose. Associate Professor David Wiley and Research Assistant Gulfidan Can in the Department of Instructional Technology at Utah State University are conducting a research study to find out more about perceptions and attitudes of doctoral students toward different sources and characteristics of written feedback. You have been asked to take part because your previous experiences with academic writing can provide important information for this research study. There will be approximately 15 participants who will participate in the first part of the study. There will be approximately 200 total participants in this research.

Procedures. If you agree to be in this research study, the following will happen to you. In an interview that will last about 1 hour, the researcher will ask you questions about your experiences, perceptions, and attitudes toward different sources and characteristics of written feedback. If you agree, the interview will be recorded. You will also be requested to bring (or send to Gulfidan Can) one of your previous academic writings in two versions: one with feedback on it and the other one with revisions made after having feedback.

Risks. Participation in this research study is considered minimal risk.

Benefits. There may or may not be any direct benefit to you from the results of this study. However, this study will provide comprehensive information to feedback providers about doctoral students' perceptions and attitudes toward different sources and characteristics of written feedback, so that they can make rational choices while giving feedback to doctoral students. This will be helpful for doctoral students to improve their academic writing and will help them practice and participate more effectively and productively in their academic community. 
Payment. You will be paid $\$ 20$ (as a gift card) for your participation in this study.

Voluntary nature of participation and right to withdraw without consequence. Participation in research is entirely voluntary. You may refuse to participate or withdraw at any time without consequence.

Confidentiality. Research records and the copies of your academic writings will be kept confidential, consistent with federal and state regulations. The interview recordings and data will be kept in a locked file cabinet in a locked room in the form of a CD. The researcher will make sure that the recordings and the copies of your writings will not include any identifying information. The researcher will prepare a code list that includes the record number of your session, your name, and e-mail address. This list will only be accessed by Gulfidan Can and will be destroyed at the end of the study (in 1 year). Your transcribed interview data (with no identifying information) will only be accessible to the dissertation committee of the researcher. Your name and e-mail address will be asked just in case the researcher needs to contact with you electronically to clarify some of your answers. The recorded data and the copies of your writings will be destroyed at the end of the study (in 1 year).

IRB approval. USU has reviewed and approved this research study. If you have any questions or concerns about your rights, you may contact the IRB at (435) 797-1821.

Copy of consent. You have been given two copies of this Informed Consent. Please sign both copies and retain one copy for your files. 
Investigator statement. "I certify that the research study has been explained to the individual, by me or my research staff, and that the individual understands the nature and purpose, the possible risks and benefits associated with taking part in this research study. Any questions that have been raised have been answered."

David Wiley, Ph.D.

Gulfidan Can

Principal Investigator

Research Assistant

(435) 797-7562

(435) $720-3972$

Signature of participant. By signing below, I agree to participate. 
Appendix B. Informed Consent Form for Questionnaire 
Date: March 18, 2008

USU IRB Approved 04/26/2007

Approval terminates 04/25/2009

Protocol Number 1776

\section{Informed Consent \\ Perceptions and Attitudes of Doctoral Students Toward Different Sources \& \\ Characteristics of Written Feedback}

Introduction/ Purpose: Associate Professor David Wiley in the Department of Instructional Technology at Utah State University (USU) and doctoral candidate Gulfidan Can are conducting a research study to find out more about perceptions and attitudes of doctoral students in social science departments toward different sources and characteristics of written feedback for their academic papers and the relationship of these perceptions and attitudes to their revision decisions.

Participants: Any current or recently graduated doctoral students (PhD, EdDs, etc.) in social science departments are invited to participate in this research study. There will be approximately 200 total participants in this research.

Procedures: If you agree to participate in this research study you will be asked to complete an anonymous online questionnaire which may take about 30 minutes. You may quit the questionnaire at any time and your data will not be saved. You may also skip any questions that you do not want to answer. However, answering each question completely will provide important information for the study.

Risks: Participation in this research study is considered minimal risk.

Benefits: There may not be any direct benefit to you from the results of this study. However, the information you provide may inform the design of effective written feedback for doctoral students.

Confidentiality: Research records will be kept completely confidential, consistent with federal and state regulations. Your responses will be anonymous. Furthermore, the online survey is being hosted by a 
professional company website that specializes in psychological research and maintains high standards of confidentiality and data security.

Gift cards: As a token of appreciation the researcher will do a drawing and give four participants $\$ 100$ gift cards. At the end of the questionnaire, you will be a given an email address and a code. If you would like to participate in the drawing you may send an empty email to that particular email address with the code. This process will ensure that your responses will not be related to your contact information.

Voluntary nature of participation and right to withdraw without consequence: Participation in this research is entirely voluntary. You may refuse to participate or withdraw at any time without consequence.

Contact information: If you have any questions, you may contact the researchers at any time.

Gulfidan Can, Doctoral Candidate

Utah State University

College of Education and Human Services

Instructional Technology Department

2830 Old Main Hill, Logan, UT 84322

Email: gulfidan.can@gmail.com

Phone: (435) 720- 3972

IRB approval statement: The Institutional Review Board for the protection of human participants at USU has approved this research study. If you have any questions or concerns about your rights, you may contact the IRB at (435) 797-1821.

If you do not wish to participate, you may close the browser.

By continuing this questionnaire you agree that you have read and understand this consent document. Please print this page for your records. 
Appendix C. Interview Guide 
Interview Guide

\section{Pre-Interview}

After the participants read the consent letter and signed it:

"Let me explain my study before starting the interview. The purpose of this study is to understand perceptions and attitudes of doctoral students toward different sources and characteristics of written feedback. So, my questions will be about your perceptions, attitudes, and experiences about feedback types and sources. The questions are open ended, so you can answer anyway you like. Also you don't have to be bounded with the questions; you can tell me anything that you think useful to my research.

All the recordings will be confidential. Only I will access them. At the end of the study they will be deleted. I will transcribe the recording and it will not have any identifying information. Only my committee members will access to the transcriptions.

About the questions, first questions are about your perceptions toward academic writing. Then I will ask some questions related to your perceptions and attitudes toward different feedback types and sources. The last questions will be about your specific experiences. Do you have any questions before starting the interview?”

\section{Information}

Name:

Age:

Gender:

Department:

What stage are you toward your degree completion:

Number of Publications:

Work:

E-mail: 
Record Number

Date:

Interview Number:

\section{Interview Questions}

AQ: Alternative Question

SQ: Sub-Question

FI: Further Information

1. My first question is, how would you define academic writing in your own words?

AQ: What kind of writing can be considered as academic writing?

AQ: What are the differences between academic writing and non-academic writing?

SQ: Can you give me some examples of types of academic writing?

2. In your discipline, what do you think is the purpose of academic writing?

3. Do you think there is a clear list of criteria for good academic writing in your discipline?

AQ: Do you think the criteria change according to different people?

4. During your doctoral program, what kind of academic writing activities did you engage with?

SQ: Could you tell me whether you chose to write these or someone asked you to write them?

AQ: Which one of these writing activities were required from you, and which ones were not required from you?

5. Do you usually get written or oral feedback for your writings?

SQ: Can you tell me which one do you find most useful?

SQ: Why?

//If the participant usually receives written feedback and like written feedback//

The following questions will be about written feedback only.

//If the participant receives and likes both written and oral feedback//

The following questions will be about written feedback, but you can also consider oral feedback in your answers if you like. 
6. You mentioned that you wrote <types of writing > . Can you tell me, what were your motivations and incentives for writing them? (For each paper)

7. Whom do you mostly get feedback from?

SQ: Is he/she in the same discipline as you?

SQ: (credibility): Do you find this person very knowledgeable in the area that you are studying?

SQ: (role): Is your relationship like an instructor-student relationship, or more like a colleague to colleague relationship?

SQ: (social relationship): How is your social relationship with him/her?

8. What kinds of feedback do you like or find most useful and valuable?

SQ: Can you give me some specific examples?

9. What kinds of feedback do you not like, or find not useful?

SQ: Can you give me some specific examples?

10. From whom do you not request feedback intentionally?

FI: You can tell me the characteristics of the people that you do not request feedback intentionally.

SQ: Why?

11. After you receive feedback, do you usually revise your paper?

12. What affects your decision to accept or reject certain feedback?

AQ: Is your social relationship with him/her, or that person's power over you, or credibility affect your revision?

13. Do you give feedback to others?

SQ: Can you tell me what kind of feedback do you give to them?

SQ: The kind of feedback you give to others, is it similar to the type of feedback that you want to receive from others?

The following questions will be about < source $1>$. 
14. Do you request feedback from him/her or they just give it to you anyway?

SQ: (If yes). What are the important characteristics of this person that lead you to ask for feedback?

SQ: This is a similar kind of question. What do you like about that person that lead you to ask for feedback?

AQ: (If no). Is there a specific reason for not asking for feedback?

15. What do you think are his/her motivations or reasons to give you feedback?

SQ: Do you give feedback to this person too?

16. What kind of feedback do they give to you? Can you give me some specific examples?

FI: Suggestions, feedback for motivation, criticisms, the amount and content of feedback?

SQ: Do you find this kind of feedback useful?

SQ: Among his/her feedback, is there a kind of feedback that you don't like or find not useful?

17. What criteria do you think he/she considers the most when reviewing your paper?

I will ask the same four questions for $<$ source 2>.

18. Do you request feedback from him/her or they just give it to you anyway?

SQ: (If yes). What are the important characteristics of this person that lead you to ask for feedback?

SQ: This is a similar kind of question. What do you like about that person that lead you to ask for feedback?

AQ: (If no). Is there a specific reason for not asking for feedback?

19. What do you think are his/her motivations or reasons to give you feedback?

SQ: Do you give feedback to this person too?

20. What kind of feedback do they give to you? Can you give me some specific examples?

FI: Suggestions, feedback for motivation, criticisms, the amount and content of feedback?

SQ: Do you find this kind of feedback useful?

SQ: Among his/her feedback, is there a kind of feedback that you don't like or find not useful?

21. What criteria do you think he/she considers the most when reviewing your paper?

22. Can you compare these two sources and tell me whose feedback was more useful to you? 
Now, these last four questions will be about your specific feedback experiences.

23. Do you remember a specific feedback experience that affected you some way? That you remember the most?

SQ: (If yes). Could you share it with me?

24. Have you ever had an experience where you received feedback from different people and their feedback contradicted each other?

SQ: (If yes): Can you tell me about it?

SQ: What did you think or how did you feel?

SQ: If you revised your paper, how did you do it?

AQ: How did this affect your revision?

25. Have you ever had an experience where you did not understand the feedback?

SQ: (If yes): Can you tell me about it?

SQ: What did you think and how did you feel?

SQ: If you revised your paper, how did you do it?

AQ: How did this affect your revision?

26. Have you ever had an experience where you received negative feedback while you were confident and expecting positive feedback?

SQ: (If yes). Can you tell me about it?

SQ: What did you think and how did you feel?

SQ: If you revised your paper, how did you do it?

AQ: How did this affect your revision?

27. Similarly, have you ever had an experience where you were not so confident and you received negative feedback?

SQ: (If yes). Can you tell me about it?

SQ: What did you think and how did you feel?

SQ: If you revised your paper, how did you do it?

AQ: How did this affect your revision? 
28. Is there any other thing related to your feedback experiences that you want to tell me? Anything that could be useful to my research?

I: Ask them if I can see their paper and feedback on it; and ask them to explain how and why they revised their paper, or why they did not. 
Appendix D. Recruit Materials for Interviews 


\section{Recruit Materials for Interviews \\ E-mail to the Department Heads and/or Faculty}

Dear .....;

I am a Ph.D. student in the department of Instructional Technology. Currently I am conducting research for my dissertation. For this study, I interview with doctoral students in social science departments

- who are at their later stages of their program (preferably after proposal defense)

- who are actively engaged in academic writing activities, (preferably) have at least one publication.

I would really appreciate if you could suggest me a few names (and contact information) of example students in your department who might fit these criteria.

I look forward hearing from you.

Best Regards

\section{E-mail to the Doctoral Students}

Dear .....;

I am a PhD student in Instructional Technology program. Currently I am collecting data for my dissertation. I am doing interviews with doctoral students who are at their later stages of their program and who are actively involved in academic writing activities.

Dr. ...... suggested that your participation would be useful to my research. I would appreciate if you could spare about 1 hour for an interview with me. I copied the consent letter below.

If you would like to participate, could you please let me know which day and what time is best for you? If you agree to participate, I usually do the interviews in the classroom .... , but I can come to your office too.

I look forward to hearing from you.

Best Regards 
Appendix E. Content Validity Testing Sheet 
Content Validity Testing Sheet

Thank you for accepting to review this questionnaire for its content validity. In content validity testing, a group of experts review the items of the questionnaire and comment on whether the items cover a representative sample of the constructs to be measured.

In this study, the main constructs that I want to measure are:

- Perceptions and Attitudes toward Written Feedback Characteristics

- $\quad$ Perceptions and Attitudes toward Written Feedback Providers

- Revision Decisions

Therefore, please review the questions and check if they cover a representative sample of these main constructs. If you think there should be more questions about these constructs, or if you think some of the questions should be removed, please write your comments.

Thank you 
Appendix F. Pilot Test Review Sheet 
Pilot Test Review Sheet

Thank you for accepting to review and complete this questionnaire. Your answers will only be used for pilot analysis. I appreciate your help to improve this questionnaire.

Here is a list of some common problems in most questionnaires. If you see any of these problems or any other problems please write a note next to the corresponding questions or statements.

\section{For Individual Questions}

The question is:
a) vague
b) unnecessary or irrelevant
c) very hard to answer or impossible to answer
d) too long
e) redundant
f) biased
g) offensive / or invades privacy or ethical or moral standards
h) likely to be left blank
i) likely to be misunderstood

The answer choices are:
a) unnecessary
b) not enough 


\section{For Overall Questionnaire}

\begin{tabular}{|l|l|l|}
\hline & YES & NO \\
\hline The questionnaire is too long & & \\
\hline Not all necessary questions have been included & & \\
\hline The questionnaire is boring & & \\
\hline The directions are hard to follow & & \\
\hline There are problems with the order and the flow of the questions & & \\
\hline
\end{tabular}

Note: Please ignore the formatting problems of the questionnaire. The format will be different when it is online. 
Appendix G. Questionnaire 


\section{WRITTEN FEEDBACK- RESEARCH STUDY*}

\section{INTRODUCTION AND DIRECTIONS}

Please read the following directions before starting the questionnaire.

\section{A. Questions}

The questions are grouped under the following headings:

a) General Information

b) Academic Writing

c) Program

d) Requesting Written Feedback

e) Written Feedback Preferences

f) Critical/Negative Written Feedback

g) Feedback Providers

h) Revision Decisions

i) Feedback Process in General

\section{B. Use of Terms}

In the context of this questionnaire the following terms are used:

- Written Feedback: One or a group(s) of comments, edits, marks, etc. written (handwritten or electronic) by someone who reviewed your particular academic paper.

- Feedback Provider: The person who gives you written feedback.

- Critical/Negative Written Feedback: Written feedback which points out problems in your paper. They may or may not include suggestions for improvement.

- Positive Written Feedback: Written feedback which points out good things about your paper. They may or may not include suggestions for improvement.

\section{For first year doctoral students}

When answering the questions you could also refer to your masters' experiences if you haven't had much academic writing experience at the doctoral level yet.

D. Completing this questionnaire will take about $\mathbf{3 0}$ minutes.

E. If you need any explanations about the questions, please feel free to contact the researcher at anytime (435) $720-3972$

F. Please answer all the questions

\section{Thank you for participating!}

\section{Gulfidan Can}




\section{A. GENERAL INFORMATION [Items 1-17]}

1) How old are you?<smiles>C1CCC1</smiles>

2) What is your gender?

$\bigcirc$ Male $\bigcirc$ Female

3) Do you consider English your native language?

$\bigcirc$ Yes $\bigcirc$ No

4) Which university do you attend?

$\bigcirc$ Utah State University $\bigcirc$ University of Utah

5) What is your academic major?

6) How long have you been in the doctoral program?
Less than a year
1 year $\bigcirc 2$ years
5 or more years
$\bigcirc$ Graduated
3 years $\bigcirc 4$ years

7) How do you rate your overall academic writing ability?

$\bigcirc$ very poor $\bigcirc$ poor $\bigcirc$ Average $\bigcirc$ Good $\bigcirc$ very good

8) Please indicate how many of the following you have written or participated in writing.

* Include the ones that you are currently writing.

* You may type 0 or leave it as blank for the items that you haven't written.

\begin{tabular}{|l|c|}
\hline & How Many? \\
\hline Journal Article & \\
\hline Conference Proposal, Poster, Proceeding & \\
\hline Book Chapter or Book & \\
\hline Grant Proposal & \\
\hline Masters Thesis & \\
\hline Doctoral Comprehensive Exam & \\
\hline Dissertation Proposal & \\
\hline Dissertation & \\
\hline
\end{tabular}


9) Are you currently employed?

$\bigcirc$ Yes (continue answering the questions)

No (please do not answer 9a, continue with the next page)

9a) Does your job require you to engage in academic writing?

$\mathrm{O}$ Yes

No

10\% Completed

[Page Break]

\section{B. ACADEMIC WRITING [Items 18-28]}

1) Please rate the following statements according to the extent to which you agree or disagree.

\begin{tabular}{|l|c|c|c|c|}
\hline & $\begin{array}{c}\text { Strongly } \\
\text { Disagree }\end{array}$ & Disagree & Agree & $\begin{array}{c}\text { Strongly } \\
\text { Agree }\end{array}$ \\
\hline I enjoy writing academic papers & $\bigcirc$ & $\bigcirc$ & $\bigcirc$ & $\bigcirc$ \\
\hline I enjoy writing academic papers with others & $\bigcirc$ & $\bigcirc$ & $\bigcirc$ & $\bigcirc$ \\
\hline I have confidence in writing academic papers & $\bigcirc$ & $\bigcirc$ & $\bigcirc$ & $\bigcirc$ \\
\hline $\begin{array}{l}\text { I need someone to push me to write academic } \\
\text { papers }\end{array}$ & $\bigcirc$ & $\bigcirc$ & $\bigcirc$ & $\bigcirc$ \\
\hline
\end{tabular}


Please rate the following statements according to the extent to which you agree or disagree.

\section{2) My motivation for academic writing is:}

\begin{tabular}{|l|c|c|c|c|}
\hline & $\begin{array}{c}\text { Strongly } \\
\text { Disagree }\end{array}$ & Disagree & Agree & $\begin{array}{c}\text { Strongly } \\
\text { Agree }\end{array}$ \\
\hline $\begin{array}{l}\text { To meet graduation or occupation requirements } \\
\text { and expectations }\end{array}$ & $\bigcirc$ & $\bigcirc$ & $\bigcirc$ & $\bigcirc$ \\
\hline To build up my vita & $\bigcirc$ & $\bigcirc$ & $\bigcirc$ & $\bigcirc$ \\
\hline $\begin{array}{l}\text { To gain a promotion or get into a good job in the } \\
\text { future }\end{array}$ & $\bigcirc$ & $\bigcirc$ & $\bigcirc$ & $\bigcirc$ \\
\hline $\begin{array}{l}\text { To gain experiences, skills, and knowledge as an } \\
\text { academician }\end{array}$ & $\bigcirc$ & $\bigcirc$ & $\bigcirc$ & $\bigcirc$ \\
\hline To have recognition in the field & $\bigcirc$ & $\bigcirc$ & $\bigcirc$ & $\bigcirc$ \\
\hline To share my ideas or findings with others & $\bigcirc$ & $\bigcirc$ & $\bigcirc$ & $\bigcirc$ \\
\hline To contribute knowledge to the field & $\bigcirc$ & $\bigcirc$ & $\bigcirc$ & $\bigcirc$ \\
\hline
\end{tabular}

18\% Completed

[Page Break] 


\section{PROGRAM [Items 29-36]}

Please rate the following statements according to the extent to which you agree or disagree.

\section{1) In my program}

\begin{tabular}{|l|c|c|c|c|}
\hline & $\begin{array}{c}\text { Strongly } \\
\text { Disagree }\end{array}$ & Disagree & Agree & $\begin{array}{c}\text { Strongly } \\
\text { Agree }\end{array}$ \\
\hline $\begin{array}{l}\text { I feel like I am treated as a peer and a colleague } \\
\text { here by the faculty members }\end{array}$ & $\bigcirc$ & $\bigcirc$ & $\bigcirc$ & $\bigcirc$ \\
\hline $\begin{array}{l}\text { The faculty members push doctoral students to } \\
\text { write and publish a lot }\end{array}$ & $\bigcirc$ & $\bigcirc$ & $\bigcirc$ & $\bigcirc$ \\
\hline $\begin{array}{l}\text { The faculty members are very productive in } \\
\text { terms of the quantity of publications }\end{array}$ & $\bigcirc$ & $\bigcirc$ & $\bigcirc$ & $\bigcirc$ \\
\hline $\begin{array}{l}\text { The faculty members' academic writing } \\
\text { standards are very high }\end{array}$ & $\bigcirc$ & $\bigcirc$ & $\bigcirc$ & $\bigcirc$ \\
\hline $\begin{array}{l}\text { The faculty members often write academic } \\
\text { papers with their students }\end{array}$ & $\bigcirc$ & $\bigcirc$ & $\bigcirc$ & $\bigcirc$ \\
\hline $\begin{array}{l}\text { The faculty members invite me to write } \\
\text { academic papers together with them }\end{array}$ & $\bigcirc$ & $\bigcirc$ & $\bigcirc$ & $\bigcirc$ \\
\hline $\begin{array}{l}\text { I ask faculty members to write academic papers } \\
\text { together with me }\end{array}$ & $\bigcirc$ & $\bigcirc$ & $\bigcirc$ & $\bigcirc$ \\
\hline $\begin{array}{l}\text { There are a lot of opportunities to write } \\
\text { academic papers with faculty members }\end{array}$ & $\bigcirc$ & $\bigcirc$ & $\bigcirc$ & $\bigcirc$ \\
\hline
\end{tabular}

\section{3\% Completed}

[Page Break] 


\section{REQUESTING WRITTEN FEEDBACK [Items 37-71]}

1) Please rate the following statements according to the extent to which you agree or disagree.

\begin{tabular}{|l|c|c|c|c|}
\hline & $\begin{array}{c}\text { Strongly } \\
\text { Disagree }\end{array}$ & Disagree & Agree & $\begin{array}{c}\text { Strongly } \\
\text { Agree }\end{array}$ \\
\hline $\begin{array}{l}\text { I ask others for written feedback on my } \\
\text { academic papers }\end{array}$ & $\bigcirc$ & $\bigcirc$ & $\bigcirc$ & $\bigcirc$ \\
\hline $\begin{array}{l}\text { I look for several people to give me written } \\
\text { feedback for my papers }\end{array}$ & $\bigcirc$ & $\bigcirc$ & $\bigcirc$ & $\bigcirc$ \\
\hline $\begin{array}{l}\text { I look for several written feedback occasions at } \\
\text { different stages of my papers }\end{array}$ & $\bigcirc$ & $\bigcirc$ & $\bigcirc$ & $\bigcirc$ \\
\hline $\begin{array}{l}\text { I ask for written feedback only when I come to a } \\
\text { point where I can't improve my paper any } \\
\text { further }\end{array}$ & $\bigcirc$ & $\bigcirc$ & $\bigcirc$ & $\bigcirc$ \\
\hline $\begin{array}{l}\text { I don't ask for written feedback if I am confident } \\
\text { with my paper's quality }\end{array}$ & $\bigcirc$ & $\bigcirc$ & $\bigcirc$ & $\bigcirc$ \\
\hline $\begin{array}{l}\text { I don't want to expose myself to others by } \\
\text { asking them to give me written feedback if I am } \\
\text { not confident in my paper's quality }\end{array}$ & $\bigcirc$ & $\bigcirc$ & $\bigcirc$ & $\bigcirc$ \\
\hline $\begin{array}{l}\text { My pride has a lot to do with my decisions to } \\
\text { not ask for written feedback }\end{array}$ & $\bigcirc$ & $\bigcirc$ & $\bigcirc$ & $\bigcirc$ \\
\hline $\begin{array}{l}\text { I feel comfortable asking for written feedback } \\
\text { from professors on my committee }\end{array}$ & $\bigcirc$ & $\bigcirc$ & $\bigcirc$ & $\bigcirc$ \\
\hline $\begin{array}{l}\text { I feel comfortable asking for written feedback } \\
\text { from professors outside of my committee }\end{array}$ & $\bigcirc$ & $\bigcirc$ & $\bigcirc$ & $\bigcirc$ \\
\hline $\begin{array}{l}\text { I feel comfortable asking for written feedback } \\
\text { from other doctoral students }\end{array}$ & $\bigcirc$ & $\bigcirc$ & $\bigcirc$ & $\bigcirc$ \\
\hline $\begin{array}{l}\text { When asking for written feedback from others, I } \\
\text { tell them what aspects of the paper I want them } \\
\text { to look at }\end{array}$ & $\bigcirc$ & $\bigcirc$ & $\bigcirc$ & $\bigcirc$ \\
\hline
\end{tabular}


2) How important are the following characteristics of a person to you when deciding whether or not to ask for their written feedback?

\begin{tabular}{|c|c|c|c|c|}
\hline & Unimportant & $\begin{array}{l}\text { Somewhat } \\
\text { Important }\end{array}$ & Important & $\begin{array}{c}\text { Very } \\
\text { Important }\end{array}$ \\
\hline $\begin{array}{l}\text { Whether the person is younger or older than I } \\
\text { am }\end{array}$ & $\bigcirc$ & $\bigcirc$ & $\bigcirc$ & $\bigcirc$ \\
\hline $\begin{array}{l}\text { Whether the person lives/works/studies close } \\
\text { to me in terms of location }\end{array}$ & $\bigcirc$ & $\bigcirc$ & $\bigcirc$ & $\bigcirc$ \\
\hline His/her being in the same discipline or not & $\bigcirc$ & O & $\bigcirc$ & $\bigcirc$ \\
\hline $\begin{array}{l}\text { His/her knowledge level in the content area } \\
\text { that my paper is about }\end{array}$ & $\bigcirc$ & $\bigcirc$ & $\bigcirc$ & $\bigcirc$ \\
\hline $\begin{array}{l}\text { His/her interest level in the content area that } \\
\text { my paper is about }\end{array}$ & $\bigcirc$ & $\bigcirc$ & $\bigcirc$ & $\bigcirc$ \\
\hline Whether he/she thinks my paper is important & $\bigcirc$ & $\bigcirc$ & $\bigcirc$ & $\bigcirc$ \\
\hline $\begin{array}{l}\text { Whether he/she has a decisive role in my } \\
\text { degree completion or publication }\end{array}$ & $\bigcirc$ & $\bigcirc$ & $\mathrm{O}$ & $\mathrm{O}$ \\
\hline His/her publication experience & O & O & $\bigcirc$ & $\bigcirc$ \\
\hline His/her writing skills & O & $\bigcirc$ & $\bigcirc$ & $\bigcirc$ \\
\hline His/her writing style & $\bigcirc$ & $\bigcirc$ & $\bigcirc$ & $\bigcirc$ \\
\hline $\begin{array}{l}\text { His/her thinking, organizing, and analyzing } \\
\text { skills }\end{array}$ & $\bigcirc$ & $\bigcirc$ & $\bigcirc$ & $\bigcirc$ \\
\hline Whether I like his/her personality & $\bigcirc$ & $\bigcirc$ & $\bigcirc$ & $\bigcirc$ \\
\hline Whether he/she is a responsible person & O & $\bigcirc$ & $\bigcirc$ & $\bigcirc$ \\
\hline Whether I trust him/her as a person & O & $\bigcirc$ & $\bigcirc$ & $\bigcirc$ \\
\hline Whether we have a good social relationship & $\bigcirc$ & O & $\bigcirc$ & $\bigcirc$ \\
\hline $\begin{array}{l}\text { Whether I have a mutual feedback relationship } \\
\text { with him/her }\end{array}$ & $\mathrm{O}$ & 0 & 0 & 0 \\
\hline $\begin{array}{l}\text { Whether I feel that he/she will be willing to } \\
\text { help }\end{array}$ & 0 & 0 & 0 & $\bigcirc$ \\
\hline $\begin{array}{l}\text { Whether I feel that I won't be a burden to } \\
\text { him/her }\end{array}$ & 0 & 0 & 0 & 0 \\
\hline $\begin{array}{l}\text { Whether I think they have time to give me } \\
\text { feedback }\end{array}$ & 0 & 0 & $O$ & 0 \\
\hline
\end{tabular}




\section{Continues}

\begin{tabular}{|l|c|c|c|c|}
\hline & Unimportant & $\begin{array}{c}\text { Somewhat } \\
\text { Important } \\
\text { Important }\end{array}$ & $\begin{array}{c}\text { Very } \\
\text { Important }\end{array}$ \\
\hline $\begin{array}{l}\text { His/her reasons/incentives for giving me } \\
\text { feedback }\end{array}$ & $\bigcirc$ & $\bigcirc$ & $\bigcirc$ & $\bigcirc$ \\
\hline His/her expectations of the quality of my paper & $\bigcirc$ & $\bigcirc$ & $\bigcirc$ & $\bigcirc$ \\
\hline $\begin{array}{l}\text { My previous experiences with his/her } \\
\text { feedback }\end{array}$ & $\bigcirc$ & $\bigcirc$ & $\bigcirc$ & $\bigcirc$ \\
\hline $\begin{array}{l}\text { Others' previous experiences with his/her } \\
\text { feedback }\end{array}$ & $\bigcirc$ & $\bigcirc$ & $\bigcirc$ & $\bigcirc$ \\
\hline $\begin{array}{l}\text { Whether I think he/she will give feedback } \\
\text { quickly }\end{array}$ & $\bigcirc$ & $\bigcirc$ & & $\bigcirc$ \\
\hline
\end{tabular}

$46 \%$ Completed

[Page Break]

\section{E. WRITTEN FEEDBACK PREFERENCES [Items 72- 116]}

1) Please choose one of the following:

I prefer sending my paper electronically, such as through email

I prefer handing in my paper personally, face-to-face

I have no preference

2) Please choose one of the following.

I prefer receiving written feedback electronically, such as track-changes in Word, comments, edits on the computer

I prefer receiving handwritten feedback, such as comments handwritten on my paper

I have no preference 
3) When writing academic papers, how frequently do you feel that you need written feedback for the following aspects of your papers?

\begin{tabular}{|l|c|c|c|c|}
\hline & Never & Seldom & Sometimes & Often \\
\hline $\begin{array}{l}\text { Introduction, purpose and significance of the } \\
\text { paper }\end{array}$ & $\bigcirc$ & $\bigcirc$ & $\bigcirc$ & $\bigcirc$ \\
\hline Conclusion & $\bigcirc$ & $\bigcirc$ & $\bigcirc$ & $\bigcirc$ \\
\hline $\begin{array}{l}\text { Transition and flow between sentences, } \\
\text { paragraphs, or sections }\end{array}$ & $\bigcirc$ & $\bigcirc$ & $\bigcirc$ & $\bigcirc$ \\
\hline $\begin{array}{l}\text { Logical order and organization of information } \\
\text { and ideas }\end{array}$ & $\bigcirc$ & $\bigcirc$ & $\bigcirc$ & $\bigcirc$ \\
\hline Consistency in the overall paper & $\bigcirc$ & $\bigcirc$ & $\bigcirc$ & $\bigcirc$ \\
\hline Inclusion or exclusion of information & $\bigcirc$ & $\bigcirc$ & $\bigcirc$ & $\bigcirc$ \\
\hline Clarity and understandability of the statements & $\bigcirc$ & $\bigcirc$ & $\bigcirc$ & $\bigcirc$ \\
\hline Arguments and justifications in my paper & $\bigcirc$ & $\bigcirc$ & $\bigcirc$ & $\bigcirc$ \\
\hline Grammar and sentence structure & $\bigcirc$ & $\bigcirc$ & $\bigcirc$ & $\bigcirc$ \\
\hline $\begin{array}{l}\text { Formatting (tables, figures, page design, fitting } \\
\text { APA style, giving citations, etc) }\end{array}$ & $\bigcirc$ & $\bigcirc$ & $\bigcirc$ & $\bigcirc$ \\
\hline References and literature decisions & $\bigcirc$ & $\bigcirc$ & $\bigcirc$ & $\bigcirc$ \\
\hline
\end{tabular}


4) Please rate the following statements according to the extent to which you agree or disagree.

\begin{tabular}{|c|c|c|c|c|}
\hline & $\begin{array}{l}\text { Strongly } \\
\text { Disagree }\end{array}$ & Disagree & Agree & $\begin{array}{c}\text { Strongly } \\
\text { Agree }\end{array}$ \\
\hline $\begin{array}{l}\text { I appreciate critical/negative written feedback } \\
\text { more than positive written feedback }\end{array}$ & $\bigcirc$ & $\bigcirc$ & $\bigcirc$ & $\bigcirc$ \\
\hline $\begin{array}{l}\text { I appreciate written feedback in which negative } \\
\text { things are said in a more positive way }\end{array}$ & $\bigcirc$ & $\bigcirc$ & $\bigcirc$ & $\bigcirc$ \\
\hline $\begin{array}{l}\text { I appreciate balanced positive and } \\
\text { critical/negative written feedback }\end{array}$ & $\bigcirc$ & $\bigcirc$ & $\bigcirc$ & $\bigcirc$ \\
\hline I appreciate straightforward written feedback & $\bigcirc$ & $\bigcirc$ & $\bigcirc$ & $\bigcirc$ \\
\hline $\begin{array}{l}\text { I don't appreciate written feedback that tries to } \\
\text { change the direction of my paper }\end{array}$ & $\bigcirc$ & $\bigcirc$ & $\bigcirc$ & $\bigcirc$ \\
\hline $\begin{array}{l}\text { I don't appreciate written feedback that tries } \\
\text { change my writing style }\end{array}$ & $\bigcirc$ & $\bigcirc$ & $\bigcirc$ & $\bigcirc$ \\
\hline $\begin{array}{l}\text { I appreciate written feedback that gives me clear } \\
\text { instructions for how to revise my paper }\end{array}$ & $\bigcirc$ & $\bigcirc$ & $\bigcirc$ & $\bigcirc$ \\
\hline $\begin{array}{l}\text { I appreciate written feedback that revises or } \\
\text { edits my paper for me }\end{array}$ & $\bigcirc$ & $\bigcirc$ & $\bigcirc$ & $\bigcirc$ \\
\hline $\begin{array}{l}\text { I appreciate written feedback that directs me to } \\
\text { other related resources }\end{array}$ & $\bigcirc$ & $\bigcirc$ & $\bigcirc$ & $\bigcirc$ \\
\hline $\begin{array}{l}\text { I don't appreciate suggestions in written } \\
\text { feedback that are hard for me to use while } \\
\text { revising my paper }\end{array}$ & $\bigcirc$ & O & $\bigcirc$ & O \\
\hline I appreciate written feedback about grammar & $\bigcirc$ & $\bigcirc$ & $\bigcirc$ & $\bigcirc$ \\
\hline $\begin{array}{l}\text { I don't appreciate marks without text in feedback } \\
\text { (such as underlined sentences, circle around a } \\
\text { word, question mark, etc) }\end{array}$ & $\bigcirc$ & $\bigcirc$ & $\bigcirc$ & $\bigcirc$ \\
\hline $\begin{array}{l}\text { I appreciate detailed/specific comments more } \\
\text { than overall/general comments }\end{array}$ & $\bigcirc$ & $\bigcirc$ & $\bigcirc$ & $\bigcirc$ \\
\hline $\begin{array}{l}\text { I don't appreciate receiving contradictory } \\
\text { feedback from different people }\end{array}$ & $\bigcirc$ & $\bigcirc$ & $\bigcirc$ & $\bigcirc$ \\
\hline $\begin{array}{l}\text { I appreciate written feedback which is given } \\
\text { based on only what is on the paper, not based on } \\
\text { my previous papers }\end{array}$ & $\bigcirc$ & $\bigcirc$ & $\bigcirc$ & $\bigcirc$ \\
\hline $\begin{array}{l}\text { I don't appreciate written feedback that is given } \\
\text { because of a personal preference }\end{array}$ & $\bigcirc$ & $\bigcirc$ & $\bigcirc$ & $\bigcirc$ \\
\hline
\end{tabular}


Please rate the following statements according to the extent to which you agree or disagree.

5) I appreciate written feedback comments similar to this:

\begin{tabular}{|c|c|c|c|c|}
\hline & $\begin{array}{l}\text { Strongly } \\
\text { Disagree }\end{array}$ & Disagree & Agree & $\begin{array}{c}\text { Strongly } \\
\text { Agree }\end{array}$ \\
\hline $\begin{array}{l}\text { Explain why you're focusing on these } \\
\text { dimensions. Not clear to the reader. }\end{array}$ & $\bigcirc$ & $\bigcirc$ & $\bigcirc$ & $\bigcirc$ \\
\hline $\begin{array}{l}\text { Break this into smaller, more focused } \\
\text { paragraphs. }\end{array}$ & $\bigcirc$ & $\bigcirc$ & $\bigcirc$ & $\bigcirc$ \\
\hline I have a hard time following this section. & $\bigcirc$ & $\bigcirc$ & $\bigcirc$ & $\bigcirc$ \\
\hline $\begin{array}{l}\text { I think this sentence should be said much earlier. } \\
\text { It is important. }\end{array}$ & $\bigcirc$ & $\bigcirc$ & $\bigcirc$ & $\bigcirc$ \\
\hline $\begin{array}{l}\text { This section is a bit dense, with lots of details. } \\
\text { Are they all necessary? }\end{array}$ & $\bigcirc$ & $\bigcirc$ & $\bigcirc$ & $\bigcirc$ \\
\hline I don't agree with this paragraph. I think, ....... & $\bigcirc$ & $\bigcirc$ & $\bigcirc$ & $\bigcirc$ \\
\hline $\begin{array}{l}\text { This argument is unsupported. You need to cite } \\
\text { more references. }\end{array}$ & $\bigcirc$ & $\bigcirc$ & $\bigcirc$ & $\bigcirc$ \\
\hline $\begin{array}{l}\text { You're on the right track, this is a well- } \\
\text { organized paper. }\end{array}$ & $\bigcirc$ & O & $\bigcirc$ & $\bigcirc$ \\
\hline This section is really strong. & $\bigcirc$ & $\bigcirc$ & $\bigcirc$ & $\bigcirc$ \\
\hline $\begin{array}{l}\text { Have you thought about adding one more } \\
\text { section to your paper about } \mathrm{X} \text { literature? }\end{array}$ & $\bigcirc$ & $\bigcirc$ & $\bigcirc$ & $\bigcirc$ \\
\hline $\begin{array}{l}\text { Here is an article that supports what you're } \\
\text { saying here. }\end{array}$ & $\bigcirc$ & $\bigcirc$ & $\bigcirc$ & $\bigcirc$ \\
\hline $\begin{array}{l}\text { Maybe you need a table here, listing X with } \\
\text { each column showing Y. Just an idea. }\end{array}$ & $\bigcirc$ & $\bigcirc$ & $\bigcirc$ & $\bigcirc$ \\
\hline Check the APA manual for this citation. & $\bigcirc$ & O & $\bigcirc$ & O \\
\hline $\begin{array}{l}\text { I'd like you to go in a little different direction, } \\
\text { like this.... }\end{array}$ & $\bigcirc$ & $\bigcirc$ & $\bigcirc$ & $\bigcirc$ \\
\hline $\begin{array}{l}\text { It is not clear how this paragraph addresses your } \\
\text { research question. You need to show links to the } \\
\text { research question. }\end{array}$ & $\bigcirc$ & O & $\bigcirc$ & $\bigcirc$ \\
\hline $\begin{array}{l}\text { A bit of wavering focus from this paragraph to } \\
\text { this paragraph. Check for consistency } \\
\text { throughout. }\end{array}$ & O & $\bigcirc$ & $\bigcirc$ & $\bigcirc$ \\
\hline
\end{tabular}

75\% Completed

[Page Break] 


\section{F. CRITICAL/NEGATIVE WRITTEN FEEDBACK [Items 117- 124]}

1) Please rate the following statements according to the extent to which you agree or disagree.

\begin{tabular}{|l|c|c|c|c|}
\hline & $\begin{array}{c}\text { Strongly } \\
\text { Disagree }\end{array}$ & Disagree & Agree & $\begin{array}{c}\text { Strongly } \\
\text { Agree }\end{array}$ \\
\hline $\begin{array}{l}\text { Critical/negative written feedback affects me } \\
\text { emotionally }\end{array}$ & $\bigcirc$ & $\bigcirc$ & $\bigcirc$ & $\bigcirc$ \\
\hline $\begin{array}{l}\text { I am scared to get critical/negative written } \\
\text { feedback }\end{array}$ & $\bigcirc$ & $\bigcirc$ & $\bigcirc$ & $\bigcirc$ \\
\hline $\begin{array}{l}\text { Having critical/negative written feedback makes } \\
\text { me feel embarrassed }\end{array}$ & $\bigcirc$ & $\bigcirc$ & $\bigcirc$ & $\bigcirc$ \\
\hline $\begin{array}{l}\text { I lose self-confidence when I receive } \\
\text { critical/negative written feedback }\end{array}$ & $\bigcirc$ & $\bigcirc$ & $\bigcirc$ & $\bigcirc$ \\
\hline $\begin{array}{l}\text { I lose my motivation to work on my paper } \\
\text { further when I receive critical/negative written } \\
\text { feedback }\end{array}$ & $\bigcirc$ & $\bigcirc$ & $\bigcirc$ & $\bigcirc$ \\
\hline $\begin{array}{l}\text { I feel that it is a personal attack when I receive } \\
\text { critical/negative written feedback without } \\
\text { suggestions }\end{array}$ & $\bigcirc$ & $\bigcirc$ & $\bigcirc$ & $\bigcirc$ \\
\hline $\begin{array}{l}\text { I give up on my paper if I receive very } \\
\text { critical/negative written feedback from someone } \\
\text { with more knowledge and experience than I } \\
\text { have }\end{array}$ & $\bigcirc$ & $\bigcirc$ & $\bigcirc$ & $\bigcirc$ \\
\hline $\begin{array}{l}\text { I re-write my paper if I receive very } \\
\text { critical/negative written feedback from someone } \\
\text { with more knowledge and experience than I } \\
\text { have }\end{array}$ & $\bigcirc$ & $\bigcirc$ & $\bigcirc$ & $\bigcirc$ \\
\hline
\end{tabular}

80\% Completed

[Page Break] 


\section{G. FEEDBACK PROVIDERS [Items 125-129]}

1) Please rate the following statements according to the extent to which you agree or disagree.

\begin{tabular}{|l|c|c|c|c|}
\hline & $\begin{array}{c}\text { Strongly } \\
\text { Disagree }\end{array}$ & Disagree & Agree & $\begin{array}{c}\text { Strongly } \\
\text { Agree }\end{array}$ \\
\hline $\begin{array}{l}\text { I think that written feedback is influenced by the } \\
\text { personality of the feedback provider }\end{array}$ & $\bigcirc$ & $\bigcirc$ & $\bigcirc$ & $\bigcirc$ \\
\hline $\begin{array}{l}\text { I think that people I have a close relationship } \\
\text { with (e.g family, good friends) avoid giving me } \\
\text { critical/negative written feedback }\end{array}$ & $\bigcirc$ & $\bigcirc$ & $\bigcirc$ & $\bigcirc$ \\
\hline $\begin{array}{l}\text { I think that feedback providers have high } \\
\text { expectations of me when they give me } \\
\text { critical/negative written feedback }\end{array}$ & $\bigcirc$ & $\bigcirc$ & $\bigcirc$ & $\bigcirc$ \\
\hline $\begin{array}{l}\text { When feedback providers give me written } \\
\text { feedback mostly about grammar, sentence } \\
\text { structure, format, etc. I think that they are not } \\
\text { interested in my paper }\end{array}$ & $\bigcirc$ & $\bigcirc$ & $\bigcirc$ & $\bigcirc$ \\
\hline $\begin{array}{l}\text { When feedback providers give me written } \\
\text { feedback mostly about grammar, sentence } \\
\text { structure, format, etc. I think that they are not } \\
\text { knowledgeable about the content topic of my } \\
\text { paper }\end{array}$ & $\bigcirc$ & $\bigcirc$ & 0 & $\bigcirc$ \\
\hline
\end{tabular}

83\% Completed

[Page Break]

\section{H. REVISION DECISIONS [Items 130- 147]}

1) Please check one of the following.

I revise my paper to some degree after receiving written feedback

I don't revise my paper after receiving written feedback

[Questionnaire skips to Section I: "Feedback process in General” when the second option is selected]

[Page Break] 
Please rate the following statements according to the degree of frequency.

2) If I don't agree with a written feedback comment, before deciding to ignore or use that comment for my revisions I ask myself:

\begin{tabular}{|l|c|c|c|c|}
\hline & Never & Seldom & Sometimes & Often \\
\hline Am I confident in what I wrote? & $\bigcirc$ & $\bigcirc$ & $\bigcirc$ & $\bigcirc$ \\
\hline Is there any justification for that feedback? & $\bigcirc$ & $\bigcirc$ & $\bigcirc$ & $\bigcirc$ \\
\hline Is there really a need to make the change? & $\bigcirc$ & $\bigcirc$ & $\bigcirc$ & $\bigcirc$ \\
\hline $\begin{array}{l}\text { Will there be some kind of punishment for not } \\
\text { revising this way? }\end{array}$ & $\bigcirc$ & $\bigcirc$ & $\bigcirc$ & $\bigcirc$ \\
\hline $\begin{array}{l}\text { Will there be some kind of reward for revising } \\
\text { this way? }\end{array}$ & $\bigcirc$ & $\bigcirc$ & $\bigcirc$ & $\bigcirc$ \\
\hline $\begin{array}{l}\text { How much will this revision affect my paper's } \\
\text { direction? }\end{array}$ & $\bigcirc$ & $\bigcirc$ & $\bigcirc$ & $\bigcirc$ \\
\hline Is it hard or easy for me to make the revision? & $\bigcirc$ & $\bigcirc$ & $\bigcirc$ & $\bigcirc$ \\
\hline $\begin{array}{l}\text { Will I lose my voice and writing style if I accept } \\
\text { this change? }\end{array}$ & $\bigcirc$ & $\bigcirc$ & $\bigcirc$ & $\bigcirc$ \\
\hline $\begin{array}{l}\text { What is the knowledge and experience level of } \\
\text { the person who gave me this feedback? }\end{array}$ & $\bigcirc$ & $\bigcirc$ & $\bigcirc$ & $\bigcirc$ \\
\hline $\begin{array}{l}\text { What kind of authority-power relationship do I } \\
\text { have with the person who gave me this } \\
\text { feedback? }\end{array}$ & $\bigcirc$ & $\bigcirc$ & $\bigcirc$ & $\bigcirc$ \\
\hline $\begin{array}{l}\text { What kind of motivation or agenda might this } \\
\text { person have for giving me this feedback? }\end{array}$ & $\bigcirc$ & $\bigcirc$ & $\bigcirc$ & $\bigcirc$ \\
\hline $\begin{array}{l}\text { Did the person really understand what I wrote? } \\
\text { Should I ask that person about the feedback? }\end{array}$ & $\bigcirc$ & $\bigcirc$ & $\bigcirc$ & $\bigcirc$ \\
\hline
\end{tabular}


3) Please rate the following statements according to the extent to which you agree or disagree.

\begin{tabular}{|l|c|c|c|c|}
\hline & $\begin{array}{c}\text { Strongly } \\
\text { Disagree }\end{array}$ & Disagree & Agree & $\begin{array}{c}\text { Strongly } \\
\text { Agree }\end{array}$ \\
\hline $\begin{array}{l}\text { If feedback providers start their written feedback } \\
\text { with critical/negative comments, I feel less open } \\
\text { to the rest of the comments }\end{array}$ & $\bigcirc$ & $\bigcirc$ & $\bigcirc$ & $\bigcirc$ \\
\hline $\begin{array}{l}\text { If I sense an authoritative tone in the written } \\
\text { feedback, I feel resistant to use that feedback in } \\
\text { my revisions }\end{array}$ & $\bigcirc$ & $\bigcirc$ & $\bigcirc$ & $\bigcirc$ \\
\hline $\begin{array}{l}\text { If I catch a big mistake among the written } \\
\text { feedback, I tend to disregard the other feedback } \\
\text { comments that person gives }\end{array}$ & $\bigcirc$ & $\bigcirc$ & $\bigcirc$ & $\bigcirc$ \\
\hline $\begin{array}{l}\text { If I dislike the personality of a feedback } \\
\text { provider, I tend to disregard his/her written } \\
\text { feedback }\end{array}$ & $\bigcirc$ & $\bigcirc$ & $\bigcirc$ & $\bigcirc$ \\
\hline
\end{tabular}

95\% Completed

[Page Break] 
I) FEEDBACK PROCESS IN GENERAL [Items 148- 155]

1) Please rate the following statements according to the extent to which you agree or disagree.

\begin{tabular}{|l|c|c|c|c|}
\hline & $\begin{array}{c}\text { Strongly } \\
\text { Disagree }\end{array}$ & Disagree & Agree & $\begin{array}{c}\text { Strongly } \\
\text { Agree }\end{array}$ \\
\hline The feedback process affects me emotionally & $\bigcirc$ & $\bigcirc$ & $\bigcirc$ & $\bigcirc$ \\
\hline $\begin{array}{l}\text { The feedback process keeps me from } \\
\text { progressing }\end{array}$ & $\bigcirc$ & $\bigcirc$ & $\bigcirc$ & $\bigcirc$ \\
\hline $\begin{array}{l}\text { The feedback process is a good learning } \\
\text { experience }\end{array}$ & $\bigcirc$ & $\bigcirc$ & $\bigcirc$ & $\bigcirc$ \\
\hline \begin{tabular}{l} 
It is hard for me to get others' written feedback \\
\hline $\begin{array}{l}\text { I get upset if I wait for written feedback for } \\
\text { more than two weeks }\end{array}$
\end{tabular} & $\bigcirc$ & $\bigcirc$ & $\bigcirc$ & $\bigcirc$ \\
\hline $\begin{array}{l}\text { I get upset when I am not given another } \\
\text { opportunity to submit my paper after receiving } \\
\text { written feedback }\end{array}$ & $\bigcirc$ & $\bigcirc$ & $\bigcirc$ & $\bigcirc$ \\
\hline $\begin{array}{l}\text { I rarely get surprised with the written feedback } \\
\text { on my papers }\end{array}$ & $\bigcirc$ & $\bigcirc$ & $\bigcirc$ & $\bigcirc$ \\
\hline $\begin{array}{l}\text { I feel that feedback providers' opinions of me } \\
\text { will be affected based on whether I make the } \\
\text { revisions they suggest or not }\end{array}$ & $\bigcirc$ & $\bigcirc$ & $\bigcirc$ & $\bigcirc$ \\
\hline
\end{tabular}




\section{THIS IS THE END OF THE QUESTIONNAIRE}

\section{Drawing for Gift Cards}

If you would like to enter the drawing for the four $\$ 100$ gift cards, please send an empty email to the following address with subject "WF-QDrawing". If you win, the researcher will contact you through the same email address you use to send this message.

Email: gulfidancan@yahoo.com

Use this subject: WF-QDrawing

THANK YOU

Gulfidan Can

Comments (Optional):

*Notes:

1) The format of the original online questionnaire was similar to what is presented in this Appendix.

2) The information in square brackets [ ] were not included in the questionnaire. They are used in this appendix for clarification purposes.

3) $\bigcirc$ represents radio button. The participants can only select one of the options.

4) $\square$ represents text box. 
Appendix H. Recruit Materials for Questionnaire 


\section{Recruit Materials for Questionnaire \\ Letter to Department Heads and/or Faculty}

Dear Dr. .....;

I am a doctoral candidate in the Department of Instructional Technology at Utah State University. For my dissertation I am conducting a research study to find out more about doctoral students' perceptions and attitudes toward different sources and characteristics of written feedback for their academic papers.

I have developed an online questionnaire. I was wondering if you could help me reach the doctoral students in your department by forwarding my message to them (I will send the invitation email separately). I would really appreciate your help.

Best Regards

\section{Invitation Letter to Doctoral Students \& Informed Consent}

Dear Doctoral Students;

I am a doctoral candidate in the Department of Instructional Technology at Utah State University. For my dissertation I am conducting a research study to find out more about doctoral students’ perceptions and attitudes toward different sources and characteristics of written feedback for their academic papers.

I have developed an online questionnaire which can be accessed from the following link:

https://www.psychdata.com/s.asp?SID=124041

I would really appreciate if you could complete this questionnaire. Any current or recently

graduated doctoral students (PhD, EdDs, etc.) in social science departments are invited to participate in this research study. Your responses are crucial to obtain the best results in this research.

For more information, please see the consent form below.

Thank you in advance

Best Regards

[Followed by Informed Consent Form] 
University of Utah E-mails to Department Heads and/or Directors

Dear Dr. .....;

I am a doctoral candidate in the Department of Instructional Technology at Utah State University.

For my dissertation I am conducting a research study to find out more about doctoral students' perceptions and attitudes toward different sources and characteristics of written feedback for their academic papers. My target participant group is the doctoral students in social science departments in both Utah State University and University of Utah, including the students in your department.

I have already contacted with IRB office at the University of Utah, and they informed me that I can collect data from students in your department as long as I have your permission.

a. I was wondering if you could give me permission to collect data from students in your department.

b. Also, if you give me permission, could you please make the following invitation available to your doctoral students?

This is the questionnaire that I collect my data with. https://www.psychdata.com/s.asp?SID=124041

I am looking forward to your response.

Best Regards

[Followed by Informed Consent] 
Appendix I. Questionnaire Items with Low Reliability and/or Commonality Scores 
Questionnaire Items with Low Reliability and/or Commonality Scores

Table I-1

Questionnaire Items with Low Reliability and/or Commonality Scores

\begin{tabular}{lll}
\hline Item No. Scale Items \\
\hline
\end{tabular}

My motivation for academic writing is:

Item 22 Agreement To meet graduation or occupation requirements and expectations

Item 26 Agreement To have recognition in the field

Item 40 Agreement I ask for written feedback only when I come to a point where I can't improve my paper any further (Reverse-scaled)

Item 47 Agreement When asking for written feedback from others, I tell them what aspects of the paper I want them to look at

How important are the following characteristics of a person to you when deciding whether or not to ask for their written feedback?

Item 48 Importance Whether the person lives/works/studies close to me in terms of location

Item 86 Agreement I appreciate written feedback in which negative things are said in a more positive way

Item 87 Agreement I appreciate balanced positive and critical/negative written feedback

Item 91 Agreement I appreciate written feedback that gives me clear instructions for how to revise my paper

Item 92 Agreement I appreciate written feedback that revises or edits my paper for me

Item 96 Agreement I don't appreciate marks without text in feedback (such as underlined sentences, circle around a word, question mark, etc) (Reverse-scaled)

Item 99 Agreement I appreciate written feedback which is given based on only what is on the paper, not based on my previous papers

Item 124 Agreement I re-write my paper if I receive very critical/negative written feedback from someone with more knowledge and experience than I have (Reverse-scaled)

Item 125 Agreement I think that written feedback is influenced by the personality of the feedback provider 


\begin{tabular}{ccc}
\hline Item No. & Scale & \multicolumn{1}{c}{ Items } \\
\hline Item 126 & Agreement & $\begin{array}{l}\text { I think that people I have a close relationship with (e.g family, good friends) } \\
\text { avoid giving me critical/negative written feedback (Reverse-scaled) }\end{array}$ \\
Item 127 & Agreement & $\begin{array}{l}\text { I think that feedback providers have high expectations of me when they give } \\
\text { me critical/negative written feedback }\end{array}$ \\
Item 154 & Agreement & I rarely get surprised with the written feedback on my papers \\
\hline
\end{tabular}


CURRICULUM VITAE

\author{
Gulfidan Can \\ Department of Instructional Technology \\ Utah State University \\ 2830 Old Main Hill Logan, UT 84322 \\ gulfidan.can@aggiemail.usu.edu
}

\title{
EDUCATION
}

Ph. D., Utah State University

Department of Instructional Technology, 2009

Dissertation: “A model for doctoral students' perceptions and attitudes toward written feedback for academic writing"

Supervisor: Andrew Walker

M. Sc., Middle East Technical University

Department of Computer Education and Instructional Technology, 2003

M. Sc. Thesis: "Perceptions of prospective computer teachers toward the use of computer games with educational features in education"

Supervisor: Kursat Cagiltay

B. Sc., Middle East Technical University

Department of Computer Education and Instructional Technology, 2002

\section{PROFESSIONAL EXPERIENCE}

Research Assistant, 2003-2008

Utah State University

Department of Instructional Technology

Supervisor: David Wiley

Research Assistant, 2002-2003

Middle East Technical University

Department of Computer Education and Instructional Technology

Research Assistant and co-founder of SIMGE (Simulations and Games in Education) Research Group, funded by Advanced Research Projects

Supervisor: Kursat Cagiltay

Teaching Assistant, 2002-2003

Middle East Technical University

Department of Computer Education and Instructional Technology

CEIT 112: Information Technology in Education II

CEIT 380: Computer Education Teaching Methods I

CEIT 410: Teaching Practice 


\section{PUBLICATIONS AND PRESENTATIONS}

Articles in Peer Reviewed Journals

Can, G. \& Ozdemir, D. (2006). Blogging in higher education: Theoretical and practical approach. Journal of Systemics, Cybernetics and Informatics, 4(6), 5-13.

Can, G. \& Cagiltay, K. (2006). Turkish prospective teachers' perceptions regarding the use of computer games with educational features. Journal of Educational Technology and Society, 9 (1), 308-321.

Conference Presentations and Proceedings

Ozdemir, D. \& Can, G. (2007). Effective use of self-explanation strategy for efficient learning: A cognitive load theory approach. Paper presented at the annual meeting of the Association for Educational Communications and Technology (AECT): Anaheim, CA.

Can, G. (2005). Implementing the Blogging method in graduate courses: Preferences of students towards Blogging. Paper presented at the $1^{\text {st }}$ annual meeting of the Teaching with Technology Idea Exchange (TTIX): Orem, UT.

Can, G. (2005). A method for reflection, communication, and sharing in higher education. In F. Malpica, F. Welsch, \& A. Tremante (Ed.), The $3^{\text {rd }}$ International Conference on Education and Information Systems: Technologies and Applications Proceedings (EISTA): Vol. 2, 34-39.

Can, G. (2004). Perceptions of prospective computer teachers toward the use of computer games with educational features in education. Paper presented at the annual meeting of the Association for Educational Communications and Technology (AECT): Chicago, IL.

Can, G. (2004). Problem-centered coaching on the Internet: Massively multiplayer games and text-based interaction. Paper presented at the 16th Annual Instructional Technology Institute at Utah State University, Logan, UT.

Edited Book

Original: Dewey, J. (1938). Experience and Education. Kappa Delta Pi, International Honor Society in Education. Translation into Turkish: Deneyim ve Egitim. Translated by S. Akilli. Edited by G. Can \& G. K. Akilli (2007). METU Press: Ankara, Turkey. ISBN: 978-9944-344-38-8

\section{PROFESSIONAL AFFILIATIONS}

American Educational Research Association (AERA)

Association for Educational Communications and Technology (AECT)

\section{HONORS \& AWARDS}

Awarded with a Scholarship to pursue PhD in USU, by the Council of Higher Education of the Republic of Turkey, 2003

Ranked the first among the graduates of the Faculty of Education 2001-2002, Middle East Technical University, Turkey, 2002 